Portland State University

PDXScholar

Spring 6-3-2019

\title{
Making Imaginaries: Identity, Value, and Place in the Maker Movement in Detroit and Portland
}

Stephen Joseph Marotta

Portland State University

Follow this and additional works at: https://pdxscholar.library.pdx.edu/open_access_etds

Part of the Sociology Commons, and the Urban Studies Commons Let us know how access to this document benefits you.

Recommended Citation

Marotta, Stephen Joseph, "Making Imaginaries: Identity, Value, and Place in the Maker Movement in Detroit and Portland" (2019). Dissertations and Theses. Paper 5000.

https://doi.org/10.15760/etd.6876

This Dissertation is brought to you for free and open access. It has been accepted for inclusion in Dissertations and Theses by an authorized administrator of PDXScholar. Please contact us if we can make this document more accessible: pdxscholar@pdx.edu. 
Making Imaginaries: Identity, Value, and Place in the Maker Movement in Detroit and Portland

by

Stephen Joseph Marotta

A dissertation submitted in partial fulfillment of the requirements of the degree of

Doctor of Philosophy

in

Urban Studies

Dissertation Committee:

Gerry Sussman, Chair

Charles Heying

Greg Schrock

Brian Elliott

Lee Shaker

Portland State University

2019 
C 2019 Stephen Joseph Marotta 


\begin{abstract}
This dissertation explores the maker economy and culture in Detroit, MI and Portland, OR and queries the "Made in Place" branding strategy that relies so heavily on a shared imagination of cities, identities, and values. Bridging the gap between urban economic development, political economy, and affect theory, this dissertation is centrally concerned with how imagination works as a commons and how such "imaginaries" shape each city's milieu of small, entrepreneurial, artisanal producers ("makers"). The constituent elements of "Made in" branding - "made" and "place" - suggest common understandings of each; this sense of coherence is critical for how value is added to a maker's product. Rather than coherence, however, my data revealed a great deal of tension and ambiguity: how can something be coherent, ambiguous, and mobilized as economic value all at the same time? I answer this question by analyzing data from over 70 interviews with makers in Detroit and Portland, two cities experiencing rapid development and perceptive shifts from "old" to "new." I conclude that the various imaginaries so critical to "Made in Place" branding suggest not just economic rationality, but also a desire for stability in a turbulent world. Theoretically informed by Lauren Berlant, Gilles Deleuze, and Walter Benjamin, I argue that makers' imaginaries of identity, value, and place provide a collective sense of grounding amidst the flux of transition and uncertainty.
\end{abstract}




\section{ACKNOWLEDGEMENTS}

There are so many people that so deeply affected how I think, how I see the world. And then there are those that have endured with me, or just showed me why endurance matters.

To my family: Allysha, thank you for putting up with my bizarre schedule, my mess of papers and books, my madness, my ranting, and my frustration. We've done hard things, and you've made them worthwhile. Thank you for surviving with me; one day we will flourish. Cas, thank you for your creativity and ideas, for being brave and finding yourself, and for always being stronger than I am. Casey, thank you for being resilient, for being hilarious, for helping me understand myself, for staying up late with me. To Chloe, thank you for keeping me honest, for fighting when things have been hard for you, and for teaching me how to endure. You are all my best friend. I love you all so much more than you can imagine.

To my mom and dad: thank you for your support, for talking through my impasses (sometimes on a daily basis), but also for fighting, for surviving, for putting others before yourselves, for modeling the compassion and endurance and vigor that I needed at times.

To my committee members: Gerry, thank you for pushing me in unexpected ways, for inspiring me to always do better work. I hope we can continue to visit at Ken's on $21^{\text {st }}$. Greg, thank you for entertaining my stranger ideas, for teaching me the practice of research, for investing in me. Your mentorship and friendship has been so valuable over the course of the past five years. Charles, I can hardly overstate your impact on me, 
both academically and personally. Thank you for the weekly hours-long talks in your office, for sharing stories that shaped my worldview, for giving me the freedom to discover things, practical things, while still encouraging my theoretical rambling. Brian, thank you for helping me understand who I am as a thinker, for working through difficult concepts with me, but also for being a friend and a confidante.

To my dissertation writing group: Andree, thank you for opening your home to us, making us tea, nurturing our ideas, giving us direction - all under no obligation and with no expectations. Amy, Jamaal, and Steven, in your own ways you each shaped the trajectory of my analysis; your collective mark is engrained on the pages below and in my future work. Thank you for showing up every week and being awesome. To the lot of you: maybe you don't know it, but you held me up through some difficult stretches, and I am forever grateful. I promise to pay forward the commitment, mentorship, and care that you have afforded me.

To close friends: Austin, thank you for letting me bounce my ideas off of you, for proofreading, editing, and critiquing, for thousands of cups of coffee, for being my partner in crime for the past five years. Clark, thank you for checking in on me, for your unwavering encouragement and support, for talking through ideas, for your long-term friendship. Lastly, I would be remiss not to thank the hundreds of people that in this dissertation appear as "data" or "subjects." You are all more than that; thank you for contributing. 


\section{TABLE OF CONTENTS}

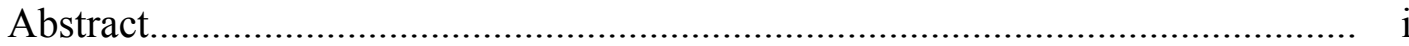

Acknowledgements................................................................................... ii

List of Figures............................................................................................. vi

Preface: Writing from the Impasse................................................................ vii

Chapter 1:Introduction............................................................................ 1

The Maker Movement............................................................................. 6

Historical Urban Context: Race and Deindustrialization............................ 8

Portland and Detroit, New and Old.................................................... 11

Dissertation Roadmap...................................................................... 19

Chapter 2: Literature, Theory, and Methods......................................................... 23

2.1 What is the Maker Movement? ......................................................... 23

Maker Identity and Subjectivity.................................................... 25

The Importance of the Urban in the Maker Movement.................. 28

Feminism, Fetishism, and Favoritism: Critiques of Making.......... 32

The Moral Dilemmas of the Maker Movement............................... 35

2.2 Theory.................................................................................. 38

Making Makers: Neoliberal Subjectivity and Creative Work....... 39

Precarity: An Impasse................................................................... 45

Affect and "Overflow".............................................................. 49

Imaginaries........................................................................ 52

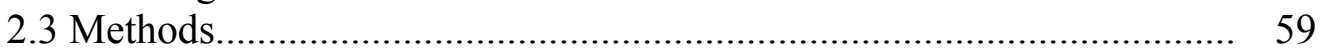

Background from Portland............................................................ 60

Background from Detroit............................................................ 62

Field Methods and Analysis........................................................... 67

Moving On: a Short Interlude....................................................... $\quad 70$

Chapter 3: Making Identity.............................................................................. 73

3.1 Aesthetics, Affect, and Identity.......................................................... 74

3.2 Making as a Different/New Form of Work........................................... 79

Crafting an Identity.................................................................... 83

Making or Manufacturing?........................................................... 89

Recognition and Rejection.......................................................... 93

3.3 Intimate Publics and the Maker Identity............................................. 96

3.4 Conclusion .................................................................................... 99

Chapter 4: Making Value(s)............................................................................ 102

4.1 Values as Prices................................................................................ 102

A Pricing Paradox........................................................................ 103

Adding value, or, loving a thing..................................................... 108

4.2 Opening Windows.......................................................................... 112

Making (and selling) transparently............................................... 113

Telling (and selling) stories............................................................ 116

Social Media and the Internet......................................................... 120

4.3 Values, Growth, and Scaling............................................................. 124 
Letting Go......................................................................... 125

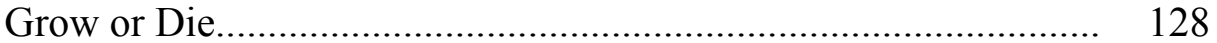

Outsourcing............................................................................. 132

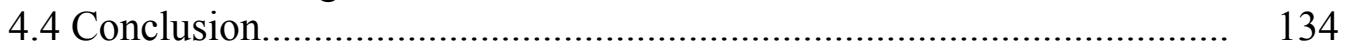

Chapter 5: Making Detroit.......................................................................... 138

5.1 Death as Preamble......................................................................... 140

The Gap-toothed City.................................................................. 140

Ashes in the Sandbox............................................................... 145

5.2 Detroit's Maker Imaginary................................................................ 152

Old Detroit... ...................................................................... 152

....And New Detroit.................................................................. 160

New Detroit, Race, and the Suburbs............................................ 173

Made in Detroit? .................................................................... 182

Made How, and in Which Detroit............................................... 187

5.3 Conclusion................................................................................. 193

Chapter 6: Making Portland............................................................................... 198

6.1 The Portland Dream........................................................................ 199

Juxtaposing Portland................................................................. 205

6.2 Imagining Portlandia.......................................................................... 213

Portlandia 1: Industrial Imaginaries............................................. 214

Portlandia 2: International Imaginaries......................................... 223

Portlandia 3: Community Imaginaries.......................................... 229

"New" Portland and Authenticity................................................ 238

Made in Portland? ..................................................................... 244

6.3 Conclusion............................................................................... 246

Chapter 7: Conclusion................................................................................ 251

Imaginaries and Collective Groundedness: Answering My

Research Question................................................................... 251

7.1 Implications of this Research............................................................. 257

An Affective Approach to Research............................................. 257

Affect and Urban Studies and Planning....................................... 260

Policy "Suggestions" ................................................................ 263

7.2 Limitations and Future Research...................................................... 266

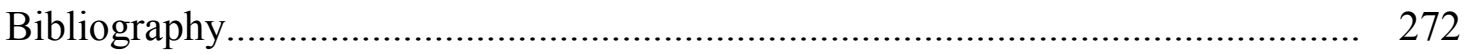




\section{LIST OF FIGURES}

Figure 1 Detroit and its immediate suburbs........................................... 147

Figure 2 The "New" Detroit central city neighborhoods......................... 147

Figure 3 The commercial strip in gentrifying Corktown........................ 148

Figure 4 Empty warehouses just outside Eastern Market....................... 148

Figure 5 A message about "comeback" along Dequindre Cut................. 148

Figure 6 A damaged apartment building in Brush Park.......................... 148

Figure $7 \quad$ Gutted houses east of New Center........................................ 148

Figure 8 Anti-Shinola graffiti and some handwritten responses on an alley wall............................................................................ 148

Figure 9 An almost completely empty neighborhood in far-east Detroit.. 148

Figure 10 Locations of maker interviews in Detroit................................ 167

Figure 11 Racial segregation between Detroit and suburbs....................... 176

Figure 12 Racial segregation between "New Detroit" and the outer neighborhoods of the city......................................................... 176

Figure 13 Portland and its immediate suburbs......................................... 200

Figure 14 Portland's central neighborhoods............................................ 200

Figure 15 Maker-style gifts celebrating Portland at Powell's Books........... 201

Figure 16 A "Love Portland" decoration (artist unknown)......................... 201

Figure 17 A bicycle maker truck emphasizing "Made in Portland"........... 201

Figure 18 An advert for a public health seminar "Portland style".............. 201

Figure 19 An art installation capturing the growing tensions of "New Portland"

Figure 20 A graffiti-laden real estate sign, also showing pushback against "New Portland"......................................................................... 201

Figure 21 The Towne Storage building shortly after its sale in $2015 \ldots \ldots \ldots \ldots .201$ 


\section{PREFACE: WRITING FROM THE IMPASSE}

I wrote most of this dissertation from an impasse: my seven year-old daughter was diagnosed with a heart condition shortly after I wrapped up my fieldwork. During 2018, she would need two surgeries to correct this condition, and the space between the diagnosis and the surgeries was a significant period of adjustment for our family. This period was an impasse because we had to manage our sense of the "ordinary" in a space of uncertainty. In the process of adjusting to this uncertainty, I found a new way of seeing the world; the heaviness of spending so much time at pediatric cardiologists' offices and hospital waiting rooms colored the analysis the reader will encounter below, whether I care to admit it or not. Like the entanglement between the researcher and the researched, the analyst and the analyzed cannot be separated; the analyst is always situated in the knowledge they are producing, as Donna Haraway's "god trick" and Walter Benjamin's Arcades Project both make clear. Analysts are still humans, and humans are never objective just because they imagine themselves as such. To think otherwise would be to ignore the inherently political process of putting something like a dissertation together.

In accepting this, that is, in allowing myself to be analytically subjective and speculative, I found an analytical framework that helped me not only with the work of unpacking my data, but also with putting what felt broken inside of me back together. It connected back to my world, and also to the world; I could see being insecure and precarious from another vantage point. It addressed what I had felt was the glaring deficit in Marxism and the other critical theories I was so drawn to, because it allowed me to experience feeling as a form of knowing. One of my goals below is to take feeling more 
seriously, because feeling is a form of knowing, but a form that is not so easy to define or categorize or really even put into words. The framework I'm referring to might be called affect theory, or it might be called something else (critical feminism, queer theory, postwhatever). In the dissertation, I refer to it as an affective approach; but what's important is that this framework invites into the analytical fray the various mysticisms and irrationalities that are often eschewed in "objective" scholarship.

How does one press on in the face of insecurity? What do they tether themselves to? Where do they get their sense of grounding? These are the questions that I asked myself and that I sought out in others over the past few years. Everyone wants to feel secure, to feel comfortable, to be optimistic and certain about the future. It would be a tall order to argue otherwise. The desire for security and certainty more than likely has something to do with why humans do the things that they do; again, it would be hard to imagine humans doing things - anything - to intentionally produce a sense of insecurity or uncertainty in their own lives.

The things that happened in my life while I was writing this dissertation now have a sense of history to them. But at the time I was doing my analysis, they were not historical or figments of memory; they were ongoing. In more than a few ways they will always be ongoing, and in a sense, that ongoingness is captured by this dissertation. I mean to get at a sense of what Elizabeth Povinelli refers to as tense or what Lauren Berlant describes as a situation. These situations are marked by their thickness, their demands for action and endurance on the part of the people within them. And yet such situations are indeterminate; the boundaries are not clear. There's no sense of finality from within a situation, yet there's no part of one's world unaffected by it. The 
ongoingness creates only a sense of structure in one's world; there are perceptions and decisions and behaviors that seem to make sense given such a structure. Other parts of one's world become wrapped up in these events: my daughter's health affected my teaching, my relationships, even the way I moved through the city. Needless to say, my research, writing, and analysis were affected.

There was eventually a point at which I realized that I wanted to embrace these affects, to think about my research in the same way I was thinking about my life. It was a different ontology; a new approach to what living in the impasse was like. But I also realized that personal impasses have an important corollary to modern social life, not just because everyone has their own small events constantly structuring their lives, but because there are larger and more collectively experienced forms of structuring events unfolding all the time. A clear example that I often return to in this dissertation is the impasse of global capitalism. There is a pervasive sense, identified by numerous scholars and evident in numerous art and media forms, that the global economy is better at producing insecurity and precarity than stability and wellbeing. On the one hand, I am interested in this collective sense of impasse within the structure of the global economy. On the other, profound shifts in urban places are no less anxiety-inducing: the two cities that I conducted research in were both situated amidst dramatic cultural and economic transformations. In neither of these cases, global or local, was a sense of finality available as to where these transformations were heading.

Again I return to the same questions: How does one press on in the face of insecurity? What do they tether themselves to? Where do they get their sense of grounding? In the work below, I focus on the ways "makers" - which might be defined as 
small, entrepreneurial, artisanal or craft manufacturers - adjust to the two impasses I described above. Much of the dissertation is devoted to building a central argument: that makers construct and rely on imaginaries of identity, value, and place as a form of collective groundedness amidst the uncertainties they operate within. But I hope the dissertation also makes clear a secondary, more implicit goal: urban studies scholarship, particularly in the US, has generally not incorporated affective approaches. I would like to think this dissertation engages that deficiency. There were times during my research and writing when I felt like investigating things like "creativity" and "urban imaginaries" seemed indulgent, unimportant, and abstract. But I don't feel like that now: it seems an important time to think about how people make sense of crises and uncertainty and what social, political, and cultural forms emerge as a result. This is what I hope to have achieved below. 


\section{CHAPTER 1: INTRODUCTION}

On my way to an interview, I approached an old red brick building that hosted a storefront and production space in the Rivertown neighborhood of Detroit. Rivertown is an old place, right along the Detroit River; I could catch glimpses of Canada between the low-rise buildings. About half of those buildings appeared to be abandoned, boarded up, or generally decaying. The other half, including the building I was about to enter, had been fixed up or repurposed. The neighborhood was obviously in the midst of a transition; given its proximity to downtown Detroit and its gritty and ubiquitous red brick ambiance, I suspected it was a desirable area for the creative small manufacturers that had come to be collectively known as "makers." Walking through the door to the building, I entered a small shop space accented by exposed brick walls, ceiling beams, and pipes. The displays looked handcrafted from wood and steel, each purposefully conveying age and imperfection, and the goods were arranged sparsely and deliberately. But what stood out to me was the view into the backroom, where the products were actually being made. The backroom was rather large, probably 3000 square feet, lit naturally by a series of large plate glass windows lining the brick walls. The machines and materials necessary to make the products and the makers bringing their handicraft to life were all entirely visible from anywhere in the shop. This was by design; the whole production process was meant to be visible. The place came together like a mood: it wasn't possible to walk in and not be absorbed by the atmosphere.

From beyond the curtain dividing the shop from the production area emerged one of the makers I was there to meet. There were about five other people in the shop, but he 
asked me if I was "the guy from Portland." My expression must have given away my intent to ask how he knew, because he immediately explained that I looked like I was from Portland. His reply actually deepened my bewilderment: what about my selfpresentation signaled Portland? And what, exactly, does someone from Portland look like? I was clean-shaven and had a button-down shirt (not a flannel) and jeans on; I could have been from anywhere. I didn't follow up, but I was suddenly aware that Portland had made the trip to Detroit with me. Somehow this person was able to detect it; something about me had triggered his imagination of Portland. It was similar to my awareness outside the building that I was in a "maker" neighborhood, or my awareness upon entering the shop that this was a "maker" shop. There was a quality outside of the ability to define "maker" or "Portland" that informed what each of us knew about them.

As the above anecdote shows, each of us relied on an imaginary (of maker, of Portland) in order to make sense of our situation. An imaginary is an oft-invoked yet "fuzzy" concept (Markusen 1999) that I develop throughout this dissertation. I use the term to describe a shared but loosely bounded imagination assembled around a specific set of contextual factors. Imaginaries, I contend, become coherent at the collective level, and yet they structure many facets of everyday life. For example, an imaginary might inform what one might expect someone from Portland to look like or what type of neighborhood a maker might prefer. In many ways, this dissertation is about how imaginaries become coherent, shared, and mobilized within a milieu (in my case, a milieu of "makers"). My particular concern is to understand how makers commonly imagine identity, value, and place. I focus on these three factors because research shows them to be central to the project that is the "maker movement" (Wolf-Powers et al. 2017). Yet 
throughout the course of almost five years of research, I have found myself routinely perplexed by the inconsistencies and tensions evident in each of these factors. As such, making sense of why identity, value, and place have inherited such collective significance to makers has become one of this project's central tasks.

Importantly, these three factors all come together in one essential expression that most makers brand their products with: "Made in [place]" (e.g. "Made in Portland"). The notion of "Made in Place" neatly captures all of the tension and incoherence that has puzzled me. The first side of the equation - "made" - draws on makers' collective imagination of the maker identity and the ethical values that are tied to that identity. As I detail in the chapters 3 and 4, "maker" and the value propositions they share with consumers are both ambiguous and ensnarled in a variety of tensions and indeterminacies. Yet the "made" side of the equation still manages to hold together; it makes sense to consumers, and in so doing, adds value to makers' products. The other side of the equation - "place" - has to do with the specific imaginaries of Portland and Detroit. As I detail in chapters 5 and 6 , each city has been popularly imagined in ways that essentialize their most visible qualities: Portland as the DIY, progressive, green, communitarian paradise; Detroit as the near-death experience that has mustered itself to one knee, poised to make a "comeback." It should come as no surprise to find that both cities' imaginaries fall short of representing the complexities of each place. I found makers to be entirely aware of this; the tensions between the city imaginary and makers' actual experiences contributed greatly to the structuring of makers' values and aspirations. But for better or worse, they mobilize those imaginaries every time they 
apply "Made in Portland/Detroit" to one of their products. Such tensions are what I hope to draw out as I deconstruct the "Made in Place" equation.

With all this said, this dissertation addresses the following questions: What makes "Made in Place" an effective strategy for makers, and what gives it coherence and power? How is it mobilized such that it expresses (and adds) ethical and economic value, and what tensions emerge from its mobilization? In answering these questions, the dissertation employs two intertwined theoretical concepts to frame the analysis. The first - imaginaries - I have introduced above. Imaginaries are important to these questions because they turn out to be a source of value and a source of tension. To better explain why this is, I introduce a second theoretical concept - impasse, which is described by Lauren Berlant as "what it feels like to be in the middle of a shift" $(2011 ; 198)$. On one hand, impasse conceptually captures the lived uncertainty of a transition; on the other, it brackets the set of adjustments people make as a transition unfolds. I argue here that this attempt at groundedness amidst change is critical to understanding why makers aspire to the values, identities, and shared place imaginations that they do. As I show in chapter 2, an impasse does not need to be defined in terms of rational evidence, but rather it just needs to be collectively felt. Given the importance of collective feeling to my analysis, this dissertation takes affect theory as its epistemological standpoint.

What makes impasse such a powerful concept is that it embraces the uncertainties and ambiguities of enduring a transition. I use impasse to conceptually account for two general transitions below. The first is unfolding at a national and a global scale, and involves the collective sense that the political-economic promises of the American Dream are bankrupt. As Berlant (2011) argues, countless statistics bear out discouraging truths 
regarding the lack of upward mobility, income and wealth inequality, wage stagnation, job insecurity, and welfare rollbacks. In general, the bastions of meritocracy are unraveling, and it seems safe to say that most people are feeling insecure about their future. Making, and the maker movement, is a response or adjustment to this sense of precarity. Not only did a significant share of maker enterprises emerge "during and immediately following the Great Recession" (Schrock et al. 2018; 5), but many of the values makers identify with are direct responses to the collective sense that the globalized economy isn't working for most people. The transition I mean to describe, however, is only contoured by this overall sense of political-economic attrition; it is an impasse because it is unclear where the shift away from the imaginary of the American Dream is headed. In other words, for all the statistics and materially significant evidence of pervasive inequalities exacerbated by global capitalism, the feeling of living in the shift is equally defined by the uncertainty of an indeterminate future. This feeling demands a sense of groundedness, which is where the analysis of imaginaries - about making and about cities - becomes valuable.

The second transition has to do with place change through urban development, and is unfolding at a place-specific scale (although it is consumed globally, as evidenced in chapter 6). When places change, what they are becoming isn't always clear, even if the (imaginary) visions of the future that govern their development appear coherent (Marotta \& Cummings 2018). My use of impasse in terms of urban development emphasizes the perceptive shift from "old" to "new" in Detroit and Portland. The use of "old" and "new" to describe a city's imaginary, I argue, suggests a desire to make sense of change. Again, imaginaries are a form of adjustment to transition; placing value in a collectively 
imagined city ("Portland") or identity ("maker") is one way makers ground themselves amidst the feeling of flux. This is a key point throughout this dissertation: imaginaries are important because they house the aspirations of makers (and consumers) by giving them a sense of groundedness amidst the flux of a perceived impasse. Imaginaries create a sense of groundedness because they fill in the uncertainties stemming from the sense of changing conditions; if the parameters of a shift are not clear, they must be imagined. As that imagination becomes shared - especially as Internet-based technologies have simplified and even economized sharing - a sense of coherence emerges. Imaginaries, then, create coherence from the various impasses makers are confronted by, even if these imaginaries yield a host of new tensions. This is the central theoretical argument of this dissertation.

\section{The Maker Movement}

Before moving on, it is necessary to provide some context about makers and the maker movement. To begin, the maker movement is a name for the wave of creative and entrepreneurial producers that have become fairly ubiquitous in cities across the US. As has been documented in the emerging literature on makers (see chapter 2), there has been significant interest in the maker movement on the part of the public, private, and nonprofit sectors alike; aspirations range from the "onshoring" of manufacturing to a restructuring of education to a whole new regime of work/life balance. And while the effervescence of the maker phenomenon has seemed to wane a bit recently, its impact is not insignificant: just a few years ago my colleagues and I found that members of a maker collective called Portland Made employed over 1700 people and produced almost $\$ 100$ million in revenue (Heying et al. 2016). 
I take up the question of what exactly a maker is in the literature review in chapter 2 and empirically in chapter 3 . Indeed, there is a good deal of indeterminacy around defining "maker" in a precise fashion. However, a "maker" and their goods can be distinguished by a three general characteristics that virtually all makers agree on: first, a maker is a producer that both designs and makes their products (Wolf-Powers et al. 2017; Schrock et al. 2018). These products could almost be anything; makers produce everything from food to bicycles to wearable technology. But - and this is the second distinction - makers only produce physical goods. In other words, there is a general agreement amongst makers that makers do not produce software, although there is some grey area around things like music and other forms of art. Third, makers generally do not aspire to mass production, and as such they tend to prefer producing objects in small batches. The word "handmade" is used in a lot of maker branding to communicate this more deliberate process.

A few interviewees noted a superficial split between the craftier and the techier sides of the maker movement. One interviewee called these two factions of makers the "bags" and the "bots." The "bags" includes everything that is non-tech: bicycles, clothing, accessories, wood goods and furniture, even food; "bots" suggests engineered objects such as robots, drones, 3D-printed objects, and generally anything using opensource Arduino circuit boards. The two groups tend to run in different scenes and have different networks, even if they both loosely identify with "maker." This split is likely historical in nature; the "bags" more closely resembles the Arts \& Crafts movement of the early $20^{\text {th }}$ Century, whereas the "bots" have their genesis in the "hacker" movement of the mid-20 $0^{\text {th }}$ Century (Morozov 2014). What makes the whole thing a "movement" is 
each side's general pushback on the norms and values of globalized capitalism (see chapter 2). As I mentioned in the introductory paragraphs, making is largely a reaction to the impasse of globalization and the values that makers collectively aspire to (see chapter 4) flow from that impasse.

Lastly, this dissertation is generally concerned with the "bags" side of making. There are very few interviews in Portland that I draw upon from the "bots" side, and none of the Detroit interviewees represent the "bots" side. I made a few attempts at interviewing engineering makers in Detroit, particularly at a makerspace in central Detroit called OmniCorp, but none of my requests were granted. Additionally, my core interest as an academic has to do with the relationship between place, art/aesthetics, and capitalism; as such, the "bags" side of the maker movement was a much better fit for my research program. The "bags" makers also appeared to me to be more invested in the urban fabric; they generally had a great deal to say about the ways in which Portland and Detroit were changing. And indeed they turn out to be central characters in the stories of both cities' changes: lining the newly gentrified streets of the Alberta (Portland) and Corktown (Detroit) neighborhoods are boutiques and cafes specializing in local, handmade goods. As it turned out, each city's newness was inseparable from the emergence of the maker movement.

\section{Historical Urban Context: Race and Deindustrialization}

In querying the context in which so-called "newness" has affected the emergence of makers in Portland and Detroit, it is useful to consider the two cities' broader historical contexts from within the processes of deindustrialization and racial discrimination. American cities underwent a series of massive shifts over the course of the $20^{\text {th }}$ Century 
(High \& Lewis, 2007; Lloyd, 2006; Sugrue, 1996; Zukin, 1982; Massey \& Denton, 1993). Fordism, a mass production and mass consumption accumulation strategy that originated on Detroit's automotive assembly lines (Jessop 1997; Jessop 2013), dominated industry from the early $20^{\text {th }}$ century through World War II and shaped American cities' rapid growth at least into the 1950s. Politically, the Keynesian/New Deal era of "embedded liberalism" (Ruggie 1982) helped fund the creation of the freeway system and the rise of the suburbs during the immediate postwar period. After the 1950s, a period of stagflation began to set in and the Keynesian era came into crisis. Fordism gave way to "flexible" accumulation strategies (Harvey 1990b) in which industry decentralized, in part capitalizing on Federal subsidies/incentives and innovations in transportation (Jackson 1985). The neoliberal era had been blossoming since the Bretton Woods agreements, and the effects of the globalization of capital and localization of political power started to become very visible on the neighborhood level (Peck \& Tickell 1994). The so-called welfare state had largely been disempowered and could not respond to the stresses put on inner city neighborhoods, many of which by now were in decline, particularly as white flight accelerated. By the 1960s, the extreme pressure put on these neighborhoods manifested in the form of devastating racist practices such as contract selling, blockbusting, deed covenants, and redlining (Satter, 2009; Sugrue, 1996; Thomas, 1990; Massey \& Denton, 1993).

For Sugrue (1996), deindustrialization is the "closing, downsizing, and relocation of plants and sometimes whole industries" that (in the US) began in the New Englandbased textile towns as industry began to move south during the 1920s. Sugrue argues that "advances in communication and transportation, the transformation of industrial 
technology, the acceleration of regional and international economic competition, and the expansion of industry in low-wage regions, especially the South" are the factors that led to a mass and somewhat uniform process (although this process was certainly uneven and locally variant). An obvious effect of deindustrialization is the loss of jobs: Sugrue points out that Detroit alone suffered the loss of 134,000 industrial jobs between 1947 and 1963. According to High \& Lewis (2007), the US lost over 22 million jobs between 1969 and 1976, and another 2 million manufacturing jobs between 1995 and 2002 (3).

Deindustrialization also caused massive changes to the structuring of labor. While deindustrialization was partially a response to the market and partially a response to Federal incentives and subsidies, it allowed manufacturers more control over labor unrest through the fragmenting and decentralizing of the supply chain (e.g. "runaway shops"). In fact, between 1979 and 1983, the United Steelworkers alone lost 105,000 members and disbanded almost 1,100 local unions (High \& Lewis, 2007; 4).

Deindustrializing American cities were also fundamentally shaped by racial discrimination and migration. The combined effects of World Wars I \& II, racist strikebreaking tactics, and expanding industrialism (largely as a result of the World Wars) fueled a "great migration" of southern blacks to northern industrial cities (Massey \& Denton, 1993). Upon arrival, however, black migrants found a hostile atmosphere: the predominantly white labor forces of northern cities were angry that blacks were "taking their jobs" and violently lashed out. Through violence and discriminatory policy, blacks were isolated in segregated corners of the city, where the real estate industry (Satter 2009; Massey \& Denton 1993) and Federal policy (Jackson 1985) hastened the formation of the ghetto. The now-infamous practice of redlining, for example, cut entire 
neighborhoods off from mortgage capital and home improvement loans. As such, black residents had no recourse for gaining access to housing other than racist contracts with white speculators (Satter 2009).

The above evidence contextualizes the troubled history of the American cities that the maker movement has emerged from. Deindustrialization caused the abandonment and subsequent decay of warehouses, factories, and working class homes; racist migration and real estate practices contributed to the segregation, disrepair, and ruination of large swaths of residential areas. The net effect of the above processes was the somewhat uniform structure of American cities in which the suburbs were middle-to-upper class, largely white, and well connected politically and economically. On the other side of the coin was the inner city, which was working class and unemployed, predominantly brown and black, and largely abandoned by political and economic leaders. Postwar economic restructuring left massive swaths of American inner cities littered with relics of an economic structure - Fordism - that no longer existed.

\section{Portland and Detroit: Old and New}

As Carl Abbott (2000) argues, Portland was among the first US cities to experience the effects of deindustrialization. This left the city with an "absence of discarded industrial districts" and in "good position to catch the rise of the [postindustrial] information economy" (ibid, 245). Indeed, Portland has emerged as a central locus of the maker movement, which largely makes use of the city's remaining industrial districts such as the Central Eastside. Portland is a good research site for this reason, but also because the city's maker milieu is rather visible and has recognizable central figures and advocates and, perhaps most importantly, prior research projects have 
given me a good deal of familiarity with Portland's maker economy and the actors affiliated with it. Although I have done a good deal of research in and writing about Portland, there are still many questions I wanted to address about the culture of making in Portland. Portland is a city in which local boutiques sell tourists bottles of "authentic" Portland rain at $\$ 6$ apiece; rain is not exactly a scarce object in Portland. So why do people buy it?

The construction and circulation of a city imaginary seem especially powerful for Portland's makers. The elements of this imaginary - coffee, gloomy weather, DIY and local everything, an allergy to big business and mass production - have coagulated into an increasingly recognizable aesthetic that is circulated across distances through a variety of media. In many ways, this is Portland's "brand" - the city's imaginary adds value to makers' products. Turning Portland's collectively imagined identity into an economic unit is distressing for a number of reasons, not the least of which is the fact that not everyone imagines Portland as a twee, cartoonish place that somehow managed to avoid the production of inequality. But what really interested me in doing research in Portland were the rapid transformations unfolding in the city at the time of my research. Concurrent with the emergence of the maker movement in Portland has been a rapid and comprehensive gentrification of the inner city (Wile 2015), and market pressures in neighborhoods like the Central Eastside Industrial District, which is uniquely zoned to protect manufacturing, are pitting Portland's makers in a competition for space with other firms (tech, creative services). Among the things at stake for Portland's makers is the ability to access Portland's place-distinctive imaginary; what would "Made in Portland" mean if makers were displaced and could not make in Portland, or at least not in the 
central neighborhoods for which Portland has become so recognizable? In continuing to do research in Portland, I was enticed to ask makers about the decision rules regarding what "Made in Portland" means as the city changes, and how that meaning is reflected in how Portland's imaginary is understood by makers as a source of added value. Portland has been an interesting place to learn about whom the "made in" branding works for and who or what it might hide.

One of the most distinctive aspects of all the change in Portland has been the aforementioned citywide handwringing over the death of "Old Portland" and the birth of "New Portland." According to a 2015 Willamette Week article, ${ }^{1}$ a local theater group actually had a funeral for Old Portland; the article actually opens with the sentence "Old Portland is dead." A week later, another article ${ }^{2}$ in the same publication actually dated Old Portland's life: it began on January 2, 1985, when Bud Clark was elected mayor, and it died on January 21, 2011, when the sketch comedy television series Portlandia turned Portland's "weirdness" into twee. The first article described the descent into New Portland in the following terms:

The birth of the "Old Portland" people loved so well seems to have happened [...] when the first big wave of transplants from California and loud people with hard vowels began arriving, pulling the region from redneckery. That era appears to have ended roughly when a second wave of those people came and filled up the existing housing supply, causing the city to become unaffordable for an existing

\footnotetext{
${ }^{1}$ https://www.wweek.com/portland/article-25196-dead-and-gone.html\# ${ }^{2}$ https://www.wweek.com/culture/2015/08/21/breaking-weve-officially-determinedwhen-old-portland-died/
} 
population that didn't have the foresight to purchase inexpensive real estate while it was available.

The narrative about Old Portland seems to be that it was a place where weird was normal; New Portland is much more conventional, as captured by this 2017 anonymous comment $^{3}$ in the Portland Mercury:

I think I've realized why I and others don't like the newcomers to Portland. It's a bit hypocritical because most of us moved here at some point, but I think the difference between the people that moved here 10 or 40 years ago and those that have come in the last several years is that the 'old' Portland folks were part of that 'Keep Portland Weird' character. They were adventurers, loners, thrill seekers, losers, drop-outs, punks, hippies, junkies, freaks and geeks. The newcomers are followers. They're trendy, pretentious, trust fund babies, groupies and pop culture consumers. They came to Portland because they heard it was cool and their friends moved here. We came because it was cheap and a place we could be ourselves.

Of course, pronouncing one version of Portland's imaginary dead and for the sake of the other's birth seems a bit rigid; I would argue there is less of a hard border and more of a transition between the two. As is evident in chapter 6, many makers actually came to Portland in those transitional years, maybe a few years too late to find the ingredients of Old Portland. But the aspirations that brought them here still matter; these are the desires - for creativity, weirdness, independent autonomy, progressiveness, and so on - that get

\footnotetext{
${ }^{3}$ https://www.portlandmercury.com/i-anonymous-blog/2017/02/28/18872940/oldportland-new-portland-us-vs-them
} 
wrapped up (and economized) in "Made in Portland." This puts the maker milieu in Portland somewhere in the impasse between New and Old Portland. Even if "old" Portlanders are sure they know who is migrating to Portland, they can only speculate on what New Portland will eventually become. For all of its anxiety-inducing prognostication, New Portland is still an indeterminate place. This is why it is an interesting geography for me, as is reflected in my research question: how is "Portland" coherent enough to transmit a value system through the use of "Made in Portland?" From the inside, "Portland" appears to be anything but stationary or stable.

Detroit is the other side of Portland's coin: in many ways, Portland and Detroit couldn't be any more different: ${ }^{4}$ Racially, Portland is roughly $76 \%$ white and $6 \%$ black, whereas Detroit is roughly $10 \%$ white and $83 \%$ black; they are (absurdly) about the same size in population $(\sim 650,000)$, but Portland is growing $(8.3 \%, 2010-2015)$ while Detroit is shrinking $(-5.1 \%, 2010-2015)$; median housing values in Portland are six times higher than in Detroit ( $\$ 285,000$ vs. $\$ 45,000$ ); median household income in Portland is double that of Detroit ( $\$ 53,000$ vs. $\$ 26,000$ ); the statistical likelihood of being in poverty in Detroit is 2.5 times greater than in Portland ( $40 \%$ vs. $18 \%$ poverty rate); the percentage of college-educated residents is 3.5 times higher in Portland than Detroit (44\% vs. 13\%). These statistical observations can only gesture toward certain differences in perception (e.g. "urban vibrancy" vs. "urban ruins"); of course the actual situation in Detroit is far more complicated than these statistics imply.

\footnotetext{
${ }^{4}$ All subsequent statistics gathered from the US Census: http://www.census.gov/quickfacts/table/PST045215/2622000,4159000
} 
The scholarship on Detroit's struggle over the past half-century is abundant. A key destination for southern blacks during the aforementioned "great migration" (Massey \& Denton 1993), the city has been an epicenter of racism, racialized politics, and failed urban renewal and community development projects (Thomas 1997). The city's complex legacy of manufacturing, racial politics, and economic transition has resulted in Detroit's exemplar status in the discourse around "legacy" and "shrinking cities" (Morrison \& Dewar 2012; Hollander 2010), terms popularized to describe the combined aesthetic, historic, sociocultural, and economic effects of depopulation, ruination, deindustrialization, and racism. Detroit is regularly (and obliviously) referred to as a "blank slate” (Dawkins 2011; Darroch 2015), or in other words, a laboratory for experiments in art, planning, and community organization. More recently, the city has been gaining scholarly recognition for its unique scale of abandonment (Hackworth 2014; Hackworth 2015a; Hackworth 2015b), its landscape of ruination and so-called "ruin porn” (Apel 2015; Millington 2013; Temple 2010; Leary 2011), and the artists and creatives that have flocked to fill the ostensible "void" (Herscher 2012; Dawkins 2011; Darroch 2015; Gorman 2007).

This is all subject to a discourse of "new" and "old," quite similar to that which emerged in Portland around the same time. By 2015, the alternative press was buzzing with the "tale of two Detroits" - one that housed the "new" and one that was still "old." As a 2016 article in Thrillist put it:

Detroit today is not Detroit 10 years ago. Hell, it's not Detroit 10 months ago; it's not even the same city it was last week. We've got foreign investors out the wazoo, transplants from some of the hippest cities in the world, and what seems 
like a new bar and restaurant opening its doors more frequently than the People Mover. There's much to bemoan: higher rent, more traffic, $\$ 5$ cups of coffee, etc. But fortunately, it's a big ass city. And even though "New Detroit" is quickly creeping in, there are still plenty of places where the "Old Detroit" lives on. The point of the article, as the last sentence foreshadows, was to tip people off as to where "Old Detroit" had avoided the wrecking ball. But "newness" in Detroit is complicated; as of yet it is largely sequestered to a small group of central city neighborhoods rebranded as "the 7.2" (it occupies about 7.2 square miles). The other 135 square miles are still predominantly "old," which is a thinly veiled code word for poor and black. It is no secret that Detroit's outer neighborhoods, which make up about 95\% of Detroit's total area and are overwhelmingly black, are not seeing much of the "newness" mentioned in the block quote above. Numerous articles make this point (see: Wey 2017; Dalmia 2017 for two great examples), and my research findings certainly bear this hidden narrative out. Like Portland, this makes "Made in Detroit" an interesting question: which Detroit makes the cut? How do makers respond to the shadow that "Made in Detroit" casts over most of the city?

Also like Portland, Detroit has emerged as a central urban hub of maker activity. In fact, at least two interviewees in Portland mentioned their excitement for Detroit's energy around the maker movement. A blog post in 2013 was almost prescient in its articulation of Detroit's "next" phase as the growth of its thriving "artisanal economy" (even if the article's overall point was to bemoan the emergent new vs. old discourse) ${ }^{5}$. Detroit currently has at least three makerspaces (Ann Arbor has two more), an accelerator

\footnotetext{
${ }^{5} \mathrm{http} / / /$ cornersideyard.blogspot.com/2013/12/new-detroit-vs-old-detroit.html
} 
devoted to maker firms (Ponyride), one prominent maker-style industrial center (Russell Industrial, although it was shut down while I was in Detroit), a handful of maker-style open-air markets (most notably Eastern Market), and even plans for a Ford-sponsored makerspace in Brightmoor (a well-known "bad neighborhood" in Detroit). But things never seem to lack additional layers in Detroit; the emergence of the maker movement in Detroit has seen the rise of suburban makers as well as Detroit-based makers, and the use of "Made in Detroit" is at stake. Who's Detroit is "Made in Detroit"? My assumption going into this project was that there would be significant tensions between urban and suburban makers; indeed, this was the case. It wasn't lost on makers, many of whom had moved to the city from the suburbs at some point in the past decade, that the historical racial tensions between city and suburb were being replicated in some ways by the "new" and "old" discourse. Makers in Detroit ended up with a complicated positionality, even if they were quite dug in on the evilness of the suburbs.

As a note of caution moving forward: every mention of "old" or "new" Detroit or Portland should be taken as sentence fragments in a larger story. This is just to say that neither "new" nor "old" comes from nowhere: as W.G. Sebald once wrote, "on every new thing there lies already the shadow of annihilation." It is important to remember that "old" was at one point "new." Old Portland, for all its drunken wackiness and public nudity, emerged alongside the nearly complete disinvestment and abandonment of northeast Portland's black community (Gibson 2007). Likewise, Old Detroit was made possible by similar racist disinvestment, although the scale of Detroit's "deproletarianization" and the political abandonment of its black population is perhaps unrivaled in scale or sheer cruelty (Sugrue 1996). With so much policy talk centered on 
"creative placemaking" and the productions of innovative and vibrant cities (i.e. the "new"), it is worth keeping in mind that it was policy that created the conditions for the emergence of the "old": Sharon Zukin (1982) makes this clear in Loft Living. It's enough to make one wonder what Portland's black population thought of Old Portland, which likely felt like New Portland to them. This is all just to encourage a more reflexive reading of what follows: "new" and "old" are not really new or old; analysts are, as Gilles Deleuze would say, always entering in the middle.

\section{Dissertation Roadmap}

The central questions of this dissertation are: What makes "Made in Place" an effective strategy for makers, and what gives it coherence and power? How is it mobilized such that it expresses (and adds) ethical and economic value, and what tensions emerge from its mobilization? Chapters 2-6 address these questions from a few different vantage points. Notably, I split the "Made in Place" phrase into two sections, one for each side of the phrase: the "made" side is addressed in chapters 3 and 4, whereas the "place" side is addressed in chapters 5 and 6.

Chapter 2 is centrally concerned with providing context for the dissertation. That chapter has three sections: the first is a literature review of makers and the maker movement. The intent is to provide a comprehensive view of what has been said about making, the maker identity, the values makers advocate, as well as some critiques of the maker movement. The second section provides some theoretical context for the dissertation, especially honing in on the two major theoretical concepts of imaginaries and impasse. Although I draw on a number of theoretical positions throughout the dissertation, these two concepts are constantly ontologically and epistemologically 
present in each of the chapters' analysis. As I have said above, the central theoretical claim of this dissertation is that imaginaries make sense of the impasses makers are confronted by; I focus on the impasses of neoliberal globalization and urban development, and am especially keen to describe the emerging tensions that imaginaries introduce. The final section of chapter 2 describes my methods for data collection. The dissertation is qualitative and relies on roughly 70 interviews from Detroit and Portland. I hesitate to call it a comparative dissertation, however, as there are divergences in data collection and sample consistency between the two cities. My general approach, both to data collective as well as to analysis, is more like a hybrid between a critical ethnography (Madison 2005) and a case study (Yin 2009). Interviews were my primary data gathering method; I used a semi-structured approach, and there was general consistency the structure of the interviews between the Portland and Detroit cases.

Chapter 3 takes up the question of what a maker is empirically. All of my interviewees were asked the same question: what is a maker? Rather than aggregate makers' responses to this question, the chapter dwells on the inconsistencies and tensions that emerged from the responses. Of course, there are some commonalities - the collective insistence on making being a unique form of work that pushes back on more corporate versions of entrepreneurialism, for example. But throughout my research the "maker" identity position struck me as contentious and at times incoherent. Certain associations - to "craft" and to "manufacturing" especially - made the waters even muddier. Yet my analysis shows that "maker" retains its coherence not because it can be defined as a universally agreeable identity position, but because it is collectively imagined in such a way that provides a non-rigid sense of belonging. In other words, 
makers can hate the term "maker" yet recognize the advantages it has for them because they don't feel trapped by it. The attachments makers have are not to the identity position itself, but rather to the "public" that making provides as a place to feel grounded by something. Maker, then, is more of an imaginary than an identity.

But producing goods in the "unique" ways makers adhere to has a major problem. Chapter 4 examines this problem, which I call the "pricing paradox." This paradox is an impasse that results from makers fastening their ethical positions to their production process; the essence of the problem is that as ethics become more important in production and consumption, the price of the goods produced swells so as to only be available to wealthier consumers. Makers are keen to this problem, and a good portion of the chapter is devoted to the methods makers devote to resolving this impasse. In reconciliation, makers attempt to open the proverbial black box of production with the idea that the value proposition between makers and their consumers has to be re-imagined. The chapter discusses the use of social media, storytelling, and a commitment to staying small (and local) as strategies to justify the necessity of higher prices. The chapter concludes by dwelling on the idea of "scaling up." If makers choose this route, they inevitably would be confronted by the very ethical conundrums that drove them to "making" in the first place. The problem, then, is tied up in value(s) - value under capitalism is represented by prices, and makers do not have the capacity to otherwise evaluate their goods. A new imaginary of value, however, might be something the maker movement positively contributes to.

Chapters 5 and 6 move the analysis of "Made in Place" toward the "place" side. Each chapter takes the complicated imaginaries of Detroit (chapter 5) and Portland 
(chapter 6) as its subject, using interviews with the cities' makers to understand their interaction with the urban imaginary. I have already described "new" and "old" Detroit/Portland at length above, and needless to say, these aspects of each place factor greatly into each chapter. Both chapters show how "Detroit" and "Portland" become coherent through the construction and maintenance of a public imaginary despite the significant changes represented by the more local imaginaries of "new" and "old." In each city, makers rely on these imaginaries to derive a sense of place amidst each city's changes, but the shape that this sense of groundedness takes is different in each place. In Detroit, makers tended to lament the uncomfortable advantages that "Made in Detroit" presented them with. Race and class inequality is exceedingly visible in Detroit, and makers ended up in a position where they must choose between exploiting a "Detroit" brand that does nothing to alleviate inequality and surviving as a business. In Portland, coping with the shift from old to new manifested in a set of aspirational values that makers invested in the city's imaginary. These values - community, autonomy, authenticity - were a form of pushback against the threats makers perceived, both from the global impasse of neoliberal capitalism as well as the local impasse of New Portland's emergence.

All of the above are inputs into "Made in Detroit" or "Made in Portland." As I hope is by now clear, neither "made" nor "Detroit/Portland" is a stable thing: instead, they are mired in a variety of impasses, and they derive their appearance of stability through the imaginaries described below. What follows is my attempt to deconstruct "Made in Place" and draw out the tensions housed in the notions of identity, value, and place amongst Detroit and Portland's makers. 


\section{CHAPTER 2: LITERATURE, THEORY, AND METHODS}

\subsection{WHAT IS THE MAKER MOVEMENT?}

Before presenting my empirical findings (Chapters 3 through 6), I am tasked with some important questions on behalf of the reader: what is the maker movement? What is a maker? The first part of this chapter will answer some of those questions by reviewing the emerging literature on the maker movement. There is a general agreement that the maker movement has its roots in the American Arts \& Crafts movement and subsequently the "hacker" culture inspired by the counterculture of the 1960s, particularly Stewart Brand's Whole Earth Catalog first published in 1968 (Morozov 2014; Kneese et al. 2014; Martin 2015). Both movements focused on physically making things as a way of resisting the capitalist order, but both came up short of their radical goals, suffering from an inability to deal with essential inequalities, inaccessibility of goods and tools (due to expense), and eventual absorption into the larger political economy (Morozov 2014). The two movements, however, germinated "production sensibilities" (Kneese et al. 2014) relative to each - a nostalgic, artisanal, craft-based sensibility and another focused on open-source programming, electronics hardware, and $3 \mathrm{D}$ printing ${ }^{6}$ - that have converged under the umbrella of the maker movement. Referred to variously as the "Maker Faire" and the "Brooklyn" milieus (Wark 2013) or "artisans" and "hardware makers" (Heying, 2010; Wolf-Powers \& Levers, 2016), this duality is further nuanced by Martin (2015), who adds to the maker genealogy the term "tinkerer,"

\footnotetext{
${ }^{6}$ These are what we have been referring to in the Kauffman project as "bags" and "bots" respectively
} 
which has roots in the MIT Media Lab and the associated "Lifelong Kindergarten group," as well as the term "bricolage" used by anthropologist Claude Levi-Strauss in the 1950s to describe a "do-it-yourself" or "ad hoc" attitude toward creative producing.

Heying (2010) should be credited with one of the first empirical attempts to understand the emergence of maker or "artisan" culture. Conducting fieldwork between 2006 and 2010 and using data from over 115 interviews, Heying's research argues that makers are characterized by:

- An integration of production and design (i.e. the designer also produces)

- An appreciation of the material of production (i.e. the development of a relationship between producer/subject and produced/object)

- The blurring of work and leisure (also see: Lloyd, 2006)

- The clustering into like-minded communities/milieus (also see: Currid, 2007) that avoid hierarchical organization

- And a predilection for local materials, supply chains, consumers, and terrior, all of which find a home in the object of production.

Additionally, Beauregard (2014) notes some further motivations of makers:

- The desire to make the things one uses

- The desire to "connect to the physical city" through DIY projects,

- And the desire to remedy the ecological devastation and the wastefulness of planned obsolescence brought on by Fordist capitalism Martin (2015) attempts a definition of making, describing it as "a class of activities focused on designing, building, modifying, and/or repurposing material objects, for playful or useful ends, oriented toward making a 'product' of some sort that can be used, 
interacted with, or demonstrated" (31). Wolf-Powers and Levers (2016), however, argue that "making" is a slippery term with an inherent "fuzziness" (Markusen 1999), and therefore can be defined in a variety of ways. Embedded (non-mutually exclusive) contexts in such definitions can include degrees of localness, relations between maker and objects of production, consumption and aesthetic preferences, or even an entire mode of production potentially capable of challenging corporate forms of production. The popular notion of the "democratization of technology" (Richardson, Elliott, \& Haylock, 2013) is often used to express the diminishing barriers for small firms and individual makers to access new technologies such as rapid prototyping (Fallows 2016a) and shared access to expensive and large machinery through the development of makerspaces (WolfPowers \& Levers 2016; Roy 2015). This new access, along with the development of ICTs, e-commerce (Fallows 2016a), and social media (Kneese et al. 2014; Marotta et al. 2016) have allowed the visibility and popularity of the maker movement to explode over the past decade.

\section{Maker Identity and Subjectivity}

The combination of inputs that have led to the rise of the maker movement have led to a variety of takes on what the "maker mindset" (Martin 2015) or "maker subjectivity" (Lindtner 2014; Marotta et al. 2016) consists of. There is a clear lineage between making and art/creativity (McRobbie 2016), urban DIY movements (Douglas, 2013; Finn, 2014), design (Richardson, 2012), and craft economies (Dawkins, 2011; Luckman, 2013), so it seems safe to assume that a maker subjectivity would share many characteristics with these other "creative" identities. With that said, a few authors have engaged directly with what a maker subjectivity might look like. Martin (2015), for 
example, identifies four characteristic of what he calls the "maker mindset": playfulness and experimentation; an orientation toward expansive growth and the idea that they are capable of anything; the celebration of failure and the notion that success actually requires a series of failures; and the ability to work collaboratively and to share ideas, materials, and aid. Toombs, Bardzell, \& Bardzell (2012) ${ }^{7}$ largely concur, perhaps reframing Martin's notion of playfulness and experimentation with what they call "adhocism," or a work process in which projects are not planned ahead of time, but rather undertaken with the confidence that problem solving - which is not anticipated or codified in any way - will be done in real time.

The question of what forces operate to construct the maker subjectivity is of course place and time dependent. In China, for example, Lindtner, (2014) locates the development of maker subjectivity within a particular contradiction between makers and the Chinese government. China's government is pivoting their economy away from manufacturing things designed elsewhere (e.g. an iPhone) toward an economy that is based on local creativity, innovation, and an empowered citizenry, a position that Chinese makers fully support. But the government sees the transformation of the economy as a state-led, top-down project, ${ }^{8}$ whereas makers see this the empowerment of the individual as necessarily bottom-up. The tension between the two positions, Lindtner argues, is the

\footnotetext{
${ }^{7}$ It should be noted that the makers they interview are all a part of the same makerspace in Indiana, and largely all work in the "bits" and "bots" fields of making. In other words, the coverage and diversity of their sample is not as reliable as the Kauffman study of makers.

${ }^{8}$ As of July 2016, China is reportedly experiencing a real estate bubble due to the overbuilding of incubators/accelerators in China's cities. See: http://www.reuters.com/article/us-china-economy-innovation-insightidUSKCN0ZM2KY
} 
site for the development of maker subjectivity. Marotta, Cummings, \& Heying (2016) also focus on the role of place in the normative formation of maker subjectivity. The tension here is between the imaginary of place (distributed over social media networks) and the concrete changes in space (experienced as the reification of aesthetic preferences). The authors argue that Portland's transformations of space reflect the negotiated performance of the maker subjectivity, at once capturing the creative vibrancy of the maker milieu while displacing the conditions that support the milieu. The maker subjectivity, then, is a complex entanglement of fragmentation (displacement) and belonging, material and immaterial, and local and global.

To all these characteristics of a maker subjectivity we should add entrepreneurialism: "We are all entrepreneurs now," claims Szeman (2015), who is not necessarily speaking on the productive capabilities of the maker movement but rather to the sensibility that entrepreneurs need to adopt in order to survive. This increasingly celebrated sensibility concerns Szeman, who indicts the university-corporation-public sector nexus championed by the likes of Dougherty (2012) and Fallows (2016b) as generative of this entrepreneurial "common sense." Any subjectivity that celebrates failure, Szeman argues, further naturalizes the extreme risk entrepreneurs must take on and makes the high wire act without a net seem exciting. Needless to say, such a form of common sense also legitimates the roll back of the welfare state (Tickell \& Peck 2002; Peck \& Tickell 1994), leading makers (and all entrepreneurs) to believe that if they fail, the onus is not on structural or historical conditions, but rather their own fault. 


\section{The Importance of the Urban in the Maker Movement}

Authors such as Beauregard (2014), Iveson (2013) and Douglas (2011; 2013) argue that young people - increasingly concentrating in cities - have applied a DIY ethos to their urban surroundings. This "back to the city movement" (Hyra, 2014; Smith, 1979) is yet another set of discourses unavoidably entangled in the maker phenomenon, and yet the maker movement literature remains reasonably mum on this connection. ${ }^{9}$ The making phenomenon being largely urban (see the bevy of city-specific "made in" organizations and the Urban Manufacturing Alliance as proof) and more than just tangentially related to art and creativity, this review would be remiss not to visit the literature on artists' relationship to gentrification.

This literature is somewhat ambivalent: some positions confront and explicitly accuse the "art world" (the conglomerate of artists, scenesters, gallery owners, curators, etc.) of complicity in gentrification (Deutsche \& Ryan 1984), while other positions argue that artists (and makers) are treated like pawns by developers (Nicodemus, 2013), and yet others promote the role of art in economic development regardless of whether artists and makers are gentrifiers or not (Currid, 2007; Markusen \& Nicodemus, 2010). Carducci (2015) disputes the artist-led gentrification model, arguing that there are neighborhoods in Detroit that should have gentrified a long time ago if that model were true. Typical gentrifiers, Carducci argues, want the "loft-living lifestyle, minus the starving artist part." Drawing on Bourdieu, Ley (2003) argues that artists' privilege comes in the form of

\footnotetext{
${ }^{9}$ One of the clear anxieties in the Kauffman study, especially in New York and Portland, is the pace of gentrification and neighborhood change; affordable space for manufacturing is quickly drying up in places like Portland's Central Eastside Industrial District, a protected industrial reserve.
} 
cultural capital (e.g. a college education), which can be converted into economic or social capital through various channels available to artists. Zukin's (1982) analysis of the "artistic mode of production" (AMP) provides the most integrated (between economy and culture) take; Zukin argues that economic restructuring cannot happen without an complementary cultural strategy. Zukin describes the spatial transition of lower Manhattan from low-rise manufacturing to "loft"-style housing - the "highest and best use" - as evidence of a spatial and economic strategy to maximize ground rents by shifting from manufacturing to service; this economic shift was lubricated by a cultural shift, which Zukin identifies as the emergence of Manhattan's "art world." As a cultural economic strategy, the AMP ushered in the urban service economy while pronouncing urban manufacturing dead.

Whether gentrification is driven by "rent gaps" associated with the movement of capital (Smith, 1979), the cannibalization of urban space by successive waves of artistic milieu and cultural consumption (Beauregard, 1986; Gonzalez \& Waley, 2013; Ley, 2003), or arts-oriented public policy (Cameron \& Coaffee 2005), the fact that the maker movement has risen to prominence concurrent with the "super-gentrification" of places like Brooklyn (Lees 2003) and Portland (Wile 2015) cannot be ignored. Considering Zukin's (1982) insistence that the AMP put the proverbial "nail in the coffin" of manufacturing by retrofitting urban manufacturing space for housing (i.e. "loft living"), it is interesting, then, that manufacturing is largely defining the urban sensibilities of the maker movement. Perhaps this is why Zukin (2010) updated her thesis to include the perception of the loss of "authenticity." The architecture and infrastructure necessary for manufacturing begs its present day users to think through the "wish images" (Benjamin 
1999) of the generations that arranged urban space in such a way. Perhaps this is partially why manufacturing - albeit in a relatively new formulation (Stangler \& Maxwell 2012) and tinged with nostalgia (Kneese, Rosenblat, \& Boyd, 2014) - has become so important for this particular urban milieu.

Richardson, Elliott, \& Haylock (2013) argue that indeed, the inchoate maker movement is beginning to transform the physical space of cities, particularly cities that have experienced decline due to the flight of Fordist-style manufacturing. The assemblage of values that serve as the cultural glue for makers - open-source everything, sharing and collaborating, the collapse of the producer/consumer and designer/producer binaries, changes to site specificity (work, home, leisure, etc.), increased access to tools through the rise of makerspaces - has generated a more distributed form of manufacturing, which they define as "domestic-scale manufacturing." This "anywhereness" of production, however, can be characterized not by the spatial scattering it might suggest, but rather by a return to "co-location," or the dense agglomeration of multiple layers of manufacturing (suppliers, workforces, engineers, distributers, etc.). Stangler and Maxwell (2012) argue that a major benefit of co-location is cultural spillover. The combination of the "open source ecology" of such maker communities with the so-called democracy of technology, the momentous energy being invested in entrepreneurialism, and the connectivity of Internet-based technologies have created a physical, cultural, and economic milieu that together broadens the idea of a "producer" and more generally the conception of manufacturing. One obvious outcome is the emergent possibility that anyone can become a producer (cf. Benjamin, 1968), but the authors also argue that aside from the spillover effects that add new value to the 
manufacturing process, this new formulation of manufacturing is far more efficient and lowers costs across the board.

Recent attention to entrepreneurial ecosystems (Auerswald 2014; Bell-Masterson \& Strangler 2015) help to clarify the importance of urban co-location for maker firms. One particular advantage of such ecosystems has been the emergence of "maker-enabling entrepreneurs" or "MEEs" (Doussard et al, 2014); these entrepreneurial ventures fill a variety of infrastructural gaps brought on by an assortment of market failures. WolfPowers \& Levers (2016) argue that the field of maker-enabling entrepreneurs is complex, diverse, and place-specific (and thus will look different from site to site), and addresses a variety of fractures within the emergent maker economy and culture. These fractures may include fragmented (local) networks, a lack of business services and know-how, and poor access to capital, all of which hamper maker firms' ability to scale and increase the amount of jobs created. They also point to the enabling role of co-working and hacker/makerspaces, arguing that such spaces are inherently collaborative and provide much needed access to otherwise inaccessible tools and business advice. Moilanen (2012) finds that motivations to be a part of such spaces are largely social, citing altruism, community, having fun, and meeting other makers/hackers as common values in his research on European hackerspaces.

Tierney (2015a) also raises the question of MEEs (he refers to them as "enablers"), but only forwards three important categories as fundamental to the maker movement: makerspaces, crowdfunding platforms, and local retailers. Retailers are particularly valuable because they are where makers become oriented to the market and consumption practices as well as distribution challenges - local retailers are like a 
proving ground for makers. The retail aspect of the maker movement allows this section of the review to come full circle, back to the notion of neighborhood change: for example, Sullivan \& Shaw, (2011) argue that Portland's Alberta Arts district, which is a gentrified neighborhood and a hotspot for maker-oriented retail in Portland (Heying, Marotta, \& Cummings, 2016), has undergone a shift from instrumental retail to reflective retail. Instrumental retail, in their case, describes retail options that fulfill local residents' needs - convenience stores, barber shops, grocery stores, and so on - whereas reflective retail reflects the new milieu's lifestyle - sidewalk cafes, an inordinate amount of bars and restaurants, art galleries, high end clothing boutiques, and so on. This shift, perhaps captured best by what Deener (2007) calls the "symbolic ownership" over the identity of a specific space, formulates an aesthetic displacement of instrumental retail in favor of boutique-style consuming (Zukin et al. 2009) and a new normativity for urban space that is often captured in changes to cities' zoning codes (Keatinge \& Martin 2015) or the public re-branding of an area to conform with its new identity (Deener 2007; Hyra 2014). In many gentrifying neighborhoods, it is clear that locally made goods play an outsize role in such transformations, thus complicating the notion of what "made in [your city here]" really means (Marotta \& Heying, 2018).

\section{Feminism, Fetishism, and Favoritism: Critiques of Making}

The meteoric ascension of the maker movement is due in part to the fact that so many pundits, educators, foundations, and politicians see the movement as a panacea for many of society's ills: "making" (and "creativity" in general) can retool our "rigid" education system (Martin 2015), re-energize public-private relations (Fallows 2016b), provide corporations with a labor pool already steeped in the art of risk-taking and 
innovative thinking (Dougherty 2012), and renew urban space that has suffered for decades at the end of deindustrialization's sword (Richardson et al., 2013). But before it becomes a religion, the challenges inherent in such cheerleading must be excavated. Leonard (2013), for example, argues that the access granted by the so-called democratization of technology largely benefits the mostly white, mostly male, wealthy, educated upper-middle class. ${ }^{10}$ In other words, the "Etsy model of capitalism" and the democratization of access to rapid prototyping technologies (3D printers) is largely only benefitting the people that don't really need the help in the first place.

This B-corp, "postcapitalist" (Larocca 2016) Etsy model has run into challenges from authors that see it as exploiting an illusionary "postfeminist" movement (Dawkins, 2011; Luckman, 2013a; Luckman, 2013b; McRobbie, 2016). So-called "craftivism" movements have indeed been important in the political activation of (traditionally female) craft (Luckman, 2013a), but the trade-off is that women are too often put in the position of seeking "self-fulfillment" as remuneration (Dawkins 2011) or having to add an entrepreneurial, Etsy-based career to their list of domestic caretaking responsibilities (Luckman, 2013a). Etsy ends up frustrating feminism in these cases, as women must trade a desire for autonomy and "passionate work" (McRobbie 2016) for a host of unpaid tasks necessary to promote their (self as) brand and distribute their goods (Duffy \& Hund 2015). The increasingly entrepreneurial structure of the craft economy eventually further regulates the lives and activities of women (McRobbie 2016), blurring the realities of precarious work and reproducing the (masculine) economic imperatives that created the

\footnotetext{
${ }^{10}$ Leonard's methodology is questionable, however - he relies on a survey of Make media subscribers, which yields very different demographic and economic numbers than Heying et al $(2014 ; 2016)$ found in two annual surveys of Portland Made Collective.
} 
desire for feminist autonomy in the first place (Dawkins 2011). For Chachra (2015), these things all get wrapped up in the maker identity, thus perpetuating a value system that dehumanizes people in favor of commodity production.

Other authors focus on the fetishizing elements of the maker movement. Kneese, Rosenblatt \& boyd (2014) and Wark (2013) argue that both aspects (i.e. the craft and the electronics milieus) of the maker movement obscures "elsewhere" labor processes by conflating "made here" with "assembled here" or with a sense of nostalgia. This is made more egregious by the emphasis on transparency in the making process, an emphasis that pays little attention to the overseas production of Arduino boards and other electronics components or the working and living conditions of local farmers or materials suppliers. ${ }^{11}$ Wark (2013) adds to the list of maker fetishes that the "Brooklyn" crowd (i.e. artisanal makers) fetishize labor in the sense that the notion of "handmade" is substituted for a more substantive conversation about the ordering of the material world around the contemporary logic of labor organization, an argument that gestures toward the growing literature on creativity and labor precarity (Raunig et al. 2011; de Peuter 2011; Gill \& Pratt 2008; Neilson \& Rossiter 2008). Additionally, maker milieus rely on global networks facilitated by technology such as iPhones (made in China), 3D printing (plastic spools made overseas), and e-commerce/social media sites (profits accumulating to a small cadre of wealthy executives), not to mention the need for makers to promote their lifestyles as urban, mostly in gentrified areas of cities that rely on a host of hidden

\footnotetext{
${ }^{11}$ In our interviews on localism in 2014, we did not have the same experience: most makers understand these connections and are realistic about what "made here" really means. See (Marotta \& Heying, forthcoming).
} 
gendered (Duffy \& Hund, 2015; McRobbie, 2016), aesthetic (Hracs \& Leslie, 2014), and “immaterial" labor (Dawkins, 2011).

Lastly, the maker movement is also, perhaps arguably, often enrolled into the academically disparaged yet oft-implemented "creative class" discourse (Florida 2002). In a nutshell, Florida's thesis essentially refocuses the developmental gaze of cities from physical structures (e.g. suburban tech centers and business parks) to the labor pool (Pratt 2008). Innovative firms, the argument goes, should rationally be looking to hire creative people, thus the call for cities to feed the necessary beasts - mainly in the form of particular amenities - that attract the creative class. Besides forwarding "specious" explications of creativity (Rodney 2009) and a shoddy methodology (Markusen, 2006), Florida has been accused of transforming the experience of poverty and vulnerability into the excitement of living in a "gritty" area (McRobbie 2016; Lloyd 2006a) and giving “urban entrepreneurialism” (Harvey 1989) a practical framework for disciplining labor forces into more and more precarious working conditions (Peck 2005), all of which results in a "beauty pageant" between places (Pratt, 2008) instead of proper support for the people and cities that need it the most (Rodney 2009). To make things worse for Florida's thesis, Silver \& Miller (2013) actually find that the presence of the creative class (according to Florida's taxonomy) has a generally ambivalent to negative correlative effect on wages, thus making the implementation of Florida's recommendations by cities even more confusing.

\section{The Moral Dilemmas of the Maker Movement}

The firms and organizations that have birthed much of the discourse on the maker movement do not shy away from what they believe is a paradigm-shifting phenomenon. 
Mark Hatch, the CEO of TechShop, and Chris Anderson, the oft-cited author of the book Makers, both summon Karl Marx’s "democratization of the means of production” thesis and promise some sort of revolution from the maker movement (Morozov 2014). Etsy, originally conceived of as an "anarchist artist collective" and named for a line from the Fellini film $8^{l} / 2$, was founded on the principle that "doing good" should be encoded into the process of making a living (Larocca 2016). Of course, this wouldn't be the first movement that dreamed of a better world through making and hacking: Morozov (2014) argues that the Arts \& Crafts movement and the hacker movement of the 1960s both envisioned self-empowerment and alternative forms of work as socially transformative, although each movement's physically "made" gadgets, even with their genesis in radicalism, came to be controlled by the same institutions that they were originally trying to resist, the end result being digression into naked consumerism and apolitical tinkering for tinkering's sake: "Never before have so many had access to thermostatically warmed toilet seats" (ibid). The overinvestment of energy in the power of tools and technology what Morozov calls the technological sublime - ends up reproducing the current order of political economy while peddling illusions of emancipation.

Other (arguably) related urban movements, such as DIY urbanism (Iveson 2013; Deslandes 2013), creative placemaking (Markusen \& Nicodemus 2010), and “art as social practice" (Bishop 2012) have similar imaginations of social transformation. DIY urbanism, for example, has radical roots traced by Finn (2014) back to Situationism (Debord 1983), experimental architecture (e.g. Gordon Matta-Clark’s Anarchitecture), and the punk scenes of the 80s (Holtzman, Hughes, \& Van Meter, 2007). Despite these radical roots, DIY urbanism has recently been described by Douglas (2013) as more 
functional than political - new residents to an area, ${ }^{12}$ that is, are more interested in fixing up dilapidated infrastructure than making a political statement about the public and institutional neglect these areas endured for decades while hosting racialized lower classes. Embedded in such discourses are tensions between quality (aesthetics) and equality (ethics); temporariness and permanence; and (produced) object and (production) process. These tensions often result in a "directed reality" rather than meaningful social change (Bishop 2012).

The questions, then, of whether the maker movement is alternative or oppositional to capitalism (Beauregard, 2014) and whether or not it is capable of transforming the state (Fainstein 2014) remain open. In addition to these organizational, political, and cultural tensions, the maker movement also seems to be subject to the Jurassic Park question (i.e. just because we can doesn't mean we should) and the contemplation of a moral framework for things such as 3D printed black market goods (e.g. 3D printed guns), malicious hacker groups, and even the emergence of "synthetic biology" (Tierney 2015b). With a statement seemingly begging for a biopolitical analysis (Foucault 1978), Tierney describes Jameis Cascio's ${ }^{13}$ conjuring of "a near future in which the maker impulse is applied not just to making things, but to making life." He is referring to the possibility that 3D printers will soon be producing human organs, food, surgery needs (knee joints), and so on. Cascio pondered aloud, according to Tierney, on what society

\footnotetext{
${ }^{12}$ Douglas stops just short of naming these residents as gentrifiers, mentioning that they are largely white and educated and moving into minority-majority neighborhoods.

${ }^{13}$ Cascio was a panelist at the 2015 Conference on World Affairs, reported on by Tierney for The Atlantic
} 
should do with this God-like power, invoking Stewart Brand's introductory quote from his 1968 Whole Earth Catalog: "We are as gods and might as well get good at it."

\subsection{THEORY}

While the above literature describes the maker universe primarily from an empirical perspective, in part 2 of this chapter I will contextualize the maker phenomena from a theoretical perspective. In the first part, I will draw out some of the implications of neoliberalism and the neoliberal subject, and the economic entanglement with ethics on the emergence of the creative economy and the maker movement. The discussion of neoliberalism and creativity is meant to ground my research subjects in a particular cultural-political-economic moment, a moment that is rife with precarity. In the second part, I use Lauren Berlant's view of precarity to move toward one of the central theoretical concepts I animate throughout this dissertation: the impasse of modern work and life. An impasse, for Berlant, is a structured moment of transition in which fending off crises has become so ordinary that one's ability to anchor themselves to something solid is compromised. Impasses produce the experience of fluidity, such that people need to agree on and create ways to contain that fluidity in order to prevent it from overwhelming them.

The emergence of imaginaries - of "making" or being creative, of belonging to a movement or a place - is one way makers make sense from an impasse. Imaginaries are a second central theoretical concept; I make extensive use of it throughout the dissertation and for that reason, I spend a good deal of time constructing it below. I theorize "making" and the maker milieu as dependent on a set of intimate yet imaginary relations. One of my strong claims is that the maker movement is reliant on affectively distributed, 
commonly felt imaginaries of identity, value, and place (i.e. the cities they produce in), the combined power of which is often collapsed into something like a brand: 'Made in Detroit' or 'Portland Made.' The term 'imaginary' here is grammatically indeterminate, acting like a noun with action-descriptive characteristics. Imaginaries are objects, but only if we accept Berlant's (2016b) claim that "objects are always looser than they appear" (394). An imaginary's thingness, in other words, is "a convergence of force and value in patterns of movement that's only solid when seen from a distance; $[\ldots]$ a projection effect of interest in a thing we are trying to stabilize" (ibid, 394). Important to this sense of stabilization is the notion of "overflow," which I have developed elsewhere (Marotta \& Cummings 2018) and mean to describe the aspects of affective comprehension that exceed one's capacity to be affected. As I will show below, certain imaginaries around identity, value, and place emerge from this overflow on the level of the milieu. I begin with the significant emergence of the figure of the entrepreneur, which under neoliberalism has become something of an imaginary of its own.

\section{Making Makers: Neoliberal Subjectivity and Creative Work}

In The Birth of Biopolitics, Foucault (2004) painstakingly discusses the ascendency of neoliberalism with the intention of laying out the conditions for the development of "biopolitics." Biopolitics is Foucault's term for the establishment of a formal and normative political sphere organized around the management and order of life processes. The key figure for Foucault - the neoliberal economic subject - is homoeconomicus, or "economic man." Neoliberalism is new because of a series of realignments in economic and social life; the most pronounced shift, Foucault argues, is the refocusing of economic man from the management of exchange relationships to the 
subject formation of the entrepreneur, or more specifically, the "entrepreneur of himself."

Neoliberal economic subjects derive in part from Foucault's criticism of Marx's acceptance of certain classical liberal aspects of political economy. According to Foucault, Marx curiously does not sufficiently deal with labor as a form of human behavior. The problem is in "abstract" labor, Marx's significant discovery that concrete (individual, qualitative) labor under capitalism is necessarily converted into a (quantitative, aggregate) commodity called "labor power." Foucault thinks this discovery is valid, so long as we follow Marx in believing that the embedded processes of capitalism are responsible for the creation of abstract labor. Neoliberal economists such as Gary Becker, however, rejected this logic and instead argued that abstract labor is a figment of classical economic theory itself: Marx, in other words, was led to the conclusion of abstract labor by accepting such theories despite doing so in the service of critiquing them. ${ }^{14}$ Neoliberal economists reject the accounts of classical economists, and therefore perceive no need to engage with Marxism. Their engagement with labor does not see labor power as a commodity (object), but rather takes labor as a form of human behavior (subject) conditioned by the allocation of scarce means that cannot be evenly distributed. Neoliberal economists ask: "What does working mean for the person who works? What system of choice and rationality does the worker conform to?" (223). These questions, ostensibly from the perspective of the worker, shift the idea of wages from the

\footnotetext{
${ }^{14}$ Perhaps it bears mention that Foucault does exactly this with neoliberal theory in The Birth of Biopolitics
} 
(aggregate) selling price of labor to the amount of income one takes in, conceived by neoliberal economists as the return on a worker's (human) capital.

This raises an important point in terms of the maker-entrepreneurial subject: what form of income does a maker produce? The answer is not reliant on a theory of abstract labor, but rather the ability of the maker to curate $a$ set of conditions that warrants them an income. These conditions include: a milieu, exchange networks, a recognizable brand, the right ethical values, the right aesthetic, a social media presence, and so on. Makers are successful as entrepreneurs when they cultivate and perform a particular subjectivity that allows them to access essential relationships, norms, and practices. In other words, makers' incomes are fused to an assemblage of cultural and aesthetic practices. In The Use of Pleasure (1990), Foucault thinks through these practices, which taken together constitute the "techniques of the self":

What I mean by the phrase are those intentional and voluntary actions by which men not only set themselves rules of conduct, but also seek to transform themselves, to change themselves in their singular being, and to make their life into an oeuvre that carries certain aesthetic values and meets certain stylistic criteria (10).

Foucault also refers to these "techniques of the self" as the "aesthetics of existence" (11). This reference to aesthetics can hardly be reduced to "style" or trendiness. Instead, it refers to anything that presents itself to sense perception. Framed as such, aesthetics provide a key analytic for how boundaries are constructed (an "inside" and an "outside") within or between communities or milieus. This conception of aesthetics logically demands a system of distribution and policing - a "partition of the sensible" (Rancière 
2004) - that makes particular forms of aesthetics legible while policing and suppressing others. In such a "community of sense," only certain actions, thoughts, visions, practices, and habits are possible. Subjects within such communities are forced to curate the conditions of their existence according to such aesthetics.

This curation of the self is similar to what co-authors and I have referred to elsewhere as the "performance of aesthetics" (Marotta et al. 2016), an increasingly important set of practices that (Portland's) makers adopt in order to create, distribute, and consume specific meanings at the intersection of subject, place, and product, or what we might think of as the realm of the "brand" (Pike 2009; Arvidsson 2005). Moreover, the advent of the Internet and social media has had a transformative effect on the development of such "techniques of the self," especially with consideration for the spatial effects of global ICTs on meanings embedded in specific places such as cities or neighborhoods (Hjorth \& Lim 2012; Schwartz \& Halegoua 2014; Leszczynski 2014; Williams \& Dourish 2006).

So Foucault gets us to a place in which we can examine makers as "entrepreneurs of the self" that curate and perform a subjectivity laden with particular cultural values. But the neoliberal re-presentation of homo-economicus as human capital begs an analysis of how this capital is accumulated. The constituent elements of human capital, as Foucault shows, accumulate by applying "economic analyses to completely new fields and domains" (227). Suddenly all sorts of previously noneconomic domains are economically valuable, because they all get reoriented as inputs to be accumulated by the unit of human capital (i.e. a person). Familial devotion, cultural knowledge, technological prowess, a support network, higher education, and the ability to migrate to "sunnier 
climes" (e.g. "maker-friendly" cities like Portland) - inputs Bourdieu (1986) has called "cultural capital" - become key investments for the entrepreneur of himself. In fact, Foucault is almost prescient of Richard Florida's (2002) “creative class" thesis, pointing out that all this leads logically to an explosion of public investment in human capital development. Here we see extraordinary material and discursive investments in increasingly "measurable" urban conditions such as livability, sustainability, localism, and vibrancy (Frank 2012), all investments which transform (and spatialize) biopolitical statistics into an aesthetic logic (Ghertner 2015). The reliance on homo-economicus as a development strategy for cities is the essence of Florida's thesis: subsidize and nurture the amenities- and values-rich environments that human capital desires - the aesthetics of social reproduction - and your city will thrive.

Foucault's characterization of homo economicus certainly seems relevant at a moment when the enthusiasm for entrepreneurialism is reaching a fever pitch (Szeman 2015). The field of creativity provides a stage for entrepreneurialism, evidenced by scholarly attention to the rise of the "artrepreneur" or the creative entrepreneur (Chang 2008; Pasquinelli \& Sjöholm 2015). These cultural producers often describe creative work as their "destiny" (Duffy \& Hund 2015) and are inexhaustible in their efforts to properly self-brand (Banet-Weiser \& Arzumanova, 2012; Marwick \& boyd, 2011). This "ethos of 'passionate work"” (74) is the basis of McRobbie's Be Creative (2016): building on Foucault, McRobbie argues that finding emotional rewards in one's work is more than just a counter to alienation, it also is a characteristic whose celebratory rhetoric masks the "normative requirement" for marketing creative wares or services. McRobbie points out that this is where we see the rhetoric of creative "dream jobs" (an extension of 
childhood into professional life), the disappearance between work/life boundaries, the "economization of the imagination" (76), and the illusion of progress.

The obvious problem here is that monetary remuneration is substituted for satisfaction and emotional reward (Dawkins 2011). This is despite the fact that makers and other "creatives" are in effect required to present themselves as doing emotionally satisfying work in order to maintain their personal brand. In Be Creative, McRobbie (2016) steers toward the notion of 'affective labor,' an assemblage of analyses tied to scholars from myriad disciplines (Ahmed 2004; Negri 1999; Hermes 2015). Although nuanced by the frame of analysis, affective or emotional labor generally refers the increasing economic importance of emotions and affect in one's work (more on affect below). In many lines of work, the expression of emotional connection to one's work is becoming a condition of employment or entrepreneurial viability. In addition, McRobbie points out (107) that having a "dream job" or seeing passionate work as one's "destiny" is a preventative measure against forms of collective angst around which workers can organize. McRobbie sees these inputs as giving rise to a "romantic ethic" (108) for (neoliberal) capitalist production that displaces Max Weber's seminal "Protestant Ethic" thesis: "Passion it appears has become a means of production" (originally in Arvidsson 2009; cited in McRobbie 2016; 109).

In The Culture of the New Capitalism, Richard Sennett (2006) describes his experiences doing ethnographic work with a variety of labor forces, from white-collar executives to temporary laborers to "new economy" tech workers in Silicon Valley. What emerges is a set of conditions that Sennett argues workers must ascribe to in late capitalism's workforces. These conditions include subjective orientation to immediacy, 
potential performance and skill development, and the ability to forget the past: Sennett argues these make for an "unusual" human being, because most humans need the exact opposite - a sense of past experiences, an intimacy with what their specific abilities are, and a "sustaining life narrative" (5) - in order to prevent themselves from feeling adrift in a sea of uselessness. New capitalism, in other words, requires workers to form attachments to ways of life that make them more precarious. As I will describe below, feeling precarious in a variety of work/life situations is significant to the modes of adjustment and endurance that structure makers' collective attachments.

\section{Precarity: An Impasse}

Precarity or precariousness is now a well-worn descriptor for the class position of homo-economicus: chefs, restaurant servers, artists, actors, musicians, adjunct professors; anyone fitting the "gig economy" billing that sees work and life as having been transformed into the management of insecurity (Lorey 2015). Precarity as an optic has been applied to the creative economy by numerous authors (Raunig et al. 2011; Dawkins 2011; de Peuter 2011; Ross 2008; Hracs \& Leslie 2014). What a lot of this literature has in common resonates with what I have described above: the production of a precarious subject alongside the production of insecurity, both of which support the political downloading of state responsibilities onto its necessarily entrepreneurial constituents (Peck 2005; Tickell \& Peck 2002). It's telling, for example, that the response to the Great Recession was fiscal austerity, which as Lauren Berlant points out, is tantamount to the state telling its citizens that they have become too expensive to care for.

Berlant (2011) examines precarity as a more-than-economic condition. For Berlant, precarity is wrapped up in the ability of people to affectively sense the changing 
infrastructures of their various worlds (love, work, political, etc.). Being precarious is at its root a condition of dependency (also see Lorey 2015); when people sense the attrition of the things that their notion of "the good life" is dependent on - upward mobility, an anxiety-free and satisfying work life, and so on - they are forced to make adjustments. But adjustments that compensate for precarity are hardly accomplishments, even if their pervasiveness has begun to make such adjustments feel productive; and they are definitely not flourishing. Despite this, Berlant shows how people tend to cling to their fantasies about the good life, even when they can intuitively and affectively sense the collapse of the very institutions on which those fantasies are based. They do this because they need to feel grounded, especially in extended moments of uncertainty. Apart from being a condition of dependency, precarity is also a state of indeterminacy in which people are forced to make rapid and constant adjustments to change while at the same time coming to terms with the broken promises offered by the fantasy of "the good life" (e.g. the American Dream).

The aforementioned class of precarious-entrepreneurial-creative producers, which makers fit well, has been analyzed theoretically in a number of ways. The neo-Marxian position on such precarious work, Berlant points out, sees a central tension between the desire for autonomy and "lateral freedoms" such as creativity and craft on the one hand, and the desire for security (vis-à-vis the state) on the other. This position (e.g. Hardt \& Negri, Harvey) still holds the "dialectical/radical possibility" door open in the hopes that there really is something to be gained in the restructuring of work. The contrasting poststructural positions (e.g. Rancière, Agamben, Adam Phillips), however, see the class of homo-economicus as responding to precarity through the antidemocratic hoarding of 
privilege. Poststructural authors do not see much radical potential in neoliberalism; their position, Berlant claims, is to eradicate the structures and hierarchies of both capitalism and democracy to the point that equality becomes a state of pure placelessness (she cites Phillips' claim that sensual equality is "not knowing where one is"). Berlant doesn't adopt either position, however; she argues that people generally have attachments to the "soft hierarchies of inequality" that give them "a sense of their place in the world" (194; emphasis in original). On the one hand, inequalities don't always inspire revolution; and on the other, pure escape - Deleuzian "smooth space" - would give people anxiety because they wouldn't have anything to tether their fantasies of a good life to.

According to Berlant, these positions have two things in common: the first maps back to Berlant's claim that the present, in all its precarity and ongoingness and attrition, is perceived affectively - it is felt - before any other information about it is gathered.

Second, people must make sense of the present as it is still unfolding; the present, in this way, is a stretch of time in which the parameters that define it are yet to be detected (4-5). But the real fun begins when the crises that make the present so palpable become ordinary, because at some point the constant management of crises unmasks the "the good life" as mere fantasy. This sensation, when one encounters "what it feels like to be in the middle of a shift" (198), is what Berlant is referring to by the term impasse. An impasse literally means a deadlock or a predicament from which there is no escape, but Berlant means something more by the term: she uses it to describe the modern encounter with precarity, in that precarity forces one to keep moving (in order to maintain or "reproduce" themselves) while actually not moving. The demands of this form of suspended life are such that people are forced to constantly evaluate and adapt to 
changing conditions, a reality that bends toward anxiety on one pole and exhaustion on the other. Moreover, adaptation is nuanced and uneven, because the bodies living in the impasse have lost the signposts of solidarity or collective movement. But people adjust no less, which is ultimately why impasse is a significant analytic term: it provides a way to understand what bodies do as they negotiate their sense of place within a situation as it unfolds, and to think through the adaptations and adjustments that give them a firmer sense of the ground beneath them.

Shaped by a sense of the present that is shaped by crisis, an impasse is something of a temporal holding pattern in which the precariousness of not knowing what comes next “opens out into anxiety" (199). In this dissertation, I adapt Berlant's notion of impasse in a variety of ways, most notably in the concept of transition that marks the space between "new" and "old" in both Portland and Detroit. I argue that impasse speaks to the sense of betweenness that people find themselves in as places undergo change; in both cities, makers collectively described a tension that stems from transition. In Detroit, makers were ambivalent - even at times distraught - at the inequalities being generated and exacerbated by an urban transition ("New" Detroit) that actually benefited them in a variety of ways. In Portland, makers often clung to the aspirational values of "Portland" in its late stages of gentrification; they were often trying to make sense of an imaginary which was vital to their marketing - that was coming apart in "New" Portland. The transitions that makers in each city were experiencing, I argue, introduce an impasse that is unique to each milieu yet structured by common factors (e.g. the recession, consumer demand for ethical production, gentrification). This explains the unique elements of each place's imaginary (chapters 5 and 6 ) as well as the sense of collective belonging and 
common value propositions that makers feel regardless of place specificity (chapter 3 and 4).

These imaginaries, shaped by the impasses each city's milieu finds themselves in, are important to understand in the affective realm. As I have pointed out, an impasse is an indeterminate transitional space-time that creates aspirations to uphold norms and practices that appear to be disappearing. These aspirations, I argue, become tied up in the imaginaries that makers rely on. An impasse compromises one's ability to comprehend a transitional situation; short of the ability to fully comprehend something, one becomes reliant on the imagination to make sense of a situation. As I explicate in the next section, the relationship between comprehension and imagination can be clarified in the realm of affect.

\section{Affect and "Overflow"15}

Throughout this dissertation I refer to affect and the affective realms of makers and making. This section will frame the way I conceptualize affect. One of my core intentions is to explain why definitions are so important to me in this work. Throughout my empirical chapters, I explore the fuzziness of a variety of words, names, identities, values, and even cities. The name "Portland," for example, has come to mean something specific in the maker milieu (including its consumer base), but as chapter 6 shows, the name "Portland" (and, relatedly, the 'Made in Portland' brand) is more of an aspiration for makers than a material reality. Affect is especially useful here, because it allows an analysis of the things that exceed materiality without dismissing them as mystical or

\footnotetext{
${ }^{15}$ Parts of this section are adapted from the paper "Planning Affectively" in Planning Theory (Marotta \& Cummings 2018)
} 
inconsequential. Yet it also allows for a material analysis (the actually existing effects on people) of the collectively imagined worlds they construct and inhabit. I begin with a description of power, because one of the clearest ways to describe affect is through the power relations that affect bodies' comprehensions and imaginations of the worlds they occupy.

Power can be framed broadly in (at least) two ways, best exemplified by two different French words for power: puissance and pouvoir. Pouvoir corresponds to relations of force, whereas puissance corresponds to scales of intensity, a point made by Brian Massumi in the translation notes to $A$ Thousand Plateaus (1987; xvii). Consider the different framings of power Foucault $(1975,1978,2004)$ and Deleuze \& Guattari $(1977$, 1987): across his oeuvre, Foucault describes a series of progressively interlocking powers - sovereign power (control through inducing fear and docility); disciplinary power (control through various forms of behavioral and normative programming); and biopower (control through systematic management of populations). If these powers of control can be characterized as pouvoir, puissance might be thought of as a "range of potential" or a “capacity to affect or be affected" (1987, xvii; also see: Deleuze, 1988). Whereas pouvoir denotes the techniques of power ("how"), puissance denotes the level of intensity ("how much"). Both affect the range of potential actions (or inactions), but puissance is what gets at the potency with which power is felt. Deleuze \& Guattari mobilize both terms for power, for example in their distinction between the "socius" and the "body without organs" (Deleuze \& Guattari, 1977; 9-16) where the latter is something of a (deterritorialized) raw material that - through political inscription - is captured and organized (reterritorialized) into the former (Marotta \& Cummings 2018). 
Epistemologically, this affective power is implied by Deleuze \& Guattari's use of Spinoza's theory of affections (Deleuze \& Guattari 1987; Deleuze \& Guattari 1977; Deleuze 1988). Far from the metaphysical framework that affect and emotion might suggest, Spinoza denounced philosophies of consciousness in favor of a philosophy of the body. He was interested in what the body can do based on "the affections of which [it is] capable, by the excitations to which [it] reacts within the limits of [its] capability" (Deleuze, 1988; 27). According to Spinoza, when a body encounters another body, the interaction between the bodies either combine and intensify a body's overall coherence (joy) or decompose and diminish a body's coherence (sadness). Each conditions the body's power to act depending on the affects - joy or sadness - that the body experiences in the interaction. In Spinoza's (and Deleuze's) accounting, such bodily affects cause a great deal of anguish for the mind (consciousness), because in struggling to comprehend the affect that the body has felt, the mind generates a series of illusions (e.g. theological, freedom/autonomy, conflation of cause/effect). In other words, the mind is always operating under the power of its own imagination, because it cannot fully comprehend the myriad ways the body is being affected by the bodies around it (Deleuze 1988; 18-20).

So often, affect is simplified by the phrase "the capacity to affect and be affected" (Deleuze \& Guattari 1987). But what I am interested in is the point at which bodily capacity becomes overwhelmed. I see this exceeded-ness of affective capacity as an "overflow" of affect (see: Marotta \& Cummings 2018), the result of which creates a tension between attempts to comprehend or capture affective experience and the inherent inability to represent affective experience in language or images (Thrift 2007). I argue here that this tension forms the basis of an imaginary, rooted in the affective realms that 
exceed comprehension and cohesion. As Deleuze (1988) argues, there is a fundamental distinction between comprehension and imagination. The power to comprehend a "common notion" between bodies lies within the capacity of a body to be affected. If this capacity is exceeded - if it overflows - bodies stop comprehending and affectations move into the realm of the imagination. In such cases, the imagination becomes reliant on abstracted representations constructed around an "essential trait," thereby making sense of a density of affections. Moreover, such abstract representations get hazier and less definite as they become grouped with other abstractions and circulated throughout a milieu, consumer base, or "public" of any type. For example, the collective imagination of "Portland" might be mediated by images of quirky hipsters drinking beer or coffee while riding a bike under a canopy of Douglas Firs. But in reality, Portland obviously exceeds such abstractions; actual or "true" Portland, that is, cannot be represented as such.

\section{Imaginaries}

The term "imaginaries" is used in a variety of literatures, and it is almost always modified with an adjective: ecological or environmental imaginaries (Gandy 2006;

Goodman 2004; Gabriel 2014), spatial or geographic imaginaries (Harvey 1990a; Devadason 2010; Boudreau 2007), festival imaginaries (Jamieson 2013), urban imaginaries (Kelley 2013; Leurs \& Georgiou 2016; Mah 2012; Huyssen 2008), public imaginaries (Dawkins 2011), post-industrial imaginaries (Millington 2013), and so on. The insinuation is that without modification, an "imaginary" is rather immaterial and needs to be oriented toward a more specific object. In other words, without the modifier we might need to ask: an imaginary of what? Of course, the relativities and juxtapositions 
between these different modifiers are significant. Gandy (2006), for example, relates the emergence of an ecological imaginary to the historical acceleration of urbanization. For there to be an imagination of the ecological, there has to be a counterpoint of sorts, which Gandy locates in the image of the industrializing cities of the $19^{\text {th }}$ century and the associated biopolitical emergences of financialization, planning, public health, and strategic visioning of urban futures, all of which were experienced both collectively and in the routines of daily life. Likewise, Millington's (2013) post-industrial imaginary requires the imagination of what/where a city should be and what/where nature should be; we couldn't imagine "post-industrial" without a collective imagination of the urban and the natural.

Another explanation for the prevalence of modifying adjectives is the problem of defining something called an "imaginary.” Huyssen (2008) and Çinar \& Bender (2007) both point out that scholars have had enough difficulty defining cities, no less trying to define something as nebulous as a city's collective imagination of itself. Both authors refute the need to rigorously define the term 'imaginary,' instead opting to understand the city as always already imaginary, a "field of experience" (Çinar \& Bender, 2007) that is at once local yet global, real yet mysterious, indefinite yet productive of sincere attachments and material consequences. Huyssen (2008) picks up on the relationship between real and unreal, arguing that urban imaginaries are experienced in a real, material way - with all the associated emotions and affects - despite the immateriality and unrealness that a term like "imaginary" suggests. Imaginaries, then, resemble collections of embodied images that shape the reality of urban subjects, and therefore imaginaries blur any distinction between real/unreal or material/immaterial (also see: 
Dawney 2011). Çinar \& Bender (2007) turn their attention to the relation between individual and collective imagination, inquiring directly about how imagination works to generate commonly understood ideas about the city. Collectively expressed through print- and image- media and intensified by tourism and travel, cities tend to become metonymically imagined as a singularity: "Portlandia" or the "Motor City," for example. As the circulation of these singular-yet-collective imaginations of urban places intensify, the circulation of people also intensifies, as does their expectations of what they might find in "Portlandia." In other words, travelers expect a certain ROI (return on imagination) and residents often reify such expectations, a relationship Urry (1990) captures in the notion of "tourist gaze."

Imaginaries are epistemologically useful in describing cities because cities have large populations in which it is impossible for everyone to know everyone else, yet a city's inhabitants are obviously conscious of each other's existence and often share a sense of belonging with these unknown co-inhabitants. This sense of imagined connectedness and belonging is what Anderson (1983) calls an "imagined community," a description that maps well onto large urban places in which most individuals will never meet yet have the means to imagine a communal existence with other (in my case) Detroiters or Portlanders. In this way, urban imaginaries are communities precisely because of their affective and emotional impact on the members; such imaginary bonds begin to pull the curtain back on why the way Portland and Detroit are commonly imagined matters to each city's makers.

But how do certain place-specific values become shared, such that they create an emotional impact? Anderson points to a key shift in communication technology, which 
he attributes historically to a flattening of language and the rise of "print-capitalism" (the printing press plus capitalist relations). The ability to mass-produce and distribute print materials created a new (imaginary) relationship between people who, for the first time, had a tacit knowledge of others - and the struggles and experiences of others - across great distances. The parallel for print media in my work is social media, a technology that mediates the aesthetics and affects of place belonging and value aspirations over global distances (cf. Marotta et al. 2016). Although Anderson's overall argument is far more complicated and gets wrapped up in discussions on nationalism, colonization, and sovereignty, the key point I wish to retain is the emotional/affective power that imaginary relationships have on people. One of Anderson's central questions, in fact, has to do with why people feel so strongly about the imaginary of nationalism: why would they die for people they will never meet?

While Anderson usefully thinks through how imaginaries structure governance and rely on technological change that can be modeled (and pirated), Walter Benjamin helps think through the temporal and cultural construction of collective imagination in the context of change. In chapters 5 and 6 of this dissertation, the transition between "old" and "new" plays a significant role in makers' imaginaries of Portland and Detroit. In Benjamin's work (especially throughout The Arcades Project), Benjamin frames such transitions in the context of technological change, with technology broadly understood as the processes and materials society mobilizes in its desire for progress. In the first place, the continuities between the old ("obsolete") and new ("innovative") are visible in the forms given to innovative objects, even though the innovative/new is meant to overcome 
the failures of the obsolete/old. ${ }^{16}$ For example, take a quote from French literary critic Leon Pierre-Quint in 1927 (1999; Convolute F): "In the beginning, railroad cars look like stagecoaches, autobuses like omnibuses, electric lights like gas chandeliers" [F7,3]. As Buck-Morss (1991) points out, Benjamin cites Marx's observation in Capital Vol. 1 that the first locomotives were designed to look like horses; the obsolete (past) form of the workhorse was inscribed upon the productive (future) imagination, thereby giving rise to a technological object (the locomotive) that sought to overcome the deficiencies of the horse. The traces of the old on the new are what Benjamin called "wish images" (Benjamin 1999).

That old forms governed the imagination of new ones meant, for Benjamin, that every new thing has something of a conservative imaginary clutching its ankles, the result of which is a circular or even stationary relationship between new and old. Somewhat akin to Berlant's notion of impasse, this "not yet" conception of the historical present is contoured by an incompatibility between the optimism that society has for technological "progress" and the political-economic framework that governs its access, effect, and distribution. The anachronistic collective sensibility of optimism (in my case of makers) reveals a "restorative impulse" (Buck-Morss, 1991; 111), a set of aspirational values emergent from something's obsolescence in the hopes of overcoming the obstacles that limited the ability of whatever is vanishing to create flourishing (chapter 6 is largely based on this notion). The desire to reach backward and reconnect with a previous time even if reaching back is imagined as new - gestures toward a set of unfulfilled promises

\footnotetext{
${ }^{16}$ Special thanks to Brian Elliot; without his help, I never would have distilled these lessons about Benjamin
} 
(for security, for equality, for a "good life") and a social imagination of the future as the location for this utopian experience: "Where else but the dead past can imagination turn in order to conceptualize a world that is 'not-yet' (Buck-Morss, 1991; 124)?"

This reconciliatory notion elides hopelessness for the future by framing cultural memory as communicating with the present through moments of intersection between new and old that have been inscribed into the objects and processes of production (including urban space itself). Makers embody this in many ways: encoding a desire for a simpler, more ethical, more local way of producing into their products; locating in industrial spaces that rejuvenate the affects of working with one's hands; concretizing a changing city's aspirations in a brand like 'Made in Detroit,' just to name a few examples. Both cities I investigated are undergoing transitions; their "not yet" imaginaries are wedged between fantastic conceptions of "old" and "new" that are circulated around the globe on emergent technologies such as Instagram. The result is something of a repository for the collective imagination of a global audience that produces places both inside and out, in both material as well as mythos (Marotta et al. 2016). As with Benjamin's notion of phantasmagoria - a term used in the nineteenth century to describe a collection of objects organized in such a way to induce illusion and fantasy - this repository of collective imagination blurs the boundary between fantasy and reality. Importantly, imaginaries do not represent fantasy or reality; they live in the interstitial space - the impasse - between the two.

Circling back to the discussion of affect, I see "overflow" - the part of an interaction that overwhelms one's ability to comprehend - as the basis for an imaginary. An imaginary is no less real than the effects it has, the way it affects people and influence 
their subsequent actions. Sometimes the actions imaginaries provoke are extreme: as Anderson (1983) points out, throughout history people have shown to be willing to fight and die for nationalist and religious imaginaries. Every chapter in this dissertation revolves around imaginaries and the sense of belonging, emplacement, and ethical/economic value they affect. An imaginary, I argue, is an instantiation of collectiveness or in-commonness, even if it isn't coherent between the individuals that collectively construct it.

Imaginaries are affect worlds: what makes them impactful are the feelings they generate, the desires they create to do something ("make") or be somewhere (Portland). They are aspirational, in the sense that they come to inherit the desires people have for a place, a time, a group, an identity, and so on. Often times these aspirations are expressed in discordant ways, even in the same milieu. But, as I argue in chapter 3, incoherence and even rejection do not transgress or negate a particular imaginary, but rather they give it depth (Berlant 2008). Lastly, and related to aspirations, imaginaries are often juxtapositional. They often arise as a way to fend off the anxieties of other places, times, identities, and values. "Making" itself is a form of juxtapositional imaginary, in that it is juxtaposed to the globalized, outsourced, mass-produced, corporate, overly-managed forms of work that have become so normalized.

As a final note for this section: throughout this dissertation, I purposefully use the word "sense" a lot. This is because I put a great deal of stock in what Berlant (2011) says about the present: that the present is always available to us affectively first: every piece of incoming information we process is shaped by how we perceive the present. We develop a sense for things before we act; we make sense of the situations we find 
ourselves in; we sometimes have to rely on common sense to get things done. In this way, "sense" is both a primary basis for and a window into an imaginary; at any given time, we are affected by more than we can possibly comprehend, so making sense of something is always already a process of imagining. Throughout this work, the word "sense" means to trigger this perspective of the affective present.

\subsection{METHODS}

When I started graduate school, my intent was to study the relationship between art and urban change (e.g. gentrification) primarily from a political-economic perspective. And indeed, I have been able to study the "creative" transformation of cities: over the past five years, I have been involved with three separate-but-related research projects that each study creativity, entrepreneurialism, and "making," and each project has had a distinctly urban focus. Being in the field and conducting so many interviews, my ontological/epistemological perspectives went through a shift: I moved away from macro-political economic perspectives and became more interested in the emotional, affective, and imaginary aspects of both the maker movement and cities. I was routinely haunted by questions about what particular words or phrases meant to the people that used them and how such words and phrases create a common emotional space between our interviewees. In the context of the research I have been involved in, such words/phrases include things like "maker" and "Made in Detroit/Portland," each of which I analyze in various ways in the empirical chapters.

Furthermore, I was perplexed by the imaginary formulations of cities that makers had become attached to; I started to ponder what Portland meant, or at least what gave the city's name enough emotional weight that so many makers felt compelled to name 
their enterprises after it (Portland Bee Balm, Portland Juice, Portland Roasting, Portland Apron, etc.). With all this in mind, the question that inspired this dissertation was: "what does 'Made in Portland' really mean?' But in my fieldwork and through my analysis, my question underwent a transformation, eventually becoming: what gives the 'maker movement' and 'made in Portland/Detroit' its coherence? In other words, I became more interested in the various sources of gravity that makers have experienced. Additionally, as my studies moved along I became interested in the nature of makers' place attachments, especially as those places were undergoing significant transformations. I wanted to understand how a milieu finds commonness amidst rapid change and how value systems are structured by their collective sense of change. As described above, I identified imagination as a significant factor; this gave my question another layer: how is identity, value, and the city imagined amongst makers?

\section{Background from Portland}

My first foray into this research was back in 2014. Dr. Heying had enlisted me to assist his research on localism, a project that took his prior work on Portland's artisan economy (Heying 2010) as its case. We set out to understand what making goods locally meant to makers and artisans. Why was the local scale so important to them? Our first order of business was to get a grasp on the maker scene itself; we worked closely with Portland Made, a membership-driven branding collective for makers located in a makerspace (ADX) on Portland's Central Eastside. After working on a member survey and producing a report for the collective, we observed a set of meetings (one of which serves as an extended anecdote in the outset of chapter 6). That summer, I conducted 10 interviews with makers (which are part of my dataset here) in order to better understand 
the ways in which makers mobilize the notion of 'local' (see: Marotta \& Heying 2018). I also spent a great deal of time producing a database of Portland's maker firms. I found well over 700 'maker' firms in Portland, but I also documented hundreds of other "network" linkages important to makers: retail shops, educational programs, nonprofits devoted to making in some way, maker markets, and so on.

The database proved to be a unique methodological tool. The methodology I developed for it became somewhat important in my research moving forward. Not only did I use it as a model for my eventual research in Detroit (more below), but it was actually adopted by a larger, three-city, three-university comparative study of entrepreneurial makers $(n=95)$ and "maker-enablers" ( $n=41$; maker-enablers can loosely be defined as entrepreneurial firms that fill network gaps; Doussard et al., 2014; Wolf-Powers \& Levers, 2016). The PIs on this research were Charles Heying and Greg Schrock from PSU, Laura Wolf-Powers at CUNY, and Marc Doussard at University of Illinois. As for my part, I contributed to data collection, I assisted Dr. Wolf-Powers in constructing a database for New York City, and I helped to conduct many of the Portland interviews (I attended as many as I could and conducted a handful on my own). I also recorded and transcribed all the interviews for Portland. The overall goal of this comparative study was to identify similarities and differences between local maker "ecosystems" and to analyze the institutional and entrepreneurial support networks that maker enterprises tap into. Though I am of a somewhat different theoretical positionality than that of this study, there are many important methodological cues that I would like to take from this project. I will refer to this Kauffman research often, as it has provided me 
many of the "on the ground" empirical and methodological tools that I used in conducting the necessary research for this dissertation.

In fact, the Portland data that I used in this dissertation largely comes from the Kauffman project. Our team conducted a total of 47 interviews in Portland, many of which I draw from below. I supplemented these interviews with an additional set of interviews, but quickly realized that I had already achieved saturation through the Kauffman interviews. The advantage I gathered in the additional interviews was primarily collecting excellent quotes from makers, but these interviews also gave me a bit of a longitudinal perspective as well. In other words, I did these interviews in 2017 and early 2018, four years after I had done the 10 interviews for the localism project in 2014 . Portland was changing significantly the whole while; this was a unique window into the effects that urban change had on a specific milieu.

\section{Background from Detroit}

For the sake of full disclosure, I have a bit of an obsession with Detroit. I lived in metro-Detroit twice: once as a young child (mid-1980s) and then again as a teenager into my early 20s (1995-2002). In both encounters, I remember Detroit being a place of extraordinary conflict; I was privileged enough to live in the suburbs, but I was always tuned into the racial segregation, the ostensibly violent city, the decaying manufacturing buildings; in short, a grouping of perceptions constitutive of Detroit's imaginary for me (and surely many others) at the time. When I was younger, I assumed the city was a place to be avoided. It wasn't that anyone directly said not to go, but more so that the news reporting from the city was always bad (e.g. "Devil's Night") and when we did go to the city, I brought what I had heard about the city with me and connected it with the way the 
city looked. When I was older, however, I was drawn to the city. I was there for the birth of the "Detroit Techno" scene, and spent many Saturday nights (and Sunday mornings) inside the abandoned factories and warehouses of Detroit's near east side. I was enamored by these spaces and their repurposing, but also with "Detroit" more broadly; it struck me as a teenager that everything I had learned about the city as a child was wrong. This feeling stuck with me even after I left Detroit for good. In 2010, I went back to Detroit to do research for my master's thesis. For that project, I was interested in all the attention Detroit's artists had been getting in the media. My sister had gone to art school and lived in Detroit in the 1990s, and told me that the artist-as-revitalizer narrative had been played out repeatedly in the city without ever resulting in the SoHo-style transformation. Moreover, I knew that art and creativity had always been a thing in Detroit - it is the birth of Motown after all. So why were Detroit's artists getting so much attention? I found that the city was much emptier than I remembered it: it even had become a locus for the flyover photojournalism style pejoratively branded as "ruin porn." At the time, the city's decline was profound; it was hard to navigate the city and not be affected by its physical condition. But this was a city that was historically black majority - by a large margin - that had abandoned, shunned, shamed, and effectively caged in by the predominately $(\sim 80 \%)$ white suburbs. My thesis ended up concluding that all of it was racist: the media attention on artists (not the artists) and decaying buildings, the "planned shrinkage" so many championed, the isolation of the poor and black residents, and the imaginary narrative that structured so much of it. But I was sold on the fact that Detroit's artists had an opportunity, a platform to create conversations that were long overdue. 
This is all to say I have a history with the city, so in doing analysis of the city, I had a significant amount of context to draw upon. But I still needed a point of access - an entry - into the maker scene in Detroit. That entry came by way of Greg Schrock, whose colleague at Wayne State University had read some of the research that had been published by our Kauffman research team. Schrock's colleague - Prof. Robin Boyle wanted to do something similar to the Kauffman project in Detroit for a local economic development class he was teaching in Wayne State's Masters of Urban Planning program. When Schrock told me about this, I contacted Prof. Boyle and asked how I could be involved. Boyle was enthusiastic about my participation, so I shared my database methodology as well as a database I had been putting together on Detroit's maker scene (at that point, the $n$ was around 75 maker firms). Boyle and I talked often while his course was moving along; his students ended up adopting my database methodology and adding to it, eventually doing a variety of innovative forms of inquiry with Detroit's makers. They did surveys, conducted interviews, and made observations in a variety of milieu-related contexts.

Near the end of the course (May 2017), I flew to Detroit to attend the final presentations of the groups. There were four groups: one tackled policy, one tackled maker enablers, and two tackled makers themselves (one urban, one suburban). While their findings could take up a significant amount of space here, I was most struck by each group's struggle with producing categories: one of the core findings common to all the groups was the impossibility of defining what exactly a 'maker' is and where urban/nonurban boundaries should be drawn. This resonated with what Prof. Heying and I had seen in Portland; if 'Made in Portland' adds value to a (handmade) product, who gets to claim 
it? Who has access and who is cut off? Furthermore, the groups were collectively exasperated about who they were even trying to talk to - who was a maker? Was being an Etsy producer in the suburbs good enough to be surveyed? One of the two maker groups ended up using NAICS codes to order makers, but claimed that even these categorizations were somewhat arbitrary. Again, this resonated with what we had seen in Portland: categorization was basically impossible as a scientific endeavor. This led me to the conclusion that describing a maker had to be a central theme in my work.

But the presentation was important for another key reason. Some of the makers that the students had interviewed saw the importance of doing such research, and as such they were in attendance. Moreover, in his introduction to the project, Prof. Boyle had introduced me to the audience and credited me with helping him develop many of the ideas in the course. In so doing, he made the makers in attendance aware of my presence in the city as well as my experience doing research with makers. After the presentation concluded, some of these makers introduced themselves to me; in fact, one of the makers in attendance was someone I had been really hoping to interview (it turned out to be one of my best). Prof. Boyle saw me talking to her and asked her to join us for drinks. The conversation that followed (at the bar) was critical: it significantly shaped the questions I asked to makers in Detroit.

There was one other connection that was pivotal in my Detroit research: through a maker/manufacturing survey I was working on (Greg Schrock was PI), I had been connected with Lee Wellington, the Executive Director of the Urban Manufacturing Alliance (UMA) in NYC. The project had a team in Detroit, and the Detroit survey was open while I was in the city (summer 2017). This connection was important for two of 
my interviews: first, I asked Lee Wellington if she could introduce me to someone at Shinola. She did; I was able to meet with the Vice President of Manufacturing for Shinola, who gave me a rather in-depth tour of the manufacturing facilities and then took me out to lunch. This was pivotal for my perspective, especially considering Shinola's lightning rod status in Detroit's making scene (more in chapter 5). Second, I had a chance encounter at the end of another interview in which I was introduced to someone from Detroit Creative Corridor, an economic development nonprofit. That employee was able to connect me to a colleague that was in charge of Detroit's UMA survey, which yielded another important interview as well as numerous informal conversations with people familiar with the maker movement and the messy distinctions between making and manufacturing. Additionally, this connection gave me some important "in-the-know" information that I was able to use to secure an interview with a key maker firm; this firm had originally not wanted to meet, but I was able to convince him to meet with some of this knowledge. Access to these people, all of whom were central to Detroit's maker scene, was critical in my analysis for chapters 3 and 5.

In all, I interviewed approximately 20 makers in Detroit. I scheduled interviews by recreating my Portland database for Detroit and contacting makers regarding their interest in being interviewed. Most makers I contacted replied, and most of my replies were willing to be interviewed, although some of them had conditions (e.g. one asked for a "working" interview). My overall $n$ in Detroit would have been higher, but I had a handful of makers cancel while I was there (I spent a total of two weeks across three trips). I did, however, have a couple of interviews that became more like focus groups. In one case, I was at a brewpub interviewing a husband and wife team of makers when they 
saw some other maker friends and called them over. The interview ended up being over 3 hours long, had a total of 4 maker firms represented, and covered every thought I've ever had on the maker phenomena, on Detroit, and on a variety of other topics I hadn't even considered as connected to my research.

Throughout my visits to Detroit I stayed very active while in the city, spending all of my free time observing the city, talking to people, and taking field notes. I had many informal interactions with Uber drivers, bar patrons and bartenders, people at shops and markets, as well as a variety of chance interactions with people on the street. I did not rent a car while in Detroit; this was purposeful, because it forced me to rely on other, more public ways of getting around. I found rides with old friends I had in the city; I got rides from academic friends that were doing fieldwork in and around Detroit as well; I got Ubers; and I rode the new streetcar. But I mostly walked (and jogged) while I was there; I walked a lot. Walking allowed to me to dwell in certain places, to take the city in more so than I could do in a car. On my second trip, I recorded my movements through the city using a pedometer on my watch: during that trip, I averaged 11.69 miles and 24,228 steps per day (I logged almost 60 miles on foot in a 5-day stretch). These supplemental observations and the interactions they yielded gave me so much more context in which to ground the interview data that I draw from in my analysis below.

\section{Field Methods and Analysis}

My central field technique for data collection was interviews. The interview protocol I developed largely followed the suggestions of Lofland et al (2006; 99-108). Developing my interview guide was the first task. After brainstorming the major "puzzlements" presented by the research problem, Lofland et al advise sorting reflections 
into straightforward macro categories that can individually be broken down into specific questions. Next, specific "probes" were constructed around specific questions or themes that might be of great interest. Not all probes were appropriate in every interview; they were prepared more for me to draw upon in case interviews went in such a direction. In my experience, the interview guide was more of a checklist that steered conversations than a strict questionnaire; Lofland et al suggest that interview guides be outlines through which an interview is guided. In developing my interview guide, I heeded their advice to avoid two types of problematic questions: leading questions and closed questions.

Leading questions (e.g. "Don't you think that...") produce "self-fulfilling answers" (105) and do not yield reliable data. Closed questions (e.g. "Don't you feel better about yourself on a good day" versus "tell me what a 'good day' is like for you") truncate any sort of richness and generally tend to yield a yes or no answer from the respondent.

Lofland et al also suggest briefly introducing the research topic to the interviewee ahead of the interview. I accomplished this through an introductory email sent to every maker I interviewed. In that email, I outlined my project and stated my goals, then offered to send an information sheet if they wanted to know more. I also had a consent form that each interviewee signed ahead of the interview; the consent form was to notify the interviewee of their rights and protections as prescribed by Portland State's IRB requirements. These rights specifically include the interviewee's freedom to intervene in a line of questioning, and the interviewee's right to stop the interview at any time. I also asked each interviewee for their permission to record the interview at the outset of the session. Lofland et al strongly suggest recording interviews, which I did; the audio files were kept securely on a drive on my personal computer. Recording interviews allows for 
a more natural conversation without needing to do a lot of writing while giving the respondent your undivided attention. They suggest note taking to be sparse during the interview; notes should keep the researcher clear on what has already been and still needs to be discussed. Lofland et al, however, recommend taking field notes for each interview. These notes should include observations from the setting of the interview, emotional responses of the interviewee, and methodological problems encountered. Furthermore, de Wit (2013) suggests that noting these details is especially important in interviews for which the notion of place or sense of place plays a primary role.

I also followed Lofland et al's suggestions for transcribing and preparing data for analysis. First, they suggest transcribing interviews as quickly as possible to maximize the fidelity of the data and seek key themes in the interview related to the research question. Lofland et al advocate for general summaries and notes over verbatim transcriptions, with the caveat that particularly important parts of the interview should be transcribed verbatim. This is how I had treated transcription for the $50+$ interviews from the Kauffman and localism projects, and I used the same techniques for the additional interviews I conducted for this dissertation. I used Microsoft Word to transcribe interviews, using the "track changes" function to note any developing themes, codes, or memos I would want to add in my QDA. My transcriptions were typically between 5-10 pages of bulleted notes; verbatim quotes were time-stamped in case I wanted to revisit them on the recording.

The QDA I used was Dedoose. I chose Dedoose primarily for two reasons: first, I have a working familiarity with Dedoose. Because I used it in the Kauffman project, I am familiar with Dedoose's system of coding (e.g. building a codebook, applying codes, and 
selecting codes for analysis). Second, I used data from the Kauffman project to answer some questions about maker-entrepreneurial subjectivity, and it was easy to link my Dedoose account to the multiple projects that I was pulling data from. Like other QDAs, Dedoose has the option of collating codes from across my dataset and exporting them into a single document. This was extremely helpful in analysis; my technique was to organize the coded excerpts I wanted to use for a particular section and export them from Dedoose as a Word file. Then, I read through the coded excerpts, using the "track changes" feature in Word to add comments to the file as I worked through it. I also highlighted the verbatim quotes in yellow that I wanted to use in my analysis. The last step before beginning to write was to arrange all the excerpts from the exported document (by using "cut and paste") into the order that I wanted to move through them in writing. I mapped out the story of each chapter section in this way; it made writing each section a matter of connecting the dots between each excerpt.

\section{Moving on: a short interlude}

What follows below is the culmination of five years of work; there are many ways I could have framed my analysis, but my goal was to let my theoretical interests and empirical observations find each other at some sort of disappearing point. What emerged throughout my analysis is the importance of the emotional, affective, and imaginative realm that makers occupy. Perhaps it is worth mentioning that such an analysis is pretty far from where I expected it to be; theoretically, I have always identified as a materialist interested in matters of political economy, so putting such an emphasis on affect and imagination is a bit of a surprising turn. But it was what I experienced in the field as a researcher that shifted my ontological and epistemological approach. The critical 
moment, which I will discuss in chapter 6, was a meeting at a makerspace that Charles Heying and I attended in 2014. Professor Heying had been interested in deconstructing the term "local," so our antennae were up when we heard that term often thrown around during the meeting. I remember being completely taken aback by the use of a different word, however. That word was Portland: it had significant weight to the people there, but it was also undergoing a significant shift from "old" to "new," and the meeting attendees were clearly trying to find their feet amidst this shift.

This was the moment I first saw the strange but magnetic power that an incoherent, vague, imaginary concept could have: as a term, "Portland" is powerful because of its indeterminacy, its constant vulnerability to change, its tenuousness. I don't see "Portland" as a signifier; making such a claim requires a cataloguing of what Portland really represents, and I don't think such an analysis is possible or even desirable. To be sure, what Portland really is will always exceed the ability of any analyst to capture its “essence.” From my ontological perspective, defining or demarcating the boundary between real and imaginary, material and myth, requires an attempt to capture some sort of "rational" or "real" position for Portland to occupy. The opposite, then, would be the “imaginary” Portland that isn’t real and isn't rational. This is not how I approached my analysis: I don't feel that claiming my research subjects are all under some sort of spell that positions them outside of reality is an effective analytical approach. Instead, I'm interested in the way something imaginary - like "Portland" - creates the perception of structure for the material world, especially as the imaginary becomes a space of commonness within a specific milieu. 
In The Birth of Biopolitics, Foucault (2004; 19-20) points out that his whole oeuvre is concerned with understanding the practices by which things that do not exist sexuality, criminality, politics, the economy - become perceptible and then organized into forms of rational truth. Portland (and Detroit, for that matter) is an example of such a dispositif: "Portland" is not an illusion; the wide-ranging effects it has are very real. It has to be repeatedly imagined and the practices that transform it from "not something" into "something" have to be constantly refined. What makes "Portland" matter analytically is not the illusion it constructs for makers, it's the fact that makers have constructed a collective imagination of Portland that is somehow coherent despite all of its incoherence. I found this to be true of three key aspects of the maker movement: identity, value, and place. Chapter 3 takes up this problem of coherence with the term maker: the central puzzle is in how the identity position of "maker" coheres into something attractive for producers, something that creates a sense of belonging. 


\section{CHAPTER 3: MAKING IDENTITY}

Chapter 3 begins the empirical foray into my central research question: what gives "Made in Place" strategies its efficacy for makers? In order to answer this question, this chapter begins a deconstruction of the "Made in Place" strategy, taking the "made" side (chapters 3 and 4) and the "place" side (chapters 5 and 6) of the equation in order. This chapter is built around an interview question that every maker was asked: "what is a maker?" The research team from the Kauffman project intended this question to yield an aggregation of responses that answer that question literally (see: Wolf-Powers et al., 2017 for the summary analysis). Throughout the interview process, I was struck by the fact that makers' descriptions of the maker identity are rather diverse and often divergent.

Furthermore, a good number of interviewees rejected the identity altogether. "Maker," as an identity position, was difficult to pin down. It was coherent at the collective level; the "maker movement" was clearly a thing that our respondents identified with in some way. But as I will show below, at the individual level, the "maker" identity was vague and indeterminate. Put differently, "maker" only appears coherent as one backs away from it; the closer one gets, the more fragmented it appears. The question I pose about identity, then, is not "what is a maker" but instead "what makes the maker identity coherent"?

In this chapter I explore how disparate interpretations and performances of maker identity characteristics such as amateurism, craft, and manufacturing come together in such a way that a milieu is detectable and a sense of in-commonness is achieved. My goal is to better understand the magnetism of "making" and the identity position that complements it, especially given the obscurity of the boundaries between what "making" 
is or is not. To be clear, I am not interested in defining the term "maker." I am interested in examining how dissimilar individual conceptions of the maker identity cohere as something familiar, normative, and gravitational. Amid all the chaos of the term "maker," I found that there is an unmistakable and even instinctive collective understanding of it amongst our interviewees. The rest of this chapter will make the case that despite the fuzziness at the individual level, "maker" holds together at the collective level.

As I hope to demonstrate, this coherence is largely expressed aesthetically and affectively, even by those that reject the maker identity altogether. I argue that "making," the maker identity, and the milieu of makers and maker infrastructure have emerged from a commonly felt sense of precarity, frustration, and impasse in the socioeconomic worlds of globalization, mass production, and planned obsolescence. Making and the maker identity have emerged partly as a result of this frustration: following Berlant (2011; 2008), I claim that makers are unconvinced that the global economy can provide a pathway to "the good life." The result is a desire to belong to something else, something that won't make belonging feel like being trapped. This explains the loosely governed boundaries of what comprises a "maker": a more rigid definition of the identity would enclose it, whereas the elimination of the term would erode the sense of belonging that it produces. The solution - what I argue has actually materialized - is an identity position that prefers ambivalence.

\subsection{AESTHETICS, AFEECT, AND IDENTITY}

As we will see below, many interviewees were quickly able to aesthetically describe a "maker" and their preferred environs; they often expressed an "I know it when I see it" method of description to the question of "what is a maker." But such an aesthetic 
approach confronts us with a problem: how does one know something when they see it? How do the boundaries of something like an identity become perceptible to an observer? The question of visibility and sensibility is at the center of Jacques Rancière's partage du sensible thesis $(2004 ; 2010)$, where the French term partage takes on the double meaning of sharing in and sharing out (Mechoulan 2004). Rancière describes a system of "self evident facts" that dictate the boundary between "in" and "out" - that which can acceptably be seen, spoken, made, and imagined in a particular social order. "Self evident facts" refer to the realm of taken-for-granted things that humans perceive in everyday life relative to the institutions and norms that assemble and organize them. These facts tell us much: what the various parts included in the system have in common, how these commonalities come to define specific "communities of sense," who has a part in such communities and who is superfluous - in short, who and what belongs and does not belong. Out of this "distribution of the sensible" emerges what Ghertner $(2015 ; 1)$ calls an "aesthetic normativity" in which aesthetics do the work of defining the boundaries within which one comes to know something when they see it.

Identification is the embodiment and performance of these boundaries. According to Sara Ahmed (2004), subjects are "surfaced" or bounded by the movement of affects and emotions between bodies; bodies in this case can be individual or collective. This movement sustains and propagates adjustments to the specific habits, routines, and attachments that become "ordinary" for a subject, and thus affect works to "align individuals with communities - or bodily space with social space - through the very intensity of their attachments" (ibid, 119). Conceptually, affect has to do with the ways one's relationships map the actions that they take, the routines they develop, the 
attachments they seek to cultivate or strengthen or diminish; in other words, the way a subject interprets and reacts to what they experience in moving through various spheres in their lives. One of the ways this interpretation happens is through identification (Berlant 2016a): "maker" is an example of how affect is filtered and performed as an identity. What Ahmed crucially adds is that affect creates definition between bodies singular or collective - thereby providing a housing for identity and a way to detect similarities and differences between bodies. When particular affects are appraised in common ways, the major effect is the binding together of subjects in common value structures that result in common actions, desires, and routines.

Identification is a form of locating something, which is one reason why bounding an identity is so fraught with politics; who gets to determine such boundaries? Who has the ability to speak within these boundaries and what can they say? On the one hand, identification is a power relation, a distribution and policing of normative roles, actions, and beliefs (Rancière 2004). In this way, identification is a form of social and political ordering, a reification of hierarchy and inequality. On the other hand, Lauren Berlant (2011) shows how this is not the full story: in line with other affect and queer theorists (Stewart 2007; Ahmed 2004), Berlant pries open the affective register of the "ordinary" to discover the embedded forces that structure the process of locating one's self within the ordinary. While norms do indeed govern such boundaries, they also generate attachments by providing a mooring for people that are enduring the "thick moments of ongoingness" $(2011,200)$ that constitute everyday life. In other words, norms can be oppressive, but they also turn out to be aspirational, the stuff of fantasies that can bind 
people together in the extended moments of "not-knowing-what-comes-next" that wear so many people out (Duschinsky \& Wilson 2015).

Moving beyond precarity as only an economic position (without removing it from that category), Berlant shows that precarity is a "condition of dependency" $(2011,192)$ in which people are increasingly unable to secure the type of life they imagine or fantasize about. The result for many is a desire to move away from other imagined anchors of security - a "good" job in a cubicle, for example - and toward autonomy, craft, and a sense of "freedom." Berlant notes an interesting "synergy" here, in that security is being both rejected (by makers) and withdrawn (by the capital-state nexus) at the same time. But the central tension that Berlant identifies is the feeling of being adrift, an affective sense that the institutions that have supported the "good life" are collapsing and that the good life may have been a fantasy all along. On the one hand, this sensing of crisis reinvigorates attachments to the collectively imagined "good life," which in the United States has been sutured to the value structures of autonomy, self-reliance, hard work, innovation, and creativity. On the other hand, individuals are forced to adapt to the changing conditions of their ordinary, everyday lives despite the socially distributed fantasies that structure their desires for abstract satisfactions. In other words, people must make adjustments in order to cope with instability. New forms of identification are an example of such an adjustment, because they offer a way to ground oneself in otherwise fluid and precarious conditions. Rather than a source of control, the norms associated with identity can be a source of comfort. Even seeing oneself in opposition to a specific set of norms - as those that reject the "maker" identity do - can function as an anchor in a milieu and thus alleviate the bewilderment of feeling adrift or abandoned (Berlant 2008). 
"Making" was almost certainly accelerated by the job losses meted out by the Great Recession (Heying 2010; Schrock et al. 2018), and as such, the maker identity is one attempt to locate oneself in an ongoing moment of collective insecurity. As detailed in chapter 2, Berlant calls this extended moment an impasse: "what it feels like to be in the middle of a shift" $(2011 ; 198)$. An impasse forces subjects to make adjustments; one adjustment I see emerging in this chapter is a negotiation of what it means to locate oneself in a specific milieu or community by way of identification. Whether rejecting the maker identity or fully embracing it, the fantasies of the American "good life" have largely managed to survive despite the fraying relationship many makers have with the institutions that supposedly support such a good life. The identity itself might best be thought of in terms of an affect world or an "intimate public" (226) in which makers can negotiate a space that resembles something like a support group for those that have found similar methods of coping with the precarity of economic life.

What follows is an analysis of my interview data regarding how makers think about themselves and about "making." I first look at how makers - regardless of whether or not they identify as a maker or not - often think of their work as something other than "normal" economic activity. Collectively, makers see making as something other than mass-produced, rote, globalized work, even if that "something other" gets murky at the individual level. Second, I look at how particular words such as "craft" are imagined in completely different ways within the maker milieu. Despite this incoherence, such words yield an unmistakable in-commonness, because makers always positioned themselves somewhere adjacent to such words and therefore derived meaning from them. Third, I look at how the intersection between making and manufacturing is variously understood 
in the milieu. Regardless of whether individuals see themselves as manufacturers or not, I found that makers tend to resurrect a particular imaginary of manufacturing that positions making (as an identity and a form of work) both inside and outside of the manufacturing realm. Lastly, I describe situations in which the maker identity was completely rejected. Rejection is a far cry from unfamiliarity; to the contrary, those that rejected the maker identity were intimately aware of it. The thread that connects each section is composed of a collectively imagined affect world that makers locate themselves in juxtaposition to and identify with in some way.

\subsection{MAKING AS A NEW/DIFFERENT FORM OF WORK}

At one of my Detroit sites, four makers and I spent a good deal of time before the formal interview talking about all the outside attention the maker phenomena has attracted in Detroit. They were reflecting on all the things that they had been called in the media, when one of them said, "I couldn't care less, personally. Like call me whatever." A second maker quickly added, "we'll let the academics figure that out." Their concern was not at all with the label their company got or the individual identities they were assigned by the media, but instead that there was a growing recognition that the collective work they were doing (both their business and makers more generally) is different. That their business does not outsource production; that they do not import materials for the goods they make; that they are really making things by hand; these considerations should be enough to warrant some sort of distinction.

This was a common sentiment in my fieldwork: most makers think of making as a novel or different form of work. Important to this imaginary of work are the values that build a sense of collective affectation that affirms this form of work as better than others, 
or at least good enough to entice makers to not be doing something else. As a form of work, many of the main tenets of making can be found in one interviewee's description of a maker as:

A real person physically making something with their hands using a variety of tools. And so those tools could be digital, they could be physical, they could be whatever tools, but it's a real person with their hands, making something physical using a variety of tools.

What jumps out about this imaginary of work - "making" - is that it is primarily described as a physical form of work. Furthermore, this interviewee used the word "real" to describe who performs that work (i.e. makers). These notions of physicality and realness came up again and again, as if to refer back to a form of work that is not physical and not real. This is where we see the importance of the object - the actual produced thing itself - in the form of work: most makers agree that physically producing a tangible thing is fundamental to what they do, which explains why "manufacturing" is the metacategory makers are most often ascribed to. Being a physical form of work also means that makers work with their hands; the source material, and how they procure it, matters to makers. This physical process of making goods requires physical space in which to place machinery and store finished products waiting for distribution. It also requires raw material procurement, which means more storage space on the front end of the production process as well as a supply chain that requires spatial management. These are all logistical effects that flow from the desire to work in a physical manner; but these don't really make "making" a different form of work. 
Where making started to separate itself from other forms of (remunerated ${ }^{17}$ ) physical work is in how this sense of physicality juxtaposes "making" to the types of work that making isn't: it isn't tech, it isn't office or cubicle-based work, and it isn't mass-produced. The desire to break from something intangible or immaterial (making is not tech), being managed (making does not happen in a cubicle), and repetition (making's process is not an assembly line) allowed makers to imagine themselves as informal, capricious, unstructured, and grounded in real communities in real places. In other words, the collective imagination of "maker" seemed to desire distance between itself and the abstractions and infrastructures of other forms of work.

This juxtaposition to "other" or past forms of work often surfaced as a collective distaste for professionalism, or at least whatever makers commonly imagine professionalism to be. Many makers, particularly in Portland, made reference to a sense that being untethered to professional work would lead to everything just working out:

I feel like to be a maker there's also a, just like how I've approached doing my business, I don't know, I have this underlying sense that I can do it, even if I don't know how to do it, like I'll make it up as I go. And that, yeah, it has served me well.

A handful of makers encapsulated this sentiment with the idiom "fake it till you make it" (an inherently problematic statement without the addendum question of who is able to "fake it" and with or without what safety nets). Many of the statements in this vein have something of a quasi-rebellious character; one interviewee postulated that makers existed

\footnotetext{
${ }^{17}$ It would be absurd not to recognize here the forms of unpaid and forced physical work ranging from slavery to feminized household work/labor that have existed throughout human history.
} 
in a realm in which "nobody was there telling [makers] they can't do that." Here makers are imagined as the vanguard of a changing business atmosphere: there must be an alternative to working in offices and being managed and bored. According to one makerspace manager, those that have the "courage" to forego a university education and a standard office job can "till their own soil" and gain some control of their livelihoods through making.

In this way, people do connect to the maker identity insofar as they envision it as a form of work, because positioned in this way the maker identity creates a collective sense of liberation from old forms of working that makers perceive to be malignant. The promise of such freedoms implicit in the maker identity does circulate affects like enthusiasm amongst makers, even if it is somewhat tongue-in-cheek, as evidenced by this maker's reaction to the maker identity question: "We're a maker! I had to give up my hand-modeling career! My hands are shred! I am a maker! I make things!” But there's something else that this particular statement suggests: a sense of sacrifice. One can identify as a maker, and in doing so can access the affective register of enthusiasm, synergy, autonomy, and so on, but the suggestion is that it comes at a price. Working with one's hands mean they will be "shred." This may seem like a joke, and indeed there was a detectable sense of jest when this proclamation was made, but in many ways she was being quite serious: adopting a maker identity does not resolve the confrontations between belonging and exclusion, nor does it alleviate the sense of precarity that neoliberalism produces so effectively. In other words, becoming a maker requires sacrificing the security of working in a cubicle and being managed for the solitude, physical toil, and sheer magnitude of responsibility ("wearing all the hats") of being a 
maker-entrepreneur. Adjacently, sacrifice denotes something of a shared project, of sacrificing oneself for the sake of another. Often when one feels compelled to make a sacrifice, they forego certain aspects of their individuality in the service of the common. This sense of a shared project gives the individual a sense of purpose defined around a core group of values.

This sense of what making is - a physical, "real" form of work that pushes back on "professionalism" and requires sacrifice - opens a space of collective imagination where it is possible for makers to (commonly) experience work in the ways described above. It should be noted that I rarely (if ever) sensed an over-inflated sense of social importance; in fact, most makers wanted to be left alone by third parties interested in how they were "transforming the economy" or "saving the city" (the latter especially in the case of Detroit). But the question of why the collective imagination drifts toward autonomy, physicality, bootstrapping, and many other trappings of the proto-American "good life" is interesting. And while this imaginary of "making" and the maker identity is somewhat coherent at this collective level, in the next section I discuss how it became more vague and incoherent between individual interviewees.

\section{Crafting an Identity}

Collectively, there is a good amount of identification amongst makers on the grounds that "making" is a distinct form of work. Whether it is called making or not, makers generally recognize the aspects of their work that makes it distinct from other forms. At the collective level, there were emotional, economic, and social rewards for makers. When the identity is applied at the individual level, however, it was experienced as problematic. This is especially true when the maker identity is put into context with 
other terms of identification that have become existentially attached to "maker": scale/size (e.g. "small business"), craft, artisanship, and manufacturing are all examples.

In one interview, for example, two interviewees argued between themselves about the maker identity in the context of scale. The argument revolved around how big a maker business can get before it becomes something other than a maker business: one said size matters and one said it doesn't. The first said that a larger firm can employ makers, but those at the top are actually business people. The second argued that in the world of design the same thing could be true (i.e. designers as workers, businesspeople as managers, capitalists as owners), and despite this, we still think of these firms as design firms. Why wouldn't the same be true of maker firms? The argument was somewhat astonishing; the importance of the term "maker" was clearly at stake and each interviewee appeared passionate about their position. But the point here is that an individual understanding of the maker identity was unsettled, even between two close friends that had gone into business together.

Looking deeper at a couple of cases that are especially reliant on the terms "craft" and "manufacturer" - both of which can be located in modern production culture somewhere adjacent to the maker umbrella - further substantiates the point that identities at the individual level are ambiguous at best. In the following examples, it is important to remember that each response is related to a set of questions I had been asking them about the maker movement, so the context always maps back to the ways "craft" is tied to the maker identity. It was common for respondents to structure their answers by juxtaposing identity terms (e.g. "maker" versus "crafter" versus "manufacturer"). As evidence, consider this excerpt (I'll call him the "first maker" below): 
When I was sewing custom bags out of my basement I think I was a crafter. When I moved my studio out of my basement and I started to sell to shops, I think I was more in maker category. I had a more professional website, better photography, better pricing. Now I identify more as a manufacturer, where we have distributors, we have 50 [product] shops that we service in the US, we have a website that sees serious sales every week and we have to meet that demand. It's more about efficiency than it is about making a unique product.

In the passage above, the craft identity is positioned as amateur or hobbyist and in juxtaposition to more serious or professional forms of production (e.g. manufacturing). This maker uses craft to denote the seriousness with which a maker approaches their growth intention; manufacturing, as an identity, is something of an affirmation of progress in one's efforts. Craft, for this first maker, is the beginning of an upward trajectory toward manufacturing.

A second maker, when asked the same set of questions, also thought of craft in terms of a "seriousness with which you approach what you make." Like the first maker, she thought of craft as a form of hobbyism or being not-so-serious, whereas the maker identity represented something more serious and more committed to a process that began as a craft. In her response, there was not so much a sense of scale, but more of an investment in time. But as she continued to develop her imagination of craft, she seemed to base her appraisal of these identities on style or taste. Instead of making a scalar comparison between craft, maker, and manufacturer, she juxtaposed craft to the maker and artisan identities. She described the artisan identity somewhat pejoratively, as "old" 
and representative of a suburban art gallery. Against the artisan identity, she sees a maker as more urbane and more "hipstery."

At first glance, we might have concluded that these are actually similar statements and that craft and making can be determined to be a stage in the development of one's production capacities. But these two apparently similar ideations of the term craft are actually pretty divergent; the difference is in how the makers imagine such identities in relation to other identities, or how makers group such identities and what they juxtapose them to. The first maker grouped the "craft" identity with maker and manufacturer and the grouping was done on the grounds of scale, whereas the second maker grouped it with maker and artisan on the grounds of style. Perhaps we can say the first maker grouped the identities vertically and economically whereas the second grouped them horizontally and culturally. On the individual level, in other words, there is fuzziness even when the maker identity is accepted as descriptive of one's own subject position.

Even where these two makers seem to agree - that craft has to do with a sense of hobby or non-seriousness, whereas making implies a sense of deepened intentionality other makers forcefully protest. The notion that craft can be reduced to cultural or economic smallness frustrates some makers. This Detroit maker, for example, saw craft as fundamental to his identity:

In the same way someone would embrace queer theory or reclamation tactics to invert something that would be pejorative on its head, I mean that's how I approach craft.

In this case, craft is not something that can serve as a proxy for hobbyism. Instead, he points out that craft (as an identity or a way in which one approaches their work) has 
been so marginalized that it now needs to be reclaimed from those that would diminish it. Additionally, according to this maker, craft and manufacturing have a shared history that can be revisited in the service of investing a sense of flatness to common maker- and place-based identities:

Being in Detroit, moving fluidly through craft and manufacturing and production, using all those terms to describe what's happening without creating a hierarchy between them or using craft production or craft manufacturing as a term to describe what I'm trying to do sort of breaks down this thing where there's a dialectic between craft and manufacturing.

The forced antagonisms that this maker perceives felt outdated to them (him and his spouse, who co-own the business), because they felt forced to choose between $\mathrm{craft} / \mathrm{maker} / \mathrm{manufacturer}$ or locate themselves somewhere on a hierarchical path between these identities. Splitting the terms craft and manufacturing, he continued, is historically contingent on a designer designing something and then a (dispensable, unskilled) worker actually making it, which he argued is an increasingly obsolete form of production:

And I think that's just not the future of American manufacturing. People who are dispensable become dispensable by either being outsourced or by being replaced by technology. So the manufacturing that's going to stay here is going to be sustainable, it's going to be skill-based and involve some level of expertise and some level of design [...] That's craft, in my opinion."

In the final sentence it is apparent that he intends to rescue the term craft in order to reconcile the split between the design and production functions of manufacturing. Even more, this particular imaginary of craft suggests that craft could be a solution to the very 
problems that have plagued manufacturing and played a key role in Detroit's own troubles, namely rote and repetitive production that has historically been (and continues to be) replaced by machines. The major point here is that this maker envisions craft as pretty far away from a relatively unimportant activity (a hobby) or the beginning point in a firm's evolution (scale) or the sense of style one identifies with. In his mind, craft takes a more central role in the culture of production; it is something like a modern metasolution to the historical problem of runaway manufacturing.

Competing uses of the term craft came up in other places as well. For example, one interviewee filled me in on how Detroit's craft fairs are loosely filtered into the categories of "mom and pop" and "indie." Since the two terms sounded very similar to me, I asked whether that differentiation was along the lines of an urban/suburban dichotomy. She responded that it's essentially two separate networks; each network is determined and bounded by the type of craft fair a maker frequents, the end result of which she referred to as a "circuit." Still somewhat perplexed, I asked a different interviewee, who is recognized as a central figure in the Detroit craft fair scene, if she understood this dichotomy; I could barely finish the sentence before this second interviewee began explaining the classification. She described "mom and pop" craft fairs as the type that might be in a church parking lot on a Sunday morning in the suburbs. An "indie" craft fair, on the other hand, was more likely to be urban, somewhat younger, and more aesthetically current with the trends. The two craft makers in this case both access a common imaginary of craft fairs but understand and describe it in two different ways one by describing the networks of people that populate the craft fairs and the other by describing differential craft fair aesthetics and locating them in an urban/suburban 
relationship. What sticks out is that despite understanding the dichotomy in different ways, they knew exactly what the other was talking about.

All of these divergent examples of craft emerge from the same general interview questions, none of which stumped, confused, or otherwise mystified the interviewees. In other words, they all grasped the context from which the questions were being asked, as if they has already at some point given thought to the answers they ended up giving. Many makers even added, "I was just having this conversation the other day" or "yeah, I have been thinking about that recently." If I am to belabor a point here, it is that somewhere in the murkiness of all these competing visions of the maker identity, there is a common understanding about what they are all doing. And it seems possible to me that this sense can be captured in a public or common identity of sorts, for which "maker" seems the best placeholder at the moment. I am left with the conclusion that the identity seems intact at the common level, where the most visible aspects of the identity can be essentialized and converted into representations for media production and consumption. We might think of this common-ness as the "maker imaginary," and as anyone with an imagination knows, sometimes the things we imagine can be hard to put into words.

\section{Making or Manufacturing?}

As I have already begun to address above, the collective or common maker identity is often brought into conversation with another work imaginary: manufacturing. The fuzzy line between the two is persistently contested; some makers see a clear and necessary difference between the two, whereas others balk at any suggestion that what they do is not manufacturing. One interviewee in Detroit described the process of setting up two focus groups for a research project she was conducting. She hoped one group 
would be populated with makers and the other with manufacturers. To her surprise, getting the groups to self-identify as one or the other (and thereby choose the "right" group) turned out to be all but impossible. According to her, the "makers" were all signing up for the manufacturing focus group and the manufacturers weren't interested in signing up at all. She tried sitting down to figure it out with makers only to find that most of the businesses that she assumed would refer to themselves as makers wanted to be classified as manufacturers instead.

I asked this question often: is there a difference between making and manufacturing, and if so, what marks that division? What does such a distinction do? Some makers almost seemed upset that I would even posit a division, and one even told me that they perceived the question to insinuate something negative about manufacturing. Others flatly rejected the question; one laughed as he told me there's "not really" a difference and that maker is just a "catch phrase" that discounts his work as a manufacturer:

It sounds special, doesn't it? It's like this thing you want to coddle - oh, he's a maker. It's like, we make things with our hands, I've been doing this my whole life, it's what I do. Everything we do is handmade, you know?

But other makers did see a distinction. For some it goes back to a matter of scale (small makers versus large manufacturers); as one interviewee put it, the two terms belong to a spectrum that ranges from making a product at a kitchen table to building ships along the Willamette River. She argued that referring to a business or a form of work as maker "only when you're cute" ignores the potential for "cute" companies to grow and create jobs. Another maker agreed that the distinction has to do with scale, but thought about it 
in terms of the object of production - specifically the prototype. He argued that anything that is eventually manufactured is first "made." In this way, there can be making without manufacturing but not manufacturing without making. He summarized his thoughts by saying that the difference is part scale and part intent. A third maker agreed about the importance of intent in differentiating between the two. For her, intent is not just about the quality of work that goes into the production of a good, but also about an intentional ethos - which apparently manufacturers don't have - tied to values like community: I think it's more respect for the art and craft of what you do, more focus on quality in the craftsmanship, and respecting the hard work of others that do it. I think we have a real community here where everybody is just trying to lift everybody else up. I don't know if that happens between machine shops. The end of this quote opens an interesting door; she doesn't know if there is a sense of community between machine shops. But who does know? Do these makers have a legitimate way to compare making and manufacturing as (potentially) distinct forms of work? Of all my interviewees, there was one especially well situated to address this question due to the fact that she works at a larger manufacturing facility in addition to running her own maker business. I asked her what sorts of tensions, if any, exist between the two worlds. She answered that there's a certain amount of "eye-rolling" that goes on. On the maker side of things, there's this dynamic of “can't you see how valuable this culture is?" On the manufacturing side, the dynamic is: "Culture? Shut up! Money money money. It's different generations of people, it's a different set of values. And they don't meet in the middle a lot of the time." She felt that manufacturers don't understand the emotional and aesthetic value of a made object. But people at the manufacturing facility 
wouldn't understand why someone would choose the more expensive, more inefficient option. She added that the aesthetic ideals of makers sometimes contradict the "hands in the mud" style of business-building that manufacturers identify with. But people can be unreasonable on both sides of the maker/manufacturer divide. Her personal experience has led her to the conclusion that the "design class" often assumes manufacturers to be beneath them in terms of education and culture; she says makers sometimes talk to manufacturers "like they're dummies."

Most makers can only make judgments about distinctions (or lack thereof) between making and manufacturing by drawing on an imaginary of manufacturing. This last maker, though, spends equal amounts of time in both worlds and seemed pretty convinced that they were indeed culturally distinct. So distinct, in fact, that she referred to herself at one point as a "translator" between the two worlds. Armed with this insider look at the fault line between the maker and manufacturer forms of work, I can conclude that in order to draw meaning from a particular identity, makers have to fabricate imaginaries of adjacent identities that provide a sort of mirror to understand their own identifications in terms of the work they do. This helps get at why these identities are so hard to express in individual terms; as argued in the last section, the common imaginary of work relies on the essential characteristics of a particular work world. Manufacturing is valued because it is messy, physical, requires sacrifice, and even somewhat nostalgic, especially in cities like Detroit or urban manufacturing zones like the Central Eastside in Portland. But manufacturing is also repetitive, mass-scale, and more and more mechanized - all things makers tend to push back on. 


\section{Recognition and Rejection}

This pushback comes in a few different flavors. A couple of interviewees emphasized how annoying it is that the maker movement is so often posited as a new thing when they've been "making" for a very long time. In fact, this seems to explain for some why the term is so slippery - it's somewhat analogous to a change of clothing:

I feel like you're asking that question and I don't know if I can really answer it. [...] It's just broad, and people are trying to take it and make it some definition for this new movement, like you're an artist, you're a craftsman, now you're a maker. So it's kinda like it's trying to re-identify, or like, maybe there's been a paradigm shift and that's the moment that we need a new name for it? Now, people are like conscientious about where their stuff is coming from, maybe that's the subtext of 'maker.' And I think that's really important. But it doesn't mean that we haven't been doing it for decades, you know, people were makers 3,000 years ago when they were making glass vessels before the iron age [...] Where are you not a maker?

The final question in this quote - "where are you not a maker" - reveals an ambiguity: the same sense of openness that's attractive to some makers is the basis for other makers' rejection of the identity. In other words, the fact that "maker" could literally apply to anyone that makes things is exemplary of some of the key values emergent from the maker imaginary: it is open (source), accepting, and community-oriented. But this openness is still contingent on the formation of a new identity position that juxtaposes itself to the oppositions of these values (exclusivity, greed/profit-driven, singularly economic); why else would a new identity be necessary? Are there no already-existing 
identity positions based around production that encompass openness and community? The maker from this quote was wrestling with exactly this line of questioning. The fact that the maker identity is - in its commonly circulated formulation - somehow synonymous with these notions of openness contradicts its own necessity. One of the reasons this is true is that once "maker" is captured as an identity position, especially as it is more broadly circulated, the boundaries of its normativity become more clearly defined: values such as openness and being community-oriented become normative requirements for adopting the maker identity. Some makers were actually drawn to the identity position because of this, while others perceived it as an enforced normativity enacted by the introduction of a new and unnecessary identification.

Other makers were ambivalent because they sensed the demand for "made" goods from their consumers but didn't trust the "maker" term. They recognized the benefits they had gained access to by way of the maker movement while also holding the term "maker" in suspicion. One interviewee doubted the legitimacy of the term, assuming it must have emerged from a focus group hosted by some advertising agency. The major issue for him was that the term feels too perfect, like it was molded specifically to arouse the romantic imaginary of a "maker" swinging a mallet in a fire-lit artisanal workshop. To him, describing his actual experience by assigning a word to it limited the way the milieu that he was familiar with could be expressed; he felt that it was much more broad than a preformulated identity term could possibly suggest. The maker identity, in this way, is a limitation rather than a synonym for openness.

Another maker also doted on the idea that "maker" was a manufactured (a-hem) identity. "There's a battle for who owns that term maker," he said during the interview. 
"And ADX (a prominent Portland makerspace) is winning, let me just say it right up front." His perturbation seemed to rest on the relatively high level of visibility that the more outgoing and active part of Portland's maker segment has, although he assumed this visibility was coming to them as a result of their ability to market themselves as makers and sell "the thought of some guy in a garage tinkering" and "bootstrapping" a successful business. Needless to say, he located the notion of bootstrapping somewhere near the end of the digestion track of American folklore. It struck me that he felt deceived, as if a hostile takeover of the maker identity had led him to soberly conclude: "a maker is whoever has enough marketing and sales skills to convince you they are a maker."

This last maker wasn't didn't necessarily reject the term "maker," he seemed to just want it to be commonly understood in a different way. But some interviewees didn't want to be associated with the maker identity at all; one interviewee called the term "cringe-worthy" and said anyone that self-identifies as a maker runs the risk of "not being cool anymore." Others drew a hard line against it:

I don't embrace the term at all. Like if someone asked me 'are you a maker' I'd say 'yes I make things.' I embrace the term artist and entrepreneur, business lady, but I don't embrace the term although I'm finding [...] it identifies us in the realm. And we are a making facility or whatever, but it's a made up term [...] it feels fraudulent a little bit sometimes like I was saying earlier, anyone can put on an apron, it's this whole thing that I don't want to be a part of, that other people are doing and like I don't want to be over there. But I'm obviously very obsessed with, or very aware of my image, or aware of what I include myself in. 
Again, we can see here that as a form of work, making still remains important: she values being identifiable in the realm of makers because that's where her ability to make a living derives from. On the one hand, she needs the maker identity while on the other hand she rebels against its "fraudulent" nature. In the quote, the interviewee (I best not typecast her as a maker) refers to something she was saying earlier; the following is what she was referring to:

The idea that anyone can be a maker - it's the apron, bearded, Portland, tattooed, Instagram, all white background thing that I don't really want to be a part of that. I'm already from here, that's a new thing to me [...] It feels too trendy.

The list of a maker's aesthetic characteristics - and the speed with which she was able to recall and catalog them - suggests the clarity of the maker imaginary for her. This imaginary is something that is shared, held in common. Consider another conversation that yielded a similar maker imaginary with a similar aesthetic catalog. In that interview, the woman I was talking with said that when we were talking about the maker identity, she imagined a "dude with slicked back hair, jeans, an apron, a nice grey T-shirt, a big beard, and he's making cool things or a girl with cool earrings and a cute dress who's making jewelry." She added, "when you hear maker, you kind of know what to look for." In other words, she knows a maker when she sees one.

\subsection{INTIMATE PUBLICS AND THE MAKER IDENTITY}

As this last example shows, if makers collectively can't (or refuse to) define the identity, they don't seem to have any problems describing it aesthetically. If "maker" as an identity is so unsettled, how does everyone know what each other is talking about? How does one know a maker (or a "made" good) when they see one? In one case in 
Detroit, a pair of maker business owners thoughtfully mined the shortcomings of "maker" as an identity but then realized that they refer to one faction of their friends as their "maker" friends. Despite not adopting the maker identity for themselves, they were applying it to their network of other "makers" - regardless of whether or not those people adopted the maker identity - because it identifies them in a particular realm. Aesthetics are a primary way of "distributing" the boundaries of this realm and the roles that are played within it (Rancière, 2004).

What stuck out the most to me about the maker identity is how a sense of incommonness emerged despite its divergences and dismissals. Perhaps it is telling that in Portland, we engaged most of our interviewees through their common belonging to a local maker collective. What drew them together? As I noted above, there is of course a certain recognition that works aesthetically, but aesthetics provide something of a structure for the affective and the intimate. The maker milieu is evocative of what Lauren Berlant calls "intimate publics." Intimate publics are a type of public sphere that are accessible to anyone that identifies with the emotional and historical cohesions that give it visibility. There is a sense of commonness with others in such a public, and the relative commodities, markets, and patterns of consumption arise around it and structure how people live within such a public. In a way, intimate publics are the where and the why of identification: an intimate public "flourishes as a porous, affective scene of identification among strangers that promises a certain experience of belonging and provides a complex of consolation, confirmation, discipline, and discussion about how to live as an $x "$ (Berlant, 2008; vii). In my case, the $x$ is "maker." 
Intimate publics offer a way for people to feel grounded in moments of flux. People gravitate to specific publics because they are not rigid - there are no laws to follow or auditions necessary to belong - but yet they affirm one's experiences and allow for intimacy with others that feel similarly about the world. In The Female Complaint, Berlant (2008) argues that commonly recognized norms provide members of an intimate public a sense of "belonging as an alleviation of what is hard to manage in the lived real" (5). Such groups are structured by shared common normative aspirations and a sense of intimacy, even if the people don't know each other (or even know each other exists). What distinguishes such groups is an "emotional generality" that eludes hard definitions and "flourishes by circulating as an already felt need" (5). Berlant points out that coherence and rationality are not necessary for such groups to be able to recognize each other, even in their rejection of certain aspects of the group. As such, vagueness, incoherence, rejection, and ambivalence are not counter to the sense of belonging that someone tied to the maker milieu might derive from the maker identity. Vagueness and incoherence, Berlant argues, can also be a defense mechanism, a form of collective protection from a more rigid, restricted, or forced sense of togetherness.

The incoherence and rejection (of "maker") that I sensed from makers suggests a feeling of togetherness that doesn't compromise the sense of autonomy that individual makers tend to value so highly. As the evidence above notes, many makers weren't concerned with what outsiders or media outlets called them or how academics produced maker taxonomies. My interviewees rarely wanted to feel trapped by the maker identity; many of them even gestured toward other adjacent and more established identities (crafter, artist, businessperson, entrepreneur, manufacturer) in order to escape or reject 
"maker." But as Berlant makes clear, rejecting the norms that begin to coalesce in an intimate public is still a way of participating in the emergence of a public; rejection and ambivalence are ways of structuring the maker milieu: who it is open to, what affective and emotional registers are resonant within it, and what promises the maker world can offer its participants. This is what Berlant calls the "juxtapolitical" - a sentimentality that operates contiguous with the political realm without becoming antagonistic or threatening the public's loose coherence.

\subsection{CONCLUSION}

This chapter was the product of responses to a simple question posed to makers about their identity: "what is a maker?" While there were commonalities that gave the "maker" identity some analytical weight (e.g. it is a unique form of work), I found that there were a variety of disparate ways makers thought about the identity position. Furthermore, many of these ways of thinking about the maker identity were often either mutually exclusive (various notions of "craft"), held in tension (disagreements about what values represent "manufacturing"), or outright rejected. Yet I argue that given this apparent disparity, the maker identity still maintains its coherence; it still holds together, even when rejected. In fact, it is actually important that the maker identity is vague, because the loose boundaries eliminate the need for makers to submit to some form of purity test in order to derive a sense of belonging from the identity. Put differently, makers can form attachments that don't make them feel trapped. Yet having such attachments provide the perception of stability, because they anchor makers to a community, even if that community is imagined. 
I argue that the coherence of the maker identity is a function of the affective realm more so than any system of economic rationality. As Wolf-Powers et al $(2017 ; 6)$ argue, the core elements connecting makers across a variety of geographies are attachments to place and an ethical approach to economic relationships (e.g. the desire to be collaborative and a focus on positive social effects rather than strict economic gain). These elements are indeed economic, but they are also notably affective. My claim is that it is the affective aspects of making that draw them together: given the absence of clear boundaries around the identity, the emotional ties are why "making" as a form of work feels different to makers. In other words, whether or not "making" is actually a new or unique form of work is beside the point; what matters is that makers feel a sense of belonging or in-commonness with one another, even if they cannot agree on what exactly making is. The imaginary of making, as I argue in chapter 2 , is an instantiation of this incommonness; it yields a sense of intimacy even if it isn't coherent between the individuals that collectively construct it.

Moreover, I argue that the affective infrastructure that holds "making" together can be contextualized by a commonly felt sense of impasse and antipathy toward the inequitable and environmentally destructive value systems of mass production and consumption. Many of the excesses and inequalities of neoliberal globalization were laid bare during the Great Recession, which in fact coincided with the intensification of making. Indeed, most maker firms in the Kauffman sample were established in the years after the Great Recession (Wolf-Powers et al. 2017). It follows that making (and the maker identity) has emerged partly as a result of the sense of frustration and disappointment that makers have commonly felt about the value system that supports 
globalized production: as I will show in the next chapter, makers appeal to a different value proposition - they imagine value differently than the "rationality" of globalization, even if such an imaginary of value introduces a certain "pricing paradox" due to the evaluation of makers' ethical values in the same economic terms as global capitalism. Regardless, makers seem unconvinced that the global economy can provide a pathway to "the good life." The point, for this chapter, is that this common feeling about the failures of the global economy brings makers together. It is an affective space where they can think about belonging to something else, to a form of work that provides them purpose and pushes back on the mandates of globalization, while also introducing a sense of community that doesn't impose rigid limitations.

If this chapter provides a look at how makers identify themselves and each other, the next will probe how makers identify with their consumers. More specifically, the next chapter deals with the entanglements of social, affective, and economic considerations of value. I'm interested in how these values become interpreted in specific ways and then (re)aggregated, shared, and uploaded into the economic world. In my interviews, most every maker described the importance of opening up the "black box of production" to their customers or clients, a sensible reversal of Marx's commodity fetishism. In other words, a focus on the process and then the sharing of that process - particularly over social media - opens a "window" between the maker and the end user of a (hand) made good. The maker and the end user can communicate through this window, and this communication is mediated by the evaluation of both the maker's product and process. It is this opening of the production process - and the mediation of affective relations through the object of production - that I will turn to next. 


\section{CHAPTER 4: MAKING VALUE(S)}

\subsection{VALUES AS PRICES}

"The fascination of handicraft derives from an object's having passed through the hands of someone the marks of whose labour are still inscribed thereupon: we are fascinated by what has been created, and is therefore unique, because the moment of creation cannot be reproduced."

\section{- Jean Baudrillard, The System of Objects}

In the above quote, Baudrillard hints at a theme that arose often in the Kauffman research (Wolf-Powers et al., 2017; Wolf-Powers et al., 2016) as well as Heying's (2010) prior research on Portland's artisan economy: the process of creation really matters to consumers of maker goods. Our research has turned up interesting stories of consumers quizzing makers about the process that "made" objects have undergone - what tools were used, what does the space that it was made in look like, who made it and what are their social values, where are the raw materials sourced from, and so on. Many consumers are almost less interested in the made object than they are in the making process.

As I will argue throughout this chapter, the conditions of production are an important point of value communication in the consumer/producer relationship. Consumers have shown a willingness to pay (a lot) more for a handcrafted, locally made good over a good that is mass-produced and sold at a "big box" store. The thrust of my argument in this chapter is that the ability of makers to communicate their value proposition to consumers is essential (also see: Schrock et al. 2018). Makers do this, I argue, by opening up the production process for consumers - a tactic one maker referred 
to as the "burden of proof" - thereby affecting the way consumers respond to maker goods. This tendency toward visibility or transparency is what I refer to as "windows" throughout the chapter.

\section{A Pricing Paradox ${ }^{18}$}

Pricing is a significant challenge for makers. Many of the makers we talked to freely admitted that they marketed to people in major cities that have large discretionary incomes: in cities like LA, New York, Chicago, or San Francisco, there are enough consumers willing to pay four and five times more than "normal" for a handcrafted, highquality good that came inscribed with the story of the human that made it. This led one maker to conclude that "Portlanders are cheap"; consumers in these other cities "wouldn't bat an eye" at the prices that makers have to charge. But even these makers that target wealthy consumer bases - many because they have to - struggle with the ethical aspects of pricing. The maker that called Portlanders cheap, for example, quickly recognized that massive inequalities between consumer bases have given her a "skewed value" of the goods she makes, which she said depresses her at times.

All this adds up to a central problem for makers: the necessarily high prices of their goods make them inaccessible to the average consumer, which exposes makers to a swarm of "by association" criticisms, such as complicity in gentrification or elitism. A Portland maker described an interaction at his production site (which has a storefront) with a neighborhood resident. The resident was irate after she had walked by and noticed the prices on his goods, after which she barged in to this maker's workspace and yelled at him for what she perceived to be a practice of price gouging that reflected the gentrifying

${ }^{18}$ Thanks to Jamaal Green for the title of this section 
nature of Portland's inner neighborhoods. Another maker, this one from Detroit, told me that she occasionally has confrontations on pricing at craft fairs. When people ask her how much her goods cost, the reaction to her pricing is often: "for this?" I asked how she feels about that: "I'm like yeah! I made that! And you have to like bite your tongue because people are like straight up insulting you." Another Detroit maker told me that her partner's father "is still mad at him" because of the "unethical" prices they charge for their goods:

Especially in a city that's very poor, it's bougie as hell, $\$ 250$ [product] you know? But we know we're not getting insane profit margins, we know we're not gouging people, and we know what goes into [the products].

A major implication for makers is that they are constantly trying to make adjustments in order to accommodate less terrifying price tags. The above maker from the craft fair told me that she has about 12 different Excel spreadsheets that she uses to try to figure out what her prices should be. Often times it is her labor that gets left off the price tag because "I have to." A different craft maker, who had mechanized some of her production, said that if she did every stitch by hand, she'd never sell anything because she'd have to charge more than anyone would ever be able to pay. In Portland, one firm I spoke with surprised me when they said they do so much free work that they haven't actually been able to make their business (which very much looks like a business online) into an actual business. Referring to their own business as well as their maker friends' business, they said that if they did a cost-effectiveness analysis they'd probably learn that they are making about $\$ 3$ per hour. It is worth noting that aside from the maker in the block quote above, none of these makers have employees. 
We have established that makers have to undervalue their goods in order to keep prices somewhat reasonable. But in trying to sell such objects to a broader consumer base, makers end up competing with an industrialized consumer imaginary generated collectively by a middle and working class whose wages have stagnated. This stagnation - the opposite side of which has been an extraordinary acceleration of profit for the top income earners - has been possible in large part thanks to the falling prices of industrialized goods made in impoverished countries by underpaid and underprotected workers. Even if the "average" consumer identifies with similar social and moral values to the maker, the line of communication between the maker and the consumer is obscured by the cultural and economic firewall that the pricing mechanism introduces. Regardless of whether or not most people want a revitalized ethics embedded in the objects they consume, if they can't afford it then the values that drive such desires are moot.

We have also already seen that pricing works affectively, clearly repelling and even angering many people even though makers tend to over-exploit themselves just to get prices down to where they are. In an interview in Detroit, a maker and I were discussing this "pricing paradox" in context with the perceived failures of the Arts and Crafts movement ${ }^{19}$ of the early $20^{\text {th }}$ century. I had asked if he thought makers were now re-living the same conundrums, largely for the same reasons:

Ultimately the things that [Arts and Crafts artisans] made were more for the middle to upper class, and there's no getting around that because what industrialization did was to make things cheaper and more accessible. That has not been solved [...] I don't think there's any solving that. I don't think the work

${ }^{19}$ For more on the Arts and Crafts movement, see chapter 2 
can get any less expensive. The people that have that as their goal end up compromising a lot of things that create integrity in the work.

Here we see an important conflict around value - by holding on to certain moral, social, or cultural values (e.g. "integrity"), makers end up confronted by the reality that these values must be appraised economically. This evaluation, what we might describe as a "value adding" process, necessarily translates certain social or moral values into economic values. One of the distinctions about "making" is an approach to production (the "process") that focuses on these social and moral values. And as this maker points out, industrialization has the effect of stripping these socio-cultural values away as operations scale:

Any time you're trying to compete with anything that's outsourced and manufactured or mass manufactured, even if it's made locally or regionally or nationally, once you scale volume it's going to get cheaper, but for a lot of people who are working in traditional crafts it's not necessarily a goal. The goal is to make a living.

Perhaps I can draw the conclusion that the economy has been affectively normalized for mass production and consumption; this normalization includes commonly accepted prices for industrialized goods. Industrialization makes things cheaper, as Marx (1976) brilliantly points out, by concealing the production process, particularly by transforming the process (and the social relationships necessary to make it a process in the first place) into "objective" relationships based on money. In attempting to reverse this and make the production process visible - the "how" of which makes up much of the rest of this chapter - makers cannot achieve industrialized prices. Therefore, they need new 
imaginaries of value and new forms of communication with their consumers. One of the important functions of these new imaginaries of value is something of a rationalization for the higher prices. It is important to remember that makers often do not recuperate the additional value produced in the process (Heying et al., 2016; Heying \& Marotta, 2014), and indeed are being threatened (e.g. through rising rents) by the added value that they create; as mentioned, small maker firms have to charge high prices and still aren't even calculating labor into their cost-of-goods-sold formulas. In other words, what strikes the industrialized imaginary as an exorbitant price is barely a survival wage for small maker firms; maker firms can only access this added value once certain tradeoffs that come with scaling are entertained (more on this below).

Perhaps I can return to the Detroit maker from above whose partner's father considered their prices unethical. The quote I pulled referenced the "bougie" nature of high-priced goods in a place like Detroit, where almost no one living in the city limits (i.e. not the suburbs) would be able to afford them. This conflict is what is thought to be unethical. But the maker that this quote came from closed her thoughts on the matter with this addendum about her products: "[but] we offer lifetime complimentary repair and they're not made by 12 year olds in Indonesia." These two qualifications are important: the first rejects the "throwaway" culture of consumption that sees goods as quickly obsolescent; the second points out the problem of globalized labor in commodity value chains. The irony here is that an "unethical" price is the result of attending to the moral hazards of overconsumption, waste, low wages, brutal work environments, and so on. This irony reveals the centrality of value(s) in the pricing structure of made objects. The 
pricing mechanism is an effect of the bigger value structure; the conflict for makers is located there.

\section{Adding value, or, loving a thing}

To address the way opening the production process produces "added value" for makers, we must trace the movement of value from the producer to the object. Rooted in his early writings on alienation (1988) and more fully developed in Capital (1976), Marx showed that value flows from the activity of the laborer; by laboring, humans "realize" (make real, or transform into an object) their desires, wants, needs, and passions, all of which are captured and congealed into the object of production. Laboring under capitalism, however, introduces a specific set of rules to this realization of labor. Under these rules, human labor is valued in aggregate form (abstract labor) and converted into a commodity (labor power), then sold to the ruling class for a wage. These rules constrain humans to produce things not in order to satisfy their own desires, but rather to satisfy the abstract demands of the market.

In Marx's theoretical framework, then, we have a situation in which a portion of the subject (labor) is converted into an object (labor power/commodity) that confronts the producer as something "alien" and "hostile" to them, in part because the capitalist laborer no longer produces the object of their desire. As a result, individual labor becomes specialized, repetitive, controlled, mechanical, banal, and often brutal. Needless to say, the laboring subject will never fully recover what it has lost in the process - these unrecoverable fragments of human desire and labor constitute the "golden eggs" of surplus value. The importance of the "made" object follows; the object is what all this subjectivity gets "stuck" to (Ahmed 2010). The object, now thrust into circulation, 
becomes a vessel of communication that transmits value(s) from maker to consumer. But this communication needs a common language; under capitalism, that language is money. Money makes all of the other values - ethical, libidinal, financial, etc. - invested in the object recognizable to everyone. Marx called this 'exchange value,' an extension of which is the price of a thing. In the case of an industrialized good, the price of a good is the only perceived relation between a producer and a consumer; the labor process itself, which can only be represented by the price of a thing, is lost - or concealed - in translation.

In a perfect system, prices would manage to completely measure the use value of an object, or in other words how much "socially necessary labor time" of their own a consumer would trade to gain access to the use of an object. Again, this ideally gets wrapped up in the price of that object. But perhaps the dichotomy between use and exchange value, the ostensible unison of which is the price of the object, is too simple. In that certain values become stuck to objects through the process of (alienated) production, produced objects offer something beyond a use value for consumers. Returning to the notion of alienation, Marx describes a process in which the worker's labor (desire) has been transferred to and congealed in the object; in capitalist production, the subject is objectified. But by the same logic, production is also the subjectivization of the object. The object has traces of the laborer, like a window of communication between the producer and the consumer.

Walter Benjamin recognized this and described it across his body of work. Benjamin conceives the object of production as a tool of communication, a part of a process of transmitting sensuousness between humans. Every produced thing has a 
subjective (human) origin, although that origin is fiercely guarded by capitalist interests (hence Marx's need to introduce the fetishism of the commodity, or what can be interpreted as the concealment of the human sensuousness inherent in the production process). If the sensuousness that affirms a sense of humanity on the part of the producer were visible to a consumer, then we might say that "ethical" consumption can be understood as the desire for connection with others. The purchase and collection of objects, in other words, is something of a material reconciliation with the consumer's own experiences of alienation (Rose 2014). Consumers can seek, and to some degree find, connection with others through a more deliberate kind of consumption. But this desire for connection can also be used against consumers; advertising does this very well, as does state-level propaganda (Benjamin was quite concerned with the latter, arguing that the Fascists were quite successful in aestheticizing politics through state propaganda).

The attachments that people develop to "made" objects suggest a manner of coping with their own alienation and insecurity. In The Arcades Project, Benjamin shows (1999) how people cope with the alienations of work by curating their interior spaces (e.g. of a home or an office) with collections of objects that represent memory and love. As I argue above, Benjamin did not see the dialectic of use and exchange value as sufficient to describe such objects. Benjamin claimed these objects agitate against the notions of use and exchange value, ${ }^{20}$ instead taking on a "lover's value" or "sentimental

\footnotetext{
${ }^{20}$ Benjamin, of course, is writing before the discovery of much of Marx's early work in which Marx more directly discusses the relationship between objects, affects, and value. For example, Marx says in The Holy Family: "it is love which teaches man to truly believe in the world of objects outside of him" (quoted from Fromm, 1970; 69).
} 
value" (Stallybrass, 1998). In this way, people come to love things, perhaps because such attachments to things offer a way to reconcile the fragmentation inherent in capitalist production (cf. Jameson, 2011). That is, collecting objects offers reconciliation because these objects - which have been "freed from the drudgery of being useful" (Benjamin 1999) - carry within them the subjectivities of others, the inscription of the labor of others, and thereby activate an oblique form of connection or community.

The problem is that in doing so, it reproduces Marx's fetishism from a different angle. Fetishism is in part about the application of a price tag to an object of human passion, because the price tag becomes a proxy for the affective exchange that occurs in the process of making, and therefore the process is reduced to a quantitative relation that renders invisible the human aspects of making things. This strikes me as a central aspect of what the "movement" that makers collectively embrace is pushing back on. But in pushing back on certain fetishized aspects of production - the concealment of the production process (especially through globalization), the "distancing" of subject/object and producer/consumer, the trend toward "immaterial" production - the ethical response becomes a site for economic valuation.

Makers, then, are left in an absurd situation where they are forced to defend prohibitive prices that barely afford them a livable wage. As we will see below, being "transparent" about their process, telling stories about doing "passionate work" (McRobbie, 2016), being explicit about the values that matter to makers, and connecting these stories and values to specific places (chapters 5 and 6 ) are all tactics that have become critical to makers' success. But this wouldn't be possible if there weren't consumers desiring (and willing to pay for) a closer connection to makers. "Ethical" 
consumption expresses a desire to belong to something better than globalized capitalism and a desire to re-establish control of one's social relations, especially the fetishized gap between the maker and the user of an object. The materiality of the handmade object is vital, especially in an increasingly virtual world, because the humanity transmitted therewith in is tangible to the consumer. Allowing consumers access to the making process intensifies the affects stuck to the handmade object; the maker just needs to open the window for the consuming world to peer into.

\subsection{OPENING WINDOWS}

In Interrogating Localism (Marotta \& Heying, 2018), Charles Heying and I argued that Portland's maker economy put great effort into bridging the gap between producers of craft objects and the end user of those objects. Our way to think about this was to present a term - "windows" - that captures the process by which makers invite consumers into their workshops. In that article we were interested in expressions of localism, eventually concluding that "feeling" local and actually being geographically proximate weren't strongly correlated. Part of the reason why we found this to be true was because of these windows: makers, contractors, end users, and other parties interested in the making process could all mingle in the wispy filter-driven corners of Instagram or the micro-expressionism of Twitter regardless of where they were located on the map. A key technique for makers, we showed, was to communicate the production process to the consumer as if it were a progress report; windows importantly fill gaps in the imaginary of production, but they also handle the "burden of proof," as one maker put it, that these goods are indeed handmade. 
In this section, I will explore how windows have become a vital aspect of value production and communication for makers. First, it is increasingly desirable for makers to emphasize the process of production to consumers and make it as transparent as possible. Second, it is just as important to describe the biographical story behind the product. Lastly, it is social media and the power of the Internet that has made windows possible. But this type of connectivity has also allowed consumers to actually participate in the production process, a feat that deepens attachments between makers and consumers. Opening windows for consumers, I demonstrate, yields three tendencies amongst makers: the valuation of transparency; the curation and communication of biographical stories; and a significant reliance on social media. These tendencies are how makers open windows, how they communicate their value propositions. I close the chapter by describing makers' positions on scaling their operations up. Generally speaking, scaling would reduce prices and solve the "pricing paradox." But most makers are resistant to scaling up, for the most part because scaling up compromises the value proposition that makers need to convey to their consumers.

\section{Making (and selling) transparently}

During interviews, I asked this question often: "Is it important to show your consumers the making process?" Nearly every maker answered emphatically that "transparency" was paramount: "It's one thing to tell people you're hand making [the product], it's another thing for them to actually see it," one maker told me. As many of my interviewees pointed out, consumers are increasingly concerned with where their products come from and what goes into the making of such products. "Now everything has to be labeled so consumers know exactly what they are consuming," said a maker in 
Portland. In Detroit, one maker told me that as a society we are emerging from three intense decades in which people were shielded from how the things they use were made. Kids don't understand how food ends up in grocery stores or how their clothes appear in their closets, she said, and consumers desire a remedy:

When people can see how things are made, the value proposition changes, right? Now you understand what you're paying for. I think it helps to discourage the wasteful mentality; I mean you don't throw away your kid's artwork that they put on the fridge. Right? You don't do it just because they made a new one.

In this way, "transparency" describes the conversion of something that was purposefully made invisible (i.e. the production process) into something purposefully made visible. As the above maker points out, this emerging visibility changes the value proposition. Now consumers are spectators to the production process, thus layering this visibility onto the product as a value:

People get a real kick out of coming into our shop and seeing [their product] being made and reducing the gap between the maker of the product and the end user of the product. The typical model that you see, like at Nike, the person that uses the bag is over here and the person that makes the bag is over here and the person that owns the company is over here, it's really disparate. That's part of the simplicity that we're trying to achieve. We want a transparent process.

This example gives us a glimpse at how bringing the making process in-house and making it visible to the consumer creates an extra layer of value. This maker actually referred to this added value as a "perk" that sells the product a little more - if a consumer was on the fence about buying the product, seeing it be made often helped them justify a 
purchase. Additionally, the fact that consumers can see that production operations are smaller than they imagine manufacturing being helps them relate to a product more. Production is less abstract; it's at a scale that they can comprehend. Transparency allows makers to communicate the process to the consumer, and as such to covert the visibility of the production process into economic value.

But the consumer isn't buying the process as much as they are buying other, noneconomic values that are tied up in the process. One maker, for example, was comparing the pros and cons of scaling a product, and paused to reflect on why consumers have begun to desire production processes that are so clearly inefficient. He used the example of a soap maker that makes things by hand in small batches and uploads pictures of him or herself making it. The exact same recipe probably can be scaled up, he reasoned, and it would produce almost exactly the same bar of soap, perhaps even more consistently and certainly more efficiently. He was building up to a central point: "But what you want is you want the feeling of the person that made it in the small pot and poured it into the small mold and chopped it one by one and they wrapped the label on. That's what the person's buying."

In short, consumers want to feel like they are a part of the product's journey. They want to feel like a good is embedded with the maker's values, which are often also their values. They want to feel good about the things they buy as a way to validate the choices they make and their capability to make those choices, a sense of control that they have regained in their lives. This is where the value proposition changes: rather than an invisible hand stuffing unnecessary goods into consumers' shopping carts, "windows" make the hand visible; consumers want to see and feel the hand as well as the body 
attached to it. Knowing where their products come from and seeing the process by which it was created captures a sense of intentionality in their consumption. Like the intentionality and artisanship that goes into the production of a "made" good, consumers are granted the ability to "craft" the set of purchases they make. Put differently, they invest emotionally in their consumption. It's capitalism, to be sure, although a weird version of it; the magical powers of the commodity are still found in the exchange value -

which, as the first section above ("Pricing Paradox") shows, becomes rather inflated - but the production process is fetishized in a very different way. The production process develops a new use value that resides in the world of affect and emotion, an exemplar of Benjamin's aforementioned "lover's value."

\section{Telling (and selling) stories}

Windows enable a different way of structuring exchange relationships. As the distance between the producer and consumer is decreased and they become visible to each other, a sense of familiarity stewards new attachments between them. It's like a localism of sorts, although local in this sense has more to do with the perception of commonality, or being aligned with the same values as someone else. Rather than naked exchange, consumption can provoke a feeling of belonging to a "community of sense" (Rancière 2004). It's easier to understand a maker's value system - and become attached to it - when the maker presents their story to potential consumers.

One group of interviewees in Detroit told me that on each product they sell, they handwrite where the wood comes from and who worked on it, which is a key to the story of the product. One of them continued by explaining what the story does to the value proposition: 
Really you could leave here and go to the suburbs and go to Michael's and buy a $4 \times 6$ picture frame for $\$ 3$ and it would hold your photo very well. And that frame for us [he was holding one of their frames at the time], that's an oak, it's $\$ 46$. And a big portion of that price difference and that value difference for the customer is the story. It's where it came from and who made it.

Similarly, a Portland maker pondered why a consumer would buy her product when they could get a similar one at Target for one-sixth the price. She argued that there was an aspect of quality that factors into the decision-making of the consumer, but that decisions really rest more so on the values and ethics that come with an attachment to the maker's story:

So you have to convey why it's worth [the higher price]. A lot of it is craftsmanship - it's not going to break, it's not going to peel or flake, but a lot of it also is that you're actually buying it from a person, like you know who made this and you know where they sourced it. It's such an important part of the story to convince people to spend money and also to make them have that personal connection.

Additionally, she speculated how that story might circulate between consumers:

If you have a hairpiece from Target, you just say 'oh I got it from Target' and somebody compliments you. But if they know the story behind the thing and somebody compliments it it's like 'oh, I got it from this really cool place and they do this, this, and this and they'll remember the brand and they'll remember the story. 
The benefit that telling a story provides for the maker is two-fold: first, it creates repeat business. In fact, the above maker told me that she sees many of the same names on orders throughout the 8 years she has been in business; when she sees them, she includes a personal note with their order. She also mentioned the fact that some of her repeat customers have entire groups of friends that have begun to buy from her. Second, the story works to validate the high prices that "made" goods demand. The narrative shifts from mindless consumption to intentional consumption, and intentionality is not cheap. This maker also pointed out that she feels obliged to pass this intentionality on to other makers through her own consumption patterns; it affects the way she consumes and the values she associates with consumption.

A retailer that specializes in locally made goods told a co-researcher and I that the makers' stories are "very important" to their brands. In fact, reading about each maker their individual stories - is one of the most popular activities of consumers at this boutique. This being the case, he arranges goods in specific ways that emphasize these stories, using props and other cues to create more of a complete environment around specific goods. In another interview, a pair of photographers that I talked to told me that consumers love the opportunity to peer into a maker's life, to connect with the philosophy that drives the maker to do this type of work over something else. These photographers specialized in documenting makers in their workshops; they told me that giving people the ability to see inside makers' homes and (especially) workshops is "very effective" for makers, so effective in fact that it developed its own hashtag on Instagram ("workshop porn" - don't Google this...). They said that makers sometimes "clean too much," which dilutes the maker's story because people want to experience "authentic" 
workspaces that are "a little messy." Often times they have to "re-mess things up" in order to set the stage.

One of the more interesting conversations I had on this topic was with two travelassociated employees. Having spent a significant amount of time in Japan, they described their interactions with Japanese tourists interested in traveling to Portland specifically to experience the maker scene:

Employee 1: "They want to go there, to see the scene of makers, they want to be a part of that. They want to be in the shop and in the studio and talk to the makers." Steve: "So it's not necessarily Portland they want to see, it's the place where something was made?"

Employee 1: "Yes, the particular place."

Employee 2: "Because it adds value when they go back and their friends say 'man there are some kicks!' And they say 'yeah so I was in there talking with the owner and this leather was sourced from Eastern Oregon' or whatever it is. They'll be able to add value to what they're wearing or using by having a back story."

The story of a product and its maker adds an affective layer to the "transparency" that foments attachments between makers and consumers. In Detroit, I spoke with a maker that accidentally stumbled into the importance of a product's story. Consumers that came into her shop could hear the production happening and wanted to "see back there." At first her response was "no that area's a mess, it's our production area." But upon seeing it, her customers told her it was beautiful back there and people wanted to take selfies with the various machinery and product materials. She further likened it to people wanting to "give their compliments to the chef." For her, there were two major effects of 
this: first, and echoing what so many makers said, the price of the product made more sense to consumers; they could see what went into the goods' production. Second, this maker's central philosophy was that her customers should be in a relationship with makers in the same sense as they should have a relationship with their farmer. She says she wants to live in a world where she knows where all of her materials were made, and maintaining a window between her and her customers helps her "walk the walk."

If there was a point to belabor, it is that these stories open a line of communication between producers and consumers in such a way that adds a significant amount of value to the product. This value is rooted in the affective exchange (attachments) that gets wrapped up in the economic exchange (prices), even if prices have no promise of ever representing such attachments. Cynically, the emphasis on stories might strike the reader as a postmodern form of marketing linked to a generation of young entrepreneurs that grew up with the Internet and social media and don't know how to otherwise communicate. But such an analysis leaves value in the realm of the economy without attending to the appraisals of emotional and moral values that consumers find attractive. These values are the foundation on which prices are built; consumers are largely buying the connection they feel with makers that emphasize the values consumers desire. The stories attached to the products bring to life the norms and values that this specific type of consumer aspires to.

\section{Social media and the Internet}

Up to this point, I have pointed out that a window has opened between makers and consumers and that makers have taken note of the window's importance. But opening such a window isn't always straightforward, even if a maker understands that a 
heightened sense of interaction with their customers would be beneficial. When asked about how she tries to bring production closer to the consumer, for example, one maker reflected on attempting to host open studio sessions for interested consumers. But the planning and execution of opening the production space, she said, was like "herding cats." So while hosting open studios may have allowed the consumer a glimpse into the making process, it didn't make for efficient producing. The trick for makers, then, is in figuring our how to show the process most effectively. As it turns out, social mediaespecially Instagram - has been critical in opening windows.

In the first place, one of the distinguishing characteristics of a maker is the aesthetics of their designs, their branding, even their identity (see chapter 3). As one maker put it, makers and their products are "imagery driven." As such, Instagram - with its emphasis on images and aesthetics - is a natural fit for makers trying to communicate the values that animate their creative process to a world of consumers. Other social media platforms have certain utility, but Instagram allows more of an instantaneous connection: consumers, trendsetters and even other makers can make quick aesthetic judgments of a makers' value propositions based on the images they post. There is an element of belonging at work here: consumers often know what they are looking for, what they want to be a part of, which companies they want to support; these things are often expressed on social media in terms of who someone follows. Makers have gotten good at expressing the aesthetics that align with the value and identity traits consumers are looking for; on Instagram they are often encoded into a font, a filter, a camera position, a color scheme, a material, an arrangement of objects, a set of hashtags, a carefully worded caption, and so on. 
Secondly, and given Instagram's aesthetic sophistication, the format allows makers to keep an open line of communication with consumers while a product is being produced. A few makers told me that they use videos posted on social media to invite their followers into their workshop. As far as showing the process, the ability for a consumer to follow the journey of their product into existence is substantially beneficial for makers that need to communicate their value proposition to the consumer. One maker company (two people) told me that people have a visceral reaction to this: they literally post pictures of their employees making products so consumers can see "this is what's happening at this point in the process of making." It's about giving people access to the production process, they claimed: it distinguishes them (and other makers) from a typical factory. They were emphatic that it's not advertising, but rather emblematic of a different way of doing business.

But many makers do see social media and the Internet as important in terms of advertising. In fact, a handful of Portland makers told me that the main functionality of their social media was free advertising. Of course, there is a body of literature that disputes how "free" such advertising is (Duffy \& Hund 2015; Duffy 2015; McRobbie 2016); staging images and curating a bio/story for public consumption on Instagram involves a good deal of work. Interviews confirmed the degree to which maintaining an Instagram presence requires a good deal of work. A confections maker in Portland described the process of finding and then strategically deploying hashtags and stylizing pictures to fit the trends. If a maker can effectively stay on top of the trends, they can draw attention from other makers and trendsetters. An apparel maker in Portland told a co-researcher and I that getting certain trendsetters to wear their item in a post or - even 
better - follow their account could result in a rapid uptick in attention and sales. This is true even outside of social media, on the Internet's blogosphere. I encountered two other makers that told similar stories of their interaction with a trendsetting online publication (Gizmodo). Both makers were able to get their product reviewed by the publication, and the results were astonishing. One electronics accessories maker was flooded with so much new demand that they had to expand from 5 to 20 employees virtually overnight.

Makers rely on social media for another important reason: connecting with other makers. As my co-authors and I have shown elsewhere (Marotta et al. 2016), social media can be an effective coping mechanism for makers dealing with the isolation of working from home by themselves. As one maker put it:

It's very isolating working from home alone. [...] The other people I know are working from home, handmade people, I'll post something and it makes you realize we're all sitting at home doing the exact same thing. We can't all hang out because you gotta focus when you're working, but when I'm like ugh, I just need a little break from the sewing machine for like five minutes, I go on Instagram. The data from a survey that my team and I conducted in 2015 (Heying et al., 2016) showed that $40 \%$ of sole proprietor makers work from home. In my interviews, social media was often described as a way for makers to feel a sense of belonging to a community; as one maker says, it offers a way for maker businesses to imagine themselves as a "circle of firms moving together" rather than individual, one-off firms trying to figure out what to do next. Instagram offers a way for makers to check on their own progress against the progress of other makers, to gauge their aesthetic prowess against that of others; in short, to compare the value propositions that they are making to 
the consuming world.

Social media, then, works as a window between producers and consumers because it grants producers a way to communicate the process to the consumer - that is, it opens the window between producer and consumer such that the value proposition involved in exchange becomes explicit. But social media also works as a window between producers, and that window has two important functions. First, it is an important component of identity construction. Makers are using sites like Instagram to connect with each other, but in so doing they are adapting to each other's aesthetics through activities such as "trend watching." Indeed, several makers admitted to using the collective influence of other makers' Instagram accounts to stylize the images they use in their own posts. Second, given this sphere of influence between makers, it can be said that value propositions circulate between makers, not just between makers and consumers. In other words, the values that flow between makers and consumers are often curated over Instagram between makers. It is outside of the evidence that I have to make an argument about which window (i.e. maker-maker or maker-consumer) is more forceful than the other in curating values. In any case, it seems clear that these windows are a central aspect in both the value transformations (i.e. between ethical and economic) as well as the communication of those appraisals of value. This is not to mention the fact that the "story" of an individual maker can be curated, unfold over time (across posts), and be consumed by other makers as well as consumers.

\subsection{VALUES, GROWTH, AND SCALING}

A question that I (as well as my co-researchers) often asked was: "How big do you want your company to get?" In many cases, the conversation that followed this 
question led to scaling, its logistics, supply chain management, and the variety of impediments they have experienced in trying to scale. But many other makers recognized in this question an opportunity to say something about how scaling and growth might change the value proposition at the core of their operational philosophy. If we look back to where this chapter started - the pricing paradox that many makers find themselves grappling with - it seems clear that short of rewriting the operating system of capitalism, overcoming such a problem finds its solution in scaling up. Many makers, however, were frustrated by this solution, because the tradeoff is to compromise the very values that made the "making" endeavor worth pursuing in the first place. In this section I am interested in the responses that eschewed or rejected scaling up for reasons that ended up entangled in makers' value systems. What follows below has to do with scaling and makers' perception on scaling, but often times what we were really talking about was what value compromises makers were willing to make.

\section{Letting Go}

The need to control certain elements of production was a common sentiment, especially amongst the bigger maker firms that had employees and maker firms that were right on the precipice of getting to that point. One food maker I spoke with in Detroit had been experiencing rapid growth and had recently been introduced to a serious investor. At the point at which we spoke, she was still the sole proprietor, the distributor, the maker of the product, the bookkeeper, the marketing person - she was wearing all the proverbial hats. Upon beginning work with the investor, he told her she was going to have to "let go - you can't make it anymore." She explained the "deer in headlights" reaction she had to this; the product she had developed was "her baby," and not being the one that actually 
did the making was a difficult possibility for this maker to entertain. She emphasized to me that nothing was set in stone, because she clearly was still pondering whether she could stomach such a change in her level of control.

Another maker in Detroit that had already scaled up a few times told me that there are certain "natural plateaus of capacity" for each industry at which the relationship between a maker and their craft is altered. She was wrestling with the notion that in scaling any further, she would need to cede control of certain aspects of the production process to other firms. This meant managing relationships between contractors rather than having direct control over the conditions of production. She was clearly uncomfortable with the thought of not knowing how exactly the products were being made or how the employees making them were being treated. Implicit in what she was saying was that the value proposition that her company relied so heavily on - responsible production and paying living wages is integral to her brand, to its attractiveness to consumers, to their price tag - was at stake. If she couldn't control the conditions of production, she couldn't price her product as such. The tradeoff, of course, was lower prices and more products, potentially a benefit to her. She was clearly not interested in this: "For us, the scale has a lot to do with the relationship we want to have with the craft and the relationship we want to have with our employees and how we want our business to be structured and organized. I don't wanna have a ton of employees that I don't know."

The question of letting go of control is deeply related to the relationship makers have with their employees. One maker reflected on our question - how big do you want your company to get - by positing that it was fundamentally a question about values, about what threshold marked out the space in which the nature of their decision-making 
would change. For example, would scaling mean that the company would have to be run on price rather than on quality? The two co-owners present for that interview expressed their desire to never have to make such a change in philosophy and that scaling didn't necessarily mean that, but the question had made the possibility feel present. Additionally, they questioned between them what the benefit of scaling might be in terms of creating a broader market and therefore more access to their product, which they saw as a positive thing socially (they make a natural product that, if the price could be lowered, would in their mind be a better alternative than mass-marketed brands). But the two makers were firm about one thing: they would not make compromises on the type of work environment they provide for their employees. One said that scaling could be a positive, because more income means they might be able to do more for their workforce. They insisted, however, that if growing to a certain point detracted from their ability to do well by their employees, they would not do so; in other words, it was more important to be able to control the conditions under which their employees labored than increasing their bottom line.

At the smaller firm size, many makers were uninterested in becoming managers. I heard from a few makers that they are interested in expanding, but not to the point at which they lose the ability to know everyone that works for them or the ability to control the quality that goes into the making process. A few even used the same expression - "I don't know what that number is" - to denote the optimal size of their workforce, because that size would be dependent on their capacity to have meaningful relationships with both their employees and the products being made. An accessories maker told a co-researcher and I that having too many employees would compromise the "magic" that goes into the 
making process; scaling would create levels of bureaucracy that would inhibit the company's ability to pivot quickly if creativity struck. Furthermore, smaller workforces mean knowing employees really well; this means being in sync with them, being able to read each other's moves in a way that production remains nimble and still creative: this is the "magic."

The ability to control these things were central to the makers that I spoke to. I should add that outside investment was oftentimes shunned because makers would have to sacrifice control for the sake of growing. Says one maker of outside investing: "it doesn't look like much fun, you don't get to make your own decisions anymore, I've seen a lot of disaster stories." What makes this all interesting is that none of the makers I have spoken to seemed willing to compromise on the things that would give them the ability to sell their goods at less than boutique prices. The insertion of the ethical values present here into the production process still has the effect of adding economic value to the product: the pricing paradox, and capitalism in general, is unresponsive to such moral stands.

\section{Grow or Die}

A handful of makers we spoke with were familiar with business culture, usually either because they had been a part of it in another job or because they had studied business at university. One maker in Detroit told me that studying business helped to push her into the maker world. She wanted to do something that was slower and more deliberate; she described the discipline of growth she was exposed to in school:

Everything I was learning was like growth, growth, growth, new products, how to acquire other companies, I was like [ugh], when does it stop? I mean, just have a 
good product and be happy where you're at? Why does it always have to keep getting bigger?

Other makers described the mandate to grow as a social pressure that equates growth with success. An apparel maker told me that she feels like what she has done has been successful but also feels the pressure to grow and expand more, despite the fact that she doesn't really want to. In a different conversation about growth in Portland, a coresearcher asked a different apparel maker what she made of the "grow or die" mandate typical in business culture. She responded by saying: "Do I look like I've ever done what I was supposed to do?"

In one interview, two women that document the maker scene in Portland said that more than a few makers they know have quit their day jobs in search of a greater ability to express their creativity. Working from home and staying small were better options than their previous jobs, which had bludgeoned their creativity and demanded 60-hour workweeks. Those experiences, the women said, meant that makers were perfectly happy maintaining their small size and the autonomy that they had gained as a result. A retail owner and practicing artist had similar reflections on staying small. He argued that most makers are more creative than rational, more passionate than analytical: "They don't think in measured, realistic ways." In his mind, most makers are closer to artists than businesspeople, and they don't enter into a creative venture thinking about things like scaling and cash flow. According to him and his partner:

The fear of becoming a businessperson when you're an artist is tough. (Partner): Right. People get into it for the love of the passion of the work, because they 
actually love making the thing, and then they have to learn how to do taxes and hire employees.

The two retailers bolstered their point with an example. The two had a client/maker that sold a popular product in their shop but had suddenly decided to stop making the product. One of the retailers had stepped in to help the maker with a business plan to hire people and scale up a bit, to which the maker told the retailer "that sounds like a nightmare." The point for them was that for a lot of artists, the business aspects of making are anathema to why they make something.

Others feel that staying small reflects the values of where they operate; it helps them feel like they belong to the milieu they have found themselves in. Portland is a city where most makers say they feel comfortable being small, independent businesses; in fact, from a consumer point of view, many say that the city goes out of its way to support small businesses. The other side of that support, however, is a general disdain for big businesses; according to more than a few interviewees, Portlanders tend to associate big business with malicious ethics, captured well by this maker (some context: he was characterizing many people's attitudes in his "liberal, inner southeast Portland" neighborhood):

Yeah as long as something is big it can't be good. It's like Whole Foods got too big, they have to be evil now. They're traded on the stock exchange, they have a board of directors, and it just can no longer be good. And they do have significant faults, but I try to push back like 'if nothing big can ever be good you're just stuck making small impacts here.' It's like People's Co-op is an awesome place but there's like one location in inner SE Portland, they're not going to make a 
nationwide impact. And say what you will about Whole Foods and their faults but they started this whole movement around natural foods and spread it across the whole country and now there's all these other ones popping up and without them having done that, without a big company coming in and going public, raising money with equity, and just like expanding like that, we'd still just be like 'oh cool there's some co-ops in like Berkeley down in California and we've got ours here, and like everyone else would still be shopping at Safeway.

This quote is important in that it recognizes a double bind for makers that are looking to grow. Some growth is OK, if they want to maintain their stature as local, independent, and authentic. But growing past a certain size moves them into the categories of notlocal, not-independent, and inauthentic, a valuation that in Portland is perhaps best captured by Stumptown Coffee's acquisition by Peet's Coffee in 2015. In maker circles, however, the fact that their production process is typically made visible to consumers adds another wrinkle - this visibility is a proxy for the value proposition itself, because being able to see the maker actually making the product means, for consumers, that it is authentic, local, and small. Most often, the deliberate, handmade processes by which makers produce their goods are not scalable, because the process itself is dependent on inefficient and "bespoke" techniques; this is in part what makes such products attractive to consumers. The above maker recognized that implicit in Portlanders' valuation of small business was a desire for products that were not scalable by design:

It's almost like one of the values people want is inefficiency. Like the fact that this thing is not made efficiently and isn't scalable is what they want. And it's like ok, so how do we scale that? I mean there's a bunch of other values in there but 
that's definitely one of them that people are like 'oh that's awesome and this thing is like so impossible to make in a large scale. That's why I want to have one.' And it's like ok that's cool, I like those things too, but it's hard to make a huge movement on that.

\section{Outsourcing}

The scalability of a material good (i.e. not software) often comes with the implicit (or even explicit) notion that production needs to be outsourced to a specialty manufacturer that can handle large volumes at lower costs. Over the past few decades as American infrastructure for manufacturing has been decimated, this has meant outsourcing to China. Interestingly, in my interviews China was such an oft-used word that I coded it as a proxy for the values that were entangled in conversations about outsourcing. When asked about what values makers were not willing to compromise on, outsourcing production - in many cases specifically to China - was a common answer.

On the more engineering-focused side of the maker movement, many makers talked about China as a part of the narrative taught to engineering students. One conversation was particularly telling; an accessories maker, who had recently left his job as an engineer, described his recent "brain shift:"

I kind of felt like I was just this guy sitting there designing things and then all these people that I didn't know were doing all the dirty work and actually making it happen and then, well I don't know if I'm the one being rewarded for it but I kind of felt like, yeah, for some reason, well like at [his previous company] for instance, [they are] the one getting all the reward for doing all this stuff but not doing any of the dirty work, which is the manufacturing work [...] When you can't 
see a product being made you don't know how it's being made or who's making it - how are the workers being treated? You eventually start thinking about those things.

He continued to ruminate on what had happened in American production culture over the past few decades, associating the elimination of shop class with the fact that most Americans can go their whole lives without thinking about how things are made or who is making them. After high school, when he was studying the business side of engineering, outsourcing manufacturing overseas was taught as "this is just how it's done." At one point in the conversation he turned and said with a wrinkled face: "Is it weird or is it not weird that everything that I use is not made here?" Needless to say, he has made not outsourcing a definitive value, even if that presents a limit to his company's growth.

Some makers even talked about fearing the possibility of backlash from their consumers regarding outsourcing. A co-researcher and I talked to a cut and sew manufacturer, a majority of whose clients are small apparel makers. According to them, most of their clients are wary of having their brands associated with China, which is why so many of them choose to work with this facility. Concern with how workers are treated came up time and time again, and almost every time makers were emphatic about how keeping the making process as local as possible gives them the ability to know their employees and know exactly what is going into the product. Again, this doesn't do much for reducing the costs involved in production and thus the price of the finished good, but, as one maker put it: "I don't want to make anyone feel bad, but if you bought [a product] that cost less than $\$ 40$ a slave made them. And that's not us." 
Other makers are concerned with the "increasingly indefensible" environmental costs of flying and shipping products all over the world. A Detroit maker put it this way: "Why take something from here, ship it half way across the world, then ship it all the way back across the world, and it costs less? [...] It doesn't make any sense.” Another maker, this time in Portland, asked a similar question:

There's a lot of people right now talking about this imported [product] from China is like a dollar, like how can it be shipped across the world and be selling for like a dollar? You know, it's a viable question, what's worth the resources, you know?

These questions raise an obvious frustration for makers. Somehow we live in a reality where it is cheaper for consumers to buy products that are environmentally destructive and encourage despicable labor practices, and the only weapon at their disposal turns out to be the "windows" that make the production process - the deliberate, handmade, fairlabor, locally sourced, sustainably harvested process - visible to consumers. "Windows" don't make the product cheaper, they just make the consumer aware of what they are buying, or as a maker above put it, they make the value proposition between the maker and the consumer visible. The truth, as some makers made clear, is that most consumers do not have the ability to choose to buy a $\$ 250$ product when they have the option of buying a $\$ 40$ version, regardless of the origins, shipping distance, or conditions of production.

\subsection{CONCLUSION}

This chapter has intended to show the importance, for makers, of the value proposition as a mode of communication between themselves and their consumers. I have 
demonstrated that pricing is a significant challenge because of a particular impasse related to neoliberal capitalism: in taking steps to overcome the ethical shortcomings of the globalized mass production economy, makers have had to price their goods so as to be only available to wealthier, more privileged consumers. Put differently, the ethical dilemmas of mass production have been transformed into higher prices rather than solved. This chapter has also shown how makers address this pricing paradox through making their process transparent, using storytelling and marketing their own biographies to foster deeper producer-consumer relationships, and creatively instrumentalizing social media. Lastly, I have shown that despite its possibilities as a solution for the pricing paradox, scaling is not a preferred fix for makers because it would force makers to compromise the very values that motivated them to become makers in the first place.

The theoretical proposal of this chapter is that value is not solely a production of human labor; value is also a manifestation of human emotion and desire. Following Foucault, we might say that value is a thing that doesn't exist - it is imaginary - and yet it has become something that wields extraordinary power and significantly affects people's ordinary, everyday lives. Value conceptually connects one's material, spatial, affective worlds with the imagination: working toward a "better life" involves desiring a world in which one can easily secure the resources and relationships they need to flourish; value(s) is a primary way to appraise or measure such desires. Collectively imagining a flourishing future is a part of why makers' value propositions are so important. In order to manage their lives as makers (and ostensibly work towards such a future), they need to bridge a gap between production and consumption. This gap, which has been exploited so intensely by capital, and which is responsible for many of the inequalities that makers are 
pushing back against, requires a common imaginary of value that bridges the gap between ethics and economics and can be shared by producers and consumers. Currently, that imaginary is governed by prices, "rational" exchange, and efficiency. For better or worse, "making" introduces a different way to think about values as a function of goods exchange: the value propositions of makers gesture toward an attempt to build new relationships between consumers and producers, primarily based on the way production and consumption makes one feel. These relationships are based on overcoming the failures of globalized mass production; as was the case in Chapter 3 with identity, it turns out that values are as much a function of affects and ethics as they are economics.

The pricing paradox, however, is not overcome in the maker movement, just as it wasn't by the Arts and Crafts movement in the early $20^{\text {th }}$ century. But perhaps it is unrealistic to imagine one socioeconomic "movement" as capable of restructuring social relations radically enough to reorganize capitalism across the globe. Instead, I argue that it is more instructive to look at the practices themselves, because these practices can tell us much about the type of future that might emerge from alternative imaginaries of value. What small role might makers' perspectives of value play in the slow transformation of neoliberalism into whatever is next? Is this 'maker imaginary of value' a fool's errand or a fantasy? Is there a role for fantasy in creating the type of world that finally addresses inequalities in meaningful ways?

Finally, there is another factor that I need to address: attrition through change. Makers and their predilection for ethical production are part of a socioeconomic assemblage borne from a specific set of conditions that congealed at a specific point in history and in specific places (primarily urban centers in the Global North). But these 
conditions are constantly changing. So while makers have been struggling to emerge from the chrysalis of the "old" mass-produced industrial and service economies, they have also begun to struggle with "new" and increasingly hostile urban conditions. In both cities I conducted research in, the "post-industrial" urbanism that gave rise to makers' aesthetic, affective, and material environments is in flux. As I will detail in the next few chapters, the urban imaginaries of Portland and Detroit are significant players in each city's maker milieu. But these imaginaries have become destabilized by each city's rapid changes. What significance can "Made in Detroit" or "Made in Portland" have if those cities are changing? How can makers construct value propositions that make sense amidst so much change? Finally, what does all the change mean for makers trying to endure it, and what new conundrums does urban transformation pose for each city's maker milieus? These are the questions that I will turn to in the next two chapters. 


\section{CHAPTER 5: MAKING DETROIT}

The next two chapters mark a bit of a transition: chapters 3 and 4 are about makers and the imaginaries that govern their sense of belonging and the values they ascribe to; they are about the "made" side of the "Made in Place" equation. Chapters 5 and 6 shift to the "place" side of the equation: the next two chapters are about the imaginaries that govern the way makers interact with the cities they produce in. More specifically, these two chapters are about imaginaries of place and the tensions that each place confronts makers with. What interests me in particular about these cities is the struggle between attempts at representing a place (e.g. Made in "Detroit/Portland") and the changes that constantly destabilize representation (e.g. development). Both cities I conducted research in are undergoing periods of rapid change, so much so that the idea of "New" and "Old" Detroit/Portland has become common in the everyday language of each place. In fact, the new/old juxtaposition plays quite heavy in the next two chapters. As I will argue throughout the chapters, the emergence of "new" and "old" as ways of imagining Portland and Detroit is important because they suggest that something feels different in those cities. It would be easy to say that new/old is just another way to think about gentrification; indeed there is a wealth of literature that would easily fit such an argument. But I am more interested in the way makers are affected by the sense of ambivalence that they articulated in my interviews.

Chapters 5 and 6 are also fundamentally concerned with the "lived-ness" of an urban imaginary; what is it like to experience a shifting imaginary, to be emplaced while that place is undergoing transformation? How do such changes push, pull, and stretch the 
milieu of makers? Chapter 5 examines the effects of such questions on makers in Detroit. For the uninitiated, Detroit is a city of unparalleled inequality: the city is overwhelmingly African American ( 84\%), and this population has been isolated, "deproletarianized," and politically abandoned to the benefit of the more affluent white population in and around the city for over a century (Sugrue 1996). At one point a manufacturing powerhouse, the globalization of the world economy brought unprecedented deindustrialization and disinvestment to Detroit in the second half of the $20^{\text {th }}$ century. The result was "white flight," suburbanization, and urban decay. But after filing for bankruptcy protection in 2013, the city has seen a resurgence of activity and is being written up in the international media as a "comeback city." Makers, who took root in the city primarily after the Great Recession in order to take advantage of cheap vacant land, play a starring role in this resurgence. But my experience with makers shows a deep ambivalence about their role in Detroit's changes: they largely feel that the city's "comeback" is not benefitting the city's poor residents of color, who need it most. The central argument of the chapter is that Detroit's makers have experienced the city's changes with a sense of frustration and missed opportunity, even if makers were aware that "New" Detroit presented them with a variety of benefits.

The first part of the chapter traces Detroit's narrative from its oft-imagined death to its liminal classification as an experimental city and eventually to its more recent imaginary of rebirth. Part 2, which makes up the largest portion of the chapter, describes makers' imaginary of Detroit in terms of the juxtapositions that I found best portray it: new/old; black/white; and suburban/urban. I also discuss the "tale of two cities" that has emerged in Detroit, a division that makers often referenced and that mirrors the new/old 
juxtaposition. Spatially, this division is between the central city, which is rapidly gentrifying, and the "neighborhoods," which are largely still in decline and not seeing any positive effects from the city's purported comeback. Makers continuously questioned this division and why Detroit's future was playing out this way: who's Detroit is New Detroit? Who belongs there, and by what set of permissions? Additionally, makers often struggled with their place in it all: how were they supposed to make their own ends meet, but do so in a way that wasn't exploitative of a city that had so many disadvantaged people in need? I conclude that the city's changes are both better and worse for Detroit's makers, and that this ambivalence is responsible for the significant tension tied up in "Made in Detroit" branding as well as makers' sense of frustration around how to live through the impasse of place change.

\subsection{DEATH AS A PREAMBLE}

\section{The Gap-toothed City}

“And where I lived, it was house, field, field. Field, field, house. Abandoned house, field, field."

- Danny Brown, “Fields” (2011)

Detroit has so thoroughly been described as a dying or dead city that the sudden "turnaround" or "comeback" it is experiencing can only be unsurprising. Its only other option would have been to fully decompose, as if it were a human body unworthy of a proper burial. This is not hyperbole; it is literally how the city has been written about in the recent past. After the city's "last days" had been infested with zombies (Temple 2010), it had its "autopsy" (LeDuff, 2013) and can finally rest in the "afterlife" (Binelli 
2012). How should the public resist the popular imaginary of Detroit as a dead city? It's interesting to note that these analyses of Detroit's death came a full decade after The Detroit Free Press ran a headline proclaiming "Detroit Rising"21 in reference to the city's ostensible turnaround at the turn of the millennium. For years people in Detroit have been adhering to the rose-colored notion that "the only way is up," that the city had already been dead and was "rising from the ashes." Indeed, it is too bad the name Phoenix is already taken, lest Detroit was to completely rebrand from its name on up. But if we believe the popular arc of Detroit's story, Detroit still continued to die for at least another decade, which begs an odd sort of question: how do we know when a city is "dead"? What does "rising" look like? Is Detroit somehow different, as its growing funeral party seems to suggest, or is a Brooklyn growing in Detroit?

With all the rhetoric about the global explosion of urbanization, it has become easy to forget that urbanization is uneven. In the US, it is common to see certain parts of cities grow rapidly while other parts decay, a creative destruction that births ideas like "creative placemaking" (Markusen \& Nicodemus 2010) and "urban triage" (Simmons \& Casper 2012) from the same womb. Detroit, a "shrinking" city (Hollander 2010; Rieniets 2009) in the age of global urbanization, has received intense scrutiny over the past two decades for the unique scope of its decline. Fairly or unfairly, the city has been inscribed with ever more extraordinary post-isms: post-industrial (Millington 2013), post-American (Solnit 2007), post-post-apocalyptic (yes, that's two "posts"; Austen, 2014), and so on.

\footnotetext{
${ }^{21}$ I cannot find evidence online, however I remember seeing the headline clear as day and I know it was 2002 because it was celebrating Detroit's $300^{\text {th }}$ birthday
} 
This assault of post-isms has generated a variety of new imaginaries and representations of Detroit (Millington 2013; Dawkins 2011; Darroch 2015). Gandy (2006) describes the imaginary that post-industrial cities conjure, citing fictional films and novels as picking up on the notion that something has ended in older industrial cities, even if that thing isn't industry itself. It is an ambivalent imaginary, expressed in dialectics of there/not-there, nature/city, living/dead. "The post-industrial metropolis, and its cultural representations," says Gandy, "is a city for which we are still searching for an appropriate conceptual vocabulary." Perhaps Detroit is an exemplar of whatever is meant by post-industrial. In many discourses, the burden of proof for Detroit is on proving that it is still a city at all. The city has been repeatedly portrayed as being taken over by nature - stories about pheasants, beavers, deer, etc. running wild in Detroit are rampant (LeDuff, 2013; Solnit, 2007; see: Millington, 2013 for an insightful analysis); endless amounts of empty blocks have become urban gardens (Solnit 2007); even community development advocates are touting things like tree farms as solutions to the abandonment and decay in Detroit ("Community Advocates of Detroit," 2010). Trees are sprouting right through factory floors and on top of skyscrapers (see: Temple, 2010 for a sensationalized view; Leary, 2011 for the critique), urban prairies have taken the place of once-densely populated neighborhoods (Morton 2009), and photojournalists are not missing a moment of it (witness the birth of so-called "ruin porn"). As Millington (2013) argues, these dystopian portrayals of Detroit oppose (non-human) nature to any form of (human) urbanism, thereby obscuring the social forces that created Detroit's decay and "naturalizing" nature as a revanchist force of repossession, framed in binary opposition to “declensionist” humans (Melosi 2010). 
As Solnit (2007) notes, over the course of the past half century Detroit has increasingly taken on the appearance of a fort that has been turned inside out, complete with what feels like a moat along the six-lane 8 Mile Rd that separates Detroit from its suburbs. In a sense, it's an inversion of Foucault's Panopticon (1975): between the 1970s and 2000s Detroit was a place in which many people likely internalized the fact that nobody was watching. As evidence, a reoccurring refrain in LeDuff's (2013) Detroit: An American Autopsy is that in Detroit, the violent, the desperate, and the absurd are the norm because nobody cares. Over the past decade, however, and coinciding with the bizarre imaginary of 'ruin porn' (Greco 2012; Strangleman 2014; Vultee 2013), it has become clear that people - outsiders - are indeed watching. Some are watching with horrible myopia; this is mainly politicians and pundits comparing Detroit to Hiroshima ${ }^{22}$ or summoning Detroit's stature during the 1980 s as "murder capital of the world" to convince white voters that the only alternative the encroachment of the black ghetto is market fundamentalism. ${ }^{23}$ These mental conceptions of Detroit create a veneer of loss (Herscher 2010), which forecloses on any potential upshot while maintaining the image of an anti-sustainable city in which humans and nature have never learned to co-exist (Millington, 2013).

As little as I am interested in reproducing certain "ruin porn" narratives, the decay on Detroit's east side certainly stands out. LeDuff (2013) depicts Detroit's eastern neighborhoods as "checkerboarded with an inhabited house next to a burned out

\footnotetext{
${ }^{22}$ Glenn Beck delivered this commentary while I was sitting in my hotel's breakfast area during my thesis research in Detroit in 2011; the audible gasp in the room was memorable. See: http://video.foxnews.com/v/4560891/?\#sp=show-clips

${ }^{23}$ Rudy Guiliani and Meg Whitman, for example, have both used Detroit as an imaginary for what lies at the bottom of the slippery slope to socialism
} 
shell...something like a meth addict's mouth" (47). Also employing dental metaphors, Austen (2014) uses the term "gap-toothed" to describe the aesthetic of many of the city's neighborhoods. The reoccurring narrative goes something like this: where dense neighborhoods once stood, now observers see a house with a manicured lawn next to an overgrown field adjacent to an abandoned house that is some combination of boarded up, fire damaged, or entirely collapsed. Solnit (2007) captures this narrative with vivid imagery:

On so many streets in so many neighborhoods, you see a house, a little shabby but well built and beautiful. Then another house. Then a few houses are missing, so thoroughly missing that no trace of foundation remains. [...] Then there's a house that's charred and shattered, then a beautiful house, with gables and dormers and a porch, the kind of house a lot of Americans fantasize about owning. Then more green. This irregular pattern occurs mile after mile, through much of Detroit (Solnit 2007).

During an interview in East Detroit, the makers I was speaking with walked me outside their space - an old postal building in at least its third life - in order to show me how nature and neighborhood were merging. Stepping under a rolling metal door onto the loading dock, I was greeted with a stretch of grass split by a thin neighborhood street going southwest (middle-left image below). Looking to the north and west, there was more of the same - a gas station, a smattering of houses; but mostly I saw fields. There were clear signs that houses at one time stood on these now grassy lots, and the makers I was speaking with noted that perhaps as recently as 5 years ago that was the case. Looking into a small wooded area behind the building, the makers showed me some 
scraps from recent demolitions, and I could make out driveways and sidewalks now leading to nothing. The closest house was almost a quarter mile away, and I could only see houses on one side of the street. The other side was cleared entirely. The houses that were still in the area were largely damaged, decaying, and in varying states of ruin, although there were still houses that appeared well kept and ringed with chain-link fences. My interviewees were making the point that the speed of the demolitions had really picked up out here in the neighborhoods; this demolition seemed to be intensifying in conjunction with the sudden skyrocketing in land values closer to downtown. Looking about a half mile east I could see the very edge of Detroit, where the transition into Grosse Pointe Park couldn't have been anymore obvious. My interviewees seemed convinced that the recent addition of traffic circles heavy with giant planters were meant to limit who enters Grosse Point Park from Detroit.

\section{Ashes in the Sandbox}

The imaginary of deindustrialization and ruination has underwritten the emergence of a new, intersecting imaginary, perhaps captured by Austen's (2014) aforementioned reference to Detroit as "post-post-apocalyptic" in his New York Times article of a similar name. Detroit filed for bankruptcy in 2013, an action that in many ways carried a sense of finality, perhaps marking the end of the era of "ruin porn" and the beginning of something else. The city is no longer dying, it has died, and the new imaginary reflects the social interest in whatever laboratory may have emerged from the city's cremation. This is what I mean by "ashes in the sandbox" - a nascent imaginary that exists in a grey area between "a city in perpetual ruin and a petri dish of cultural experimentation" (Darroch, 2015; 299) with no necessary adherence to forms of 
governmentality based on law (LeDuff 2013) or the market (Darroch 2015; Herscher 2012). In other words, Detroit's new emergent imaginary is no longer obsessed with death, but rather with the forms of post-death the city might take.

The Detroit I found in 2017 was not the Detroit I knew when I researched my master's thesis there in 2010. It was not the Detroit I knew from living there in the 1980s and then again in the late 1990s and early 2000s. Central Detroit - what has come to be known as "the 7.2" - had been largely reinvented, with all kinds of new restaurants and shops, building-sized murals and graffiti-inspired alleyways, and even a new streetcar. Outside of downtown (but still within the city limits) had not seen the same types of changes, however. The "neighborhoods," as locals refer to the massive ring of residential areas around downtown, had changed to some extent, but more so from the perspective of demolition. There were more empty spaces, especially on the near east side and far outer east side; there were still a good deal of collapsing houses; and the division between white spaces (in or near the CBD) and black spaces (in the neighborhoods) still felt stark to me. In other words, the changes in the central city did not appear to me to be "trickling down" to the neighborhoods. 


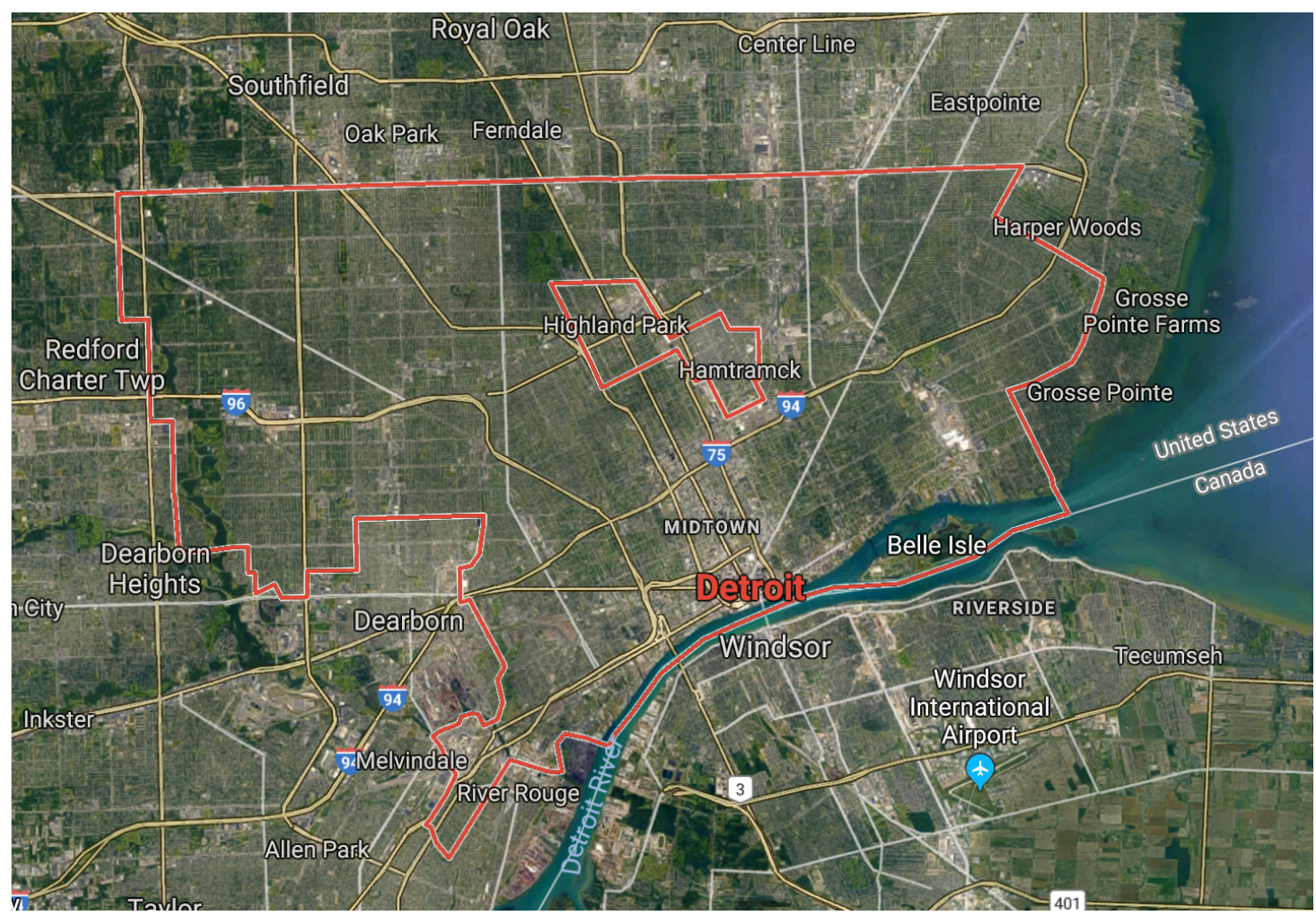

Figure 1 (above): Detroit and its immediate suburbs; most makers are located in the "Midtown" area (south/central Detroit)

Figure 2 (below): The "New Detroit" central city neighborhoods, also becoming known as "the 7.2"

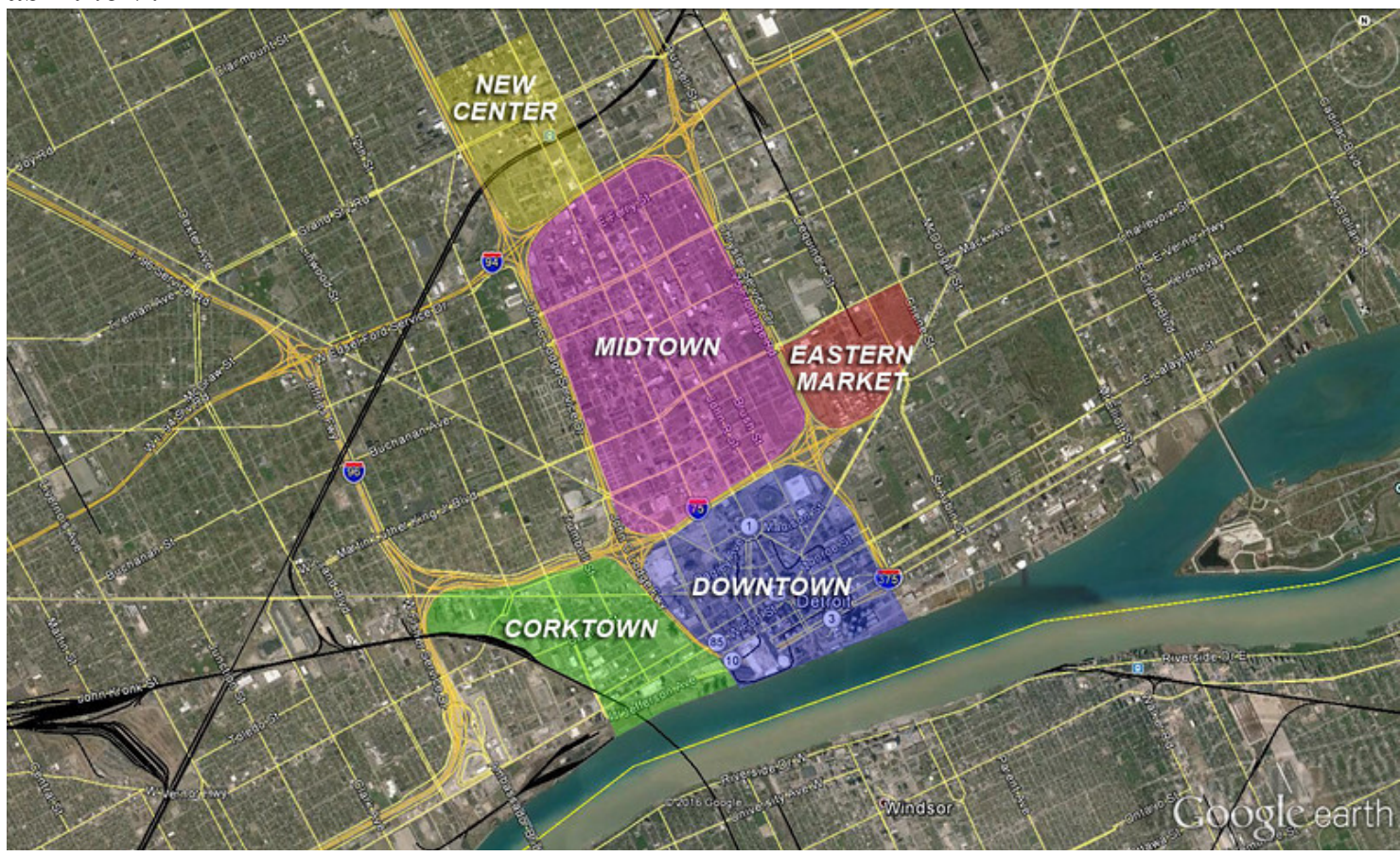




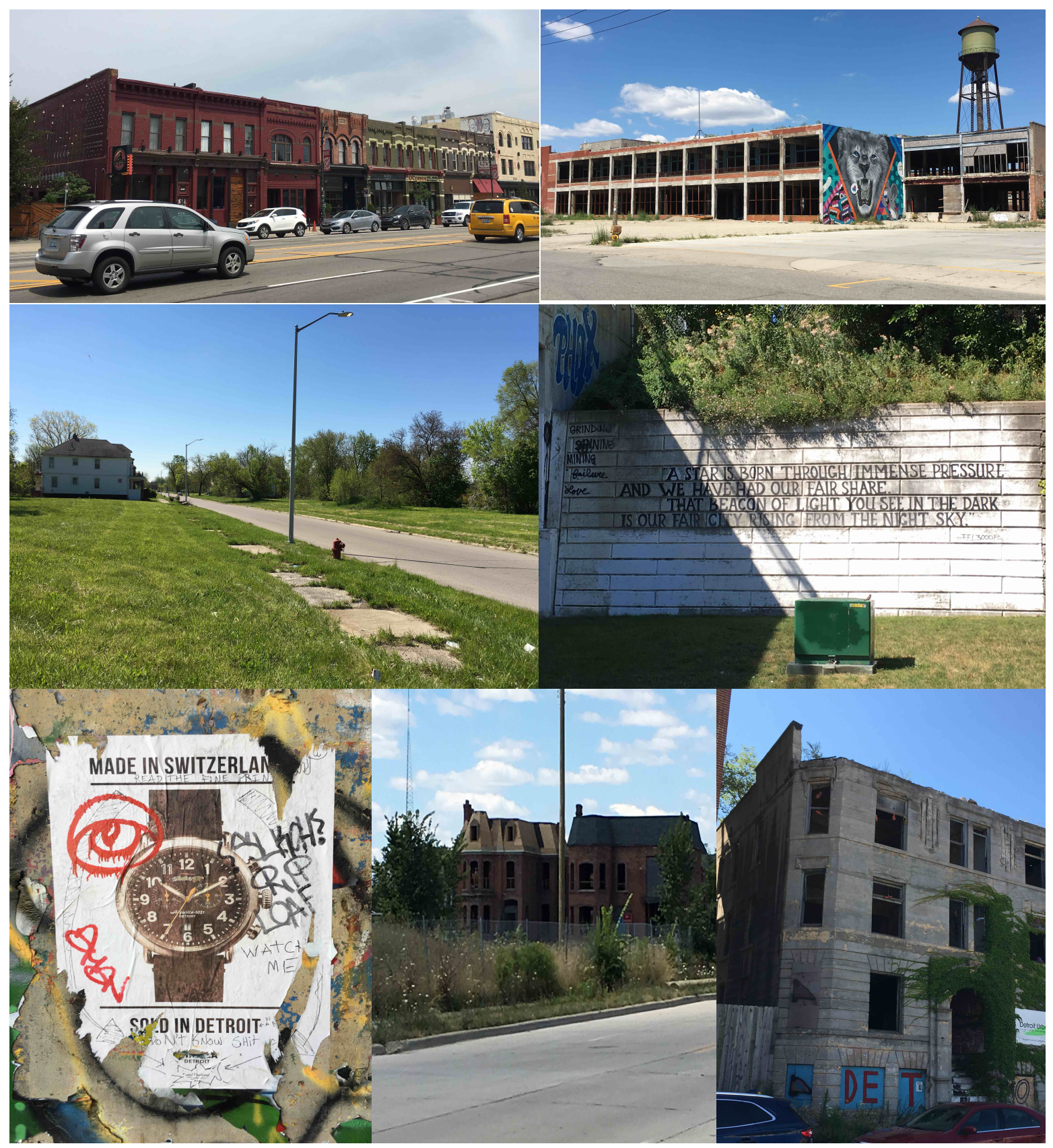

Clockwise from top: (Figure 3) The commercial strip in gentrifying Corktown; (Figure 4) empty warehouses just outside Eastern Market; (Figure 5) a message about "comeback" along Dequindre Cut; (Figure 6) a damaged apartment building in Brush Park; (Figure 7) gutted houses east of New Center; (Figure 8) anti-Shinola graffiti and some handwritten responses on an alley wall; (Figure 9) an almost completely empty neighborhood in far-east Detroit. All photos taken by author. 
This was all just the impression I got from walking, jogging, getting Uber rides, and generally wandering around the city. I realized that being in Detroit in the midst of all this change gave me a unique opportunity to ask makers about how they perceived the city's immediate history and where the city is now; I wanted to capture a moment of collective imagination about Detroit, located within a specific milieu (that of "making"). The spatial imaginary that I found can best be couched in a handful of juxtapositions: white Detroit and black Detroit; urban Detroit and suburban Detroit; "new" Detroit and "old" Detroit. I also asked makers about how they felt those outside the city were imagining Detroit, what other researchers and media outlets had asked of them, how they had been portrayed in the media, and what they felt the shortcomings of Detroit's ostensible comeback have been. Getting reactions to Detroit's recent changes was about as easy a task as I've ever accomplished in my short research career: Detroit's makers as well as the numerous other Detroiters I engaged in conversation, such as Uber/Lyft drivers, bartenders and bar patrons, store clerks, other academics, friends I still have in the city, even the people around me at the handful of Tigers games I attended - were very quick to offer their opinions on what is happening in the city.

There were a few lightning rods in conversation, notably Dan Gilbert and his well-documented takeover of downtown Detroit's real estate. Gilbert, the polarizing owner of Quicken Loans and Detroit's most omnipresent real estate firm (Bedrock), is seemingly everywhere, and everyone has a strong opinion on him. Gilbert owns an astonishing number of properties in downtown Detroit; according to Detroit news site 
MLive, ${ }^{24}$ Gilbert owns roughly 100 properties in the CBD. In a handful of conversations I was told of a large, detailed model of downtown Detroit housed in one of Gilbert's executive offices; this was seemingly confirmed in a CityLab article in late 2017 (Wey 2017). One person even told me that properties would light up as Gilbert bought them, although I think this may have been hyperbole. Gilbert was also pivotal in getting Detroit's brand new QLine streetcar operational. As I show below, opinions on Gilbert were diverse to say the least. But in passing conversations, the sentiment about Gilbert was generally that he was "activating" space, which was a novel thing in a city long known for real estate speculators that bought cheap properties and then let them decay while waiting for a market turnaround.

Another lightning rod was the probably-too-large-to-be-called-a-maker company Shinola. Shinola occupies almost two entire floors in the massive Alfred Taubman building just north of Midtown; they also recently purchased the 1400 Woodward building and are converting it into Shinola's first hotel. Most of the conversations I had with makers in Detroit referenced Shinola in some way; in my analysis, the use of Shinola's name is complicated. I did in fact spend some time with people at Shinola conducting formal interviews and touring their facilities in Midtown. As I must protect the confidentiality of those I spoke with, I cannot refer to Shinola in some instances. What I will say about their operation is that the relationship Shinola has with the maker community is not passive. The people I talked to are deeply involved with the outside community, and this involvement did not strike me as supercilious. Shinola's

\footnotetext{
${ }^{24}$ See: https://www.mlive.com/news/detroit/index.ssf/2017/12/dan_gilbert_acquires_buhl_buil.h tml
} 
embeddedness in Detroit is complex, to be sure: they are a high-end firm producing luxury goods in a city whose poverty rate has been hovering around $40 \% .{ }^{25}$

Lastly, everything in Detroit maps back to the intersection between race and class. As Hartigan (1999) shows, race in Detroit is never reducible to class, but it is always textured by it. In this way, discourses that appear to be framed in other juxtapositions urban versus suburban Detroit, for example - it is still fundamentally about Detroit's complex and intertwined histories of race and class. To confirm this, one would only need to look back to the rapid expansion of Detroit's suburbs in an era of "white flight," the federally-subsidized freeway construction that bulldozed neighborhoods of color and provided suburban white "professionals" direct access to downtown businesses, a disappearing urban labor market (Sugrue 1996), rampant hiring discrimination, racist housing covenants, blockbusting, contract selling (Satter 2009; Massey \& Denton 1993); and so on. As Sugrue (1996) argues:

Detroit's postwar urban crisis emerged as the consequence of two of the most important, interrelated, and unresolved problems in American history: that capitalism generates economic inequality and that African Americans have disproportionately borne the impact of that inequality (5).

Detroit's Dan Gilbert-fueled "comeback," its wide-open spaces that provide the space so many ostensible experiments, its fiercely contested city/suburb relationship, its attractiveness to artists, its manufacturing-friendly, maker-ready infrastructure; none of

\footnotetext{
${ }^{25}$ See: https://www.freep.com/story/news/local/michigan/2016/04/26/detroit-has-highestconcentrated-poverty-rate/83395596/. It should be noted, however, that reports of a dramatic reduction in Detroit's poverty circulated in 2017, with reports claiming that the city added 20,000 jobs between 2016-17.
} 
these things exist without a history in which Detroit's black population was politically and economically marginalized, subjected to rounds of violence and discrimination, and then isolated and abandoned by the state of Michigan and Federal governments. The open space that makers often discussed was not there by any sort of accident; it was historically produced. This racial history is implicit in everything that follows.

\subsection{DETROIT'S MAKER IMAGINARY}

"One never commences; one never has a tabula rasa; one slips in, enters in the middle; one takes up or lays down rhythms."

- Deleuze, Spinoza: Practical

Philosophy (123)

\section{Old Detroit...}

Much of this chapter mobilizes the notions of "new" and "old" Detroit. By all means, talking about "new" or "old" Detroit with makers is fraught with issues. After all, what is old Detroit to one person is someone else's new Detroit. In other words, there is no actual new or old Detroit with definitive and universally agreed upon start and end points. This is why the quote at the outset: a city can never really be old or new, but rather one version that emerges from and overlaps with other versions. There was never a tabula rasa in Detroit; the various spaces in the city have always been something to someone. People that are drawn to a city for whatever reason - artists or makers drawn to the open spaces, lack of official regulation, and cheap rents - enter into this process of emergence, as Deleuze says, in the middle. The point here is that "old" Detroit is not 
some point of origin; in many ways it would be more aptly described as a point of disappearance.

But for anyone familiar with Detroit over the course of some time, it would be hard to argue that what has happened in the central core of the city over the past 3-5 years is not "new." The central CBD and surrounding neighborhoods of the central city, the sum total of which has now been rebranded as the "7.2," has seen a meteoric turnover of space. New apartment buildings line the major thoroughfares; countless new restaurants and bars have emerged on every corner in the CBD; there's even a Whole Foods in Midtown. At least 4 of my interviews took place in bustling coffee shops that wouldn't have been out of place in Portland's hippest (read: most gentrified) neighborhoods. Everyone I talked to - maker or otherwise, white or black - either knew what I meant by "new" and "old" Detroit or they used it themselves before I even had a chance to ask. In other words, no one needed clarification; they knew that "old" Detroit came before Dan Gilbert, before the Super Bowl, before Whole Foods. All this is to say that in framing Detroit as "new" and "old," I am simply attempting to demarcate a hopelessly blurry line, a liminal space in which something feels like it has changed.

My interviewees commonly perceived old Detroit to be a complex open world of experimentation, space, and affordability. Many of them openly lamented the loss of such spaces, even if old Detroit was a "pretty scary place":

It was fucked up. It was scary...it wasn't a safe space to be and when you're behind closed doors for so long or behind bullet-proof glass and that you're always thinking to go, where are those places of interaction? How do you meet your neighbors? 
On the one hand, I did hear stories about how old Detroit had been dangerous, but no one dwelled on that sense of danger for long. In the above quote, we can see how quickly she moved on to the "real problem" which was a lack of neighborhood interaction. Danger aside, there were plenty of other mentions of how challenging it was to live in a city with so much vacancy, decay, and crumbling infrastructure. One maker talked about how "nonsensical" old Detroit was; no one ever got parking tickets, but there also were no streetlights. Another maker, who seemed almost exasperated in a conversation about Detroit's sudden magnetism for makers, put it this way: "This is a town that wrote a press release just because we got street sweepers." On the other hand, and as one artist I spoke with put it, the same social breakdowns that led to the city's notorious crime problems and eventual decay also "exposed this space to do things, primarily because there was nobody there to stop you." Many of my interviewees talked somewhat nostalgically about this thick moment of transition where anything felt $\mathrm{OK}$ to do.

Some of the makers I spoke with were artists that had been living in Detroit for quite some time (i.e. before "new" Detroit). According to one maker, everything was cheap and there wasn't anywhere to work, so her and her friends just started making things. She said they could spend a small part of their day making something to sell and that would cover their rent; this meant more "time to live." Eventually people from places like New York or California would come visit their Detroit friends and pick up some small amount of work and end up staying because their money went so much further in Detroit. This maker told me that she suspects there were all kinds of informal makerspaces going on all over the city, like groups of craftspeople working on collaborative projects in houses that cost them almost nothing; a woodworker from 
California would come visit a woodworker in Detroit and decide to move, as the folklore seemed to go. And even as prices on real estate started to rise a bit, to someone from New York or California they seemed "dirt cheap." She told me that there was a couple "waves" of artists and makers from other places that found their way to Detroit; she described it as a bit of a "snowball" effect.

Like has been documented in many other similar "artist colonization" stories (Zukin 1982; Ley 2003; Lloyd 2006b; Deutsche \& Ryan 1984), these waves of inmigrants over the past decade have become emblematic of gentrification. As Neil Smith (1979) pointed out decades ago, cities that had so much apparent cheap space at some point become attractive to those with the resources to invest in it, be those resources economic or cultural (Ley 2003). A professor at a Detroit art college told me that a great deal of privilege played into the transition: as he put it, "a lot of white people with small trust funds" started to show up and buy cheap houses. A stretch of time followed in which all kinds of unusual art and experimental projects suddenly began to capture the attention of the media (see especially "Wringing Art from the Rubble" in the New York Times $\left.^{26}\right)$.

The original and probably still the most prominent project, according to the professor, was Tyree Guyton's Heidelberg Project on the near east side of Detroit. Guyton created the "project" in the 1980s as a way to generate attention to Detroit's dramatic depopulation and decaying neighborhoods. The project is an installation in which Guyton wallpapered the outsides of empty houses in his neighborhood with found objects ranging from stuffed animals to shoes. He also painted the streets with polka dots

${ }^{26}$ https://www.nytimes.com/2010/08/04/arts/design/04maker.html 
and has used the empty lots to showcase a variety of odd and almost surrealist arrangements of discarded objects. City officials and neighborhood residents loathed the project and took turns (respectively) bulldozing and torching the abandoned houses that were the canvasses for Guyton's experimental art. The professor I was speaking with went into a story about how a Japanese person wanted to buy the whole project and take it back to Tokyo. In response, a Detroit newspaper article chronicling the encounter apparently ran the following quote about the Heidelberg Project: "The farther away you get from it the better it looks."

Although makers often criticized the notion that old Detroit was some sort of "blank slate" or could be equated to some postmodern version of the "Wild West," the language of experimentation consistently resonated, especially in the sense that such experimentation was in the late stages of disappearance. I asked one maker if she felt like the days of experimentation were gone, to which she responded that answering such a question is complicated by the fact that while Detroit has been changing, so has her business. The freedom to experiment came primarily from a double sense of freedom: first, businesses could afford to make mistakes because everything was so cheap, and second, their business was embryonic and wasn't accountable to anyone other than her (and her partner). They didn't have employees, or payroll due every two weeks, or a large space with (an increasingly high) rent due every month. She said they both long for what they jokingly refer to as their "dilettante days." Back then they could just say, "let's make stuff!" whereas now, given their added responsibilities, they find themselves saying, "make that faster!" 
Another maker linked the city's changes directly to changes in her business: "The city that [her business' name] started in is not the same city that [it] is in today," she told me. She said that so many of the early "movers and shakers" are close friends of hers and that the scene they belonged to had begun to fade away. In old Detroit, there weren't many places people could go to hang out, so everyone went to the same places and knew each other. So many ideas and projects emerged as a result, including a handful of businesses and nonprofits that many Detroiters credit with inaugurating the maker movement in Detroit. She located herself in that milieu and was emphatic about their devotion to the city's betterment at the time. In those days, "you choose to get involved or you don't, and I don't think it is that way, now you can be kind of wishy-washy, you can be pro-Detroit but you don't have to live in Detroit to be pro-Detroit now." She told me that the explosion of small businesses in that area - restaurants, cafes, bars, and other maker-style boutiques - has changed the sense of engagement: “it doesn't feel as tight knit as it used to." I asked her if there's a bit of a "professionalization" going on in the area, to which she emphatically said yes; I followed up by asking her if "new" Detroit was weighing on her, to which she responded, "a thousand and twelve million percent." All of this talk of experimentation and autonomy seems to dovetail well with another aspect of old Detroit that similarly admires the individualist mythos. This aspect rests on what so many US consumers were exposed to by Chrysler's famous "Imported from Detroit" advertising campaign in the early 2010s: that Detroit is tough, gritty, hardworking, resilient, and honest. Take this response from a suburban Detroit maker after I asked what differentiated Detroit from other cities: 
We tell each other the truth. I feel so much creativity comes out of Detroit because number one, it's cold and it's shitty. You're stuck inside all day long and what better to do than hone your craft; play guitar, knit, paint, do something other than watching TV because you're stuck inside. It's either 110 with humidity or it's -12 . We get like 10 nice days a year. We're not at the beach hanging out; heck, if I could be at the beach hanging out I wouldn't be [making her specific product]! And we've all fallen on tough times at points in our lives so we don't sweat the small stuff as much when you're stressing about paying a medical bill or when you're stressing about losing your job; when you have real life problems all the other stuff just like, get over it. That's what's special.

While I can't say to what degree Detroit's makers agree that these tropes actually represent the city's people (as well as its imaginary), there seemed to be a general awareness amongst makers that people outside the city felt that these things $d o$ in fact describe the city's public imaginary. One maker argued that not many outsiders "would say fuck Detroit. [...] It's an easy city to root for," in part because the city's comeback story profits from these "bootstrapping" and hard work tropes. For the record, my impression is that this maker was being somewhat satirical. Yet these narratives about Detroit's imaginary are never totally absent from the conversation, even in jest.

To emphasize the point about outsiders' imaginary of Detroit, a Portland interviewee - completely unprovoked - discussed Detroit in exactly this way. She was making the case for how Portlanders are independent and hardworking; she said that in Portland, everywhere she looks, "someone else has put their blood, sweat, and tears" into a project that fixes something. This mentality, she theorized, came from the same sense 
of experimentalism, tethered to cheap real estate, that Portlanders and Detroiters both had available to them (but at different times). She conceded that the histories of the two places are radically different, but insisted that when a city (she actually used the word “community") has been brought to its knees by a recession, for an entrepreneur, that's opportunity. And if that city is cheap enough, people will move there. She pondered whether Portlanders would rather have their identity be aligned more so with Detroit's or with San Francisco's, and eventually decided that most Portlanders would say Detroit. When asked why, she said, "because they don't see Detroit the way we see it."

This statement begs a few questions. In the first place, upon analysis it isn't clear who "they" is, but I'm not sure it matters; the point of the statement was to draw a connection between Portlanders and Detroiters on the grounds of their creative, independent, sweat equity-driven form of city rehabilitation. Second, the idea that (white) people will move to a place just because it's cheap doesn't explain why it took until the late 2000s for (white) people to start moving to Detroit; after all, it had been cheap for over half a century. Both of these questions, however, say a lot about what from old Detroit - and the rugged individualist tropes that have magnetized to the city's fortunes has survived and become something of a basis for new Detroit (a la Benjamin’s “wish image"). The city's comeback owes a good deal of its ideological appeal to this imaginary of innovation, hard work, and so on. Her comment gave me a glimpse of the complexity of a city's imaginary, of what an imaginary is capable of doing even far removed from its material location. The fact that people clear across the country were so sure of what Detroit is and who the people there are gives power to the various iterations of Detroit's brand, in my case in the form of "Made in Detroit." 
There is a well-known Shinola focus group story that I heard at least four times in my interviews; it has essentially become folklore in maker circles. The story goes something like this: when Shinola was looking for a city to locate in (Shinola is owned by Bedrock Brands, which also owns Fossil), they commissioned a study of which city/country/price point would have the most clout with consumers regarding where their products were made. I've heard a variety of options consumers were presented with, but the most commonly mentioned choices were Made in NYC, Made in the USA, or Made in Detroit (Dora Apel's Beautiful Terrible Ruins recounts the story with China as an option instead of NYC). Everyone I spoke with confirmed that Made in Detroit was - by a large margin, and even at higher prices - the preference of the surveyed consumers. Many makers all said similar things about this result: "Detroit has making in its cultural DNA"; that it has to do with the desire to see "something that used to be great come back"; that people want to play a role in not wanting to let a great American city go by the wayside. The significance, regardless of one's feelings about Shinola, is that something had clearly changed in the way people outside of Detroit perceived Detroit. And Detroit began physically changing just as rapidly.

\section{...And New Detroit}

“It's crazy, it's so strange." This is how one maker framed Detroit's sudden thrust into the realm of "coolness" after so many years of holding down "America's Most" in a variety of other, more pejorative categories. The above maker's partner continued by saying that telling people that you were from Detroit used to be grounds for becoming the target of a host of "weird looks and rude jokes." But that has changed, as has Detroit's narrative, both inside Detroit and out. One maker told me that her friends and 
acquaintances from around the country had been contacting her a lot and taking vacation time to come visit. Another told me that Detroit now versus six years ago is "night and day," noting that there are more people out on the sidewalks. But she also said that people she knew were starting to get priced out of the central city - something unfathomable just a few years ago.

The same maker, who has been in Detroit for 6 years, said that the past 2-3 years have seen a "quick 180 " and that she has been hearing of people moving back to the city from the places like Chicago and New York, places they originally left Detroit for, again something that would have been hard to believe just a few years ago. For her, however, the collective imaginary of Detroit outside the city still seems unsettled. She does trade shows around the US, and she said when she mentions being from Detroit there's always one of two responses: that the city is making an impressive comeback and has a thriving art scene, or that it is desolate and depressing. The latter was at times referred to as the "Detroit cringe," or in other words the combined wince and recoil that people react with when told someone lives in Detroit. A jewelry maker told me she was recently in North Carolina and told some people she was from Detroit, to which they responded, "oh that's horrible." When on the road, she always has to explain that Detroit is "really cool" now. But a different maker told me that the Detroit cringe has all but vanished. Upon hearing she lives in Detroit, people now say, "really? Tell me more about it!" She was a bit cynical about it all however, telling me that the same people that used to hate Detroit (i.e. people that she grew up with in the suburbs) now visit Detroit all the time and can't believe they ever hated it. "God," she said, exasperated. "It took a white billionaire to give people permission to live in this city.” 
The white billionaire she's talking about is Dan Gilbert. He was omnipresent in my time in Detroit - on the TV and in the media, in casual barroom conversations, and in my interviews. It's impossible to miss his influence on Detroit; in fact, many Detroiters refer to a section of downtown Detroit as "Gilbertville." And while Detroit has been ostensibly "making a comeback" for a long time, he seems to have changed the conversation around Detroit's trajectory. Take this conversation:

Steve: But Detroit's changing, right?

Maker: We're in a renaissance, but it's been like what, 3, 5 years?

Steve: So you don't buy into the whole...

Maker: Oh no, I buy into it, it's happening. For the last 20 years Detroit's been turning around (said with an eye roll). But for the last 3 to 5 years, it really is turning around.

Steve: So what's different about the past 3 to 5 years?

Maker: Dan Gilbert.

In aggregate, the Detroit makers I spoke with have a generally ambivalent to negative view of Gilbert, often associating him with central Detroit's intensifying gentrification. The maker from above continued:

There's two sides of every coin, but from what I see he's keeping the historical stuff and there's just - the gentrification is starting to happen already and people are getting pushed out of their places. Businesses like Harry the Hatter man, that guy has been on that corner for forty freaking years making awesome top hats and all of a sudden he can't afford his rent and he's getting pushed out. 
In many makers' eyes, Gilbert's presence has been almost frustratingly fruitful for the city, but only because of what he has added to Detroit's revitalization that has never been there: a significant amount of investment capital. Makers often seemed frustrated that all the benefits have been flowing toward the largely white middle and upper classes that have the cultural capital and mobility to capitalize on Gilbert's investments, which in the end actually just makes Gilbert more wealthy while simultaneously making him look like a hero:

What's to hate? I mean, he's been a pure and utter capitalist. He buys the buildings that his businesses are working out of, his employees then rent from him, and he makes money back on his money. It's fascinating, right? Because that's what development is, real estate development is you buy from me with the money I give to you because you work for me.

This maker also pointed out that the new QLine streetcar, which opened while I was in Detroit, is basically a shuttle for Gilbert's employees to get back and forth from their apartments in the increasingly hip Midtown area and Quicken's offices downtown (Gilbert owns Quicken). Between Midtown and Downtown is a stretch of Detroit that has come to be known as "The District," pejoratively referred to by some makers as "Illitchville" in reference to amount of real estate in that area owned by a prominent Detroit family named the Illitches. The Illitches, who also own Little Caesar's Pizza, own the local professional hockey (Red Wings) and baseball (Tigers) teams and have built new stadiums and relocated both teams to The District within the past ten years. The QLine passes right through The District; the combination of the new streetcar, the sports teams all concentrating into a district, and the gentrification of Midtown and Corktown 
has led to a ravenous development frenzy and stratospheric rent growth in the immediate downtown neighborhoods. Dan Gilbert is probably the single most financially invested player in Detroit's so-called resurgence.

Gilbert's foil, perhaps, is another large (and wealthy) landowner named Matty Moroun. Moroun owns the Ambassador Bridge (which connects Detroit with Windsor, Ontario) as well as a significant amount of land in the Corktown neighborhood directly west of downtown Detroit. According to a maker based in Corktown, Moroun is of a breed of developer that has plagued Detroit - the type that buys cheap land and sits on it until huge opportunities come along. So many developers sitting on land is a prominent explanation for so much decay in Detroit. Gilbert is not of this breed, and according to almost everyone I spoke with, this makes him different. The Corktown maker told me that whereas Moroun has been a nuisance to the local community, Gilbert (or, more likely, his "people") has actually worked with the maker community. She mentioned getting his company's help in monitoring their building with security cameras and generally supporting what her and other local makers are doing. Gilbert is activating space, as a Wayne State University professor I spoke with put it; many other developers, such as Moroun, are actively producing decay in parts of Detroit.

The same Corktown maker, however, wasn't convinced that Gilbert's presence was really what Detroit needed. She had been living in Detroit a long time and saw Corktown's recent changes as problematic, even if they are couched in rhetoric of economic and community development: "If it's just going to be people who have acquired wealth to now come and find value in something, what are we really doing?" She said that some of the new places popping up all over Corktown really "feel like such 
white space[s]," and they weren't supposed to be that. She told me that the 2006 Super Bowl, hosted by the brand new (at the time) Ford Field in downtown Detroit, played an interesting role in the development of Corktown as a white area. Back in 2006 there were not many hip places to eat in Detroit, but Corktown had a "cool" restaurant that USA Today featured in a "where to eat in Detroit" article targeting Super Bowl attendees. According to her, it was a hip place white people could eat close to downtown, and it brought in a significant amount of money and attention to Corktown.

Something that I kept hearing was that outsiders - visitors, tourists, in-migrants, etc. - assume that today's Detroit is still the same as 2009 Detroit, and that's not the case. Many people still think there are copious amounts of houses available for pocket change; from the accounts that I heard, housing was actually becoming a challenge, especially close to downtown. One maker told me that the "frontier mentality" that was a hallmark of old Detroit were pretty much a thing of the past. She maintained that Detroit was still more experimental than New York, primarily because makers didn't have to have a 9 to 5 to supplement their maker income. But I got the sense that was changing quickly. One of the issues, which has long been an issue in Detroit but has been approaching fever pitch, has been out-of-town investors snatching up real estate and holding onto it as it appreciates: "We don't really need more people coming from out of town because even my friends from Detroit are having trouble finding a house." She said that wealthy investors from cities like New York have been buying houses in cash for $\$ 10,000$ over the asking price. Her reaction to such "investment" was: "Oh, well I actually wanted to live in that house." 
I asked a food maker about all the newcomers to the city expecting to find cheap real estate. She responded that finding cheap land or housing might be possible through the land bank auctions, but that in reality "rents and real estate have gone batshit crazy" over the past two years. Buildings that were $\$ 10-15,000$ three or four years ago, she said, were now being sold for $\$ 300-400,000$ and still in the same condition (e.g. they still had no roof or were otherwise heavily decayed). She said newcomers often think Detroit is still like the Wild West; she told me a story about a husband and wife from Boston who recently opened an avant-garde restaurant and thought they'd just show up and "make a ton of money because Detroit had never seen a Mexican restaurant before. Are you serious?" I asked her if that kind of stuff ever worked in Detroit, to which she laughed and bellowed, "no!" I pushed her on how she felt about people assuming Detroit is a "blank slate." She said that Detroiters are usually accepting of new people and new things, but their acceptance is contingent on a certain civility and whether newcomers make an effort to get to know the community. She was quick to note that many Detroiters never left the city and that a lot of them are still upset about Detroit's racially unjust history. "People from Detroit love Detroit [...] A lot of people are just trying to make a living and for some rich rat from New York to come in and say 'I'm gonna save you all' - we don't need your saving. We're doing just fine on our own."

But people keep coming, and real estate prices are acting accordingly. It didn't take much prodding in conversations with makers to get an idea of how they felt about this. A conversation with a ceramics maker was telling: I had asked about how she had seen Detroit change. She said when she moved into the city 6 years ago, there were probably 6 "cool" restaurants and she could afford to eat at all of them, whereas now 
Figure 10 (below): Locations of maker interviews in Detroit; this map shows makers clustering in "New Detroit"

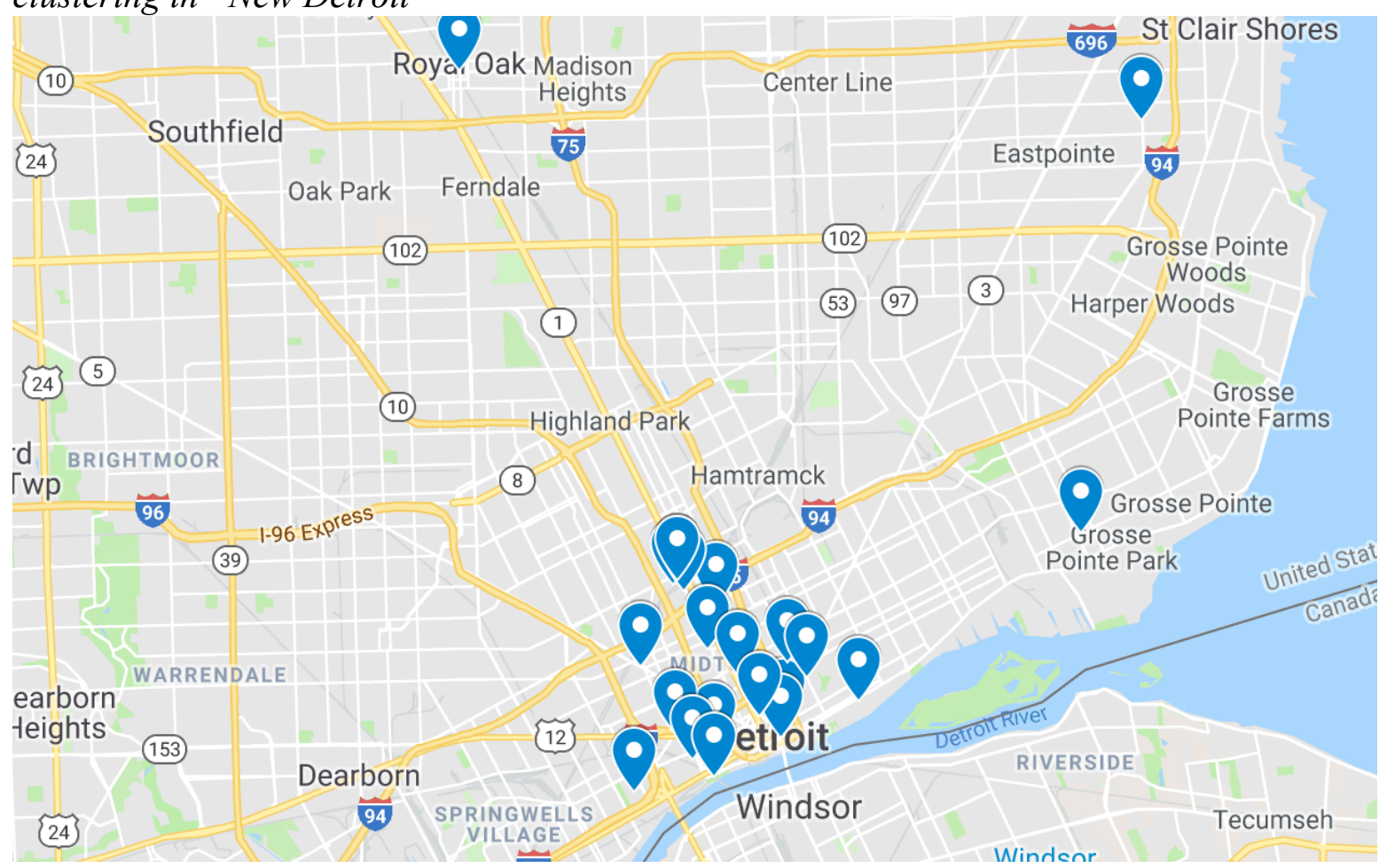

there are hundreds and she "definitely can't afford to eat at them." I asked her how much and how fast rents were going up, and she started telling me about how houses in the stillrough-around-the-edge neighborhood her business is in were selling for $\$ 300,000$. She says she's constantly waiting for the letter that displaces her studio from the basement location they have been in for years. But there were deeper and more broad feelings of resentment within her, which were intensified by the (at the time) just breaking news of Detroit's multi-year illegal property tax assessments that had displaced a number of lowincome Detroiters from houses they owned. She started wondering if all the newcomers from Chicago, New York, and LA have imported their sense of cost of space with them, because they were buying buildings and charging rents that no local had ever imagined 
possible. And she was further incensed by the reported subsidies and tax breaks that the purported heroes of Detroit, such as Dan Gilbert, were getting:

This is what's really happening here, you know, the big corporations getting tax breaks and whatever to buy all these buildings and do all this bullshit downtown that isn't helping anybody. Like what about everybody else who's still out in these corners of the city, you know, their lives aren't changing. I'm more interested in hearing that story than the renaissance of Detroit, even though I know I'm part of it. So I struggle with this.

She told me that in Northeast Detroit, where she lived, there were zero signs of gentrification or development but they had also just gotten their streetlights turned back on. The neighborhoods, what she referred to as "the corners of the city" and where most of the city's black population lives, are not benefitting from this so-called comeback. She says it's such a double-edged sword, because of course she wants the city to have more people, a larger tax base, and new businesses:

But who are these new businesses for? Not the people who have lived here for forty years. So how do you do development that works for everybody? And where I fit into that? Because I know I'm selling a luxury good, and - um - that's hard, you know? Selling is hard because I'm like 'you don't need this, I think you like it, and I think you want it, but you don't need it.' Obviously I don't say that to people but that's kind of like how I really feel.

So while I didn't sense an immediate fear from makers that they would be displaced, I did sense a sort of guilt around what the role of the maker economy played in this comeback story. This is what the maker in the quote above was getting at - her company 
is one of those that will benefit from downtown Detroit's transformation: there will be more stores for her goods to be featured in; those stores will get more foot traffic as more and more outsiders adjust to Detroit's new imaginary (creative, safe, white) and tourism picks up; and maker businesses will surely benefit greatly from Detroit's recent designation as a UNESCO City of Design (the first US city to receive the designation). Detroit's makers often realized this conundrum, even if they are hopeful that the comeback narrative is tethered to the cultural assets that the city has always offered rather than the "new" amenities that can be found in any city. As we see in the quote below, the latter, in fact, threatens the former:

I'm very, very excited about the fact that the tone of the conversation about Detroit, nationwide and globally, has changed. That it is not 'do you know anyone who's been killed' when I tell people that I've lived here most of my life. [...] I'm glad that people have a better understanding of the treasures that are in the city and the people that are in the city that are really doing something [...] I'm happy for the press, I'm happy for the turnaround, but at the same time I don't want to lose the character and the culture that we've had for decades. Because other people are moving in because they see an opportunity. I want the people who live here to have the opportunity more than anything.

The conundrum for makers gets more complicated here; as Detroit changes, the cultural "treasures" that have largely been produced by the people she wants to be afforded the opportunities associated with all this newness are threatened by Detroit's new identity. Instead of preserving its character, Detroit's identity is becoming absorbed by a larger, well-financed national and global narrative that feeds on cool, gritty, creative urban 
places, and the maker movement is all tied up in it. It is hard to argue that makers do not benefit from "new" Detroit, even if they lament the cost of that benefit, namely the displacement of "old" Detroit - all of the old Detroits.

A nonprofit worker (who works with makers) I talked to, however, found "new Detroit" to be largely a fantasy. She told me that Detroit can be "very unhealthy": “There's the illusion of money, there's the illusion of better, there's the illusion of safety." But, she said, the winters are long and hard, prices on everything are going up, car insurance is going up,$^{27}$ and the willingness of people to contribute to a better city (rather than just a more wealthy city) is going down. "We have a chance to rebuild a city here," she said, getting more and more demonstrative as the interview went on. She felt that "Detroit has an opportunity to get a bunch of weirdos to do crazy things that solve problems." She clearly felt that opportunity slipping away. She was emphatic that businesses - maker or otherwise - will never solve Detroit's problems: "Shitty developers from Royal Oak [a Detroit suburb] will just be shitty developers in Detroit." Her feeling was that since Detroit had become "safe" and "interesting," the people that hated Detroit for a half century now want to be a part of its revitalization. The problem for her - and perhaps the heart of the problem with the city's comeback story - is that there is a lot of confusion about the difference between people and buildings in "new" Detroit.

${ }^{27}$ As an interesting aside: car insurance rates were brought up a lot in interviews. One maker actually investigated car insurance rate hikes, coming to the conclusion that there was no data to back up the "stupid expensive" insurance rates. She told me that the data showed that car theft and break ins were more common in the suburbs than in the city. 
Gentrification is a tricky topic in a city in which no one really thought it could ever be a problem. "There's so much Detroit," one maker said, implying that there's enough to go around without prices skyrocketing all over the city. It all becomes so complex when considering the actions that the city has taken to hasten the emergence of new Detroit. Of prominence was the city's bankruptcy in 2013. One maker told me that move was "more powerful than people understand. It allowed the city to start building and not just plug holes." She thought bankruptcy was pivotal, because it allowed investors to feel safe with their investments; she added that investors wouldn't invest if they felt the city was on the verge of financial collapse or if city services might not be available.

But others felt that bankruptcy opened a door to crack down on the type of experimentation that many makers and artists valued about old Detroit. A scholar at a Detroit art college told me that post-bankruptcy, the city has become much more "activist" in terms of regulation. In old Detroit, the city could have cared less about what people did in abandoned buildings (see, for example, Detroit's famous "rave" culture during the 1990s); now, he said, the Russell Industrial Center (a very large and long-time informal home for hundreds of artists and artisanal businesses) is being shut down due to a litany of violations. He told me that moving into the Russell Building has always come with the tacit understanding that if a window was broken it wouldn't be fixed and there wouldn't be any heat in the winter; it was essentially an abandoned industrial building that the owner allowed artists to do whatever they wanted in for extremely cheap rent, so long as they could stand the lack of amenities. "So from the point of view of the city and managing things in a rational way, everything they're doing makes sense," the scholar 
told me. "From the point of view of the idea of Detroit as the Wild West and the land of opportunity it kind of sucks." He told me that some of the regulation is unnecessarily heavy handed - the graffiti task force has been out in full force writing tickets to property owners, including artists that have sanctioned the graffiti on their personal property and consider it art. (As a note, this is especially ironic considering the fact that most of downtown Detroit is suddenly covered in graffiti-styled murals). While artists have become increasingly regulated, he said, an (unregulated) investor class has swooped in and bought entire neighborhoods and quickened their decay.

He told me that he understood the hard shift of Detroit's imaginary in terms of dueling de- and re-constructive narratives (rather than new and old). The former sees Detroit as a place of failure and ruin, the graveyard of modernity; the latter sees Detroit as an artist and maker paradise. At the time I talked to him, there was a lot of investment in a regulated version of "creativity" backed by foundations and nonprofits, which led him to ask, "what do we do? Bite the hand that feeds us?" (He added that theorists like Pierre Bourdieu would say, “yes, that's exactly what you do.”) His larger point was that independent artists and makers had been put into the position of servicing the interests of capital, using the 1950 "Treaty of Detroit" between General Motors and the UAW as an analogy: "it was easier to pay off the worker than shut down the line [...] That's how the system works. You buy into it."

It is altogether unsurprising for anyone to determine that money and investment was what Detroit needed all along. But the old Detroit projects that had attempted to raise such money - micro-investment projects such as Detroit SOUP and Jerry Paffendorf's 
“inchvesting” idea - could not fill Detroit's rent gaps and infrastructure needs. The scholar I was speaking with saw these projects as fun, but only fun:

In an evening you raise like $\$ 1000$. Great, to fix a pocket park. Cool. So we need a bridge between the US and Canada, and based on what it's projected, what that thing is gonna cost, every person in America would have to go to Detroit SOUP and vote for it at $\$ 5$ a head to fund it. What the hell? That's the question of scalability.

He acknowledged that there is an ethical dimension to consider, but that small, community, direct democracy projects are largely feel good stories that cannot rebuild crumbling bridges or replace hundreds of miles of leaking underground water infrastructure: "why is it that artists are feeling compelled to take [ethical concerns] on? Is that a part of the new spirit of capitalism?" Like artists, he said that makers also seem to be hopelessly caught between ethics, business, and art. I told him that I was especially taken by the fact that every maker business in Detroit seems to be driven by a social mission. He appeared to shrug this off, noting that a few years ago he saw something of a utopian opportunity that he just doesn't see anymore; like the distraught nonprofit worker above, he feels the opportunities that old Detroit presented have slipped away as new Detroit has emerged. "In my heart of hearts," he said, "I feel like we're doomed, but you have to act as if there is hope just in case."

\section{New Detroit, Race, and the Suburbs}

Detroit's historical problems with race are not lost on the city's makers. Many of them were quick to point to deepening racial inequalities as evidence that new Detroit was worse than old Detroit. New Detroit, in which investment capital has feasted on 
cheap space, has been made possible by a history of disinvestment in neighborhoods. The nonprofit worker I mentioned above spent a good deal of time protesting this aspect of new Detroit, making the case that without the ability to capitalize on home equity (because home prices had been long declining and then were pulverized by the Great Recession), the majority black neighborhoods in Detroit had no ability to invest themselves. She began citing statistics that supported racial inequality in Detroit - that the city is $88 \%$ black but $60 \%$ of homes don't have Internet, $40 \%$ make less than $\$ 12,000$ per year, $47 \%$ are unable to read - and yet Detroit is somehow better because white people feel safe in Detroit: “That's fucked up! [...] Is Detroit really better?” She was further vexed that white people have suddenly discovered that Detroiters (she was implying black Detroiters) are nice: ${ }^{28}$ "Are we all just so blown away that people are kind?" She continued:

I am a white woman that grew up in the suburbs talking to you that has lived in the city for 9 years. I am not an expert, but I've watched a lot of things change and grow and a lot of folks were just OK with the way it was. And a lot of folks were not OK with the way it was either. I just don't think that this was the way we thought it was gonna change. And I think when the story revolves around Dan Gilbert it's already wrong.

She argued that white people use a lot of "separation" and "shame language" that alienates black people. As I had with other makers, I pushed on the language of

\footnotetext{
${ }^{28}$ I actually had a few makers tell me that their friends came to visit them from around the country and were surprised by how nice Detroiters were. One maker referred to this kindness as what she suspected was "Southern hospitality." Additionally, I had an Uber driver tell me that she always heard from her passengers that they were surprised by how nice people in Detroit were.
} 
experimentalism and Detroit as a "blank slate" or a Wild West and how those things are tied to racially problematic histories. She told me these things were usually said by "shitty bros being shitty," and they are usually influenced by racism: "If white people didn't do it then it must be a blank slate [...] White people don't live there. So is it empty?" She was clearly frustrated about what all this said about Detroit's racial dialogue; how did a city with over 700,000 people develop the public imaginary of being empty? Perhaps "invisible" would be more apt?

A clothing maker, who was very honest about the relationship between race and Detroit's maker scene, said she had been living in Detroit for a decade but said that after bankruptcy (2013) things started changing rapidly:

Watch them white kids from the burbs come in here and make this sexy and get a bunch of press coverage about it, and that's kind of what happened - well that's not the whole story but it's something I've wrestled with as a business owner because we had the privilege to have access - [her partner] had a $401 \mathrm{~K}$ to tap into to start this. We had a social network of people that introduced him to [a central figure in Detroit's scene], who got him started at [a local makerspace] with really low rent. We couldn't have started without that.

This is a similar sentiment to another maker above; in Detroit, it is impossible to ignore the role that white privilege plays in a business' ability to secure space, to access capital and grant money, and to produce goods and content that appeals to wealthy suburban white people that want to feel a part of the city's resurgence. I asked a maker of color about this specifically, and while she said that one of her target markets is suburban people with money, she confirmed that access to capital and other resources was one of 
Figure 11 (below left): racial segregation between Detroit and suburbs; red $=$ white residents, blue $=$ black residents

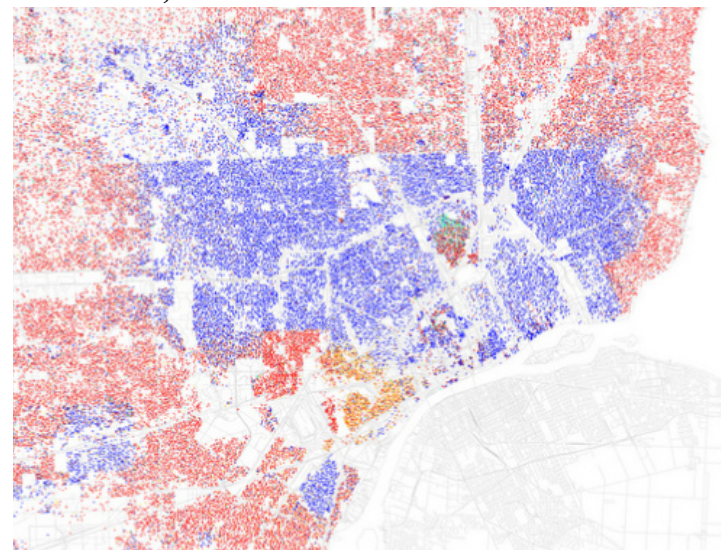

Source: Eric Fischer (Flickr)
Figure 12 (below right): racial segregation between "new Detroit" and the outer neighborhoods of the city

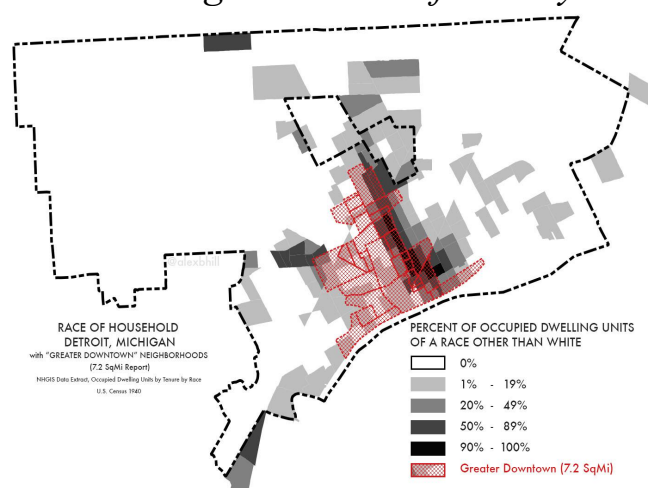

Source: Rebecca Kinney (Beautiful Wasteland, 2017)

her biggest challenges. When I asked her about Detroit's "comeback," she told me the comeback is "specifically defined over who has money" and that her business hasn't been able to benefit as much.

A maker from a more established firm told me that she was optimistic about race relations in Detroit. Events like Slow Roll, an every-Monday bicycle takeover of Detroit's streets, show off Detroit's cultural diversity. But most makers were more realistic about new Detroit:

The revitalization, I think there is a narrative out there about the revitalization that's happening in the 7.2 square miles of downtown or the central Woodward corridor is primarily to the benefit of educated white people. Not exclusively, but the city's $81 \%$ African American; the city's actually become more white since I've lived here, it was $86 \%$ African American when I moved back. How is the economic revitalization serving the people who have been here, who need jobs? 
Picking up on his comment about Detroit getting whiter, I asked where all the new white Detroiters were coming from; I was assuming the answer was the suburbs. Most of the white makers I spoke with, in fact, had moved to Detroit from the suburbs at some point in the past ten years; others had left Detroit and recently come back, often for the combined fact that Detroit was cheap and they felt they might be able to make an impact. He told me that he was a fifth generation Detroiter, and that he chose to move into the same neighborhood that his grandparents left before he was born. But he admitted that living there had led to him grappling with "difficult identity politics" and white privilege: "At the end of the day it's about what are you doing, and how conscious are you being of its impact or what opportunities it creates or doesn't create. And then owning it."

An economic development nonprofit worker that I spoke with told me that they had been trying to be more deliberate about working with neighborhoods of color and local commercial corridors such as the well-known and largely black-owned "Avenue of Fashion" area at 7 Mile and Livernois. She said they were in discussion with local business owners about "why design matters to their business" and why they might consider working with professional design services. Given Detroit's designation as a UNESCO City of Design, this was perhaps understandable. But from my vantage point, I couldn't help but to wonder if she was inadvertently asking these small business owners to "whiten" their aesthetic so as to attract more suburban and wealthy customers. She was quick to admit that their organization has had to account for the racialized economic divide in the city, and that there has been tension because of it. But the art professor I spoke with said the questions being asked about economic development are not being informed by the people that live there, namely the city's black population. He didn't hold 
back how he felt about new Detroit: "Since the Second World War, white people have abandoned the city of Detroit and now they want it back."

Detroit's history of racial strife, perhaps more so than any other US city, maps back to the development of its suburbs. As southern blacks migrated to Detroit looking for work (often having been recruited to break white union power), they were forcefully corralled into densely packed neighborhoods such as Black Bottom and Paradise Valley in Central and East Detroit. Under the guise of urban renewal, these neighborhoods were completely razed to build the I-375 and I-75 freeways through downtown (Sugrue 1996). Those same freeways allowed white people access to the central city while also allowing them to travel at high speeds right past the increasingly devastating experiences of Detroit's inner city black population. Needless to say, Detroit's largely white suburbs and largely black inner city have never had a very good opinion of the other, although only one of them was justified in their disdain. When I lived there, suburban white people rarely suppressed their contempt for the city; even as I child, I remember implicitly understanding that "the city" really meant "the black city."

So I had some personal context about the relationship between the city and its suburbs; I was keen to ask about how that relationship has shifted given the emergence of new Detroit. After one maker told me that suburban people had been coming into the city to because they want to support Detroit, I asked her if she found that to be a new thing: "Yeah," she said with a bit of a laugh, "because people in the suburbs were scared to come down here for so long." Another maker who, in a similar conversation, was lamenting the type of producer that puts "Made in Detroit" on goods that are actually made in suburbs, told me that someone living outside of Detroit saying they're from 
Detroit is dishonest. I asked her why she felt that way: "City services are spotty, and..." She paused for a minute and her tone changed: "shit's just harder here, it's just so much harder." She said that all of her neighbors get broken into all the time - the only reason her house hadn't is because her and her boyfriend have two terrifying dogs. She said there are things she never had to worry about while she was growing up in the suburbs:

Not leaving any type of bag in my vehicle because it's gonna get broken into, not having streetlights on my street although we do now which is cool. And there's just things that you have to think about here that you don't have to think about outside of the city so I just don't think it's fair to tell somebody that you're from Detroit and you're from the suburbs. You like already changing their frame of reference for like who you are and it's like lying in my opinion.

The suggestion here is that white, affluent suburbanites have the luxury of benefiting from the positive attributes of the suburbs (in this case, safety) while also being able to claim association with Detroit once it had become "cool." In other words, suburban Detroiters could benefit from the Detroit imaginary once it was convenient; but hundreds of thousands of black Detroiters never had such options available to them. She didn't really buy the fact that Detroit's suburbs had bought into Detroit's resurgence, however. She said people in other cities might be rooting for Detroit, but in her mind, while some suburbanites had begun apprehensively exploring (central) Detroit, many others still saw the city as a "shit hole."

In an interview with some furniture makers, I asked about the city/suburb relationship. They were all laughing before I finished the question, and one said I could spend the rest of my life reading about the relationship between Detroit and its suburbs. 
He gave the example of Grosse Pointe, which apparently put up a shed to store their snow removal equipment across the street from the border of Detroit as a sort of middle finger to Detroit's struggles (Detroit has famously not been able to plow their streets in the past). This maker said that all the side streets between East Detroit and Grosse Pointe Park are blocked off or become one-way streets going into (not out of) Detroit. "They just can't let it go," said another maker referring to suburbanites' collective disdain for the city. He said that people still cringe when he tells them he works in Detroit. I asked the group if things have gotten better recently, and the first maker scoffed and said that L. Brooks Patterson - the current and longtime County Executive of Oakland County - is a "racist motherfucker" that had once said (directly quoting the maker) "we should round up all the Indians and build a fence around the city and give out small pox blankets." The rest of the group chimed in: "By the way this is current!" Another said, "this isn't in 1952, it's right now!"

The group said they've never seen the level of interest in Detroit so high from suburbanites. They said it is very trendy to come down to neighborhoods like Corktown and Midtown to eat and shop. But not all suburbanites are looking for trendy, hipster spaces. One of the makers told me that the same people that cringe when he tells them he works in Detroit are those who get "triple 7 fever" and spend long nights at the city's casinos. Other suburbanites just come to the city for the sporting events but treat the area poorly, throwing trash anywhere, getting drunk and relieving themselves on the street. Detroiters, they say, have a lot of anger over this: "[suburbanites] would never do these things at home in Shelby Township." Another maker in a different interview saw the city/suburb relationship in the same way, telling me "people come in from the burbs, they 
go downtown, they go to the new stadium, and they make sure they never have to go through Highland Park." Yet another maker described a dinner with suburban friends in which she felt that her and her husband were being treated like safari animals - her friends asked her where they park and whether they stop for gas at night. Somebody else at the dinner told her that the problem with Detroit was that there's no community, at which point the maker became defensive and called out what she believed was obvious racism.

Throughout this section, the double bind that makers are in should be coming into focus: while they see in greater detail the racial and economic inequalities that have plagued the city for decades, they generally have to target the (white) suburbs because that's where the money is (see chapter 4 for more on the conundrums of pricing/marketing). One maker told me that they market to suburban (likely liberal and white) women who will pay more for a quality good that is handmade: ${ }^{29}$ "it is all made here in Detroit and we're using better materials and we pay all of our ladies a livable wage. So that all factors into our higher price point." Things get more complex when we consider the benefits that Detroit's white makers accumulate from "new" Detroit; their whiteness is an added benefit when they have to target suburban white consumers (although I should note that the maker quoted in this paragraph is black, as are all of her employees), if for no other reason than the fact that many of them grew up in suburbs and have a certain amount of cultural capital that can be mobilized.

\footnotetext{
${ }^{29}$ The company only hires at-risk women, which is something liberal suburbanites are attracted to about this particular company
} 


\section{Made in Detroit?}

I had guessed that the city/suburb tension would really manifest in the question of who gets to put "Made in Detroit" on their product. I asked most makers how they felt about suburban makers putting "Made in Detroit" on their goods. "That's a tricky question isn't it?" one maker coyly replied after letting out a long sigh. She does almost all of her work in Detroit but does not live there:

“As someone who's lived in the suburbs most of her life, I could absolutely understand why someone who lived in the city of Detroit would have an issue with someone in the suburbs using that term. And then I know people in the suburbs that say 'all of metro Detroit is Detroit; we're all Detroiters.' I don't know if that issue - does that happen in other cities or not?" Me (on the phone, in Portland): "Here it does, but I think the context is different, you know?"

The "context" I was getting at was the fact that Detroit has perhaps the most racially tense and historically problematic city/suburb relationships in the US. Another suburban maker I spoke with was somewhat defensive about not being able to access the Detroit's new "coolness" in service of her brand, saying people give her a lot of flak for referencing Detroit on her labeling: "Right now I'm on 10 Mile; 8 Mile is Detroit. So I'm not proper. Gimme a break, you know? This is our city. I love that city, I worked downtown."

The makers that live and work in Detroit were generally annoyed by suburban makers using "Detroit" to their advantage. One Detroit maker said that when she is asked where her goods are made, she gives the actual crossroads and neighborhood so there's is no question it is made in Detroit. She told me she had an investor that offered to move 
her production facility to a suburban location, but she turned the offer down in order to stay in Detroit. A jewelry maker told me that suburban opportunists have quickly realized that Detroit has an increasingly desirable brand:

The challenging thing is with Detroit and, you know getting a lot more popularity, you know, having be a sort of 'comeback city' you get a lot of companies in and around Detroit trying to make Detroit their thing [...] you get t-shirt companies are saying 'oh yeah we're a Detroit brand' but their stuff isn't being made in Detroit they're being made in the suburbs or elsewhere. They're not making an effort to actually be involved in a part of the city, they're trying to jump on Detroit and make a quick buck or make a brand around it. And so, the harder thing about that is they are generally producing cheaper products that, you know, sometimes people want them, other times its just another crappy t-shirt. And with that it's really hard for these really authentic Detroit brands to really differentiate themselves in a sense or really get people to spend that extra $\$ 25, \$ 40$ on something that is actually affecting the Detroit community.

A good percentage of Detroit's makers were upset by the notion that suburban makers were capitalizing on Detroit's name without actually doing anything to contribute to Detroit's revitalization. One maker said that maybe the suburbs aren't "actively shitting on Detroit per se" but suburban makers should do something to contribute. "Put your money where your mouth is," she said. "You want the benefits of the city but all you see the city as is a drain, you know, throw the blankets over 8 Mile kind of thing? Then no [they should not be able to use 'Made in Detroit']." She said in order to use "Made in 
Detroit" as a branding function, they should "come here, put your feet on the ground here, spend your lunch money here, network within the city."

She went on to say that while 'Made in Detroit' is "not cool" for makers outside the city to use, it was "way less cool" to buy t-shirts in China and print "Made in Detroit" on them: "and I will name names" - she became pretty intense - "because fuck them." (She did name names. I, however, cannot name names.) She said of makers in moneyed suburbs like West Bloomfield that claim their goods are made in Detroit: "Fuck you." But for makers in more working class and close-in suburbs like Ferndale or Allen Park: "meh, you might get a pass, which is not cool of me I guess, but that's how I feel." However much she hated suburban makers abusing Detroit's stature, "I would take all of metro Detroit can say Made in Detroit over designed here, made elsewhere and putting a Detroit logo on it, or the Detroit branding." She went on to describe a friend that designs a product in a suburban studio, has them produced in Mexico, then brands them as 'Made in Detroit.' The maker said she was livid with her friend for putting 'Made in Detroit' on them when they weren't even made in the United States.

I asked her if Made in Michigan would be better for suburban makers. She said she has used it before for a product that they couldn't get completely made in Detroit; only one element was made in the suburbs, but she was unwilling to put 'Made in Detroit' on it as a result. She said everything else her business makes is completely made in Detroit, and she knows how difficult that really is to maintain, especially when so many people just screen print "Detroit" on something - candles, t-shirts, whatever - and sell it to someone that thinks they are supporting Detroit. Another maker was similarly bothered by the exploitation of the nascent consumer desire to support Detroit: 
I think that there's the perception that you're operating a business that accrues some economic benefit to a disenfranchised and socioeconomically depressed locality that your not actually accruing to the people, and that's what's objectionable to me.

He said that in a sprawling city like Houston, the borders are relatively porous so it's more difficult to distinguish the cultural details that would dictate where Houston really ends (just relying on a political map, we had already discussed by that point, was too simple). But in Detroit, he said, there really is a physical divide between haves and havenots. And if makers are not doing something to benefit the have-nots, most Detroit makers agree that 'Made in Detroit' should be off the proverbial table for them.

While most makers agreed that not contributing to Detroit's betterment while hijacking its imaginary was unethical, some also felt like suburban makers didn't have to put up with the stresses of being located in Detroit. I asked a home accessories maker if suburban makers should be able to access the 'made in Detroit' brand:

Maker: Absolutely not. But they do it. But really until they deal with these tax rates and with the crime and the security issues and with the auto insurance costs, hell no. That's not OK.

Steve: So it's disingenuous?

Maker: Absolutely. And they're not doing anything for the city. They're not helping in any way. They're not contributing and they're not going through the same experience we're going through.

Another maker put it this way: 
I have a problem with it [...] because I grew up in the suburbs and my life in the suburbs is nothing like my life here; it's just not reality. They're very different places [...] I'm not cool with it because your quality of life in the suburbs is so much higher than it is in the city.

Detroit's makers often talked about the buildings they worked in as being old and troubled; the group of furniture makers told me their old building had partially collapsed. They also mentioned a friend that had their equipment stolen because of the shoddy building they were working in was accessible from the street.

Some of Detroit's makers were a little more forgiving. One maker told me that makers should "just be transparent." She said that context matters to consumers: making something in San Francisco is different than making something in Oakland, and consumers should know exactly how and where something is made. Her advice to suburban makers was to use "Made in metro Detroit." Others, while still not being entirely amenable to it, can at least understand why suburban makers would want to use Made in Detroit rather than "Made in Birmingham" or "Made in Sterling Heights." Detroit has a recognizable name and a story, the arc of which most people are somewhat familiar with. For the most part, however, Detroit's makers were intolerant of suburbanites swooping in just at the moment Detroit's national reputation finally turns a corner; where was suburban interest in Detroit's public imaginary when the city was being called the nation's "murder capital"? Most makers insisted that the relationship between the city and suburbs is not improving, either. A couple of them cited a 2016 ballot initiative that would have provided funding for a tri-county transit system; the bill failed largely because voters in predominantly white and affluent suburbs (Macomb and 
Oakland) voted against it, apparently not willing to pay for a transit system that would have benefited people of color in the urban counties (Wayne and Washtenaw; both counties voted in favor of the millage). Most makers took this to be a sign that while suburbanites are more willing to explore (and in some cases exploit) the city, they don't want Detroiters to have access to the suburbs.

\section{Made How, and in Which Detroit?}

'Made in Detroit' suggests a static Detroit, a somewhat comprehensive imaginary open to all. Without a disseminated or common sense about what Detroit is (or what it has been through), the brand would likely not be very attractive to makers, because no one would be on the other end to consume it. But as the above tension between the city and the suburbs demonstrates, there is much to work out about what 'Made in Detroit' means. Even setting the suburbs to the side, a singular Detroit that can be reduced to the 'Made in Detroit' tagline does not emerge. There is notable tension within the city itself, mainly between the (at least) two Detroits that some makers referred to as the "tale of two cities" - downtown and the neighborhoods. The immediate downtown area, often referred to as the "7.2," largely encapsulates new Detroit; it is hip, under construction, and increasingly well-educated and white. If you say "the neighborhoods" anywhere in Detroit, however, people know you are referring to the outer neighborhoods, mainly north and west of I-75 and east of I-375, that are still largely representative of whatever version of "old" Detroit one chooses to conjure. The neighborhoods themselves are dynamic - there's no one "type" of neighborhood, but they are predominantly singlefamily detached housing, well above national averages in poverty metrics, and 
overwhelmingly black. Some neighborhoods are colorful and quaint, some are ho-hum working class, and others are devastated. Some are mostly just overgrown fields.

I had heard about some maker-like projects going into some of the neighborhoods, most notably a makerspace being built in Brightmoor (an historically troubled neighborhood in northwest Detroit). I asked a jewelry maker that was located nearby the neighborhood, and she confirmed its existence along with a handful of other makerspace-style co-working spaces that have emerged in the outer neighborhoods. She seemed unmoved by this trend, however; I asked why, and she told me that there's nothing around them, nowhere to get lunch, no grocery stores. She said that it's great to see some new places to help the entrepreneurial-minded to get their ventures off the ground, but the real problem is infrastructural. She wasn't convinced that the maker movement was what these neighborhoods really need.

An art professor pointed out that makers were drawn to the warehouses and industrial spaces just outside of central Detroit; in contrast, the neighborhoods didn't make a lot of sense for them. In the central city there is increased competition for space, he said, especially as large landowners such as the Illitches consolidate their land. But for artists, there are still interstitial spaces in various parts of the neighborhoods, "off the map" places where "nobody is there to stop you." Banglatown in northeastern Detroit is one example: he said the housing stock is "just for shit" but that artists, gardeners, and some makers have become rooted in the largely Asian neighborhood. Of course, large foundations such as Kresge and ArtPlace have perked up regarding the area, and those with enough cultural capital to navigate the grantwriting process have been able to access funding. So the likely debates have commenced there as well - how to fend off 
developers and other signs of gentrification (one of which might be said to be makerfriendly shops). What would 'Made in Detroit' mean to the large Bangladeshi community in the neighborhood?

Even the most culturally astute makers acknowledged they were stumped about how to facilitate equitable change in the neighborhoods. More often, however, they were uninterested in getting wrapped up in the well-tread conversation - often elevated past hyperbole in media outlets - that Detroit's makers were somehow going to save the city. They were generally in accord that they never asked for such attention and that the burdens associated with it were unwelcome and unfair. Referring to the way a popular media outlet had approached an interview with her, a clothing maker told me that she was tired of being assigned responsibility rather than just be allowed to run a business:

It's really hard to answer the question 'so what does it feel like to be a part of the resurgence of Detroit' [...] Hell yeah people are marketing their companies as Made in Detroit, like we talked about why Shinola came here. [...] For a lot of us this wasn't a marketing decision, it was just like we want to do what we want to do. We're not some do-gooders that were like we're gonna make my city better, we were like 'I wonder if I can make a small business work' and we're not assholes, and so does that help our city? Maybe, but were not out here like everyday saying 'we've got to make our city a better place.' [...] It puts us in this weird spot [...] I don't know, I don't wanna feel like that.

As mentioned earlier in this chapter, Tom Karsotis chose to locate Shinola in Detroit because of the magnetic appeal that 'Made in Detroit' had with focus groups. Regardless of whether makers want to "save" Detroit or not, there is a consumer appetite for makers 
that at least give the impression that they want to save Detroit. And the way to the heart of consumers seems to be through a romanticized version of work, namely manufacturing. It is a form of work that Americans have witnessed get exported across the world; at the same time, a class of mindful (and often affluent) consumers has developed a desire to connect on an emotional level with the objects they consume in everyday life. As a word, manufacturing means more than a form of work: in its orbit is also the desire of American consumers to be back in touch with something they feel they have lost, namely the imaginary that equates being American with being hardworking, entrepreneurial, bootstrapping, commercial, gritty, blue-collar, and so on. In the US, Detroit is essentially synonymous with manufacturing, and thus also synonymous with the laundry list of "Americanisms" above. 'Made in Detroit' is a tight and neat package that most consumers can connect with; to many of Detroit's makers, regardless of why they began "making," this relationship between Detroit and manufacturing is unavoidable. An accessories maker, when asked why Detroit's position with consumers was suddenly so magnetic, put it like this:

Detroit has a reputation for producing things in America. I think it's as simple as that. Over a very long period of time. I don't know if that's always been associated with quality, but it's been associated with American manufacturing. In one interview, which was serendipitously crashed by three other makers, a long conversation about this topic revealed how some of Detroit's makers see Shinola capturing this consumer desire. None of them were accusatory; the tenor of the conversation felt more honest and maybe even a bit reverent of Shinola's branding strategy. We were talking about how things get stuck to the collective imagination, even 
at a global level: one of the makers had been at a convention in Germany in which German maker companies - sponsored by the German government no less - were capitalizing on Germany's reputation for high quality and precision. This maker said that Detroit's imaginary is easily more desirable: "When you hear 'Made in Detroit' its like American, gritty, hard work. [...] I think that's what Shinola is. They're not selling watches, they're selling America, its soul of its 20th Century economy."

That remark, I remember, made me shift back in my seat. For better or worse, Shinola was selling the soul of the American $20^{\text {th }}$ Century in a city that had been both the "Arsenal of Democracy" and the "Murder Capital of the US" during that time. The conversation began to circulate around definitions and "stopping rules" - as confusing as "making" is, what is manufacturing? Who gets to claim that their good is manufactured in Detroit, if that is indeed what "making" is intended to convey? One maker said it's mainly about what a firm can get their consumer base to believe; she brought up a friend that makes bicycles for Shinola but she's in Minnesota. Even if the bicycles say 'Made in Minnesota' (I have no idea if they do), Shinola has so commandingly applied the 'Made in Detroit' brand to their company name that people just imagine everything being manufactured in Detroit. Not everyone in Detroit is OK with this: I asked the group about an activist poster I had seen around the city that accuses Shinola products of being "Made in Switzerland and sold in Detroit." We talked about how to define what a maker is allowed to import, what the line between assembly and manufacturing is, and who gets to make the call. One maker reminded me that the Federal Trade Commission has a say; they famously came down on Shinola for improperly using "Built in Detroit" and "Made 
in America" taglines in their branding. ${ }^{30}$ The issue has been that Shinola imports its movements from Switzerland - watch movements, by many accounts, are virtually impossible to not import - and then hand assembling the watches in Detroit. I toured this operation, and it looked a lot like manufacturing.

But the whole point of the conversation was: how does a definition for 'Made in Detroit' actually satisfy all the requirements, both for 'made' as well as 'Detroit'? What should the stopping rule be for 'Detroit'? The gentrified, 7.2-mile urban core? The outer neighborhoods (that aren't seeing a lot of benefit from the maker economy)? The suburbs (that actually are seeing benefits)? What about the stopping rules for 'made'? Is “assembling" really different from manufacturing? After all, wasn't Detroit's chief addition to modern manufacturing the assembly line? Was this not manufacturing? Is this not what Shinola is doing? One maker in our conversation sarcastically asked about whether makers should have to mine their own resources or make their own machinery. At what point, we all began to mull over, do the definitions orbiting 'Made in Detroit' become more arbitrary than objective? Is it even desirable - or possible - that they ever become objective? If they don't - that is, without the ability to measure via hard and fast definitions - what does an "equitable" or "ethical" economy really look like?

The group conversation eventually meandered into why makers want to make goods using old processes that require antique machines that are so old and expensive and hard to maintain that no one would reasonably build them today. These are niche machines, machines with no real market, machines that end up in museums as one maker

\footnotetext{
${ }^{30}$ See: https://www.freep.com/story/money/business/2016/06/17/shinola-alteringmarketing-claims-after-ftc-rebuke/86044878/
} 
put it. Yet people collect them, and makers want to revitalize their use values. The overall conclusion arrived at by the group of makers was that people want to experience these machines; such experience had everything to do with how these machines made makers and consumers feel. This feeling likely had something to do with another feeling: the feeling that the world is changing so rapidly, given the constant barrage of new iPhones and social media posts, that a common reaction has become the desire to look to history, akin to Benjamin's angel contemplating his backward-facing trajectory into the future while flailing around in an effort to piece together what has been lost. As such, "Made in Detroit" profits from this nostalgic retrospective, and makers have a pathway from which they can tap into the value(s) created by it. The problem with this is that those values, as they are tied to this nostalgic view of Detroit, are dependent on the history of racial exclusion that has run throughout this chapter and which is not being substantively addressed in the "comeback" of Detroit.

\subsection{CONCLUSION}

This chapter takes as its central concern the relationship between makers and the urban imaginary of Detroit. At its core, this chapter considers the significant tensions that have emerged from this relationship as the neighborhoods around central Detroit (the socalled "7.2") have started to rapidly develop. I demonstrate that in the course of this development, Detroit's popular imaginary has undergone a shift from a "dying" city to a "resurgent" city. Central to this chapter is the understanding, amongst makers, of this shift as an emerging dual narrative of "New Detroit" and "Old Detroit." In the chapter, I discuss makers' perceptions of each version of Detroit: makers understood "Old Detroit" to be a place of experimentation, and they described a sense of freedom at that time 
(roughly the years just before and after the Great Recession). That freedom, I argue, was complicated by a collective sense of responsibility to the city's disadvantaged: the racist legacy of Detroit was always lurking behind makers' responses to questions about the city. They were often blunt about it, in some cases notably aware that the proto-American tropes of individualism and innovation they were so prone to slipping into were based on racial exclusion and class domination.

"New Detroit" was a manifestly different place for most makers, epitomized by central Detroit's stratospheric post-bankruptcy development. It was seen as a case study in the tensions of gentrification, as the central city was increasingly white, educated, and funded by a handful of billionaires - particularly Dan Gilbert - that were getting unwarranted tax breaks and yet being painted as heroes in the popular imaginary. But makers were also clearly conflicted with their place in what New Detroit was becoming. For example, they were able to access larger and wealthier consumer bases as suburban whites began to consume the new imaginary of Detroit: New Detroit was imagined as safe and creative, and thus suburban whites began to shop in the city again; Old Detroit was scary and violent, an imaginary that had kept suburban whites (and their money) away. The racial coding of New and Old was clear to makers, and it disturbed them; yet they couldn't help but to acknowledge the benefits New Detroit presented for them.

In chapters 3 and 4, I showed how the "made" side of the "Made in Place" equation yields significant tensions emergent from the messiness of identity and value. Detroit's example shows how this is no less true of the "place" side of the equation: amidst its shifting public imaginary, how does "Detroit" become coherent? As I show in this chapter, the way "Detroit" is imagined - and how that imagination is operationalized 
- is at stake: the city's "new" imaginary can be mobilized to great effect for makers, as is especially evident in the use of "Made in Detroit" branding as well as the use of Detroit in maker firms' name (e.g. Detroit Coffee, Detroit Granola, etc.). Such mobilizations rely on New Detroit's public imaginary, which makers clearly have a hand in shaping; this is particularly true of Shinola, Detroit's most omnipresent, embedded, and sometimes controversial maker firm. But my evidence from this chapter shows that makers are deeply conflicted about exploiting the city's "new" imaginary for their own benefit, because it excludes most of the city's black and poor residents. One maker, for example, told me that she had recently removed Detroit from her company's name: 'I've just been sensitive about calling Detroit mine because it's not mine," she exclaimed during our interview. But I also show in the chapter how the city's urban/suburban relations, which are historically fraught with racist exclusions, further complicate the use of "Detroit" as a brand. In fact, few things angered Detroit's makers more than suburban makers accessing Detroit's imaginary to their brand's benefit. The supposition is that using "Detroit" is far more political than "Made in Detroit" branding makes it appear to be; the word "Detroit" is similar to "maker" or "value" in the sense that it cannot be easily defined.

Perhaps Detroit's indeterminacy can best be captured by returning to the term impasse, or "what it feels like to be in the middle of a shift" (Berlant 2011; 198). Importantly, I found that the impasse between "Old" and "New" Detroit introduced substantial dilemmas for makers regarding their use (and construction) of Detroit's imaginary: makers want an active city, but they also want a just city; they don't want to be associated with the "saving the city" narrative, yet they don't want to stand by and watch the city be actively destroyed by racism and gentrification; they want better access 
to markets, but they feel conflicted about exploiting a city imaginary that excludes the city's most vulnerable residents. There was incredible tension in the sense that the changing city was both better and worse for makers: on one hand, Detroit's new imaginary of resurgence and creativity granted them the consumer bases they needed to survive as a business. On the other, this new imaginary did almost nothing for the people that needed it the most. On one hand, Detroit was becoming walkable in places and space was being "activated" (I heard this term a lot). On the other, the experiment was over; like so many other cities, it was on to gentrification and uniformity.

My central conclusion from the Detroit case is simple: many of Detroit's makers appeared to benefit in some way from the city's changes, but collectively they didn't feel good about it. They ended up stuck in a place where they had to exploit the city's "comeback" narrative while harboring feelings of resentment about how development is actually occurring and who is (and is not) benefiting. To make matters worse, New Detroit was reproducing the race- and class-based urban/suburban divides within the city limits. I was struck by a collective sense of frustration and even melancholia, a sense that something was disappearing and makers were struggling with how to re-gather their grasp on it. Some makers felt that the opportunity to create something unusual and more just had slipped away as Old Detroit succumbed to New Detroit. In New Detroit, makers could not afford to be experimental; they had to be productive, efficient, and strategic, and one of the best options to do these things was to become reliant on the city's problematic comeback story. As one maker put it: "I just don’t think that this was the way we thought it was gonna change." 
This chapter illustrates the role an urban imaginary plays in the social, economic, and cultural worlds of a specific milieu, and the way that urban imaginary maps history onto ordinary practices. At the center of the chapter is a set of unmistakable tensions embedded in the transformation from Old Detroit to New Detroit. It is instructive that Old and New Detroit aren't actually real places per se, even if their boundaries are commonly understood. The invocation of New and Old Detroit, however, is evocative of one way that makers (and others) imagine the city in its current state of flux; "new" and "old" are the poles between which this flux exists. I don't have sufficient evidence to suggest that this dueling narrative exists outside of the maker milieu, but it is interesting that Detroit is not the only place it was evident: "new" and "old" were just as prominent in describing makers' collective imagination about Portland. 


\section{CHAPTER 6: MAKING PORTLAND}

In this chapter, I continue to query the relationship between makers and the city they produce in. Of continuing importance in this chapter is the role of the urban imaginary - this time of Portland, OR - and the way this imaginary structures the aspirations and value systems of Portland's makers. This chapter's arc is as follows: first, I discuss the emergence of the "Portland Dream" and the relationship it has to the imagined rift between "Old" and "New" Portland. Next, I examine the specific characteristics that have drawn makers to Portland and why those characteristics are juxtapositional to other places. Finally, I examine three specific imaginaries related to the emergence of the maker milieu in Portland; these imaginaries all share the problem of being disrupted by the city's imagined shift from Old to New Portland. In the process of analyzing the third imaginary - Portland's community imaginary - I argue that at the root of these imaginaries are a set of aspirations that makers ascribe to in order to ground themselves amidst Portland's larger urban transformations.

In the penultimate section, my interviewees refer to Portland as "growing up." As such, the city is entering a phase in its existence that threatens the maker milieu and the perceived authenticities that it draws on. As was the case in Detroit, makers in Portland see both opportunity and hazard from the approach of "New" Portland. The aspirational values that makers hold dear suggest a need to anchor themselves to the ways of living and working that attracted them to Portland in the first place. Aspirations are a form of optimism, but they are also a form of coping with the anxieties of a changing place: how do makers make sense of "Portland" when the Portland imaginary is crumbling around 
them, ${ }^{31}$ and when the ostensible authenticity of the city is jeopardized by urban development? What does awakening from the "Portland Dream" mean for makers?

\subsection{THE PORTLAND DREAM}

If the precursor to the emergence of Detroit's maker milieu was a collective imagination of death (and "post-death"), the Portland imaginary of the past decade or so is that of a dreamworld (cf. Buck-Morss 1995). In fact, during the course of the three years Charles Heying and I were researching Portland's "artisanal economy" (Heying 2010), we were contacted by a number of researchers looking to query this urban dream. One set of editors from the UK asked Heying to draw up a set of "best practices" for cities attempting to design or cultivate their own version of the Portland experience; we responded by publishing a chapter in their book about the impossibility of distilling a set of best practices for the Portland experience (Marotta et al. 2018). Another set of researchers from Virginia invited Heying and I to sit on a panel at Pacific Northwest College of Art to discuss the "Portland Dream" (their words) with a group of makers and local politicians. Perhaps unsurprisingly, the 40-page profile these researchers had constructed leading up to the panel determined Portland's "spiritual heart" to be its "local, sustainable, DIY ethos."32 They had sought out Heying because of his work on Portland's artisan economy, which the Virginia team considered to be the exemplar of the "Portland Dream" and its ethos.

\footnotetext{
${ }^{31}$ Credit for the wording of this question to Greg Schrock

${ }^{32}$ Source: an email sent from the researchers to Charles Heying and I in 2015.
} 


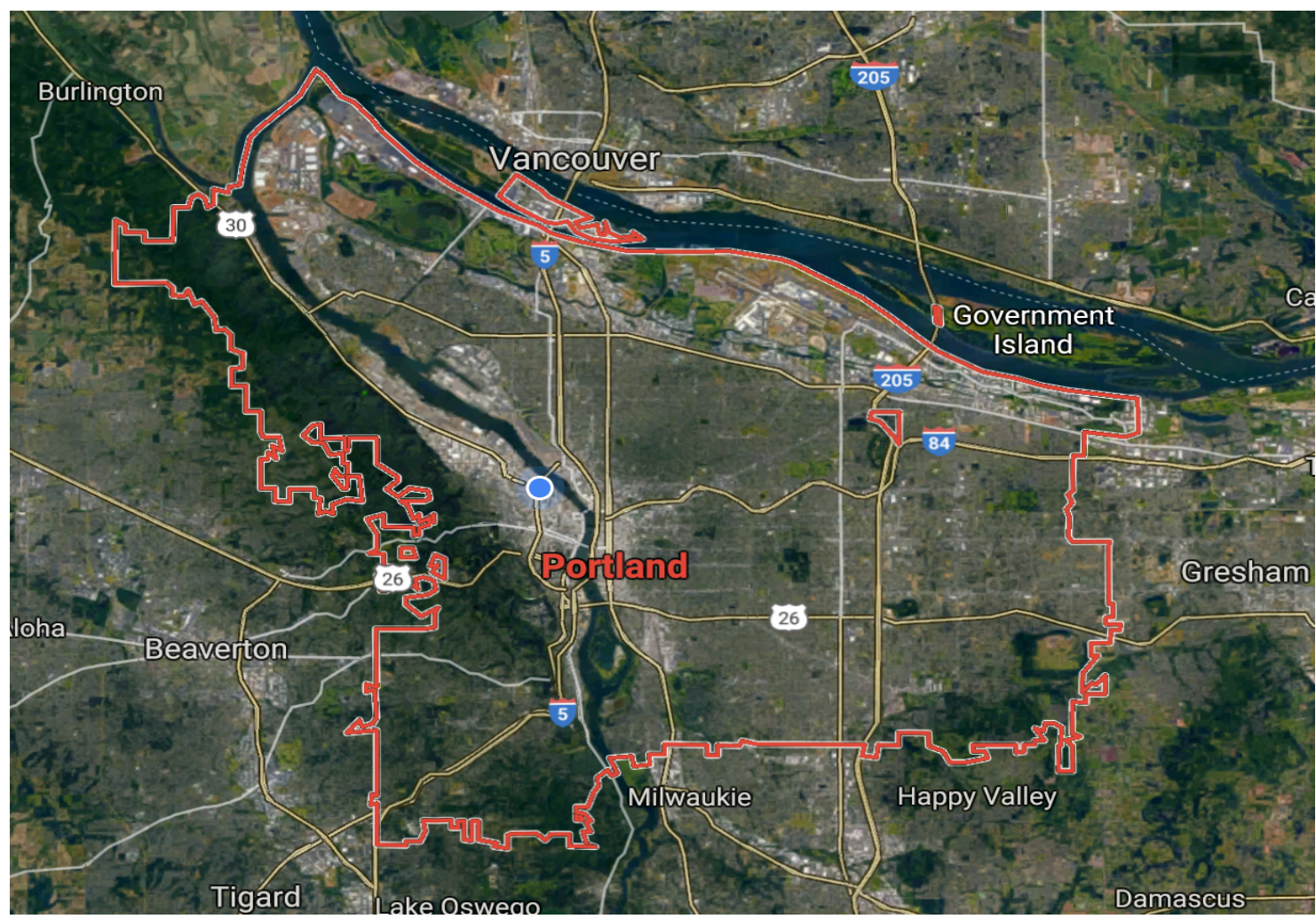

Figure 13 (above): Portland and its immediate suburbs

Figure 14 (below): Portland's central neighborhoods, (credit: Portland.gov)

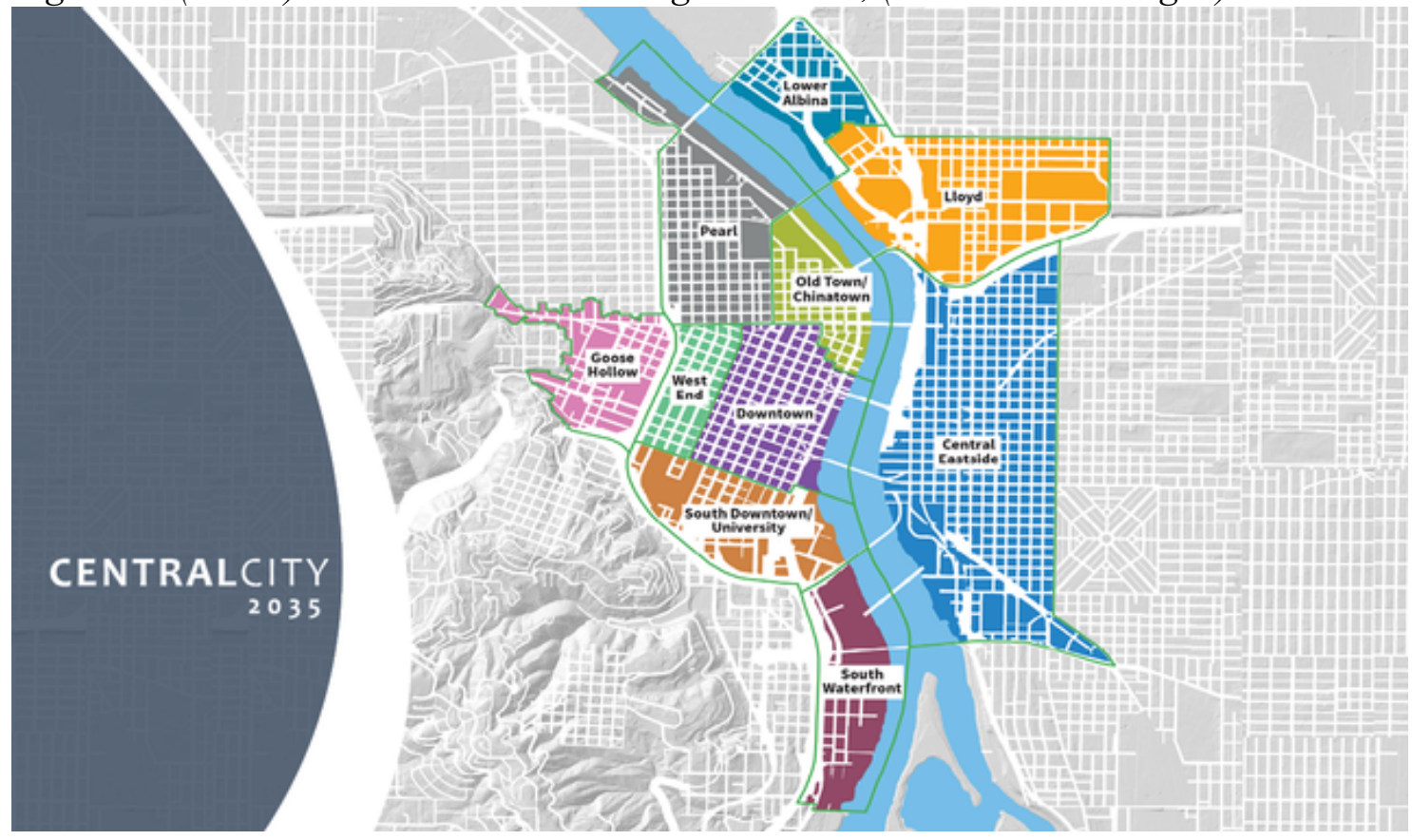



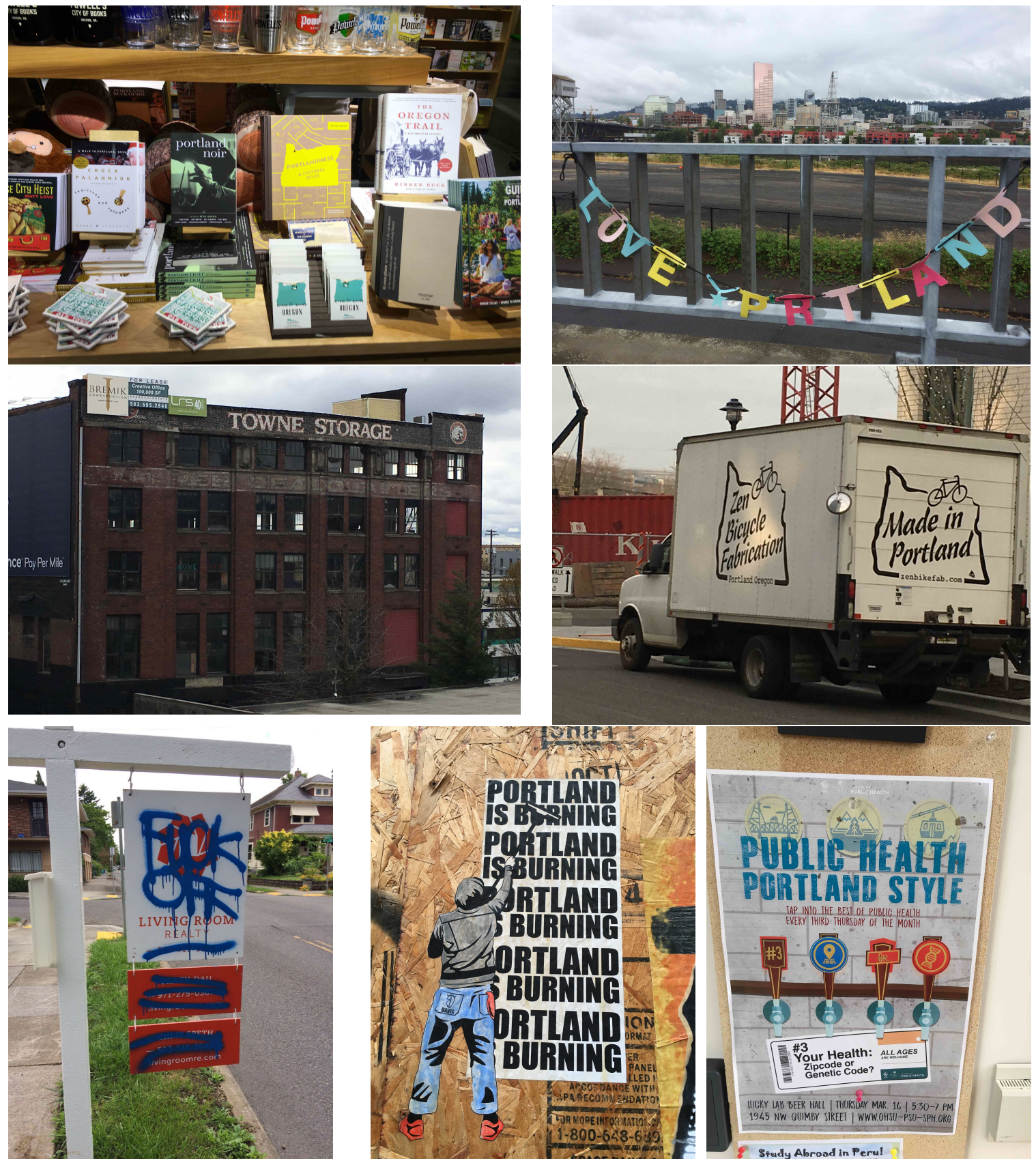

Clockwise from top left: (Figure 15) Maker-style gifts celebrating Portland at Powell's Books; (Figure 16) A "Love Portland" decoration (artist unknown); (Figure 17) a bicycle maker truck emphasizing "Made in Portland"; (Figure 18) an advert for a public health seminar "Portland style" (note the hallmarks of the Portland imaginary); (Figure 19) an art installation capturing the growing tensions of "New Portland"; (Figure 20) a graffiti-laden real estate sign, also showing pushback against "New Portland"; (Figure 21) the Towne Storage building shortly after its sale in 2015. All photos by author. 
At the time, this ethos had some real gravity to it. In maker circles, there was a strong belief that locally and ethically produced goods were more than a trend, and that a number of ingredients - including Portland's increasingly recognizable nature-abundant, small business-friendly, DIY imaginary - had aggregated into something of a gestalt that makers could tap into. In our work with makers, Dr. Heying and I could often sense the excitability between makers in their group dynamics, like they were thrilled to have stumbled upon something big.

The epitome of this collective feeling was a meeting that Dr. Heying and I observed in 2014 at a local makerspace. A prominent angel investor, a representative from an incubator, a branding consultant, and a few entrepreneurial makers (one of which owned the makerspace) rounded out the attendance. The ostensible purpose of the meeting was to discuss the financial viability and soft launch of a local branding collective, but the conversation repeatedly returned to the visibility of Portland as a brand that could be "brought to the world." While occasionally touching base with the concrete realities of jobs and economic impact, the conversation largely orbited the "Portland ethic" and the dream that the outside world had been having about Portland as a utopia for creatives and makers (it bears mentioning that at this point, the TV show Portlandia had reached peak popularity).

Dr. Heying and I were overwhelmed by the competing uses of "local" mobilized by the meeting's attendees. We quickly realized that the word itself was almost impossible to capture with a definition (Marotta \& Heying 2018). But the meeting had also painted Portland as a place in flux: the attendees casually used the terms "New" and "Old" Portland without any clarification as to what was new and what was old. The 
notion of new and old Portland resonated for the same reason "local" had: there was no effort to define new or old, likely because there was no need to do so: anyone that spent at least some of their time in central Portland would have the means to imagine what these terms meant. In other words, Portland's changes were palpable, and "New Portland" was more of a feeling than a definitive place or thing. No one at the meeting responded with "what do you mean, New and Old Portland?" There was no sentiment that resembled: "Portland is not changing so much as to require a 'new' before its name." Everyone understood what Old and New Portland meant, or at least they had some context with which to appraise it as a form of truth. In my notes from the meeting, I wrote down a verbatim question posed by one of the attendees: "what are the values of New Portland versus those of Old Portland?" The attempt to attach values to the imaginaries of old and new heightened my sense that something significant was at stake; the group seemed to have the collective sense that the transition from old to new presented both a threat and an opportunity.

In analyzing the Portland and Detroit cases, the amount of emotional weight the words "new" and "old" carried consistently surprised me. In the meeting described above, the words even become magnetized to a code of ethics; the person that asked the question about values was looking to identify what exactly was shifting in the ongoing transition between old and new. The insinuation is that makers are entangled in an unfolding "situation" (Berlant 2011), an ongoing process in which decisions or adjustments might be made within the maker milieu that will shape urban life outside of it. Furthermore, I don't imagine the question about values was a question isolated to the work makers are trying to do. Rather, it struck me as a bigger question about the 
relationship between a changing city and the people that are trying to create livelihoods within it. That's why the question about values resonated: "what are the values" is to say, “what type of person does 'New Portland' make us?" while at the same time asking, “what Portland have we made?" Or put differently: “How does 'newness' reshape our collective identities, our collective imagination of Portland as a place, our collective responsibilities for making the city something meaningful, and what sense of control can we derive from it? And what have we lost in the process?"

Such questions suggest the aspirational character of the values that makers either see as evocative of New Portland or in turmoil as a result of New Portland. As Portland changes, makers find themselves in a double bind: they feel changed by the changing city, yet they are a part of this change. They tend to be ambivalent at best by whatever New Portland is, but in many ways they exemplify it. As I will show below, this tension elicits a host of aspirations - to autonomy, creativity, community, authenticity - that makers use to ground themselves amidst the changes to the city and the maker milieu. These traits become objects of desire as they are perceived to be disappearing (Benjamin 1968). This is what I mean by aspirational: while these characteristics of Portland have become tethered to the city's global imaginary (Marotta et al. 2016), they function as continuities between the old and the new. Such "wish images" (Benjamin 1999) resuscitate the utopian impulses of the past for the sake of imagining a future in which those failed impulses are reconciled. In the case of makers, there is a clear desire to overcome the ethical conundrums of the recent past (e.g. the fetishization of production; see chapter 4) while also appealing to the utopian ideals stored in the urban form of 
places like Portland's Central Eastside Industrial District or the "passing fashions" (ibid, 5) like those we see in various forms of identification in the maker milieu.

"Each epoch dreams the one to follow": In The Arcades Project, Benjamin (1999) underscores the thread that sutures the past to the future, a dream that excavates the unfulfilled ideals of the past in coping with the anxieties of the future. In this chapter, I hope to assert the importance of the imagination on the shape that "Portland" (or anywhere) takes: makers use particular imaginaries to ground themselves in moments of flux such as those wrapped up in the transition from "Old" Portland to "New" Portland. My data reveals, among makers, a sense of being dragged along into New Portland, but also a sense that makers are shaping New Portland. Such ambivalence is perhaps why this liminal time and space in Portland was so often referred to as a "dream" (including the Portlandia theme song, which incidentally also conjures the broader collective "slacker" dream from the 1990s). Dreams are an interesting metaphor in that they are both within and beyond the control of the dreamer. Dreams are also temporary; they end in awakening. For Benjamin, awakening had to do with a social break from the repetition of innovative technologies that reify class domination. In Portland, awakening has to do with confronting the end of a fantasy by aspiring to prolong the conditions of the dream. I don't mean to accuse makers of a sort of mystification here, however: I understand these aspirations as a form of optimism that works as an anchor within the context of shifting conditions (Berlant 2011).

\section{Juxtaposing Portland}

While it is outside the scope of this research to analyze why Portland came to be imagined as creative, collaborative, and obsessed with all things local, many of our 
interviewees were attracted to Portland by the promise of finding these things to be true of the city upon their arrival. That is also to say that many of our interviewees were inmigrants to the city, with most arriving in the late 2000s or early 2010s. Portland's emigration stands in juxtaposition to what I saw in Detroit. In Detroit, makers were more likely to have returned to the city after living somewhere else (e.g. New York) or else they had recently moved to Detroit from the city's suburbs. In Portland's case, makers emigrated oftentimes from far away, and oftentimes simply because they wanted to live in Portland (one maker literally said, "I came to Portland to be in Portland.") Methodologically, it seems important to interrogate what drew so many makers to Portland, especially since many of them arrived with a collective identity for the city already sketched out in their imaginations.

The makers that had been in Portland the longest came for the cheap rents, or so the story went. One maker described the $\$ 1 /$ square foot room that he worked out of on Alberta Street in the mid-2000s, a rent currently unimaginable anywhere on Alberta Street. Everything about his set up was informal: he shared the space with other makers in what he called an "incubator scenario" in which they all had the time and space to develop their businesses. The comparatively low rents (especially to San Francisco) in Portland in the mid-2000s created what another maker called a "huge wave of Etsy folks" that saw Portland as a place where craftiness and creativity were percolating. He said that Etsy - which, for the uninitiated, is a massive online craft market - allowed makers to live wherever they wanted and meant that they didn't have to peddle their goods as hard, thereby providing something of an infrastructure for the maker movement in Portland. A duo of craft store owners agreed; the low cost of living meant that "making" could be 
one's "main gig," a virtual impossibility in a city like New York where high rents require full time professional jobs.

Most makers agreed that Portland drew artistic or creative types of people at that time. A pair of accessories makers referred to Portland as the place where creative people emigrate, equating the city in the mid-2000s to what NYC was to the beat generation. I asked a maker that was originally from San Francisco if Portland felt "creative" to her when she arrived in the mid-2000s. While I asked, I posed to her the possibility that Portland had come to be imagined as creative because of an inflow of low-rent seeking artists that had been gentrified out of San Francisco. She smirked at the possibility and confirmed that her own attraction had to do with Portland being a progressive West Coast city with comparatively low rents. But she said artists had also been arriving from smaller, more rural places like Humboldt (CA) and Ashland (OR) looking for big-city amenities and culture as well as the credibility that comes along with making art in a big city, all in an affordable package. Circling back, she concluded that California's skyrocketing housing prices did, however, have an outsized role in Portland's rapid growth: "I think that if California wasn't there, I don't think as many people would have ended up here. I think the Bay Area (inaudible) pushed people out. That's how I felt." It was apparent that many makers new to Portland had already been looking to leave the place they were, which in many cases was California. One maker said she had hit a dead end in the college town she was living in; Portland appealed to her because it was a place she could run her business (she said the move was " $54 \%$ about her business"), but it also signified a better social life for her. Another pair of makers said they were tired of living and working in Los Angeles for "what we were getting out of 
it." And yet another Bay Area native said that he had been "exploring" and traveling "aimlessly," but eventually decided it made more sense to be a starving artist in Portland than in the Bay Area. This maker added that he had heard that maker culture was strong in Portland, and wanted to develop a business idea ahead of his move. Getting to Portland was the goal for him; he just needed to figure out what he would be making once he got there. A maker from Los Angeles, who had a skilled design job there, also said his plan was to move to Portland before he knew what he'd do once he arrived. He said he and his partner visited the city and were attracted to the culture in Portland. When they arrived in the city, he said they felt a sense of belonging to the community of makers that they were looking to belong to; the ability to say their products are made in Portland gave him a sense of pride. Indeed, they had found what they were looking for.

As the last example shows, makers often came to Portland in search of something that their previous location couldn't offer. For them, Portland has come to represent a way of living and working that other cities cannot support. Things incoming makers desire include, among others, walkable communities in an urban setting, quirky neighborhoods, "refined" tastes for food and drink, and a slow, deliberate pace of living. These attributes all describe Portland's imaginary, to be sure; Portland is so often described in a variety of ways that gesture toward its community-oriented, coffeeobsessed, craft/DIY/creative-friendly, nature-surrounded form of urbanism. But what I found described Portland's imaginary just as much was the way Portland was juxtaposed to other places; I began to think about such descriptions as "anti-values" or "againstnesses." Portland was described as culturally laid back and anti-corporate, for example, which was often juxtaposed to San Francisco's fast-paced, venture capitalist 
culture. Another common juxtaposition was between Portland and China; Portland's perceived preference for all things local was, in such cases, juxtaposed to China's representative position in the structure of globalization (see next paragraph). These juxtapositions all end up as part of the "Made in Portland" narrative: if something is made in Portland, it has captured within it a part of the Portland imaginary. The rest of this section turns to examples of how these juxtapositions are imagined by Portland's makers and the milieu that supports them; this collective imagination is an important part of the scaffolding for what "Made in Portland" means to makers and consumers.

In describing Portland, makers often invoked places where they have either been disappointed or just don't identify with the public imaginary of that place. For example, one maker told us that she couldn't do what she does elsewhere by juxtaposing Portland to Phoenix: "I don't know if people in Phoenix will have the same values as me." Another maker told us that she had chosen Portland because she saw it as a place where her and her partner could "change their hairdo." She described Atlanta (her previous city) as a competitive and closed-in place in which she had learned to be protective. A third maker juxtaposed Portland's laid-back culture to the high-paced and work-oriented culture of San Francisco:

I would say it's a very San Francisco thing and it's not a very Portland thing. Which is culturally to say, 'I'm in business, what do you guys do?' You know, 'what's going on in your world?' And in Portland it's more like, 'what's your barbeque like?'

At one point in my analysis I was so taken by my interviewees' descriptions of Portland vis-à-vis other cities that I began counting them (San Francisco was the clear winner as 
Portland's "other," with 8 unprovoked mentions in the Portland interviews; Japan and China came in second and third, respectively). One maker said flatly: “[Portland]'s not Silicon Valley." Geographically speaking, this is obviously true; the emphasis, of course, is on what differentiates one from the other in how each is imagined (i.e. Silicon Valley is competitive and professional, Portland is neither of those things).

One maker, originally from the Midwest, came to the Northwest looking for a "down-to-earth, coffee-loving, grungy vibe" and found that Portland had more of those attributes than any other city. Apart from its laid-back and coffee-obsessed atmosphere, she described Portland as a better place for the creative or craft economy than SoHo (NYC) or San Francisco, both places she considered to be "over-commercialized" shopping malls that at this point just sell junk to tourists. The catch is that many tourists agree, and they - like makers - are looking for something more authentic. As Portland's public imaginary has expanded, so has the amount of tourists looking for the same form of urbanism as makers. "New" Portland certainly has tourist-focused shops, but these shops typically eschew the "crap junk from China" (maker's words) in favor of Portlandarea artists and makers that made their crafts locally. These shops rely heavily on themes that people associate with Portland - bikes, sasquatches, bridges - and capitalize on "Made in Portland" branding. One of the shop owners told us that Portland's newcomers and tourists get excited about things being made in Portland; it adds value to the things themselves.

An accessories maker that travels a lot for his day job ruminated on Portland's attractiveness by crediting the press the city got in the late 2000 s and early 2010 s, especially on the east coast. He told us that when he travels, the people he talks to 
imagine Portland as a "cool" place, a beautiful city surrounded by natural beauty where there are a lot of creative people and a casual lifestyle. He also said he and his wife sometimes encounter "culinary tourists," people that literally fly in to Portland just to eat at the restaurants. Another maker, building on the Portland-as-a-foodtopia theme, insisted that "everyone knows Portland food and restaurants." She described a burgeoning culture on Instagram in which a handful of Portland food photographers have used the "dinner party aesthetic" and Portland's foodie reputation to attract hundreds of thousands of followers around the world. Food is an example of Portland's artisanship, she claimed; it's one of the symbols that have become stuck to the city's imaginary, along with bikes, beer, natural and organic products, and so on. More than a few makers concurred: if a maker produces a good that can be related to one of these categories, consumers tend to confer a higher degree of expertise upon the maker. In other words, people outside of Portland assume that Portland's makers are both authentic and skillful if they make bikes, beer, food, etc., especially if makers use the "proper" aesthetic (see: Marotta et al. 2016). Makers have come to understand the advantages that flow to them because of Portland's visibility outside the city. In other words, Portland's imaginary has economic benefits. As a result, attaching "Portland" to the name of their enterprise (Portland Apron, Portland Razor, Portland Bee Balm, etc.) allows makers to access this imaginary and embed its more attractive components into their goods, all in a neat package that makers' consumers quickly identify with. One maker said a particular challenge in running a new enterprise is the limited opportunities for communication with consumers. He told me that he knew that if he called his product "Portland [product]," the name would communicate something to consumers that he wanted them to know. The advantage to 
him is that he wouldn't need to explain these "soft" aspects of his products to stores that carry his goods:

That definitely is the part of my brand that I'm using and relying on especially as we go outside of the northwest. It's like 'Hey it's Portland [product] - what you associate with Portland - I think - is exactly what I want you to associate with my brand.

A different maker said that calling his company "Portland [product]" was a business decision: he told us he knew that "Portland in general has a good brand for hand crafted goods" and he wanted outsiders to associate his product with the city's reputation. Being new to Portland, he said he quickly felt accepted by the small business community; this made him feel that he was authentically representing Portland.

In many ways, it appears makers and consumers are having the same dream; many makers have moved to Portland in order to find it, while consumers and tourists look for the dream embedded within the goods they buy. As I argued above, this "Portland dream" is juxtapositional: it expresses a form of collective imagination that ponders a way of living and working than is better than elsewhere, but is also understood as what it is based on the perceived shortcomings of those elsewheres. As we have seen (and will see below), people feel worn out or let down by their lives in other places. They have felt pushed out of cities like New York and San Francisco, especially by the inflationary cost of living; they feel social contracts starting to break down (as is the case with Japanese youth below) and want to live in more meaningful or "authentic" ways; or they feel nauseated by the thought of structuring their lives around a corporate or professional existence. These feelings, and the desires to escape them, have come to be 
embodied by places, or more appropriately put for this dissertation, by the imaginaries of places. If Portland is a "dream," that dream is something of a repository for the desire to invert what has been experienced as disappointment elsewhere. In this way, the "Portland dream" is aspirational and optimistic, like a "cluster of promises" for a better world (Berlant 2011). For many of the makers that have sought it out, Portland is imagined as juxtapositional to being let down, exhausted, or insecure.

\subsection{IMAGINING PORTLANDIA}

The next three sections describe three interlocking imaginaries, each of which is a part of the aggregated "Portland" imagined by interviewees. There are other ways to approach these imaginaries: in no way am I trying to define or codify them, rather I mean to describe my data in terms of the collective perceptions of Portland. First, the notion of industrialism is important to makers. There is an urban space - the Central Eastside Industrial District - that is important not just for its physical advantages, but also for the fact that makers feel at home in it; it provides the "atmosphere" that makers desire. Second, I use the case of Japan to describe one particular imaginary of "Portland" and what gives it global visibility. Third is the notion of community; in its multiplicity of iterations (openness, inclusivity, etc.), community was easily the most cited quality amongst makers, especially those that had recently migrated to the city. But "community" is difficult if not impossible to define. In that section, I describe the ways in which makers describe the community they find value in and think through its aspirational aspects. In each case, the changes involved in the transition into "new" Portland play some sort of role; these changes culminate in a final section on authenticity in a changing city. 


\section{Portlandia 1: Industrial Imaginaries}

Portland's public imaginary as a nature-ringed, creative mecca for experimental artists probably has its origins sometime in the 1990s. According to one maker, during the 1990s people started coming to the city to do his or her own thing "with no real objective." He was somewhat critical of the current climate of nostalgia about those "good old days," saying it often glosses over the poverty that lined main thoroughfares such as Sandy Boulevard and the fact that downtown was lifeless. At the time, he knew a building owner in what is today the Pearl District (he said the Pearl District didn't exist back then) that let teenagers run his bar, serve coffee, and host live music in exchange for free rent. That was a reasonable thing to do at the time, he said. People could live in the central city, live 8 to a house (even if the roof was falling in), work as a barista, and be able to afford rent, food, and amenities. That type of lifestyle was attractive for many young people at the time.

This maker, who had also spent some time in San Francisco where he observed a similar "artists colonization" model of urban development (Zukin 1982; Makagon 2010; Deutsche \& Ryan 1984), forwarded a theory based on his experiences:

I have a, I call it my cilium theory of urban development. So cilium is the [...] tendrils of fungus, and it exists on all in everywhere, everywhere in the world. When there is a forest fire, trees fall down it's a mass of destruction. It also creates an immense amount of rot, and all of the green stuff goes away. But the cilium survives underneath the ground, and the cilium [inaudible; sprouts?] immediately, starts to digest everything and it spores out and it spreads and it creates an environment in which plants can grow. And then small plants grow, 
and then bigger plants grow, and then the trees grow, and the trees choke out everything. And eventually you have bare floor, with this huge canopy, and then it burns down again. [...] There's more life at the cusp of changes, so the barren field forest, large wildlife can live in the forest hidden, but they can't find any food, they have to go to the clearances that are created by that and eat the food which is possible because of the destruction. So the same thing you have in San Francisco. San Francisco burned, what, seven times in ten years after its founding. It continuously has these constant, like, build, build, build, oh, economic bubble, crash. Artists move in. And then build up and then, I think actually San Francisco may have actually gotten to old growth stagnation, and it may never burst again, but you have, so Portland's going through a similar thing. You have created all of this great culture, which now people are going, 'oh, actually I could sell this pottery. Oh, Portland's really huge in Japan, I could create an export economy. Oh, this [his product] was fun, it's actually a major industry.'

Oh those makers and their theories of urban development. His theory is strikingly similar to the type of mythos that some academics even adhere to (Currid 2007). More criticallyminded scholars such as Sharon Zukin (1982) have long dispelled the notion that cities are naturally places of cyclical boom and bust in which vulture-like artists feed on the entrails of industry. In Loft Living, Zukin reminds readers that artists didn't occupy SoHo's abandoned industrial spaces just because those spaces were abandoned. Rather, artists were incentivized through policy to occupy abandoned loft spaces, but only after manufacturing in lower Manhattan had been intentionally ended by other policy mechanisms that assumed housing was the "highest and best use" of urban land in 
Manhattan. That is to say that the artist colonization story never began with artists, but rather with power.

A critique of the "artist colonization model" isn't really my objective in quoting this maker's theory, even if it does make for a convenient segue. I am more interested in highlighting the imaginary the maker's theory represents: that creative places emerge from abandoned ones, from places that have been burned down and left to rot; these are "gritty" places where the vestiges of the old pollinate the emergences of the new. In urban folklore, this often means industrial spaces, or at least the urban form left behind after deindustrialization. In Portland, this best describes the Central Eastside Industrial District (CEID), where many makers either are, have been, or wish they were located. The neighborhood is historically Portland's manufacturing district, even though it “deindustrialized before anyone had coined the term" (Abbott 2000; 245). Despite deindustrializing, the urban manufacturing form is largely still intact thanks to the 1980 Comprehensive Plan that made the neighborhood an industrial sanctuary.

Our research showed that makers are drawn to this neighborhood. In the first place, makers referred to a number of buildings in the CEID that housed many different small maker firms. One pair of makers rattled off half a dozen such buildings in the CEID by name, from the Thompson Building to Portland Storage to Oregon Brass Works. They said they were constantly hearing of new buildings full of maker businesses, and that even in the mid-2000s they doubted there were enough makers to fill a building. These buildings, they said, were full of "like-minded businesses" that were also very diverse (photographers, painters, designers, makers of all sorts of things). Another maker described his business when it was at full capacity (it was defunct at the time of our 
interview) as being in a CEID building in which one floor was "all makers." Being in the CEID was good for his business, because his supply chain was more or less localized to the neighborhood: they could go down the street to get their tools fixed or purchase odds and ends for the business; "all the little bits and pieces that you need" were available without ordering them from Amazon, and he was willing to pay extra for the convenience of proximity. Given that makers produce material goods (i.e. not apps or software), shipping is a concern for them. The older buildings of the CEID have loading docks, and the CEID's central city location means quick access to the area's freeways. Moreover, these buildings were originally built for manufacturing, so they are already equipped with the important internal infrastructure that many maker businesses need, such as the proper electrical outlets.

But as one group of makers was quick to point out, the advantages of locating in the CEID are just as important culturally as they are materially and spatially. These makers said they were uninterested in the lifestyle that accommodates being away from the central city. Other industrial locations - Swan Island, Northwest Industrial, the vast industrial zones by the airport and in the western suburbs - do not offer their employees the possibility of walking to work or going across the street for a beer after work. A ceramics maker told me she loves the CEID for the fact that she can walk everywhere and that the neighborhood is very vibrant. Another maker argued that his CEID location was "critically important" to his business, even going as far as to say that he (and likely half his team) would quit the business before they moved out to the suburbs: "I guess I just don't like the suburbs, period." He reflected that being in the CEID makes him feel closer to the history of the place, and that the city represents individuality for him while the 
suburbs are all the same. He said the suburbs go against everything his company stands for, and that it would be hard to be authentic in the suburbs. The manager of a makerspace told us that if they were ever forced to relocate out of the CEID they would lose the "industrial flavor" that they identify with. All this is to say that the CEID feels like a manufacturing zone to makers; it has an "affective atmosphere" (Anderson 2009) that makers feel a sense of belonging and attachment to.

In fact, a food maker told us that while the CEID has attracted a number of other makers that are complimentary to her business, what she likes about the CEID being "surrounded by different creative types" and that she wants "to be where the cool kids are." The proximity to other makers is key for collaboration and problem solving, even if they all end up vying for the same spaces:

Yeah, we are all competing for the same space so that's kind of a bummer. But on the same side, because their business model is so different than ours, they're going to view things differently than we are. So if we've got a problem, and we go to our neighbor bitching about how we can't find someone to [work on their product] or this, that, and the other thing, they're going to have a completely different perspective on it than we are. That's how we figure out creative solutions to problems that we face sometimes is to get input and advice from people that are in a completely different stratosphere as us, because they see it so differently.

But things don't stay the same - the CEID is no exception. As was the case in Zukin's New York City, changes in policy have introduced new dynamics to the area that assume industrial production is no longer the "highest and best use" of urban land in the CEID. 
There are two basic zoning designations in the CEID - general industrial (IG) and heavy industrial (IH). There are also two types of general industrial zones (IG1 and IG2), which designate areas for industry to locate while regulating their appearance and their use ("Industrial Land Bulletin", page 3). Most of the CEID is zoned IG1, but zoning in the CEID is complicated by "overlays," an additional zoning layer superimposed onto a zoned area that either preserves or utilizes the specific characteristics of an area to a specific end (historical preservation, for example; “ABCs of Land Use Workshop”, 2012). While there are sprinklings of other zoning codes utilized in the CEID, an overlay called an Employment Opportunity Subarea (EOS) has been introduced to produce "flexibility" within the district. Created in 2006, the EOS gives planners the ability to approve more office and retail space in an IG1 zone than normally would be allowed (Industrial Land Bulletin, page 3); the stated goal of the EOS is to modify the IG1 zone to include the provision of "opportunities for a broad and diverse mix of employment uses that are compatible with industrial activities and that build on the economic strengths, locational advantages and urban character of the Central Eastside" (“Title 33", 2010).

Across my interviews, makers' awareness to changes in the CEID was intensifying. Their experience with the changes to policy was colored by an imagination of what was going to unfold - the CEID would become a paradise for tech companies attracted to the red brick aesthetic and proximity to a number of neighborhoods chock full of the types of restaurants, bars, and shops that their employees would desire. A pair of makers located in the heart of the CEID admitted (in 2015) that they were starting to feel threatened by encroachment of tech companies, especially as the cost of manufacturing space started to swell. They complained that they had spent 9 months looking for a 
building with the right electrical connections, high ceilings, and other "flourishes" that would be built into a building designed for manufacturing. Tech companies, they said, would just renovate these things out of the building. Another maker said that his move from the CEID to another part of the city was necessitated by the influx of tech companies. He said space in Southeast Portland was already limited and competitive, but when he was looking for a building to expand into, he found himself competing with tech companies from San Francisco that would bid 20\% over asking. He was quite disenchanted, saying that brewers and creative office space have replaced manufacturing in the CEID.

A bellwether moment came in the summer of 2015 while Greg Schrock and I were interviewing a maker on the seventh floor of an old and repurposed storage building. The wall to our north was mainly made up of large windows, and a panorama of the CEID opened outside. We had just asked the maker if he had gotten involved in the development of Southeast Quadrant Plan; the maker responded that he hadn't (the most common response), but he gestured out the window toward the Towne Storage Building to the north. He told us rumors had been circulating that the building - home to over 500 makers, artists, and other small businesses at the time - had just been bought by an investor from California even though the building wasn't on the market. The offer was apparently so high that the owner couldn't refuse it. As it turned out, the building was sold and converted into the Portland HQ for California-based tech company Autodesk; 
the 500 makers and artists were displaced, ${ }^{33}$ setting off a series of panicked alternative media articles wondering if Portland's new "Gilded Age" was going to destroy the city's creative culture (McCann 2016; Staff 2015; Wile 2015). An article from June of 2018 entitled "The Towne Storage Building, Former Low-Rent Creative Mecca, Went Full San Francisco" no less - drives home the antipathy of the changes that Towne Storage's sale and conversion represent to makers:

The result of the upgrade is, not surprisingly, an exercise in hardcore tech office porn: sexy dark and light woods, accented by brick with occasional splashes of brightly colored paint. The aesthetic is a clash of old and new, with paint and writing from some of the old tenants still preserved on the brick walls (Willbur 2018).

That the author uses the term "clash" to juxtapose the old and new suggests that old and new don't mix as well as Autodesk's aestheticians might think. Walter Benjamin (1999) might call it a phantasmagoria, a concept used in the nineteenth century to describe a collection of things that induce illusion and fantasy. The fantasy, in this case, is the notion that Autodesk is somehow preserving the industrial past by converting the old into a decoration for the new.

I asked a jewelry maker who'd been in the CEID since 2008 whether staying in the neighborhood was important to her:

I don't know. It used to be. [...] I get to walk to work and I really like the neighborhood, I like feeling more industrial and a little more undone. Like I'm in

\footnotetext{
33 See: https://www.oregonlive.com/business/index.ssf/2015/09/sale_of_towne_storage_building .html
} 
a studio space with a dozen other makers and you know there's brands all around me that I have, like making space. And I like being part of that. But, I think the biggest attraction for me was that space was so cheap, and a lot of the jewelry suppliers, like if I needed something last minute, the diamond district was right on the other side of the Morrison Bridge and so I could walk there. And so when I think about this neighborhood getting more and more expensive, which it absolutely is, I don't think the tradeoffs are really, I don't think the benefits outweigh the cost. I think it's ending. And it's kind of a shame because I think that's why Portland has so much of, like, that maker topic is because it's been so inexpensive. And you can be so central and not spend a whole lot of money. But as it changes and it's like well I might be looking like more in North Portland or far east Portland in order to find something that's affordable or even a suburb.

And, yeah, it loses some of its charm.

The dream has been disrupted, but isn't it always? Richard Lloyd (2006b) uses the term "structural nostalgia" to describe the sense that places with a mystique to them are always already over. With this in mind, when the maker above says "I think it's ending" about the CEID, she doesn't really mean the CEID is itself ending; the evidence, in fact, would describe a CEID that everyone wants to be a part of where demand dramatically outstrips supply and zoning policies are doing their best to adapt. What "it's ending" means for her is that the CEID is becoming a place of disappointment; her imagination of the CEID and what it was in the past will always fall short of what it is in the present. Lloyd says this is true of any "bohemia" - bohemian places can never, in reality, stack up to what they are in the imagination. 
Over the past 4 years, makers and their advocates have turned to the rally cry of "affordable manufacturing space" in order to preserve the CEID space that they so cherish. There is a real need for this, and there has been a rather robust effort to figure out how to best preserve affordable industrial space, not the least of which was an urban manufacturing survey that I was a research assistant for. But one wonders if it's the ability to manufacture close to the city that makers want to preserve. There are decided physical advantages, as I have described above, for manufacturers to be close to the center city. But it seems just as likely that makers would rather preserve the culture, the milieu, the feel of the CEID; the excitement that they were on to something in their enterprises was based on the attachments that they felt to that place. Those attachments are threatened by the dramatic rise in cost of space; such is the entanglement of the economic and the emotional for makers in the CEID.

\section{Portlandia 2: International Imaginaries}

Go back, for a moment, to the lengthy quote at the beginning of the last section: after theorizing urban development (for Urban Planning folk, no less), the maker casually mentions Portland being "really huge" in Japan. Many makers understand this to be the case, and my research experience suggests there is indeed some sort of "Portland" fantasy occurring in Japan. While doing research in Portland between 2014 and 2017, Dr. Heying and I met with at least three different research teams from Japan. These teams were often trying to understand Portland's je ne sais quoi for their own research in Japan. It was around that time that PDC (now Prosper Portland) began sponsoring trips to Tokyo for Portland's makers, which they called "Pop Up PDX" and essentially amounted to a traveling craft market comprised entirely of Portland makers. Additionally, a number of 
articles have appeared in Portland's local news media ${ }^{34}$ trying to understand Japan's "obsession" with Portland. ${ }^{35}$ The author of one article travelled to Tokyo for his story, rattling off the Portland references he came across: a handful of Northwest-themed brewpubs, including one called the PDX taproom that serves Portland-made beer; an exact replica of Portland's Multnomah Whiskey Library called the Tokyo Whiskey Library (complete with wooden trusses and wall-mounted taxidermy); a cafe called Burn Side Street Cafe; a pair of Portland donut shops (soon expanding to a total of 17!); teenagers drinking Heart Coffee; and a boot shop called Stumptown Boots \& Recrafting (Korfhage 2017).

The author argues that Portland has come to represent a dream for Tokyo's young and hip residents; the constituent elements of that dream are slowness, kindness, community, freshness, and nature. As the story goes, young Japanese people are uninterested in being told what to do or how to do it, and have become attached to the Portland dream because they see Portland as liberated from corporate control, from the oppression of uniformed and common style, and from the alienation of living in a global megacity. Portland's imaginary of craft, localness, community, and progressiveness outline this Japanese dream of Portland.

\footnotetext{
${ }^{34}$ See: https://www.wweek.com/we-went-to-japan/; https://www.pdxmonthly.com/articles/2017/4/17/japan-loves-all-things-portland-thisosaka-pop-up-fair-showcases-the-best; https://portlandtribune.com/but/239-news/307979186012-japan-cant-get-enough-pdx for a couple examples

${ }^{35}$ In the comments sections of the online version of the Willamette Week article, there was some pushback from Americans living in Tokyo about how "obsessed" the Japanese really are with Portland; is it an obsession or a niche market in the world's largest city? 3,000 people did show up to a festival called "Feel Portland," but that's an incredibly small contingent of a city of over 30 million. Personally, I find the list of Portlandthemed shops and goods compelling; what other global city recognizes Portland in any way at all, other than to reproduce its model of coffee, beer, bikes, and nature?
} 
Realizing this was an opportunity to query Portland's urban imaginary as it is understood outside the US, I met with some people familiar with the Japan-Portlandmaker conduit to attempt to better understand why Japanese young people found Portland to be so aspirational. Indeed, the response I got was that young Japanese had increasingly begun to reject the lives that their parents led and expected them to lead. The assumption in Japan is that young people will move to Tokyo, attend university, and eventually work in a corporate environment. But according to my interviewees, many young Japanese were looking for alternatives to the corporate economy that they watched clobber their parents and the industrial economy that they perceived to be in decline. According to one of my interviewees, a Japanese woman working in Portland, young people in Japan tended to see "making" and DIY as a coping strategy or an escape from what they perceived to be the threat of an over-managed adult life. Another interviewee (from the same meeting), told me this:

After 15 years living in Japan I could see their economic bubble bursting and lifetime employment and social contracts kinda breaking down over there and still a really regimented sort of work culture. People were gonna need, even if it wasn't like maker culture, here [in Portland] there's clean air, there's water, there's closeness to nature, you can get out. And it's a chill, cool place to be and I just saw that this is going to resonate $-\mathrm{I}$ always thought it would resonate - with the Japanese.

I asked the first interviewee what she thought the primary ingredients of Portland's popularity in Japan were. She told me that meaning and authenticity were two things that 
come up all the time in her visits to Japan; these are the things young Japanese yearn for. The second interviewee concurred, pointing to their consumption patterns as evidence: Japanese are still very much conspicuous consumers but they're not looking for Gucci and Coach the way the Chinese are. They're looking for Danner, they're looking for something handmade, unique, certainly more rugged; they want to show that they're, to themselves as well as others, that they're in touch with nature in a way, whether it's leather goods or boots or something that at least gives an impression - and not high heels, or alligator you know (laughing). They want to be able to go off into the woods [...] They want the best, but it has to be earthier.

The pair shared a Power Point presentation with me that they use when they travel to Japan. To my amazement, the presentation essentially charts the entire emergence of Portland's imaginary in Japan: from the Portland-bound flights that Japanese tourists had available to them starting in the 1990s, to Japan's interest in Portland's nature-soaked urban planning strategies (e.g. the Urban Growth Boundary) during the early 2000s, to the intensifying media coverage that Portland started getting in Tokyo's most trendconscious media in the early 2010s. One presentation slide in particular stood out to me; it was attempting to diagnose the Japanese consumer in regards to what Portland had to offer them. Here is the text from that slide:

Japanese consumers are searching for something meaningful and authentic (bold in original). The promises of lifetime employment and increasing material gain have been challenged by $20+$ years of a tough economy, natural and man-made disasters, and the rise of other Asian nations. While Japan still has the world's 3rd 
largest economy, it has become imperative for many to find a rewarding means to express their independence, creativity and enjoyment of life.

According to the presentation, "Portland's story and unique attributes," are "authenticity, sustainability, a creative lifestyle, and the ability to enjoy life." Perhaps unsurprisingly, it was Portland's maker culture that the presentation credits with bringing these things together. The presentation continues on to show a number of images depicting the "selling" of Portland's lifestyle in cities around Japan, mainly through pop up events featuring larger outdoorsy Portland makers such as Poler and Danner. It concludes the following for its audiences: "You can't really describe what Portland is. You simply need to experience it to understand how all the diverse parts of it fit together."

Despite the fact that the interviewees told me that Portlandia (the TV show) is not translated and no one in Japan watches it, the similarities are unmistakable: Portland is a "livable" and "sustainable" dreamworld, where young people have rejected corporate and conservative culture and have charted out an authentic space of their own surrounded by the pillowy embrace of nature. Those young people have even created their own cultural economy, which in the presentation is represented by a class of makers and designers. It is vital at this point to think through the position of Portland's makers in this narrative: if Japanese young people are increasingly perceiving the social contracts governing their futures in a state of terminal decay, and their method of coping has been (at least in part) to collectively dream of a mythical place full of untouched nature and creative people free to be and do whatever they want, then the reality is that makers are market actors benefiting from this fantasy, even if makers themselves are generally still struggling to make ends meet in a rapidly gentrifying city. What's more, attaching "Made in Portland" 
to a product is clearly a proxy for this set of relations, including the struggles of makers and the gentrification of Portland.

In my interviews, makers themselves did not strike me as consciously exploiting the disillusions that young Japanese have of their country's social breakdowns. The discussions in which this Japanese imaginary of Portland came up went one of two ways: the maker would either respond with a resigned shrug ("yeah I know but I don't understand it") or an incredulous chuckle. In the category of the latter, one maker furrowed her brow and said, "so, we're exporting tight fitting lumberjack clothing to Japan?" Even as we both laughed at the comment, I remember wanting to note the presence of Portland's imaginary even in that statement. As funny as the comment was, the answer was, "yes, we are." And in fact they're buying a lot of it, because it makes them feel like they belong to something that won't disappoint them, even if it's just a fantasy.

One can only wonder how long the dream will last. The article mentioned at the top of this section makes the obvious point that this dream of Portland only features the idyllic side of this city, thus rendering the poverty and "other" lifestyles in the city invisible. "Nobody lives like the people in Kinfolk magazine," read a quote from an Oregon-bred owner of a Tokyo-based coffee shop, making reference to the globally popular hipster-on-steroids and Portland-based magazine Kinfolk. Others point to the ephemeral nature of trends such as this - trends are like dreams in that they are both temporary. 


\section{Portlandia 3: Community Imaginaries}

Throughout the Portland interviews, makers often appealed to a sense of community as a desirable facet of making in Portland. At times, it was hard to tell if makers were talking about community in terms of the local network of makers, or a neighborhood (or groups of neighborhoods), or even the entirety of Portland. But it was often clear that "community" was what many new Portlanders were drawn to in coming to the city. Even makers originally from the Northwest often cited community as a key factor in Portland's quality of life and work. Despite the contextual fuzziness regarding the geographic parameters of this community imaginary, there were some common descriptions of the community that gave it shape to some extent. When discussing community, makers often described a DIY ethos; a sense of quirkiness; an acceptance of amateurism and non-traditional business practices; and a general openness and tolerance for difference. This section will detail some of those descriptions, but it also examines why these descriptions of community values are aspirational.

In the first place, makers generally consider Portland to be a quirky, do-it-yourself (DIY) place. One maker told me that you can make stranger, less market-friendly things if you aren't constantly working to pay bills, as would be the case in more expensive cities like New York. Other makers explained Portland's quirkiness as a sort of permission to make unusual goods. The quote below exemplifies this sentiment:

Then just the sort of general cultural sense, I mean I think even for myself the idea that, yeah, I'm doing this very weird thing hand-building [his product] that don't look like anything that anybody else has done, in my basement. That feels like a reasonable thing to do in Portland. [...] It's something that [his wife] has 
said right from the beginning, there's just a sense here, that yeah, you've got kind of a wacky idea and you're trying to do something unusual, and the universal reaction from anyone you tell it to [locally] is like 'oh, that sounds cool.'” Maker's co-worker: 'Or 'only in Portland,' but supportively.

Permission here is granted not by some authoritative body, but rather by the fact that the community this maker interacts with thinks his wacky ideas "sound cool." In other words, it isn't a permission bestowed upon makers as much as it is an "atmosphere" of consent granted by a community that values quirkiness and a DIY ethos. And while there was a bit of an eye-roll attached to the co-worker's "only in Portland" comment, it functions as an affirmation for the maker that his wacky ideas are "reasonable" in Portland.

Another interviewee (she was not quite a maker, but rather what we called a “maker-enabling entrepreneur" - see: Wolf-powers et al. 2017) thought that the sense of community and DIY culture came from the relationship between Portland's residents and the city's public sector. She said that the city doesn't get in the way so much; if someone wants to do something, she said, the city will say "oh that's cool!" rather than tearing it down. She felt this made Portland unique; she has met with makers and public sector employees in other cities where people have become used to tearing things down, which she juxtaposed to Portland's "hands off" approach. This is why Portland has an "ecosystem" of many players filling small holes, she said, rather than a top-down or more corporate structure of makers, funders, and public sector agencies. She equated DIY with entrepreneurialism: people in Portland do not wait for the public sector to respond to a problem, she said, they do it themselves. And while this fits many neo-Marxist critiques 
of neoliberal restructuring (e.g. Peck 2005; Tickell \& Peck 2002), I find it interesting that makers revert to DIY, quirkiness, and community as affirmations. In other words, these characteristics are aspirational: they are what makers want, even if they are exploitative. There even seems to be something fulfilling about the city taking a hands-off approach while saying "that's cool" to whatever outcomes emerge, even if those outcomes are all tied up in economic and racial displacement.

So the "community" is quirky and DIY, both of which dovetail well with another principal attribute: an antipathy toward professionalism or corporate culture. If something is DIY, the assumption is that it is autonomous and cannot unfold in a predetermined or hierarchical fashion. As I argued in Chapter 3, in general makers are eager to escape corporate structures of work. One maker told me that Portland has become something of a bastion of anti-corporate culture, and makers come to Portland to avoid having to climb the corporate ladder. He said that instead, makers come to Portland to find a way to express themselves while making a living at it. He felt there was a general sense that people are more willing to couch surf, to work odd jobs, to figure things out on the fly. He saw Portland as lacking a "competitive materialism" and felt the community was nonjudgmental. The business atmosphere that he interacted with is casual; no one dresses up for meetings, he assured me. Another maker described this non-professionalism in terms of who is doing what jobs in the city. More traditional jobs, like accounting, are apparently not well-represented - according to her and her partner, they can't find anyone to help them with accounting. At one point in the interview, she exclaimed: "Nobody told me there are no bookkeepers in Portland!" 
There are a handful of expressions that circulate in the maker milieu, one of which captures Portland's amateur-friendly work atmosphere: "fake it until you make it." We heard this expression on a handful of occasions to describe Portland's maker community:

I think at the root of it is just the personality that the city of Portland draws. And for better or worse, it's, I guess you can describe it as people that are willing to fake it until they make it.

"Faking it until you make it" is another way of describing this ostensibly laid-back, nonprofessional, amateur way of working and living. It describes a type of permission in which they are allowed to figure things out, an imaginary in which they grant themselves - through access to and acceptance of the "community" - the capacity to feel experimental, creative, weird, and yet still productive. The maker above followed the quote by saying there is a willingness to accept amateurism in Portland "because it's so prevalent" and that there aren't many "experts" in Portland. Makers are largely after an intimate connection with their work, he said; if it makes them money, that's an added bonus.

The autonomy suggested by DIY, quirkiness, and "faking it" also butts heads with more traditional forms of entrepreneurial activity, especially in terms of funding. Interestingly, this shift is often referenced in juxtapositions between places (and the communities that collectively generate their imaginaries). For example, the paltry funding landscape of Portland was commonly juxtaposed to the high pressure, high stakes landscape of San Francisco. An accessories maker told us about a friend of his that owned a business in Silicon Valley where everyone works 80 hours per week; he said 
Portlanders wouldn't put up with that and that his friend could never run his business in Portland. Of course, the flipside of this example is also true: a few makers described the difficulty of finding funding (e.g. investor capital for "seed rounds") in a city perceived not to have any experts or professionals. A robotics maker told us that that his meetings with funders always ended in disappointment because he had "the three strikes" against him: he didn't have a partner, he was a first time founder, and he was from Portland.

Most of Portland's makers scoff at the idea that they should adhere to the modes of professionalism that would make them attractive to funders. Many see the maker community as an "ecosystem" (as mentioned above) that venture capitalists would just destroy. The competitive energies of this "VC bubble," as one maker put it, are contrary to the openness and cooperation that Portland's makers value so highly. In fact, a handful of makers even used the term "co-opertition" (a portmanteau of cooperation and competition) to emphasize the desire for companies to collaborate rather than to undercut each other. Openness, inclusivity, and cooperation were all words we heard a number of times in descriptions of Portland's maker community. This quote, from a jewelry and furniture maker, is an exemplar: "So yes, there is something distinct about being in Portland, there is something, there's just, I feel like there's this openness here, like we're really open to each other's ideas and interests and open to collaborating." The way this maker talks about this sense of openness is atmospheric: it's "in the air," something that she can feel; collaboration seems to be an outgrowth of this ubiquitous feeling of openness. But why do so many makers share this feeling? What does it have to do with community? 
The answer seems to have much to do with the solitary nature of the work makers do. Despite the constant references to open and collaborative communities, it was a common sentiment for makers to desire more connectivity with one another. As mentioned in chapter 4, a significant number of our 2015 survey respondents were sole proprietors with no employees, and in interviews some makers described the work as isolating. A few makers mentioned being Facebook friends or mutual Instagram followers of other Portland makers that they had never met in person. One maker described maker-entrepreneurial work as "a very introverted thing to do" and that the work "can be lonely." He said that because so many are introverted, they tend to need help in finding a network. A pair of retail storeowners described past feelings of exclusion and insecurity as a major influence for community-oriented design of their shops.

This is all to say that the maker community (and by extension, Portland's broader small business community) is largely comprised of single employee businesses in which the owner is "wearing all the hats" and often struggling to get by. Despite so many appeals to community, openness, and ecosystems, it struck me that maker networks were actually rather fragmented. In working so often alone, makers lack the numerous mundane opportunities for interaction that one would have in more corporate work environments (e.g. so-called water cooler chats or lunches with co-workers). On one hand, it is possible that makers do indeed tend to be introverted and have some disdain for banal encounters at work. On the other hand, many makers cited a major advantage of co-working places and makerspaces as the ability to walk over to someone making something else and ask for help in solving a financial problem or thinking through a 
design. But this, too, struck me as aspirational. We heard as many accounts of such open or communal spaces leading to the problem of "creative borrowing," or the practice of seeing another maker's technique or goods and essentially copying it. One maker, who had created a quintessential "Portland" product (it's related to bikes and beer), told me that helping others out with advice "feels pretty awesome [...] until you start getting copied." He said this "poisons the well" of artisanship and "creates a deep animosity that is hard to forgive." The only defense against this, in an ostensibly open-sourced environment, is a form of cultural shaming or restriction of access (to the community) via the proverbial cold shoulder.

I keep returning to the word "aspirational"; perhaps I can explain why I think that is the appropriate word. There is no doubt an actual community that makers have formed amongst themselves, and they are no doubt involved in other, possibly overlapping communities around Portland, the sum of which constructs a more comprehensive Portland imaginary to some degree. But it is my judgment that the sense of community so often invoked in interviews has more to do with makers' desire for community rather than their actual immersion in them, even if that desire is just to sustain the community that they already feel a sense of belonging to. This desire is intensified by the hyperindividualization of maker businesses, the changing atmosphere of industrial parts of the city (e.g. the CEID), the growing attention Portland gets from outside the city, and the rise of the ICTs (especially social media) that makers turn to in response to feeling fragmented. In other words, community is something makers aspire to because it pushes back against feelings of isolation and the anxieties stemming from the threat of change. The word "community" is vague enough to mean different things to different people, yet 
coherent enough to be collectively imagined. In this way, the extent to which community is actualized is a self-fulfilling prophecy, despite the constant references to the "naturalness" of an ecosystem.

There is something else that I felt the references to community juxtaposed: an intensifying reliance on technology. The maker I quote below felt that the emergence of the maker movement was, in fact, "a reaction against technology":

You know, everything so technological, you know it's like you stare at an iPhone all day and you can get almost everything you need from this, except personal interaction. And I think that as makers, I don't know I always thought I'd be fine working by myself in the shop and I can come in here and be very efficient and get my work done, but when I work these contracted jobs [with a local contractor of makers], for me it's like social hour. I mean I'm there to work, they're contracting me to do a job, but I'm like, I just want to be around fellow people that are working with their hands, solving problems, figuring out how to get stuff done.

In this quote we see a reference to the isolation of working alone. The maker says that he "always thought [he'd] be fine" working in isolation, but suggested that in reality, doing it every day can be lonely. That's why he desires the "social hour" of contract work with other makers. What is interesting is the connection he makes between isolating work and technology. While he's unclear about what he might be doing on his iPhone all day, I assume he is referring to online consumer interactions (ordering, shipping, feedback) and the obligatory daily updates to his Instagram and Twitter accounts, all of which he does in the same solitude that he makes his product in. The quote continues: 
What's going on in Portland, it's not technological based, it's community based. You've got the technological advancements that are helping small business like Instagram or whatever, but you still can't beat walking down the street and knocking on another colleague's door and having a conversation about 'how would you design this? I'm having troubles making this, what would you suggest?'

In chapter 4, I discussed the importance of social media as a form of connection between makers. But social media also creates a double bind for makers: on one hand, makers need it to develop their (branded) identities, and they need a way to transmit their value propositions to consumers. As chapter 4 hopefully makes clear, this reliance on social media is not indulgent or frivolous; it is necessary for makers to survive in the modern economy. But on the other hand, those identities and value propositions often rely on tactility, tangibility, and human-level contact - the opposite of Internet-based communications. As the above quote shows, makers often talked about having (or wanting) the ability to walk next door and ask their maker neighbors questions about design.

Community, then, compensates for their inability to break away from technology; community is juxtapositional to technology. In the second part of the quote ("what's going on in Portland"), the maker attributes community to Portland; this is critical evidence that relates this section to makers' collective imagination of "Portland." Despite saying that working alone is harder than he had thought and that the necessary immersion in technology has caused a reaction against technology, he maintains that Portland's maker milieu is based in community. My argument here is that all of these descriptors of 
Portland - the DIY/quirkiness, the anti-professionalism, the rebellion against technology - are aspirational. They may or may not be true: it strikes me that they all may be parttrue and part-fantasy. What matters is the aspirational character of all of it. These aspects are all part of how Portland is imagined, and this imagination is conditioned by what makers want Portland to be, regardless of how it is.

\section{“New" Portland And Authenticity}

As was the case with the changing CEID above, the question of why this sense of community is so aspirational to makers might be answered in the context of the intensifying development Portland has seen over the past decade. Citywide, residents have become attuned to the atmosphere of anxiety that is emerging alongside so much development: there has been a 60\% increase in rents since 2010 (Njus 2017), a "housing emergency" (Theen 2015) that has seen homelessness increase 10\% since 2015 (Harbarger 2017), and a collective mood shift away from the aforementioned urban imaginary of quirkiness - captured somewhat ironically by the television show "Portlandia" - and toward an uncertain imaginary of no-one-knows-what. Residents' collective attunement has been additionally stirred by nonstop coverage in the local media where weekly articles on the city's changes range from "deal with it" (Hurst 2015; Monahan 2017) to "Portland is over" (Staff 2015).

Many of the interviews I conducted either by myself or with the Kauffman team occurred during what I would consider the peak of this confluence of skyrocketing rents, increased (and increasingly visible) homelessness, and significant media attention. Similar to Detroit, the sense of loss that I felt in talking about "new" Portland was palpable: the imaginary of Portland as a charming, quirky, communitarian place seemed 
to be slipping away. By some accounts, makers and artists had become tired of what one bicycle maker called the "Portland bubble." A retail shop owner told us that her Facebook feed has been increasingly littered with messages from artists and makers saying they are leaving Portland. Her partner chimed in and said that what had made Portland different was the low cost of living and the density of underground artists. But the conversation in the artist community now, he said, is centered on how much longer Portland can sustain the community - the pressure to work a lot more, professionalize, and generally make more money was forcing the hands of the city's artists.

Unsurprisingly, a lot of the turmoil was associated with rising costs. A jewelry maker told me that her rent was going up 20\% in the next year, and that increase had been a compromise: the landlord had originally posted a 50\% increase before the tenants collectively negotiated the spike downward. She said she doesn't have an 'exact threshold" for when to leave the city, but that she is "reaching the tipping point." She had been in the city for longer than many of the makers I spoke with, so I asked her how she had seen the city change. Her response was to think back to 2008, when she was living in a one-bedroom apartment a block away from Powell's bookstore for $\$ 550 /$ month, a sum unthinkable for a one-bedroom apartment anywhere west of $82^{\text {nd }}$ Avenue in 2018. Rising costs are displacing suppliers as well; a glass maker told us that he used to be able to get all the supplies he needed in the Pearl District, but rising costs had forced those shops to close down or flee to the suburbs. A pair of craft storeowners told us that they were losing vendors (makers) that couldn't afford to stay in Portland. They rattled off a few places that makers had started to relocate to - Astoria (OR), Milwaukie (OR), and San 
Antonio - and said that makers were about to start scattering, especially after the sale of the Towne Storage Building, where many of their vendors were located.

Outside of affordability, there was a general concern about what the increased visibility of the maker and craft scene in Portland would mean for both the scene and the city. The storeowners above expressed significant concern about the changes to the maker milieu in terms of how "trendy" the maker scene had become. In that "making" had become a point of style, people were doing things that seriously frustrated them, like wearing $\$ 300$ work boots but not actually working in them. They also lamented the decline in the originality of products; they said there are hundreds of people making "weird" things now because it's a cool thing to do. Even the most positive makers were frustrated by Portland's trendiness and rapid growth. One maker, who had been extolling Portland's quirky and DIY tendencies, talked about how Portland's "creative energies" make people want to live here and "do this too." She paused before exclaiming: "but we can't all live here!"

The concern with trendiness as a harbinger for the maker scene's decline surfaced in other interviews as a broader concern about Portland losing what had made it "authentic.” As Zukin $(2008,2010)$ and Benjamin (1968) both argue, authenticity only becomes sensible when it is perceived to be slipping away. This puts authenticity in an uncomfortable relationship with the imaginary of "new" Portland. There was an ambiguity at the intersection of new/old and inside/outside regarding authenticity: it was clear that as Portland has become more expensive, makers perceived the erosion of an authentic way of living and producing. But at the same time, and as noted in the "International Imaginaries" section above, authenticity was one of the core characteristics 
that outsiders such as the Japanese imagined Portland to be emblematic of; the promise of authenticity, in other words, draws people to Portland. Speaking uncritically, this authenticity is what we might consider to be "real" or "true" about Portland, or what hasn't been compromised as the city has developed. In fact, the go-to travel guide circulated in Japan is called "True Portland: The Unofficial Guide for Creative People" (a translation is also popular in South Korea). In 2017, I had a conversation with a pair of city employees that work on Portland's branding in Asian markets about what "True Portland" meant. I was trying to understand how anything could be "true" about Portland at a time that felt so tumultuous in the city, so I asked them what "True Portland" glosses over:

There's certainly stuff left out $[\ldots]$ this place is developing everyday and changing [...] we always try to give them a real picture, for media, because it's not good unless it's real, unless it's authentic. [...] When we've had serious journalists come and say 'how about racism in Portland' or 'what's the history of race relations' we say 'well alright, this was an exclusionary state. Uh, yeah black folks were not allowed in this state.' Then the war, and the [Vanport] flood, and then Williams Avenue was totally disrupted and redlining and all this stuff exists, it's part of what the place is. Obviously that's not highlighted in the, things like that are not highlighted especially in the type of media that we do, which is like, we're supporting it, there's no illusion.

The employee conceded that they would never tell a journalist what to write about the city; they should be made to feel free to critique the city's history if they choose. But he very much understood that implicit in my line of questioning was the reification of racial 
exclusions, historically produced through redlining and disinvestment but intensified and sustained through gentrification and the privileging of (white) "creativity" as "authenticity." If "true" Portland was creative, DIY, quirky, and communitarian, what was "untrue" Portland? How do people that don't fit the narratives of "trueness" see the city's so-called authenticity? And where do they fit in the global imagination of Portland as a place?

Something else stood out to me as incongruous regarding the use of "true" in describing Portland to outsiders. If Portland is undergoing so much change, then don't the imaginaries of "true" and "authentic" gloss over the tensions and anxieties emergent from the city's rash of development? I didn't even need to ask the question, however: the employee talked for almost 5 minutes straight, weaving the history of racism into the flux of the present and the sense of yearning that Portland has come to represent for Japanese youth:

It's hard to know if we are representing [Portland] faithfully from moment to moment because it keeps changing so fast. But there's a great appreciation for the maker culture and the sense of creativity and independence and I think that's what Japanese in particular are looking for, they want to find something where they're not just somebody's pawn and they can express their creativity and independence. I asked about what they thought the future of Portland was: what happens when tourists come to visit Portland and find an atmosphere of locally intensifying panic about the deterioration of the very things that tourists showed up in search of? They responded by saying that Portland is "growing up" and the challenge is trying to figure out how to represent grown-up Portland "in an authentic way." They have heard that other "tier one" 
cities (like Chicago, Seattle, or Los Angeles) "have no soul," are "out of touch," and are "run like a business." In other words, those places are not authentic. The first employee added that he doesn't see anything stopping gentrification in Portland, and he was very worried that Portland was going to lose what makes it stand out from those other, inauthentic cities.

He named San Francisco, in fact, as the city that he feared Portland would become. As mentioned above, San Francisco was the city most commonly juxtaposed to Portland, especially as Portland's shifting atmosphere was becoming more and more palpable. The sense is that "new" Portland is no longer a small city; it is growing up, becoming a real city. Implicit in that growth is the inability to refer to Portland as a community or as authentic: real cities are too diverse, too big, too expensive to be either of these things. Makers seemed concerned that if "new" Portland equates to it becoming San Francisco, Portland's supportive "ecosystem" might implode. A spirits makeroriginally from San Francisco - had an interesting take on it:

So Portland's in an interesting shift, and I'll make a controversial statement. So half of Portland is non-native. So there is a confluence of cultures in Portland that native Portlanders are very distraught about. Which by the way is the same thing in San Francisco. Except that the native San Franciscans are 10 percent. So what you have is, oh, we all know each other, we all want to help each other, we're all very friendly we're very supportive, you'll see two knife makers supporting each other, you'll see two spirit makers. This coffee shop is not an enemy of Stumptown. It's very supportive. But at the same time you have a large population of people who are like, 'I come from tech, I come from San Francisco, 
I come from New York, I come from LA, and I have a very different perspective on all these things, I know how to do finance.' So there's a different, so Portland is at a very interesting inflection point of that friendly, smaller, but actually

Portland is not a small town. Portland is a major metropolitan area.

My interviews suggest that what makes "new" Portland new is not just the fact that the city is growing, but rather it is "growing up." New Portland is a bigger, more cosmopolitan city; which also means it's less experimental, less playful. Bigger cities tend to trade in local authenticity for a more global set of values: they become technologically advanced, impersonal, corporate, fast-paced, expensive, unequal, topdown - everything that Portland's imaginary ostensibly agitates against. Authenticity seems one of those values that must be kept secret, lest the word gets out and attracts a crowd of people fleeing disappointment and meaninglessness. But secrets don't mesh well with makers that so dearly value inclusive, open communities in which everyone should feel welcome, safe, and able to create whatever they want. Again invoking Benjamin (1968), authenticity is a value that isn't visible unless it is disappearing. It is an imaginary value, or perhaps we should say an aspirational value.

\section{Made in Portland?}

As a concluding commentary on this section, it is important to consider the context within which Portland's various imaginaries have arisen. We might be tempted to ask: if the values that originally outlined Portland's popular imaginary are in decline, then what can be made of the "Made in Portland" brand? If Portland "grows up" and becomes a more global, plugged-in, fast-paced city, can it still rely on its nature-ringed, DIY, communitarian imaginary? 
But the other side of that coin is the fact that Portland was never just those things to begin with; much has been elided in the service of sustaining that imaginary. As was the case in Detroit, Oregon's history - the history from which Portland's creative imaginary emerged - is pockmarked with cruelty and racial exclusion. As evidence, the state was determined not to let black people settle within its boundaries, passing a number of legal restrictions (including a mandate that black people should be whipped if they refused to leave) before being granted statehood in 1859. Oregon's racially exclusive laws were supplanted by the passage of federally-mandated civil rights amendments to the US Constitution in the 1860s. But Oregon, being true "individualists," ignored these civil rights protections for a century. In fact, it took Oregon 107 years to ratify the Equal Protection Clause (the $14^{\text {th }}$ Amendment), which it finally did in 1973 (Semuels 2016). Then there were Portland's Vanport floods, followed by the redlining and blockbusting of Northeast Portland, where almost all of Portland's black population was isolated and economically marginalized (Gibson 2007). Those neighborhoods have now been thoroughly gentrified (Wile 2015; Sullivan \& Shaw 2011; Shaw \& Sullivan 2011) and are predominantly white. In 2017 - the same year a prominent and raciallycharged double murder was carried out in broad daylight on the MAX light rail - an investigation found that Oregon has the highest rate of hate crime reports in the country (Pein 2017).

All this is to say that the imaginary that creates meaning for "Made in Portland" or "Portland Made" is not a very good representation of actual or "true" Portland at all, at least not as far as history tells us. It might be interesting to consider what would happen if these facets of Portland were somehow interwoven into the global imaginary of the city; 
would young Japanese still see Portland as a beacon of authenticity and meaning? Would in-migrating makers be attracted to the red brick aesthetic of the CEID and the close-in neighborhoods of east Portland, given that these places were made possible by the bulldozing of black neighborhoods to build freeways and sports arenas? What would makers' aspirations for community and inclusiveness in these now gentrified neighborhoods mean, given that black communities in these same neighborhoods were forcefully torn apart by state legislation, urban renewal, and disinvestment? I would venture to guess that most makers know at least some of Oregon's racially troubled history and are disappointed by it. Yet the imaginary of Portland as DIY, authentic, creative, and so on has emerged from the same historical conditions that have been so cruel to people of color. Like was the case in Detroit, it was this history that made the emergence of Portlandia possible. I doubt many makers would want to put a bird on that.

It's not fair to call Portland "white" because people of color do indeed live in the city, and I'm uninterested in reproducing the conditions of their invisibility. But it is well documented that Portland is the whitest large city in the US. It is fair to ask, then, whether all the aspirations and values - both of consumers and of makers - that "Made in Portland" symbolizes are fastened to a racist past and what that has to say about the utopian aspirations of the present.

\subsection{CONCLUSION}

This chapter evaluates the relationship between makers and the urban imaginary of Portland. As was the case with Detroit, I am interested in understanding how makers mobilize something - in this chapter Portland - that is mired in an impasse between perceptions of "old" and "new." To my surprise, makers in both cities demonstrated clear 
tacit understandings of the shift from old to new and positioned themselves within it, both spatially and culturally. In Detroit, the space between old and new was marked by a sense of experimentality; in Portland, that same space was marked by what I argue has been characterized as the "Portland Dream." Unpacking this "dream" reveals a variety of traits assumed to be true about Portland: a local, sustainable, DIY ethos; an amateur-friendly approach to work and creativity; progressive and quirky communities; and uncompromising support for small business (and complementary antipathy to large corporations).

As evidenced above, the Portland Dream attracted many new makers to Portland. Akin to Detroit's "comeback" imaginary, "Portland" had in many ways become aspirational. In other words, for makers that had migrated to the city, Portland came to represent something that alleviated the displeasures they experienced elsewhere. What emerged from my analysis was a set of values and an emotional infrastructure largely based on juxtapositions to other places that stirred disappointment or revulsion in makers. For makers, other places were imagined as corporate, bland, professional, fragmented, overdeveloped, and so on. The Portland Dream, however, inverted those frustrations; the Portland Dream was the optimistic reversal of the shortcomings of all these places, and thereby represented a specific vision of "the good life" for so many incoming makers. As such, it was critical for makers to reproduce the Portland imaginary, because "Portland" had become an antidote to everything they perceived to have failed them.

The Portland Dream, however, was bound to be unstable as its secrets got out; indeed, during the course of my research, a shift in makers' collective imagination of Portland was palpable as the city continued to rapidly develop. As was the case in 
Detroit, the shift from "Old Portland" to "New Portland" presented both threats and opportunities for Portland's makers. On the one hand, the city's visibility and market reach was broader than ever; on the other hand, the values makers identified as quintessentially "Portland" were perceived to be under threat as New Portland unfolded. In the chapter, I identify three overlapping imaginaries - the industrial "atmosphere" of Portland's Central Eastside, the international "reach" of the Portland Dream, and Portland's ostensibly communitarian approach to work - that owe their visibility to Old Portland while being effaced by New Portland. This shift is significant in that it gives rise to specific desires that structure the values makers emphasize, the production and distribution strategies they employ, and various changes in physical, aesthetic, and even "atmospheric" urban form (e.g. as described in Portland's Central Eastside).

Once again we are confronted with the ways the impasse between new and old are collectively imagined. In Detroit, what emerged from that impasse was a wealth of dilemmas regarding makers' place and role in New Detroit. In Portland's case, what continued to emerge was a sense of aspiration: as it relates to the city's makers, Portland's imaginary has been constructed as a reservoir for what makers collectively desire from their relationship with the city, regardless of whether or not those desires are based on concrete reality or fantasy. Of course, there is an element of marketing at play: Portland's imaginary has helped makers sell their wares, especially as so many consumers have bought in to Portland's reputation through extensive exposure in the national media and "livability" rankings. I am more interested in looking through a different window, however: my analysis showed makers' place-attached desires to be a form of coping with hyper-individualization, technological saturation, and globalized 
production and consumption cultures. The desires for localization, community, and authenticity are all forms of pushback, or what I came to think of as "againstnesses"; they are aspirations built from the rejection of globalization, fragmentation, uniformity, and precarity in both living and working. "Portland" - in its collectively imagined state - has inherited a representative role as a proxy for these aspirations.

The Portland Dream, however, can hardly represent the totality of Portland. Like "Detroit," there is a certain indeterminacy to the "Portland" that makers imagine; the mobilization of "Portland" is therefore political. On those grounds, it is fair to ask: which Portland is the "authentic" Portland? And who gets to claim the benefits of that Portland? In general, makers find value in mobilizing the Portland Dream so as to give "Made in Portland" a stable sense of authenticity, despite the changes related to Portland's rapid growth. But the evidence in this chapter shows that Portland is not just perceived to be growing, but rather "growing up" (becoming a major city). Growing up suggests an end to the conditions under which the Portland Dream came into existence; becoming a major city might mean trading local and DIY for global and professional, and such a trade would disrupt Portland's imaginary and endanger the efficacy of "Made in Portland." Amidst the shift from Old to New, how can Portland retain the authenticity that so many incoming makers migrated in search of? Addressing such a question requires an evaluation of the new/old impasse and its aspirational values: the desire for authenticity is aspirational because makers (and probably a number of other Portlanders) sense it slipping away (Benjamin 1968). The values perceived to be slipping away are desirable because they provide a sense of stability or groundedness amidst the uncertainty of the 
transition from old to new. This chapter has shown how, in Portland's case, this is true of everything from DIY to community to authenticity.

What can't get lost in all this talk of aspirations and imaginaries are their real, material, physical effects on urban space and the people that inhabit it. I argued in chapter 2 that imaginaries are not confined to the realm of fantasy; they are no less real than the effects they generate. One such effect of an imaginary is what it leaves out, or what it fails to represent: indeed, the Portland Dream emerged from a troubled history of racial exclusion and class division. This was also true in Detroit, of course; but in Detroit it is impossible to ignore the omnipresent racial and class inequalities and the stark divisions they generate. As I discuss in this chapter's penultimate section, such exclusions are no less present in Portland, just perhaps better hidden. One is left to wonder what happens when the patina of racial exclusion infiltrates the Portland Dream (as it should). With perceptions such as community and authenticity seemingly at stake in the shift from Old to New Portland, the question of what Portland's popular imaginary has excluded becomes important. "True" Portland is an exclusive Portland, one in which the aspirations of a generally privileged group (makers) has significant implications for other, non-privileged groups, especially communities of color - if makers are concerned with being displaced, those concerns were only made possible by the more forceful displacement of others. There are real questions, then, about what is at stake for members of non-privileged groups and how the Portland Dream has failed them. 


\section{CHAPTER 7: CONCLUSION}

\section{Imaginaries and collective groundedness: answering my research question}

In this dissertation, I posed these central questions for research: What makes "Made in Place" an effective strategy for makers, and what gives it coherence and power? How is it mobilized such that it expresses (and adds) ethical and economic value, and what tensions emerge from its mobilization? In the process of answering these questions, I divided the phrase "Made in Place" in half, taking each side ("made" and "place") to be the subject of two empirical chapters. The first, the "made" side, had to do with how identity and value came together to produce an imaginary around "making" that was attractive to both consumers and producers. The second side, which has to do with “place," deals with how makers interact with specific imaginaries of Detroit and Portland and how those imaginaries are mobilized and held in tension in each city's maker milieu. Each of the four empirical chapters, regardless of which side of the equation they are on, demonstrates a set of ambiguities that puts into question why the maker movement makes sense to those attentive to its implications (makers, consumers, policy and public sector interests, the media, academia, and so on).

Chapters 3 and 4 address the "made" side of the "Made in Place" equation. In chapter 3, I found makers' descriptions of the maker identity to be vague and sometimes contentious; at times, the "maker" identity struck me as unsettled and even unnecessary. Yet my analysis found that the identity not only held together, it produced an imaginary of belonging that eschewed rigidities or purity tests. In chapter 4 , I found that in dealing with the dilemmas of pricing "ethically-made" goods, makers found ways to construct 
new imaginaries of value, even if those value imaginaries never really overcome the inherently capitalist conversion of emotional attachments into prices. I found that value, for makers, had more to do with a proposition based on how one feels about producing and consuming and how that feeling is absorbed into the relationship between makers and their consumers. Taken together, and despite the apparently significant tensions in each of the chapters, I found the "made" side of the "Made in Place" equation to hold together analytically. This sense of coherence is critical in how value is added to a maker's product: if the maker's identity and value proposition didn't make sense to the consumer, we likely wouldn't be discussing the emergence of the maker movement at all.

The "place" half of the equation, taken up in chapters 5 and 6 , has to do with how the places of production - in my case, Portland and Detroit - are variously and collectively imagined. I discussed how these imaginaries have drawn makers to each city and what tensions have emerged as each city rapidly transforms. My central concern in those chapters is to understand the mobilization of place in the "Made in Place" formula. A significant finding in each city was that the maker milieu both emerged from and operated within significant and rapid transitions between "Old Detroit/Portland" and "New Detroit/Portland." These impasses between old and new made the coherence of a singular "Detroit" or "Portland" nearly impossible in my mind, yet makers in both cities described an unmistakable power in mobilizing a "made in" strategy that suggests a commonly and coherently understood imaginary of each place. In Chapter 5, I found that Detroit's makers were clearly - and in most cases admittedly - benefiting from Detroit's problematic comeback narrative. But they were uncomfortable with all of it; the overwhelming sense from Detroit was that makers felt stuck between running their 
enterprises and exploiting a city whose most vulnerable people were not seeing the benefits of Detroit's comeback. In chapter 6, the sense of "magic" that made Portland's green, DIY imaginary alluring was generally still in tact, even if there was some skepticism about where "New Portland" was heading. But I found that makers in Portland relied on their attachments to the Portland imaginary as a sense of aspiration, a "cruel optimism" (Berlant 2011) that clung to "Old Portland" even if the Portland they had migrated to had already become "New Portland." Taken together, I found less coherence in the shared imaginations of Portland and Detroit than I did in the maker imaginaries of identity and value, most notably in the impasse between "new" and "old" in each place. And yet "Made in Place" remained a powerfully coherent strategy for makers.

Returning to my research question, I am confident that the question of "what tensions emerge" is answered in detail throughout this dissertation: each element of the "Made in Place" formula is embroiled in numerous tensions, each of which destabilizes (or at least threatens to destabilize) the formula significantly. The impasse between "new" and "old" (chapters 5 and 6) the rejection of the maker identity (chapter 3), and the "pricing paradox" (chapter 4) are all examples of emergent tensions. I also believe the analysis in this dissertation sufficiently answers the methods by which ethical value becomes a facet of economic value, which then is mobilized in various ways. This transformation of ethics into economics (i.e. "added value") is most notably demonstrated by the collective construction and consumption of the identity and value imaginaries I describe in chapters 3 and 4. But answering the question of "what makes 'Made in Place' a coherent and effective strategy for makers" seems to demand a solution for why something can be ambiguous yet coherent and powerful at the same time. 
The answer, I contend, maps back to theory, specifically to the two central theoretical concepts used throughout the dissertation: imaginaries and impasse. Beginning with the latter term, borrowed from Lauren Berlant and defined in chapter 2, I claim that makers experience two impasses that are central to this thesis. The first is related to why "making" came to exist in the first place, and has to do with the collective sense of disappointment that comes from finding the cupboards of the American Dream to be bare. But it also has to do with the uncertainty of not having another cupboard to turn to: without the signposts of the American Dream, what narrative might animate makers? This impasse, which importantly suggests transition and uncertainty, begs a desire for the groundedness that can provide a sense of stability. Groundedness is achieved when things make sense and one can comprehend their place in the world. The second impasse significant to this dissertation is the rapid urban development in each city (i.e. the transition from "old" to "new"). In each place, there was a clear sense that makers felt powerless to control the trajectory of change, even though they generally recognized their roles as actors in each city's changes. As a general observation, both cities' makers were unhappy with the shape that "new" was taking. The conditions that had drawn them to Portland and Detroit were collapsing as "new" replaced "old," and makers were forced to find ways to both stay in business and find their sense of stability within the developmental whirlwind of each place. Again, achieving a sense of stability has to do with grounding oneself amidst change. Makers, given the two impasses described in this paragraph, have to do this (at least) twice at the same time.

Perhaps it is already clear how intertwined imaginaries and impasses are: my argument is that one cannot be understood without the other (or at least not in the case of 
this dissertation). It seems a conservative argument to claim that people generally desire certainty over uncertainty and security over precarity. When confronted by the uncertainty of a transition, it seems again conservative to suggest that people would tend to seek forms of stability to smooth out the rougher edges of that transition. Indeed, that is what I have found: makers rely on imaginaries - of Portland, of Detroit, of "maker" and making - to give themselves a sense of certainty amidst the impasses they find themselves immersed in. The twist is that is doesn't really matter if Portland or Detroit is what "Made in Portland/Detroit" suggests it is; likewise, it isn't even important for makers to agree upon a definition of "maker" in order for it to suffice as an identity position. In fact, makers, can actively hate or reject the imaginaries of Detroit, Portland, maker, making, and so on, and still find coherence and power in them. This is because hating or rejecting them still implies a sense of comprehension or the feeling of groundedness, that at least they know what's going on and therefore can make sense of a situation and adjust to it.

To be clear: "feeling grounded" is not equivalent to a rational resolution to an impasse. And the fact that tensions remain suspended in the urban and identity imaginaries $d o$ have very material consequences, many of which exacerbate existing inequalities based in class and race. As I have pointed out in the chapters above, imaginaries necessarily shake a lot out of the sifter, notably things like racism tied to urban development. In other words, imaginaries are built from the most essential aspects of identities or places (e.g. Portland is equivalent to roses, beer, and bikes). Imaginaries, however, are a product not of rational comprehension, but instead they emerge when comprehension has been overwhelmed and cannot rationally make sense of something 
(i.e. Portland is obviously far more complex than roses, beer, and bikes). Put differently, imaginaries service the feeling of comprehension, the sense that something impossibly complex can be grasped even when it is in the midst of rapid changes. "Made in Place" operates on the premise that "made" and "place" convey a sense of comprehension about what "made" and "place" really mean; but throughout this dissertation I've described how those meanings are anything but stable. So why does it work?

The critical last piece, I argue, has to do with the plurality of imaginaries. If I were referring to a singular phenomenon, I would be referring to one's imagination. But the term "imaginaries" implies a multiplicity of imaginations, a collection of imaginations conditioned by common encounters. There is a necessary collectivism inherent in the production of an imaginary - it is a commons of sorts, a collective defense mechanism against the feeling of being lost in the turbulence of capitalism and urban development. Imaginaries, for all their problematic and essentializing characteristics, produce a sense of collective groundedness: they are a way to collectively manage anxieties about the future, an agreed upon collective feeling of resistance or coping or innovating or enduring. This collective groundedness, I argue, is the key to understanding what gives "Made in Place" its power and sense of coherence. Imaginaries are what gives "making" its completeness given the tumult within which it is situated. As such, imaginaries also absorb makers' aspirations, or what Walter Benjamin called "wish images." These aspirations reflect what makers collectively want the future to hold for the maker movement and the cities they make in. I have described numerous ways this is accomplished throughout this dissertation, but two immediate examples are: by drawing on the imagined affective register of the past (e.g. Detroit's romantic collective memory 
of manufacturing); and by pushing back on technological saturation (e.g. Portland's desire for authenticity and community as a response to the isolating effects of technological interaction).

\subsection{IMPLICATIONS OF THIS RESEARCH}

In the rest of the conclusion, I will entertain some of the pressing implications that flow from this dissertation. This includes commentary on my epistemological and ontological approach, which is rooted in critical theory and materialism but opened toward the "non-representational" world of affect and emotion. I make this shift in ontology to account for the mysticisms and irrationalities that orthodox approaches to critical theory purposefully eschew. As I will discuss below, urban studies - particularly in the American context - has been quite slow to evaluate analyses on affect and emotion, likely due to affect and cultural studies' ontological incongruity to policy discussions.

Given that this dissertation has been concerned with the affects of transition - the central effect of which, I argue, is the construction of specific imaginaries - I find it necessary to address this incongruity before closing the discussion. Lastly, I will address the limitations that my data has for analyses on race as well as some possibilities for future research.

\section{An Affective Approach to Research}

In doing research, we are always confronted with ontological and epistemological boundaries: the questions of what count as "facts" or "truth" or "data" are often a critical part of what makes any study impactful. Researchers, as I have learned, always have to draw somewhat arbitrary distinctions around things like history (when counts?) 
geography (where counts?) and subjects (who counts?). And when we create boundaries around our research, what do we do with the stuff that gets left out? If, as I've argued, imaginaries are reductions of complexities that makers rely on in order to "make sense," then research seems to me to do exactly the same thing: it simplifies (via methodological decision rules) in order to "make sense" of something far too complex to ever be understood by a single study. But simply writing it out doesn't make it not exist, and it certainly doesn't make it not affect the aspects of the research that remain in the study. I don't mean to critique traditional forms of research; I can't fathom a form of research that accounts for every possible aspect of a given topic. What I am saying is that it is hubris to imagine the possibility of a resolution from such an approach. Like was the case with imaginaries, the tensions will either remain or just show up somewhere else.

Part of the problem is a generalized analytical reliance on objectivity and rationality, although I am writing this dissertation in the midst of what might be characterized as a crisis (impasse?) of objectivity. Thanks in large part to the Internet and social media, rational science seems to be losing some of its authority over the activities of the average citizen. This is especially true in the ever-confounding era of "fake news" and a national politics (in the US) in which decisions are clearly based more on emotional attachment than on rational objectivity. The common antidote to "fake news," for many observers, is often to demand objectivity and rational science; there are clearly places where this is important, particularly in the climate emergency that is rapidly unfolding across the globe. But what this antidote fails to account for - what it reductively writes out of frame - is the ways in which "fake news" affect people. In other words, "fake news" motivates people to do things (or not do things); it has real, material impacts that 
are often times devastating and definitely not "fake." The lesson here is that people are not always motivated by facts; emotions, attachments, values, and other things that can't be accounted for by rational science are primary motivations that cannot be ignored by researchers.

This concept of "overflow" (introduced in chapter 2) is, in part, meant to deal with the problem in traditional materialism and critical theory that casts doubt on various research inputs because they appear to be mystical or religious or "fake." It doesn't seem sufficient to me to cast something like an imaginary aside because it is "mystical," because mysticisms affect people to act in certain ways. This is a central claim of affect theorists, especially those with materialist leanings, and the evidence abounds in my data. Consider the ways imaginaries affect makers: the rapid uptick in migration to Portland and Detroit; the mobilization of a city in a firm's name (e.g. Portland Coffee) to access the benefits of that city's imaginary; the rejection of a "proper" identity despite accessing its aesthetic and economic values; and the structuring of value propositions around ethical rejections of globalization to name a few examples. But the most cogent example is the importance of "Made in Portland/Detroit" and the power that this adds to a product, in spite of all the material indefiniteness and instability evident on each side of the "made in" equation. "Made in Place" branding affects the way people shop, the ethics they invest in their production and consumption, the cities they migrate to or visit as tourists, the media they consume, the values they accept or reject, and so on.

I hope to have clearly shown that makers and consumers respond to the feelings they derive from various imaginaries (of cities, making, and value), their attachments to place and work identities, and the collective values that calcify these feelings and 
attachments to into a "movement." I hope these arguments are evidence enough of a need to deepen the overall engagement in social science with the affective and emotional realms of research. Accounting for affect does not equate to lubricating the "slippery slope" toward mystification; rather, it invites a more holistic approach to research, a formal dissolution of the boundaries between social science and humanities, and an approach to research less defined by the dictates of the managerial worlds that generate and maintain so many inequalities. Furthermore, an affective approach takes seriously the fuzziness and ambiguities that "rigorous" social science has never been able to account for. Especially in today's world of technological saturation (particularly the rapid-fire and short-form scroll of social media and Internet meme culture) people must rely on gestures, body language, images, aesthetics, and other forms of "I know what you mean" expression. These are not rational forms of communication; they exist largely in the affective register, entangled in the same "overflow" as do other "mystifications" (e.g. imaginaries). It is very difficult to envision a social science not interested in the things that make people act; this is why I contend that an affective approach is important.

\section{Affect and Urban Studies and Planning}

In the previous section, I made the case that affective approaches to research are underrepresented in the social sciences. I would like to qualify that argument with the acknowledgement that prominent critical scholars in anthropology (e.g. Elizabeth

Povinelli, Kathleen Stewart), geography (e.g. Nigel Thrift, Ben Anderson), and certainly in queer and feminist studies (although this is arguably the world of humanities, but e.g. Berlant, Sara Ahmed) have made enormous contributions to affect theory in the social sciences. Additionally, there are developing literatures in each of these disciplines that 
focus on affect. In fact, the lack of engagement with affective approaches to research and analysis is perhaps most egregious - and perhaps most puzzling - in urban studies and planning. While a few European and Australian urban scholars have argued this case (Buser 2014; Thrift 2004) and utilized theoretical affective approaches in planning research (Hillier 2008; Gunder \& Hillier 2007; Dovey et al. 2009; Wood 2009) and even produced new literatures on urban "affective atmospheres" (Buser 2017; Edensor 2015; Anderson 2009), there is virtually nothing in American urban studies and planning research that utilizes affect either theoretically or methodologically.

The absence of affective approaches in American urban studies is especially baffling because of the rich and imaginative cultures present in American cities. It would require numerous pages of additional text to describe the complex urban confrontations between the formal and informal, the police and the policed, the organic and the mediated, and the numerous cultural forms that emerge from these interactions. Furthermore, urban planning is practically implicated in almost all of these interactions, yet its scholarship is entirely mum on the role of affect and emotion in the near constant transformation of American cities. Urban planning has two fundamental roles: to imagine urban futures and to implement those futures; planning is essentially the social science tasked with transforming (urban) imagination into (urban) materiality. Yet for some reason, planning scholars tend to spend almost all of their analytical energy on implementation, which includes the policies and other forms of order necessary to facilitate implementation. The imaginative and affective aspects of planning are all but ignored in the field, particularly in the American context (there are some notable exceptions; see Mccann et al. 2013; Roy 2011; and Ghertner 2015, for example). 
In a paper I published with a coauthor in the journal Planning Theory last year, we cited Hillier \& Gunder's (2003) claim that "urban planning is intrinsically concerned with the imagination and desire: what the future city should look like, or the impact of a development proposal on the existing built form, on neighboring uses and people" (226). We also build on Holston's (1998) claim that urban planning is fundamentally concerned with the imaginary, and we argue that:

planning must navigate the space between imagined futures and the actually existing present. Planning is inexorably caught between imagination and capacity, between desire and control, between dreaming and managing; but also between the present and the future, between developers and communities, and between the material and the emotional (Marotta \& Cummings 2018).

The point of that paper was to make the case that urban planning scholarship was stubbornly ignoring the affective and the emotional registers of cities. Planning, we argued, was not only well suited to such analyses, but the process of implementation fundamentally affects the attachments people have to places. To us, it seemed an egregious oversight: if planning is tasked with imagining the future (i.e. developing plans), fomenting the change necessary to bring that imaginary future into existence (i.e. implementation), and then creating a sense of order within that transition, then we could not see how planning absolves itself of the affective worlds it creates, disrupts, or otherwise alters in the process. Even more frustrating, and as both Thrift (2004) and Wood (2009) point out, it seems impossible to ignore "the utter ubiquity of affect as a vital element of cities" (Thrift 2004; 57) - the mobilization of the "feel" or "buzz" of a place in urban development, for example. And yet planning largely eschews the 
theoretical and methodological possibilities in analyzing such affective characteristics of cities.

\section{Policy "Suggestions"}

I hope this dissertation to contribute to the aforementioned gap in urban studies and planning. In my mind, cities are where the strangest, most complex, most entangled puzzles of human life find their fullest expression. I firmly identify as an urban studies scholar, and I hope the contribution I make to the field to be an affective framework that that bridges urban culture and political economy. I find myself frustrated, however, that urban studies and planning - especially in the US - is preoccupied with policy-friendly research that largely writes culture and affect out of the picture. Policy oriented research is not bad per se; policy concerns are obviously necessary and vital to the alleviation of negative effects on underrepresented and disadvantaged peoples in the immediate impasses of the present. I do not argue here that policy or policymakers are ignorant, shortsighted, or uncritical. But my interest in urban studies is not in becoming a policymaker or a policy analyst; I am interested in urban culture first and foremost. My grievance, therefore, is that culture is not taken equally (or even partially) as serious; urban studies, particularly in the United States, does not seem to reward analyses on culture that reach beyond policy matters.

To make matters more complex, culture and policy have an uncomfortable association. Cultural policy, if we can force such a relationship, would necessarily attempt to define or capture culture - I couldn't imagine policy that didn't define the thing it attempted to regulate - and therefore force boundaries on culture. But culture would always escape those boundaries, which means there would always be unintended 
consequences of cultural policies. For example, there has been a great deal of attention on “creative placemaking” (Markusen \& Nicodemus 2010; Markusen \& Gadwa 2010; Nicodemus 2013) in urban planning, nonprofit, and policy circles in the recent past. One of the considerations of creative placemaking is: what policies encourage place-based creativity and art, which provides clear economic advantages to urban places, without displacing long-time residents or the artists that provide the creativity? But a short trip into American urban cultural history reveals how it was the unintended consequences of other policies - policies that deindustrialized urban centers in the northern US, for example - that created the space for artists to inhabit central cities in the first place (Zukin 1982). Policy, in other words, is already responsible for creative placemaking; that conversation wouldn't be possible without the pro-corporate and oftentimes racist urban policies of the past.

This is not to say that policy is incapable of producing positive cultural outcomes: that would be an absurd argument. But culture lends itself better to affective and aesthetic analyses, because while culture can be structured by policy it cannot be caged in by or reduced to policy. My argument, then, is that policy would never be able to define culture or predict cultural outcomes; there would always be "overflow." In many ways, the culture/policy problem mimics the rationality/feeling problem I examine in the last section. Affect theory, in many ways, challenges the idea that feelings can ever be captured or represented in a rational way. The question regarding policy then becomes: is there a form of policy that might privilege incoherence, imagination, ambiguity, and feelings over codified rationality and rigorous definitions? A legitimate question for urban studies and planning scholarship might be phrased as: if not policy, then what? 
Since policy suggestions have become such an important set of remarks in concluding a project, I would like to offer two "suggestions." First, and (finally) returning to the makers that are the core focus of this dissertation: the defining political need for makers is not aid in scaling up or reaching global markets or easing their relative tax burden, although each of these concerns are real and deeply affect makers' ability to run their enterprises. Taken together, however, makers' most significant political need is the reduction of precarity and uncertainty, ${ }^{36}$ a need that obviously extends well past the realm of makers and which is the central explanation for the emergence of urban and maker imaginaries. There are countless ways to address this need specific to makers, some of which can be done through policy maneuvers. For example, the public sector might create and subsidize insurance pools (e.g. for health care, unforeseen disasters such as flooding, etc.) for small manufacturing firms, possibly in trade for the implementation of first-source hiring programs. Additionally, cities with similar land use dilemmas to Detroit might engage in industrial land banking or even innovate forms of equity-driven reparative land redistribution that gifts remediated land (or land rent with site improvement grants) to people that have historically had land and wealth structurally stolen; this might consequently add some much needed racial and class diversity to the maker movement. What if Detroit created a special tax on Detroit's "new" businesses (including makers), the proceeds of which might fund reparations for families of those displaced by the destruction of the Paradise Valley and Black Bottom neighborhoods during the construction of Detroit's freeways? Even making this tax optional would introduce an avenue for makers to feel less frustrated by their necessary exploitation of

\footnotetext{
${ }^{36}$ Thank you to Austin Cummings for a most helpful conversation on this topic
} 
"Detroit" in their marketing; their participation in such a program would also surely appeal to consumers. Of course, suggesting reparations as policy would introduce a host of political wrangling, but I am not interested in those politics - history suggests that reparations are the least controversial policy stance anyone with power and privilege could take. Privilege doesn't come from nowhere; giving back what has been stolen is hardly controversial.

Second, I would like to offer a take on the question of "if not policy, then what?" The question is reminiscent of one that confronted Herbert Marcuse (1969) when his analysis led him to ask what people in a "liberated" society would do with themselves. His answer: "for the first time in our life, we shall be free to think about what we are going to do" (91). I don't see why it isn't possible to apply the same logic to policy. Perhaps for now policy is the best mechanism for dealing with urban issues, especially ones deeply involved in a city's economy. But the freedom to imagine something else, something more accepting of ambiguity, strangeness, and culture, is an attractive thought. This isn't an answer to the question of what other than policy urban scholars might suggest; it is an invitation to dwell on the question.

\subsection{LIMITATIONS AND FUTURE DIRECTIONS}

Race: This dissertation did not focus on race, but race is undoubtedly an important topic to broach. Race was one of the more difficult aspects of this dissertation; given the unfair, unequal, and unsettled racial disparities in the United States, it never feels like there is enough said or done about race. This is doubly true when race and class are taken together; in the course of a recent rash of racial awareness in the media and on the Internet, a conversation about how class has been weaponized in the service of racial 
discrimination has been popularly overlooked. There is perhaps no place on the planet where the combined forces of class and racial inequality are more visible than Detroit. In the course of Detroit's "comeback" narrative, these inequalities are hardly entertained in the media outside the tacit assumption that a "rising tide lifts all boats." But this has never been the case, and it isn't the case in Detroit. Detroit's racial disparities are not improving at this point, and the maker movement hardly has anything to offer other than lofty aspirations to provide jobs and a general melancholia about the helplessness with which makers must latch on to Detroit's rising brand.

With that said, my data can barely provide a window into the issue of race in Detroit, even though race came up in almost every interview I conducted there and it certainly is a topic in chapter 5 . But my data is pretty sparse on the topic of race in Portland or race in the maker movement in general. These omissions speak to the white privilege that many makers benefit from, something that was more or less explicit in the Detroit case and more or less unacknowledged in Portland. If there were a racial analysis to be made from my data, it would be of whiteness or white privilege, especially in the sense that many makers are well educated (i.e. have caches of "cultural capital") and have a decent understanding of how to access the resources they need to start and maintain a business. Although many makers do have the desire to see a greater deal of social and racial justice, the task of administering more just outcomes is probably outside the bandwidth of most makers. There is something interesting, and I would argue ripe for future studies, in this aspect of whiteness in the maker movement: it is a manifestation of the urban, middle-class brand of young, white liberalism that seems to be characteristic of gentrifying urban neighborhoods. The affects, political and economic imaginaries, and 
limits of this brand of white liberalism in the maker movement would make a reasonable follow up study to this dissertation.

As a last word on race, I would argue that following scholars such as John Hartigan Jr.'s (1999) analysis on whiteness in Detroit would lead to more nuanced understandings of race in such a context. Hartigan's argument, in a very small nutshell, is that even in a city that is predominantly non-white, whiteness is not a monolith. After conducting a lengthy ethnographic study of Detroit's few pockets of whiteness - none of which is completely white - Hartigan shows there are many iterations of what it means to be white in Detroit; undoubtedly, the same can be said about blackness in Detroit. This is all to say that the reality of race is enormously complicated; I did not set out to do an analysis based on race and, given my lack of expertise, it would be irresponsible to draw conclusions based on race. I do, however, acknowledge the fact that there is something to be said about race and the maker movement: makers are predominantly white, even in a city that is predominantly non-white. How is this related to the shifting public imaginary of Detroit? How can Portland's lack of racial data be understood in the landscape of "post-political" and "post-racial" American entrepreneurialism? And again, what are the limitations of white urban liberalism in cities that have been historically and politically organized for white, entrepreneurial pursuits?

Precarity: I would like the theoretical insights from this dissertation to align with a spate of recent work in critical social sciences that looks at precarity in contexts broader than political economy. In such work, the economy is still a significant consideration, but the analytical weight is on the sensation of being precarious and managing the anxiety of an 
uncertain future. Some scholars have taken to thinking through the "atmospheres" of neoliberalism (Anderson 2016); or the emotional and physical exhaustion that precarity levels on people that feel its effects (Wilkinson \& Ortega-Alcázar 2018; Berlant 2011); or the sheer endurance necessary to survive despite the affective attrition of precarity under neoliberalism (Amin 2013; Tsing 2015; Povinelli 2011; Berlant 2016b). For Tsing (2015), precarity is "life without the promise of stability." She describes the affective condition of a precarious life in these terms:

The economy is no longer a source of growth or optimism; any of our jobs could disappear with the next economic crisis. And it's not just that I might fear a spurt of new disasters: I find myself without the handrails of stories that tell where everyone is going and, also, why [...] In contrast to the mid-twentieth century, when poets and philosophers felt caged by too much stability, now many of us, north and south, confront the condition of trouble without end (2).

I am most interested in Tsing's use of the notion of "handrails:" handrails here refer to a sense of guidance, something that grounds a person and helps them make sense of where they are going. Tsing argues that the "imaginative challenge" of living with precarity is in finding unexpected forms of life in the capitalist ruins; in her case, it is an in-depth analysis of the global trade in Matsutake mushrooms. But other contexts where a similar affective framework might be employed include: climate anxiety and the sense of impending environmental collapse; infrastructure development, particularly in the Global South; the (necessary) performance of entrepreneurialism (including the maker movement); the shifting cultural conditions of rapidly changing cities; the effects of 
public austerity programs; housing precarity; the rise of white nationalism; and too many others to name here.

What emerges from these literatures is a timely and anticipatory appraisal of the apparent transition from neoliberalism into whatever is coming next. Much of this scholarship addresses precarity as an affective state that prompts a menu of adjustments specific to time, place, race, class, and myriad other considerations. What scholars like Berlant, Povinelli, and Tsing make clear is that these adjustments suggest two things: first, that the conditions from which the future will unfold are unstable and the path to stability is increasingly uncertain; and second, that uncertainty demands a normative desire to feel grounded amidst the flux, flexibility, and fragmentation that so clearly have been the primary outcomes of neoliberal capitalism. The "ordinary" adjustments that people make to this sense of precariousness are fertile and exciting grounds for future study, because the analyses would emphasize the ambiguities of imagining an uncertain future in the context of a destabilized present (which, I should mention, I find critical to planning discourse). Ambiguity yields both anxiety and optimism, each conditioned by the desire to seek "pleasures amidst the terrors of indeterminacy" (Tsing 2015; 1).

I hope the analysis in this dissertation has clearly made a case for how a specific assembly of people makes sense of perceived crises, and I hope this case to be portable to other contexts. In my case, it is collective imagination that is the space of adjustment, specifically to the impasses of globalization and urban transformation. But I also hope to take the theoretical work I've done here a few steps farther; I would like to explore other realms in which collective imagination serves as a source of groundedness for people experiencing instability. Eventually my goal is to broaden the analysis to include a 
variety of analyses of precarity relative to global economic transformations in the affective register. How are people adapting to neoliberalism's effects globally, and what can be learned about the aggregate effects? Perhaps more importantly, how is the attrition of neoliberalism itself evident, and what "handrails" might usher in something after neoliberalism? My feet are planted firmly in the field of urban studies, so I expect to do such work from the perspective of cities. Perhaps this means analyses on urban climate futures, the felt effects of neighborhood change, art that imagines urban futures, or even the affective and emotional side of economic development. I may also continue to work with makers, or whatever makers become as the trendier patina on the maker movement erodes. In any case, the analytical and theoretical disappearing point between political economy and affect theory is where I would like to position my work going forward, especially given my aforementioned frustration with urban studies over its aloofness to the implications of affect. As for now, it seems a strange suggestion to propose a collision between affect theory and urban economic development; but it doesn't have to be. 


\section{BIBLIOGRAPHY}

Abbott, C., 2000. The Capital of Good Planning: Metropolitan Portland Since 1970. In R. Fishman, ed. The American Planning Tradition: Culture and Policy. The Woodrow Wilson Center Press.

Ahmed, S., 2004. Affective Economies. Social Text, 22(2), pp.117-139.

Ahmed, S., 2010. Happy Objects. In M. Gregg \& G. J. Seigworth, eds. The Affect Theory Reader. Durham, NC: Duke University Press, pp. 29-51.

Amin, A., 2013. Surviving the turbulent future. Environment and Planning D: Society and Space, 31(1), pp.140-156.

Anderson, B., 2009. Affective atmospheres. Emotion, Space and Society, 2(2), pp.77-81. Available at: http://dx.doi.org/10.1016/j.emospa.2009.08.005.

Anderson, B., 1983. Imagined Communities: Reflections on the Origin and Spread of Nationalism Revised Ed., London: Verso.

Anderson, B., 2016. Neoliberal affects. Progress in Human Geography, 40(6), pp.734753. Available at: http://phg.sagepub.com/cgi/doi/10.1177/0309132515613167.

Apel, D., 2015. Beautiful Terrible Ruins: Detroit and the Anxiety of Decline, New Brunswick, New Jersey: Rutgers University Press.

Arvidsson, A., 2005. Brands: A critical perspective. Journal of Consumer Culture, 5(2), pp. 235-258.

Arvidsson, A., 2009. The Ethical Economy: Towards a Post-Capitalist Theory of Value. Capital \& Class, 33, pp.13-29. Available at: http://cnc.sagepub.com/cgi/doi/10.1177/030981680909700102.

Auerswald, P.E., 2014. Enabling Entrepreneurial Ecosystems, Kansas City, MO.

Austen, B., 2014. The Post-Post-Apocalyptic Detroit. The NewYork Times Magazine.

Banet-Weiser, S. \& Arzumanova, I., 2012. Creative authorship, self-actualizing women, and the self-brand. In C. \& Chris \& D. Gerstner, eds. Media Authorship. New York, NY: Routledge.

Beauregard, R., 2014. Note on the Maker Movement, Social Innovation.

Beauregard, R.A., 1986. The Chaos and Complexity of Gentrification. In N. Smith \& P. 
Williams, eds. Gentrification and the City. Boston: Allen \& Unwin, pp. 35-55.

Bell-Masterson, J. \& Strangler, D., 2015. Measuring an Entrepreneurial Ecosystem, Kansas City, MO. Available at: http://www.kauffman.org/ /media/kauffman_org/research reports and covers/2015/03/measuring_an_entrepreneurial_ecosystem.pdf?utm_source=March+ $26,+2015+$ U.S.+Cluster+Mapping + newsletter\&utm_campaign=US+Cluster+Mappi ng+Email+Newsletter\&utm_medium=email.

Benjamin, W., 1999. The Arcades Project, Cambridge, MA: Harvard University Press.

Benjamin, W., 1968. The Work of Art in the Age of Mechanical Reproduction. In Illuminations. New York, NY, pp. 217-251.

Berlant, L., 2011. Cruel Optimism, Durham, NC: Duke University Press.

Berlant, L., 2016a. Lauren Berlant Interview. Available at: https://www.youtube.com/watch?v=Ih4rkMSjmjs.

Berlant, L., 2016b. The commons: Infrastructures for troubling times. Environment and Planning D: Society and Space, 34(3), pp.393-419.

Berlant, L., 2008. The Female Complaint: The Unfinished Business of Sentimentality, Durham, NC: Duke University Press.

Binelli, M., 2012. Detroit City is the Place to Be: The Afterlife of an American Metropolis, New York, NY: Metropolitan Books.

Bishop, C., 2012. Artificial Hells, London: Verso.

Boudreau, J.A., 2007. Making new political spaces: Mobilizing spatial imaginaries, instrumentalizing spatial practices, and strategically using spatial tools. Environment and Planning A, 39(11), pp.2593-2611.

Bourdieu, P., 1986. The Forms of Capital. In Handbook of Theory of Research for the Sociology of Education. Greenwood Press, pp. 241-258.

Buck-Morss, S., 1995. The City as Dreamworld and Catastrophe. October, 73, pp.3-26.

Buser, M., 2017. The time is out of joint: Atmosphere and hauntology at Bodiam Castle. Emotion, Space and Society, 25, pp.5-13. Available at: https://doi.org/10.1016/j.emospa.2017.09.006.

Buser, M., 2014. Thinking through non-representational and affective atmospheres in planning theory and practice. Planning Theory, 13(3), pp.227-243. 
Cameron, S. \& Coaffee, J., 2005. Art, Gentrification and Regeneration - From Artist as Pioneer to Public Arts. European Journal of Housing Policy, 5(October 2013), pp.39-58.

Chachra, D., 2015. Why I am not a maker. The Atlantic, pp.1-6. Available at: http://www.theatlantic.com/technology/archive/2015/01/why-i-am-not-amaker/384767/.

Chang, T.C., 2008. Art and soul: Powerful and powerless art in Singapore. Environment and Planning A, 40(2005), pp.1921-1943.

Cinar, A. \& Bender, T., 2007. Urban Imaginaries: Locating the Modern City, Minneapolis, MN: University of Minnesota Press.

Currid, E., 2007. The Warhol Economy: How Fashion, Art, and Music Drive New York City, Princeton, NJ: Princeton University Press.

Dalmia, S., 2017. The Dark Side of Detroit's Renaissance. The Week. Available at: https://theweek.com/articles/692770/dark-side-detroits-renaissance.

Darroch, M., 2015. Border Scenes. Cultural Studies, 29(3), pp.298-325. Available at: http://www.tandfonline.com/doi/abs/10.1080/09502386.2014.937935.

Dawkins, N., 2011. Do-It-Yourself: The Precarious Work and Postfeminist Politics of Handmaking (in) Detroit. Utopian Studies, 22(2), pp.261-284.

Dawney, L., 2011. Social imaginaries and therapeutic self-work: The ethics of the embodied imagination. Sociological Review, 59(3), pp.535-552.

Debord, G., 1983. Society of the Spectacle, Detroit: Black \& Red.

Deener, A., 2007. Commerce as the Structure and Symbol of Neighborhood Life: Reshaping the Meaning of Community in Venice, California. City \& Community, 6(4), pp.291-314.

Deleuze, G., 1988. Spinoza: Practical Philosophy, San Francisco: City Lights Books.

Deleuze, G. \& Guattari, F., 1987. A Thousand Plateaus, Minneapolis, MN: University of Minnesota Press.

Deleuze, G. \& Guattari, F., 1977. Anti-Oedipus, New York, NY: Penguin Books.

Deslandes, A., 2013. Exemplary Amateurism Thoughts on DIY Urbanism. , 19(1), pp.216-227. 
Detroit, C.D.A. of, 2010. Community Development Futures Task Force: Neighborhood Revitalization Strategic Framework, Detroit, MI.

Deutsche, R. \& Ryan, C.G., 1984. The Fine Art of Gentrification. October, 31, pp.91111.

Devadason, R., 2010. Cosmopolitanism, geographical imaginaries and belonging in North London. Urban studies (Edinburgh, Scotland), 47, pp.2945-2963.

Dougherty, D., 2012. The maker movement. Innovations, 7(3), pp.11-14. Available at: http://search.proquest.com/docview/1677224353?accountid=14739.

Douglas, G.C.C., 2013. Do-It-Yourself Urban Design: The Social Practice of Informal "Improvement" Through Unauthorized Alteration. City and Community, pp.1-21.

Douglas, G.C.C., 2011. Do-It-Yourself Urban Design. Available at: http://home.uchicago.edu/ gdouglas/GCCDouglas_DIYUrbanDesignASA2011.pdf.

Doussard, M. et al., 2014. Metropolitan maker networks: The role of policy, organizations, and "maker-enabling entrepreneurs" in building the maker economy.

Dovey, K., Woodcock, I. \& Wood, S., 2009. A Test of Character: Regulating Placeidentity in Inner-city Melbourne. Urban Studies, 46(August 2008), pp.2595-2615.

Duffy, B.E., 2015. The romance of work: Gender and aspirational labour in the digital culture industries. International Journal of Cultural Studies, pp.1-17. Available at: http://ics.sagepub.com/cgi/doi/10.1177/1367877915572186.

Duffy, B.E. \& Hund, E., 2015. "Having it All” on Social Media: Entrepreneurial Femininity and Self-Branding Among Fashion Bloggers. Social Media + Society, 1(2). Available at: http://sms.sagepub.com/content/1/2/2056305115604337.full.

Duschinsky, R. \& Wilson, E., 2015. Flat Affect, Joyful Politics and Enthralled Attachments: Engaging with the Work of Lauren Berlant. International Journal of Politics, Culture and Society, 28(3), pp.179-190.

Edensor, T., 2015. Producing atmospheres at the match: Fan cultures, commercialisation and mood management in English football. Emotion, Space and Society, 15, pp.8289. Available at: http://dx.doi.org/10.1016/j.emospa.2013.12.010.

Fainstein, S.S., 2014. Comments on Urban Studies, Social Innovation.

Fallows, J., 2016a. Why the Maker Movement Matters: Part 1, the Tools Revolution. The 
Atlantic, pp.1-10. Available at:

http://www.theatlantic.com/business/archive/2016/06/why-the-maker-movementmatters-part-1-the-tools-revolution/485720/.

Fallows, J., 2016b. Why the Maker Movement Matters: Part 2, Agility. The Atlantic, pp.1-11.

Finn, D., 2014. DIY urbanism: Implications for cities. Journal of Urbanism:

International Research on Placemaking and Urban Sustainability, (January 2015), pp.1-18.

Florida, R., 2002. The Rise of the Creative Class, New York, NY: Basic Books.

Foucault, M., 1975. Discipline \& Punish, New York, NY: Vintage Books.

Foucault, M., 2004. The Birth of Biopolitics M. Senellart, ed., New York, NY: Picador.

Foucault, M., 1978. The History of Sexuality Vol. 1, New York, NY: Vintage Books.

Foucault, M., 1990. The Use of Pleasure: Volume 2 of The History of Sexuality, New York, NY: Vintage Books.

Frank, T., 2012. Dead End On Shakin' Street. The Baffler.

Fromm, E., 1970. Marx's Contribution to the Knowledge of Man. In The Crisis of Psychoanalysis. Greenwich, CT: Fawcett Publications, Inc.

Gabriel, N., 2014. Urban Political Ecology: Environmental Imaginary, Governance, and the Non-Human. Geography Compass, 8(1), pp.38-48.

Gandy, M., 2006. Urban Nature and the Ecological Imaginary. In N. Heynen, E. Swyngedouw, \& M. Kaika, eds. In the Nature of Cities. London, UK: Routledge.

Ghertner, D.A., 2015. Rule by Aesthetics: World-Class City Making in Delhi, Oxford, UK: Oxford University Press.

Gibson, K., 2007. Bleeding Albina: A History of Community Disinvestment, 1940-2000. Transforming Anthropology, 15(1), pp.3-25.

Gill, R. \& Pratt, A., 2008. In the Social Factory?: Immaterial Labour, Precariousness and Cultural Work. Theory, Culture \& Society, 25(7-8), pp.1-30. Available at: http://tcs.sagepub.com/cgi/doi/10.1177/0263276408097794.

Gonzalez, S. \& Waley, P., 2013. Traditional Retail Markets: The New Gentrification Frontier? Antipode, 45(4), pp.965-983. Available at: 
http://doi.wiley.com/10.1111/j.1467-8330.2012.01040.x.

Goodman, M.K., 2004. Reading fair trade: Political ecological imaginary and the moral economy of fair trade foods. Political Geography, 23, pp.891-915.

Gorman, M.O., 2007. Detroit Digital: On Tourists in the Apocalypse. C Theory. Available at: www.ctheory.net/articles.aspx?id=586.

Greco, J., 2012. The Psychology of Ruin Porn. Available at: http://www.citylab.com/design/2012/01/psychology-ruin-porn/886/.

Gunder, M. \& Hillier, J.S., 2007. Planning as urban therapeutic. Environment and Planning A, 39(2), pp.467-486.

Hackworth, J., 2015a. Rightsizing as spatial austerity in the American rust belt. Environment and Planning A, 47(4), pp.766-782.

Hackworth, J., 2014. The limits to market-based strategies for addressing land abandonment in shrinking American cities. Progress in Planning, 90, pp.1-37. Available at: http://dx.doi.org/10.1016/j.progress.2013.03.004.

Hackworth, J., 2015b. Why there is no Detroit in Canada. Urban Geography, 3638(December), pp.1-24. Available at: http://www.tandfonline.com/doi/full/10.1080/02723638.2015.1101249.

Harbarger, M., 2017. Portland's homeless population jumps nearly 10 percent, new count shows. Oregon Live. Available at:

http://www.oregonlive.com/portland/index.ssf/2017/06/portlands_homeless_populat ion.html.

Hartigan, J., 1999. Racial Situations, Princeton, NJ: Princeton University Press.

Harvey, D., 1990a. Between Space and Time: Reflections on the Geographical Imagination 1. Annals of the Association of American Geographers, 80(3), pp.418434. Available at: http://www.tandfonline.com/doi/abs/10.1111/j.14678306.1990.tb00305.x.

Harvey, D., 1990b. Flexible Accumulation Urbanization Through. Perspecta, 26(1990), pp.251-272.

Harvey, D., 1989. FROM MANAGERIALISM TO THE ENTREPRENEURIALISM : IN URBAN GOVERNANCE TRANSFORMATION. Geografiska Annaler. Series B, Human Geography, 71(1), pp.3-17.

Hermes, J., 2015. Labour and passion: Introduction to themed section. European Journal 
of Cultural Studies, 18(2), pp.111-116. Available at:

http://ecs.sagepub.com/content/18/2/111.abstract.

Herscher, A., 2010. Detroit Unreal Estate Agency.

Herscher, A., 2012. The Unreal Estate Guide to Detroit, Ann Arbor, MI: The University of Michigan Press.

Heying, C. \& Marotta, S., 2014. Portland Made Collective Survey Results 2014, Portland, OR.

Heying, C.H., 2010. Brew to Bikes: Portland's Artisan Economy, Portland, OR: Ooligan Press.

Heying, C.H., Marotta, S. \& Cummings, A., 2016. Portland Made Collective Survey Report 2015, Portland, OR.

High, S. \& David Lewis, 2007. Corporate Wasteland: The Landscape and Memory of Deindustrialization, Ithaca, NY: Cornell University Press.

Hillier, J., 2008. Plan(e) Speaking: a Multiplanar Theory of Spatial Planning. Planning Theory, 7, pp.24-50.

Hillier, J. \& Gunder, M., 2003. Planning Fantasies? An Exploration of a Potential Lacanian Framework for Understanding Development Assessment Planning. Planning Theory, 2(3), pp.225-248.

Hjorth, L. \& Lim, S.S., 2012. Mobile intimacy in an age of affective mobile media. Feminist Media Studies, 12(4), pp.477-484. Available at:

http://proxygw.wrlc.org/login?url=http://search.ebscohost.com/login.aspx?direct=tru $\mathrm{e} \& \mathrm{db}=\mathrm{a} 9 \mathrm{~h} \& \mathrm{AN}=84923916 \&$ site $=$ ehost-live.

Hollander, J.B., 2010. Changes Associated With Depopulation in Flint, Michigan. Cityscape, 12(1), pp.133-151.

Holston, J., 1998. Spaces of Insurgent Citizenship. In L. Sandercock, ed. Making the Invisible Visible. Berkeley, CA: University of California Press, pp. 37-56.

Holtzman, B. et al., 2007. Do It Yourself... and the Movement Beyond Capitalism. In S. S. \& D. Graeber, ed. Constituent Imagination. Oakland, CA: AK Press, pp. 44-61.

Hracs, B.J. \& Leslie, D., 2014. Aesthetic labour in creative industries: The case of independent musicians in Toronto, Canada. Area, 46(1), pp.66-73. 
Hurst, T., 2015. Why My Apartment is Good for Portland. Willamette Week. Available at: http://www.wweek.com/portland/article-24869-why-my-apartment-is-good-forportland.html.

Huyssen, A., 2008. Other Cities, Other Worlds: Urban Imaginaries in a Globalizing Age, Durham, NC: Duke University Press.

Hyra, D., 2014. The back-to-the-city movement: Neighbourhood redevelopment and processes of political and cultural displacement. Urban Studies, p.0042098014539403-. Available at: http://usj.sagepub.com/content/early/2014/07/17/0042098014539403?papetoc.

Iveson, K., 2013. Cities within the City: Do-It-Yourself Urbanism and the Right to the City. International Journal of Urban and Regional Research, 37(May), pp.941-956.

Jackson, K., 1985. Federal Subsidy and the Suburban Dream: How Washington Changed the American Housing Market. In Crabgrass Frontier. New York, NY: Oxford University Press, pp. 190-218.

Jameson, F., 2011. Representing Capital, London: Verso.

Jamieson, K., 2013. Tracing festival imaginaries: Between affective urban idioms and administrative assemblages. International Journal of Cultural Studies, 17(3), pp.293-303. Available at: http://ics.sagepub.com/cgi/doi/10.1177/1367877913487550.

Jessop, B., 2013. Revisiting the Regulation Approach:Critical Reflections on the Contradictions, Dilemmas, Fixes, and Crisis Dynamics of Growth Regimes. Available at: http://eprints.lancs.ac.uk/58898/.

Jessop, B., 1997. Twenty years of the regulation approach : the paradox of success and failure at home and abroad. New Political Economy, 2(3), pp.503-526. Available at: http://eprints.lancs.ac.uk/19240/.

Keatinge, B. \& Martin, D.G., 2015. A "Bedford Falls" kind of place: Neighbourhood branding and commercial revitalisation in processes of gentrification in Toronto, Ontario. Urban Studies, 53(April 2014), p.0042098015569681-. Available at: http://usj.sagepub.com/content/early/2015/02/11/0042098015569681.abstract.

Kelley, M.J., 2013. The emergent urban imaginaries of geosocial media. GeoJournal, 78(1), pp.181-203.

Kneese, T., Rosenblat, A. \& Boyd, D., 2014. Technologically Mediated Artisanal Production. Data \& Society. Available at: http://www.datasociety.net/pubs/fow/ArtisanalProduction.pdf. 
Korfhage, M., 2017. We Went To Tokyo To Figure Out Why They're Obsessed With Our City. Willamette Week.

Larocca, A., 2016. Etsy Wants to Crochet Its Cake, and Eat It Too. The Cut. Available at: http://nymag.com/thecut/2016/04/etsy-capitalism-c-v-r.html.

Leary, J.P., 2011. Detroitism. Guernica Magazine.

LeDuff, C., 2013. Detroit: An American Autopsy, New York, NY: The Penguin Press.

Lees, L., 2003. Super-gentrification: The case of Brooklyn Heights, New York City. Urban Studies, 40(12), pp.2487-2509.

Leonard, A., 2013. The Maker economy can' t fix everything. Salon. Available at: http://www.salon.com/2013/07/26/the_maker_economy_cant_fix_everything/.

Leszczynski, A., 2014. Spatial media/tion. Progress in Human Geography, 39(6), pp.729-751. Available at:

http://phg.sagepub.com/cgi/doi/10.1177/0309132514558443.

Leurs, K. \& Georgiou, M., 2016. Digital makings of the cosmopolitan city? Young people's urban imaginaries of London. International Journal of Communication, (October), pp.3689-3709.

Ley, D., 2003. Artists, aestheticisation and the field of gentrification. Urban Studies, 40(12), pp.2527-2544.

Lindtner, S., 2014. Hackerspaces and the Internet of Things in China: How makers are reinventing industrial production, innovation, and the self. China Information, 28, pp.145-167. Available at: http://cin.sagepub.com/content/28/2/145.short.

Lloyd, R., 2006a. Neo-Bohemia: Art and Neighborhood Redevelopment in Chicago. Cities and Society, 24(5), pp.215-229.

Lloyd, R., 2006b. Neobohemia, New York, NY: Routledge.

Lofland, J. et al., 2006. Analyzing Social Settings: AGuide to Qualitative Observation and Analysis Fourth Edi., Belmont, CA: Thomson Wadsworth.

Lorey, I., 2015. State of Insecurity, London, UK: Verso.

Luckman, S., 2013. Gender, Craft and the Creative Economy: Home-based Cultural Work and the Etsy Mum. 3rd Global Conference on The Value of Work: ..., (March 2013). Available at: https://www.inter-disciplinary.net/critical-issues/wp- 
content/uploads/2013/07/luckmanvowpaper.pdf.

Luckman, S., 2013. The Aura of the Analogue in a Digital Age: Women's Crafts, Creative Markets and Home-Based Labour After Etsy. Cultural Studies Review, 19(1), pp.249-70. Available at: http://epress.lib.uts.edu.au/journals/index.php/csrj/article/view/2585.

Madison, D.S., 2005. Critical Ethnography, Thousand Oaks, CA: Sage Publications Inc.

Mah, A., 2012. Demolition for Development: A Critical Analysis of Official Urban Imaginaries in Past and Present UK Cities. Journal of Historical Sociology, 25(1), pp.151-176.

Makagon, D., 2010. Bring on the Shock Troops: Artists and Gentrification in the Popular Press. Communication and Critical/Cultural Studies, 7(January 2014), pp.26-52.

Marcuse, H., 1969. An Essay on Liberation, Boston: Beacon Press.

Markusen, A., 1999. Fuzzy Concepts, Scanty Evidence, Policy Distance: The Case for Rigour and Policy Relevance in Critical Regional Studies. Regional Studies, 33(9), pp.869-884. Available at:

http://www.tandfonline.com/doi/abs/10.1080/0034340032000108796.

Markusen, A., 2006. Urban development and the politics of a creative class: Evidence from a study of artists. Environment and Planning A, 38, pp.1921-1940.

Markusen, A. \& Gadwa, A., 2010. Arts and Culture in Urban or Regional Planning: A Review and Research Agenda. Journal of Planning Education and Research, 29(January), pp.379-391.

Markusen, A. \& Nicodemus, A.G., 2010. Creative Placemaking, Available at: http://kresge.org/sites/default/files/NEA-Creative-placemaking.pdf.

Marotta, S. \& Cummings, A., 2018. Planning affectively: Power, affect, and images of the future. Planning Theory, pp.1-23. Available at: http://journals.sagepub.com/doi/10.1177/1473095218802317.

Marotta, S., Cummings, A. \& Heying, C., 2018. Accidents, Intentions, Movements, and Makers: Artisan Economy in Portland Oregon USA. In S. Walker et al., eds. Design Routes. London, UK: Bloomsbury.

Marotta, S., Cummings, A. \& Heying, C., 2016. Where is Portland Made? The Complex Relationship Between Place and Social Media in the Artisan Economy of Portland, Oregon. M/C Journal of Media and Culture, 19(3). Available at:

http://journal.media-culture.org.au/index.php/mcjournal/article/view/1083/0. 
Marotta, S. \& Heying, C., Interrogating Localism: What Does "Made in Portland" Really Mean? In S. Luckman \& N. Thomas, eds. Craft Economies: Cultural Economies of the Handmade. London, UK: Bloomsbury Academic.

Martin, L., 2015. The Promise of the Maker Movement for Education. Journal of PreCollege Engineering Education Research, 5(5), pp.1-30. Available at: http://docs.lib.purdue.edu/jpeer\%5Cnhttp://dx.doi.org/10.7771/2157-9288.1099.

Marwick, a. E. \& Boyd, D., 2011. I tweet honestly, I tweet passionately: Twitter users, context collapse, and the imagined audience. New Media \& Society, 13(1), pp.114133.

Marx, K., 1976. Capital Vol. 1, London: Penguin Books.

Marx, K., 1988. Economic and Philosophic Manuscripts of 1844, Amherst, NY: Prometheus Books.

Massey, D. \& Denton, N., 1993. American Apartheid, Cambridge, MA: Harvard University Press.

McCann, E., Roy, A. \& Ward, K., 2013. Assembling / Worlding Cities. Urban Geogrpahy, 34(5), pp.581-589.

McCann, F., 2016. Can Portland Artists Survive the City’s New Gilded Age? Portland Monthly.

McRobbie, A., 2016. Be Creative, Malden, MA: Polity Press.

Mechoulan, E., 2004. Introduction: On the Edges of Jacques Ranciere. SubStance, 33(1), pp.3-9.

Melosi, M. V., 2010. Humans, Cities, and Nature: How Do Cities Fit in the Material World? Journal of Urban History, 36(1), pp.3-21.

Millington, N., 2013. Post-Industrial Imaginaries: Nature, Representation and Ruin in Detroit, Michigan. International Journal of Urban and Regional Research, 37(January), pp.279-296.

Moilanen, J., 2012. Emerging hackerspaces - Peer-production generation. IFIP Advances in Information and Communication Technology, 378 AICT, pp.94-111. Available at: http://communities.ossoil.com/wp-content/uploads/2012/09/0ss2012moilanen.pdf.

Monahan, R., 2017. Sick of Portland Changing? Too Bad. Here Are 7 Places Where This 
City Could Soon Go Big. Willamette Week. Available at:

http://www.wweek.com/news/city/2017/08/02/sick-of-portland-changing-too-badhere-are-7-places-where-this-city-could-soon-go-big/.

Monroe Sullivan, D. \& Shaw, S.C., 2011. Retail Gentrification and Race: The Case of Alberta Street in Portland, Oregon. Urban Affairs Review, 47, pp.413-432.

Morozov, E., 2014. Making It. The New Yorker. Available at:

http://www.newyorker.com/magazine/2014/01/13/making-it-2.

Morrison, H. \& Dewar, M., 2012. Planning in America's Legacy Cities: Toward Better, Smaller Communities after Decline. Rebuilding America's Legacy Cities: New Directions for the Industrial Heartland, pp.115-142.

Morton, T., 2009. Something, Something, Something, Detroit. Vice Magazine.

Negri, A., 1999. Value and Affect. boundary 2, 26(2), pp.77-88.

Neilson, B. \& Rossiter, N., 2008. Precarity as a Political Concept, or, Fordism as Exception. Theory, Culture \& Society, 25(7-8), pp.51-72.

Nicodemus, A.G., 2013. Fuzzy vibrancy: Creative placemaking as ascendant US cultural policy. Cultural Trends, 22(March 2015), pp.213-222. Available at: http://dx.doi.org/10.1080/09548963.2013.817653.

Njus, E., 2017. New apartment construction has finally slowed rent growth -- at least, at the high end. Oregon Live. Available at: http://www.oregonlive.com/frontporch/index.ssf/2017/03/new_construction_has_finally_s.html.

Pasquinelli, C. \& Sjöholm, J., 2015. Art and resilience: The spatial practices of making a resilient artistic career in London. City, Culture and Society, 6(3), pp.75-81. Available at: http://dx.doi.org/10.1016/j.ccs.2015.04.001.

Peck, J., 2005. Struggling with the Rise of the Creative Class. International Journal of Urban and Regional Research, 29(December), pp.740-770.

Peck, J. \& Tickell, A., 1994. Jungle Law Breaks out: Neoliberalism and Global-Local Disorder. Area, 26(4), pp.317-326. Available at: http://www.jstor.org/stable/20003479.

Pein, C., 2017. Oregonians Are Reporting More Hate and Bias Crimes Than Anyone in U.S. Willamette Week.

de Peuter, G., 2011. Creative Economy and Labor Precarity: A Contested Convergence. Journal of Communication Inquiry, 35(4), pp.417-425. 
Pike, A., 2009. Progress in Human Geography Geographies of brands and branding Geographies of brands and branding. , pp.1-27.

Povinelli, E.A., 2011. Economies of Abandonment: Social Belonging and Endurance in Late Liberalism, Durham, NC: Duke University Press.

Pratt, A.C., 2008. Creative Cities: The Cultural Industries and the Creative Class. Geografiska Annaler: Series B, Human Geography, 90(2), pp.107-117.

Rancière, J., 2010. Ten Theses on Politics. In Dissensus. London: Bloomsbury, pp. 2744.

Rancière, J., 2004. The Politics of Aesthetics, London: Bloomsbury Academic.

Raunig, G., Ray, G. \& Wuggenig, U., 2011. Critique of Creativity: Precarity, Subjectivity and Resistance in the 'Creative Industries,'

Richardson, M., 2012. Designer/Maker: The Rise of Additive Manufacturing, DomesticScale Production and the Possible Implications for the Automotive Industry. Computer-Aided Design and Applications, PACE(2), pp.33-48. Available at: http://www.cadanda.com/CADandA_PACE_2_33-48.html.

Richardson, M., Elliott, S. \& Haylock, B., 2013. This home is a factory : Implications of the Maker movement on urban environments. Craft + Design Enquiry, (Bowyer 2011), pp.141-153. Available at: http://press.anu.edu.au/wpcontent/uploads/2013/09/ch093.pdf.

Rieniets, T., 2009. Shrinking Cities: Causes and Effects of Urban Population Losses in the Twentieth Century. Nature and Culture, 4(3), pp.231-254.

Rodney, L., 2009. Detroit is our Future. Fuse Magazine.

Rose, G., 2014. The Melancholy Science Second., London, UK: Verso.

Ross, A., 2008. The new geography of work. Theory, Culture \& Society, 25(7-8), pp.3149.

Roy, A., 2011. The Blockade of the World-Class City : Dialectical Images of Indian Urbanism. In A. Roy \& A. Ong, eds. Worlding Cities: Asian Experiments and the Art of Being Global. Blackwell Publishing, pp. 259-278.

Roy, K., 2015. Portland Made, Portland, OR: Self-Published.

Ruggie, J.G., 1982. International regimes, transactions, and change: embedded liberalism 
in the postwar economic order. International Organization, 36(02), p.379.

Satter, B., 2009. Family Properties, New York, NY: Picador.

Schrock, G. et al., 2018. Appetite for Growth: Challenges to Scale for Food and Beverage Makers in Three U.S. Cities. Economic Development Quarterly, p.089124241880837. Available at: http://journals.sagepub.com/doi/10.1177/0891242418808377.

Schwartz, R. \& Halegoua, G.R., 2014. The spatial self: Location-based identity performance on social media. New Media \& Society, (April), p.1461444814531364-. Available at:

http://nms.sagepub.com/cgi/doi/10.1177/1461444814531364\%5Cnhttp://nms.sagepu b.com/content/early/2014/04/09/1461444814531364.abstract\%5Cnhttp://nms.sagep ub.com/cgi/doi/10.1177/1461444814531364.

Semuels, A., 2016. The Racist History of Portland, the Whitest City in America. The Atlantic. Available at: https://www.theatlantic.com/business/archive/2016/07/racisthistory-portland/492035/.

Sennett, R., 2006. The Culture of the New Capitalism, New Haven, CT: Yale University Press.

Shaw, S. \& Sullivan, D., 2011. "White night": Gentrification, racial exclusion, and perceptions and participation in the arts. City and Community, 10(September), pp.241-264.

Silver, D. \& Miller, D., 2013. Contextualizing the artistic dividend. Journal of Urban Affairs, 35(5), pp.591-606.

Simmons, W.P. \& Casper, M.J., 2012. Culpability, Social Triage, and Structural Violence in the Aftermath of Katrina. Perspectives on Politics, 10, pp.675-686.

Smith, N., 1979. Toward a Theory of Gentrification A Back to the City Movement by Capital, not People. Journal of the American Planning Association, 45(4), pp.538548. Available at: http://dx.doi.org/10.1080/01944367908977002.

Solnit, R., 2007. Detroit Arcadia. Harper's Magazine, pp.65-73.

Staff, W., 2015. Portland, I Love You but You're Forcing Me Out. Willamette Week. Available at: http://www.wweek.com/arts/2015/10/21/portland-i-love-you-butyoure-forcing-me-out/.

Stallybrass, P., 1998. Marxs-Coat. In P. Spyer, ed. Border Fetishisms. New York, NY: Routledge. 
Stangler, D. \& Maxwell, K., 2012. DIY Producer Society. Innovations, 7(3), pp.3-10. Available at:

http://dx.doi.org/10.1162/INOV_a_00134\%5Cnhttp://www.mitpressjournals.org/doi /abs/10.1162/INOV_a_00134\%5Cnhttp://www.mitpressjournals.org/doi/pdf/10.116 2/INOV_a_00134.

Stewart, K., 2007. Ordinary Affects, Durham, NC: Duke University Press.

Strangleman, T., 2014. "Smokestack Nostalgia," "Ruin Porn" or Working-Class Obituary: The Role and Meaning of Deindustrial Representation. International Labor and Working-Class History, 84(84), pp.23-37. Available at: http://www.journals.cambridge.org/abstract_S0147547913000239.

Sugrue, T.J., 1996. The Origins of the Urban Crisis, Princeton, NJ: Princeton University Press.

Sullivan, D. \& Shaw, S., 2011. Retail Gentrification and Race: The Case of Alberta Street in Portland, Oregon. Urban Affairs Review, 47(3), pp.413-432. Available at: https://duca94.files.wordpress.com/2011/05/sullivan_retailgentrification.pdf.

Szeman, I., 2015. Entrepreneurship as the New Common Sense. South Atlantic Quarterly, 114(3), pp.471-490. Available at: http://saq.dukejournals.org/lookup/doi/10.1215/00382876-3130701.

Temple, J., 2010. Detroit: The Last Days. The Guardian. Available at: http://www.theguardian.com/film/2010/mar/10/detroit-motor-city-urban-decline.

Theen, A., 2015. Portland approves housing emergency plan, what comes next is unclear. Oregon Live. Available at: http://www.oregonlive.com/portland/index.ssf/2015/10/portland_approves_housing_ emer.html.

Thomas, J.M., 1990. Planning and Industrial Decline Lessons from Postwar Detroit. Journal of the American Planning Association, 56(3), pp.297-310. Available at: http://www.tandfonline.com/doi/abs/10.1080/01944369008975774.

Thomas, J.M., 1997. Race and Redevelopment: Planning a Finer City in Postwar Detroit, Baltimore, MD: The Johns Hopkins University Press.

Thrift, N., 2004. Intensities of feeling: Towards a spatial politics of affect. Geografiska Annaler. Series B, Human Geography, 86(1), pp.57-78.

Thrift, N., 2007. Non-Representational Theory, London, UK: Routledge. 
Tickell, A. \& Peck, J., 2002. Neoliberalizing Space. Antipode, 34(3), pp.380-404.

Tierney, J., 2015a. How makerspaces help local economies. The Atlantic, pp.1-8.

Tierney, J., 2015b. The Dilemmas of Maker Culture. The Atlantic, pp.1-5.

Toombs, A., Bardzell, S. \& Bardzell, J., 2012. Becoming Makers : Hackerspace Member Habits, Values, and Identities. Journal of Peer Production, (5), pp.1-8.

Tsing, A.L., 2015. The Mushroom at the End of the World, Princeton, NJ: Princeton University Press.

Urry, J., 1990. The Tourist Gaze: Leisure and Travel in Contemporary Societies, London, UK: Sage Publications Ltd.

Vultee, F., 2013. Finding Porn in the Ruin. Journal of Mass Media Ethics, 28(October), pp.142-145. Available at: http://www.tandfonline.com/doi/abs/10.1080/08900523.2013.784670.

Wark, M., 2013. A More Lovingly Made World. Cultural Studies Review, 19(1), pp.296304.

Wey, T., 2017. The Whitewashing of Detroit's Culinary Scene. CityLab. Available at: https://www.citylab.com/life/2017/11/tunde-wey-detroits-white-culinaryscene $/ 542571 /$.

Wile, R., 2015. Portland is the most gentrified city of the century. Fusion. Available at: http://fusion.net/story/44321/portland-is-the-most-gentrified-city-of-the-century/.

Wilkinson, E. \& Ortega-Alcázar, I., 2018. The right to be weary? Endurance and exhaustion in austere times. Transactions of the Institute of British Geographers, (June), pp.1-13.

Willbur, A., 2018. The Towne Storage Building, Former Low-Rent Creative Mecca, Went Full San Francisco. Portland Monthly.

Williams, A. \& Dourish, P., 2006. Imagining the city: The cultural dimensions of urban computing. Computer, 39(9), pp.38-43.

de Wit, C.W., 2013. Interviewing for Sense of Place. Journal of Cultural Geography, 30(1), pp.120-144. Available at: http://dx.doi.org/10.1080/08873631.2012.745979.

Wolf-powers, L. et al., 2017. The Maker Movement and Urban Economic Development. Journal of the American Planning Association, 83(4), pp.1-12. 
Wolf-Powers, L. et al., 2016. The Maker Economy in Action: Entrepreneurship and Supportive Ecosystems in Chicago, New York and Portland, Portland, OR. Available at: www.urbanmakereconomy.com.

Wolf-Powers, L. \& Levers, A., 2016. Planning, Social Infrastructure, and the Maker Movement in New York City. Carolina Planning Journal, 41, pp.38-52.

Wood, S., 2009. DESIRING DOCKLANDS : DELEUZE AND URBAN PLANNING DISCOURSE. Planning Theory, 8(2), pp.191-216.

Yin, R.K., 2009. Case study research : design and methods Fifth., Los Angeles, CA: Sage Publications Inc. Available at: http://unisa.aquabrowser.com/?itemid $=\% 7$ Cunisa-bibs\%7C1104221.

Zukin, S., 1982. Loft Living, New Brunswick, NJ: Rutgers University Press.

Zukin, S., 2010. Naked City: The Death and Life of Authentic Urban Places, Oxford, UK: Oxford University Press.

Zukin, S. et al., 2009. New retail capital and neighborhood change: Boutiques and gentrification in New York city. City and Community, 8(1), pp.47-64. 